Florida International University

FIU Digital Commons

$6-25-2020$

\title{
The impacts of Small Group Interactions and Social Interdependence in Introductory Physics
}

Miguel Angel Rodriguez Velazquez

mrodr1106@fiu.edu

Follow this and additional works at: https://digitalcommons.fiu.edu/etd

Part of the Other Physics Commons

\section{Recommended Citation}

Rodriguez Velazquez, Miguel Angel, "The impacts of Small Group Interactions and Social Interdependence in Introductory Physics" (2020). FIU Electronic Theses and Dissertations. 4497.

https://digitalcommons.fiu.edu/etd/4497

This work is brought to you for free and open access by the University Graduate School at FIU Digital Commons. It has been accepted for inclusion in FIU Electronic Theses and Dissertations by an authorized administrator of FIU Digital Commons. For more information, please contact dcc@fiu.edu. 


\title{
FLORIDA INTERNATIONAL UNIVERSITY \\ Miami, Florida
}

\section{THE IMPACTS OF SMALL GROUP INTERACTIONS AND SOCIAL INTERDEPENDENCE IN INTRODUCTORY PHYSICS}

\author{
A dissertation submitted in partial fulfillment of the \\ requirements for the degree of \\ DOCTOR OF PHILOSOPHY \\ in \\ PHYSICS \\ by
}

Miguel A. Rodriguez Velazquez 
To: Dean Michael R. Heithaus

College of Arts, Sciences and Education

This dissertation, written by Miguel A. Rodriguez Velazquez, and entitled The Impacts of Small Group Interactions and Social Interdependence in Introductory Physics, having been approved in respect to style and intellectual content, is referred to you for judgment.

We have read this dissertation and recommend that it be approved.

Zahra Hazari

Laird Kramer

Caroline Simpson

Geoff Potvin, Major Professor

Date of Defense: June 25, 2020

The dissertation of Miguel A. Rodriguez Velazquez is approved.

Dean Michael R. Heithaus
College of Arts, Sciences and Education

College of Arts, Sciences and Education

Florida International University, 2020 
(C) Copyright 2020 by Miguel A. Rodriguez Velazquez

All rights reserved. 


\section{DEDICATION}

I dedicate this dissertation to my parents. Without their love and support, I would not have been able to pursue and accomplish my dreams. 


\section{ACKNOWLEDGMENTS}

I wish to thank the members of my committee for their support, direction and wisdom. Dr. Hazari's knowledge and experience in research methods was critical in the development of my methodology. Dr. Kramer's wisdom and advice helped me keep my research focused and practical. Dr. Simpson's guidance and perspective has helped me stay on track while also thinking about what's next. Finally I would like to thank my major professor, Dr. Geoff Potvin. Words are not enough to thank Geoff for all that he has done for me. His advising has made completing my Ph.D. possible and having the pleasure of working with him was my favorite part of my whole experience at FIU.

I want to thank my advisor during my time at OU, Dr. Bruno Uchoa, who first suggested I conduct Physics Education Research. Lastly, I want to thank my colleagues: Jonathan Mahadeo, Jacki Doyle, Jacqueline Rohde, Derrick Satterfield, Ida Rodriguez, Deepa Chari, Benjamin Archibeque, Thomas Head, Hemeng Cheng as well as my friends/mentors: Leonard Bliss, Linda Bliss and Brian Zamarripa. They gave me feedback on all my writing and research and my conversations with them provided me great insight and their support provided a safety net for me as a doctoral student. 


\title{
ABSTRACT OF THE DISSERTATION \\ THE IMPACTS OF SMALL GROUP INTERACTIONS AND SOCIAL INTERDEPENDENCE IN INTRODUCTORY PHYSICS
}

by

\author{
Miguel A. Rodriguez Velazquez \\ Florida International University, 2020 \\ Miami, Florida \\ Professor Geoff Potvin, Major Professor
}

The collected works in my dissertation are centered around the dynamics and impacts of small group learning in introductory physics. It is motivated by a desire to better understand which classroom practices and learning processes may lead to students achieving greater understanding or affinity to physics. Several theoretical frameworks are leveraged in my work including physics identity theory, social interdependence theory and social metacognition. The research design employed quantitative and qualitative methods including regression analysis, descriptive statistics, and observational analysis.

Firstly, students across the U.S. enrolled in first semester introductory physics courses were surveyed at the beginning and end of their semester. Regression analysis finds several classroom practices predict conceptual learning gains; of particular interest was the daily use of small group activities. Expanding on these results, two additional studies into small group learning were conducted in a Modeling Instruction introductory physics course. The first of 
these took the form of a quantitative study again using regression analysis to investigate how students' social interdependence experiences may be associated with improvements in conceptual understanding and in physics identity. The final study took the form of a qualitative, exploratory observational study that examined the social interdependence of students working in small groups in situ. The latter study also analyzes students' social metacognition to explore the processes that dictate how students negotiate their understanding with one another.

The first study in this dissertation expands on existing literature to support the effectiveness of small group learning in introductory physics. The second study identifies associations between social interdependence and physics identity gains. The last study explores the mechanisms through which students engage with one another in small groups using the dual lenses of social interdependence and social metacognition. 


\section{TABLE OF CONTENTS}

CHAPTER

PAGE

1 INTRODUCTION

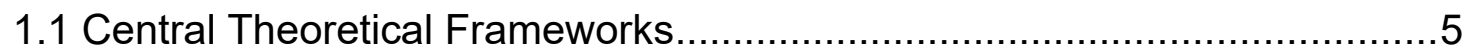

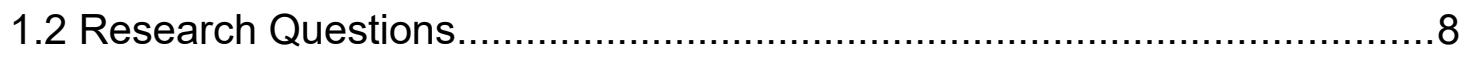

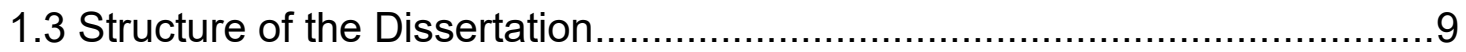

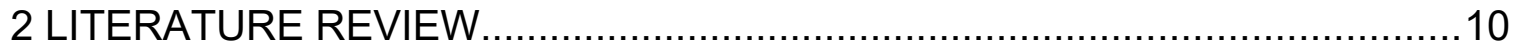

2.1 Theoretical Foundations of Student-centered Learning ......................... 10

2.2 Foundations of Social Interdependence .............................................14

2.2.1 Introduction to Group Dynamics Theory .....................................15

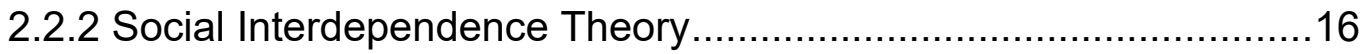

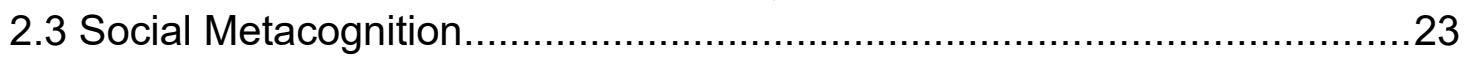

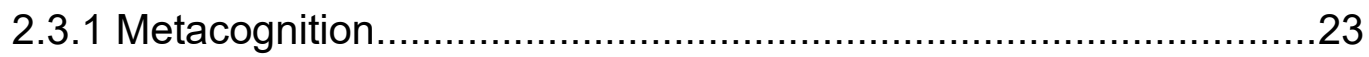

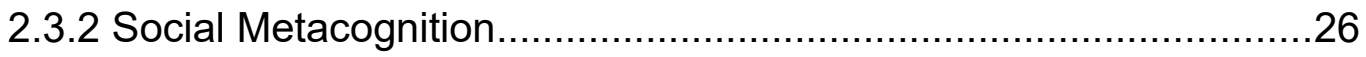

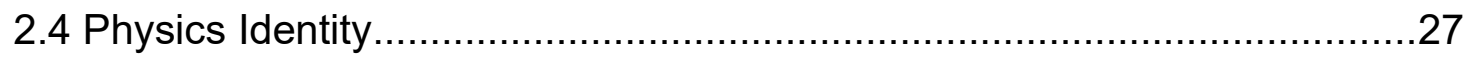

2.5 Examples of Student-centered Learning in Introductory Physics.............29

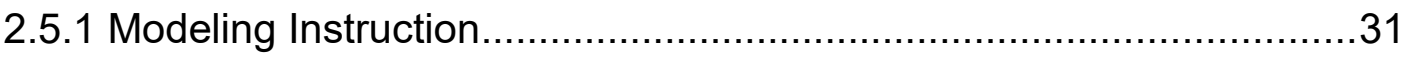

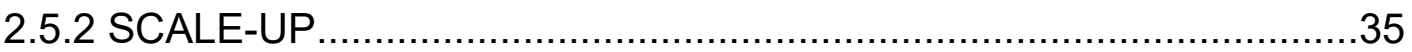

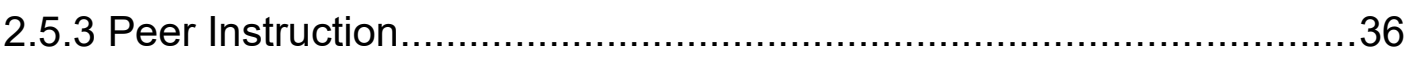

2.5.4 International Success of Student-centered Pedagogies.....................37

3 FREQUENT SMALL GROUP INTERACTIONS IMPROVE STUDENT LEARNING GAINS IN COLLEGE PHYSICS: RESULTS FROM A NATIONALLY REPRESENTATIVE PRE-POST STUDY ....................39

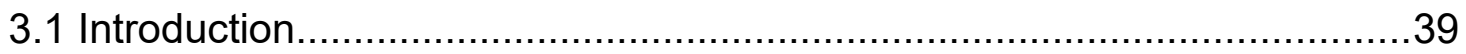

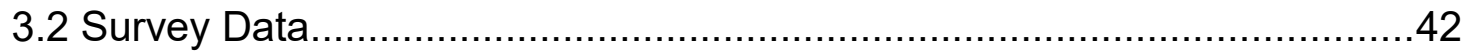

3.2.1 Assessing Physics Conceptual Knowledge ....................................4

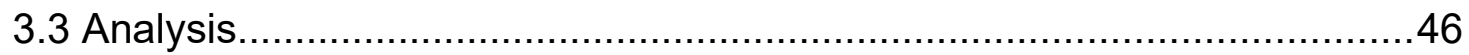

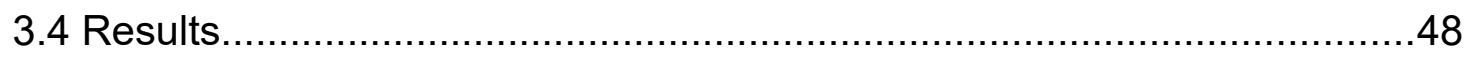

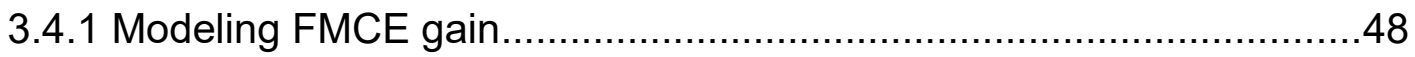

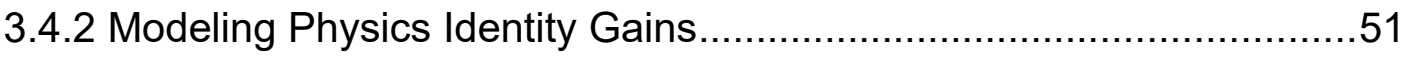

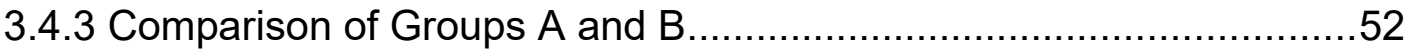

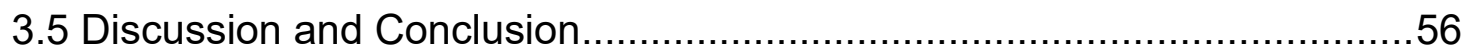

3.5.1 Importance of Small-group Learning, Connections with Other Work. 56

3.5.2 Literature Support for Other Factors Found to Improve Learning ......60

3.5.3 Physics Identity \& Research on Affective Outcomes in Physics........61 


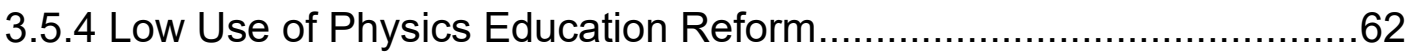

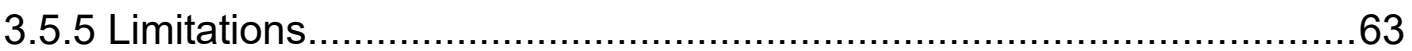

4 THE ASSOCIATIONS BETWEEN CONCEPTUAL LEARNING, PHYSICS IDENTITY GAINS AND SOCIAL INTERDEPENDENCE..................65

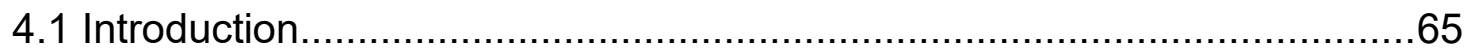

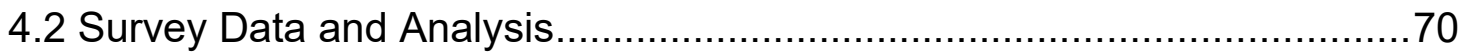

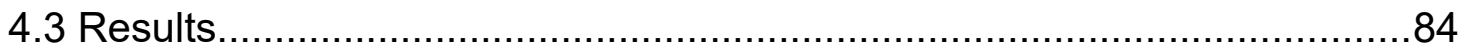

4.3.1 Associations between Task Interdependence and Physics Identity...84

4.3.2 Associations between Interdependence and Conceptual Gains........86

4.3.3 Change of Cooperation Beliefs over the Semester..........................87

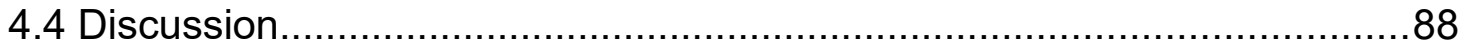

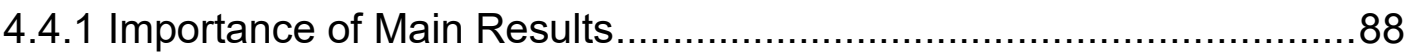

4.4.2 Implications for Student-centered Classrooms...................................

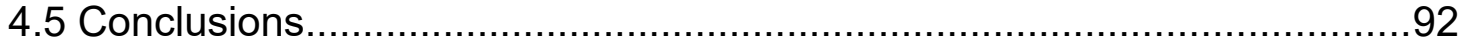

5 USING SOCIAL INTERDEPENDENCE AND SOCIAL METACOGNITION LENSES TO STUDY SMALL GROUP INTERACTIONS......95

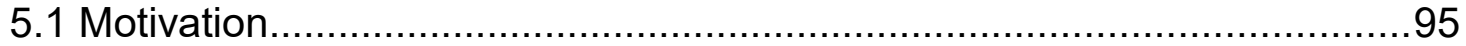

5.2 Theoretical Perspective on Small-group Learning.................................96

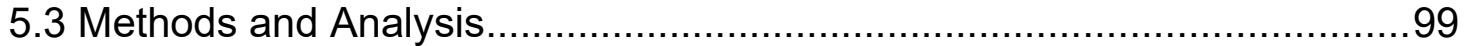

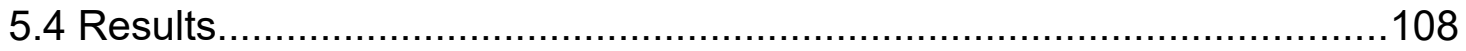

5.4.1 Overall Results of Social Interdependence Coding........................109

5.4.2 Commonalities in Social Interdependence......................................111

5.4.3 Contrasts in Social Interdependence.............................................117

5.4.4 Overall Results of Social Metacognition.......................................123

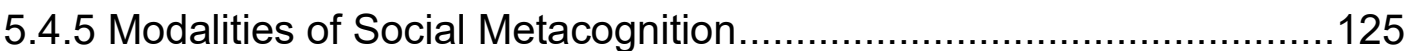

5.4.6 Contrasts in Social Metacognition.................................................137

5.4.7 Connecting Social Metacognition and Social Interdependence.......141

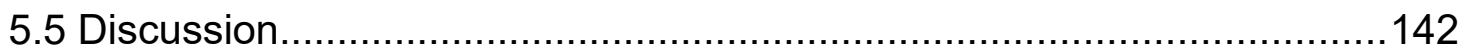

5.5.1 Modeling Instruction Provides Affordances for SI and SMC ............142

5.5.2 Individual Student Effects on Group Interactions..............................144

5.5.3 Instructors' Effects on Group Interactions........................................145

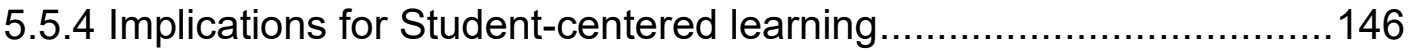

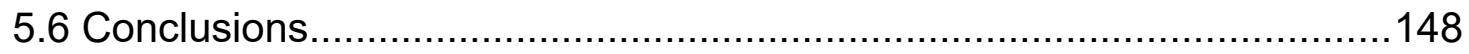

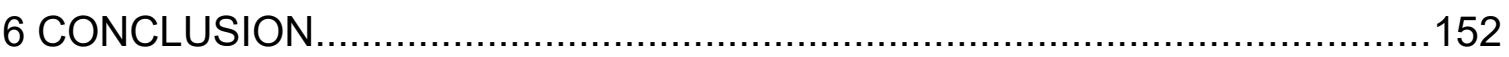

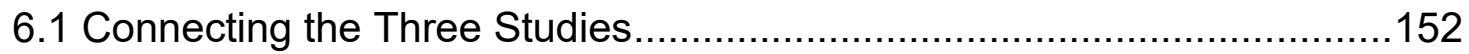




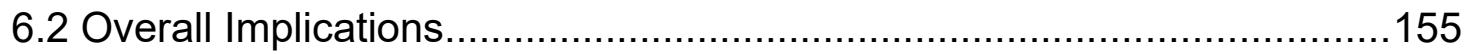

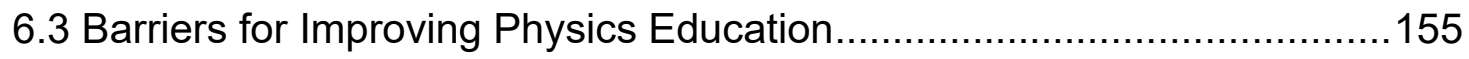

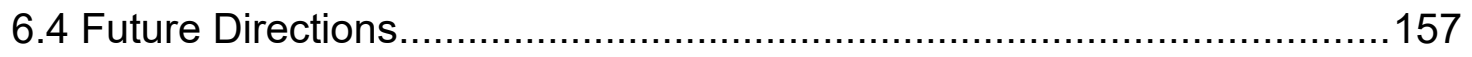

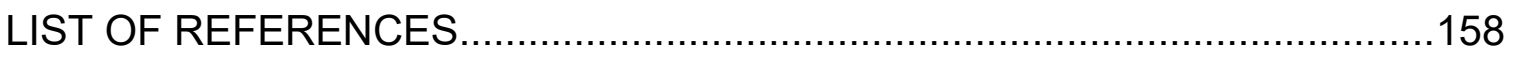

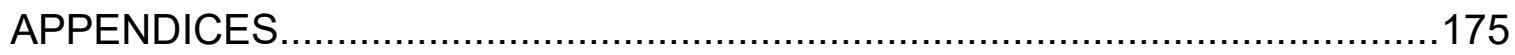

VITA 


\section{LIST OF TABLES}

TABLE

PAGE

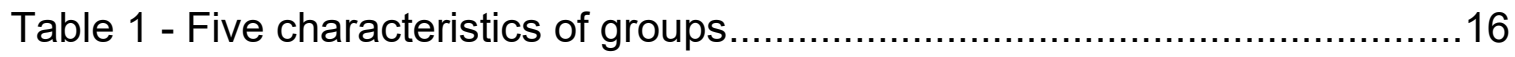

Table 2 - Linear model for FMCE and frequency of small group activities...........50

Table 3 - Linear models for FMCE and classroom practices...........................51

Table 4 - EFA of Survey 1 final items for Cooperation \& Individualism beliefs ...74

Table 5 - EFA of Task \& Outcome Interdependence scales for $1^{\text {st }}$ grouping.......77

Table 6 - EFA of Task \& Outcome Interdependence scales for $2^{\text {nd }}$ grouping......78

Table 7 - EFA of Task \& Outcome Interdependence scales for $3^{\text {rd }}$ grouping.......79

Table 8 - EFA of Task $\&$ Outcome Interdependence scales for $4^{\text {th }}$ grouping.......80

Table 9 - EFA of Task \& Outcome Interdependence scales for $5^{\text {th }}$ grouping.......81

Table 10 - EFA of Task \& Outcome Interdependence scales for $6^{\text {th }}$ grouping.....82

Table 11 - Linear model for outcome interdependence and cooperation beliefs.

Table 12 - Linear model of initiated task interdependence on gains in recognition beliefs.

Table 13 - Linear model of initiated task interdependence on gains in performance/competence beliefs. .86

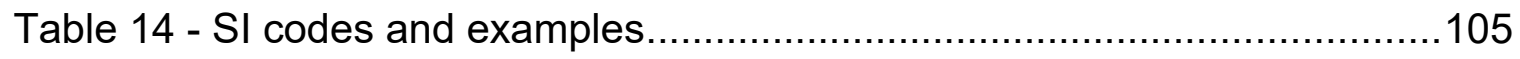

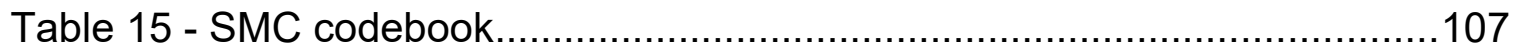




\section{LIST OF FIGURES}

FIGURE

PAGE

Figure 1 - Comprehensive model for Social Interdependence..........................19

Figure 2 - Simplified model for Social Interdependence ..................................21

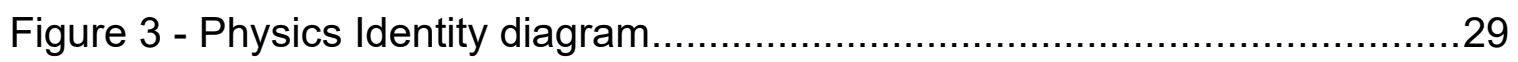

Figure 4 - Example of whiteboard with physics model.....................................33

Figure 5 - Comparison of FMCE scores by density ......................................49

Figure 6 - Histograms of group work comparison............................................53

Figure 7 - Timeline for data collection for quantitative SI study .........................71

Figure 8 - Comparison of SI codes for groups A and B ..............................110

Figure 9 - Comparison of SMC codes for groups A and B...........................124 


\section{ABBREVIATIONS AND ACRONYMS}

EFA - Exploratory Factor Analysis

FMCE - Force and Motion Conceptual Evaluation

MC - Metacognition

MI - Modeling Instruction

PI - Physics Identity

SCALE-UP - Student-Centered Activities for Large Enrollment Undergraduate Programs

SMC - Social Metacognition

SI - Social Interdependence 


\section{INTRODUCTION}

Educational approaches that motivate the use of various active learning techniques in classrooms (e.g., when students are actively participating in the learning) have existed since at least the 1930s, with the ideas of John Dewey (Dewey, 1938). Broadly, over a period of many years, active learning has been found to be more effective than traditional teaching methods, including lecturing and other didactic approaches (see, for example, Prince, 2004; Freeman et al., 2014; Michael, 2006), but the mechanisms by which students learn in these types of environments and precisely which classroom strategies are most effective at supporting student learning are still a matter of ongoing study. Further research in physics classrooms is important to address the growing national demand for physics majors and persistent problems in physics classrooms/communities including inequitable access to physics learning, continued underrepresentation of women and other traditionally marginalized students, low passing rates and retention (Ceci \& Williams, 2011; Hazari \& Potvin, 2005; Sayre, Franklin, Dymek, Clark \& Sun, 2012; Rifkin, 2016). Research that builds evidence for effective solutions to these issues may help address the growing demands for STEM majors.

My dissertation is centered around the study of small group learning, a particular subset of active learning, in Introductory Physics. Small group learning occurs when students work with each other, in groups of two to around six students, towards a common learning task. Small group learning has been 
shown to lead to higher conceptual gains and improved attitudes for students (Springer, Stanne \& Donovan, 1999), but additional research is necessary to understand the mechanisms underlying these improved outcomes and to address other issues related to physics study (e.g., inequity and underrepresentation). To investigate how students cooperate and share ideas in small groups, I used the related theoretical frameworks of social interdependence (to study cooperation) and social metacognition (to study how ideas are distributed by students) in small groups. Social Interdependence occurs in classrooms when students rely on each other to work through their activities and is essential for successful cooperation (Johnson \& Johnson, 2002). Social metacognition occurs when students regulate and monitor other students' ideas through dialogue, which can lead to building shared knowledge and distributing metacognitive demands, amongst other outcomes (Chiu \& Kuo, 2010). Improved metacognition has been generally linked to increased self-confidence (Kleitman \& Stankov, 2007), effective independent learning (Schunk, 2008), improved learning (Kleitman \& Stankov, 2007), performance on tasks, and effective problem solving skills (Schoenfeld, 1992; Hoffman \& Spatariu, 2008). Utilizing these frameworks to study student interactions may lead to better instructional strategies for forming more effective groups and encouraging more social metacognition amongst students.

My dissertation is a collected paper dissertation that consists of three related studies. In the first study, I analyzed surveys from a nationally- 
representative sample of first semester physics students and found that students who worked in small groups every class saw significantly higher gains in their understanding of physics concepts than the students who did not. Further details of the group activities (e.g., use of simulations, demonstrations, whiteboards) were also studied for the sub-sample of students who report working in small groups every class. On the basis of these findings, I studied small group learning in more depth, specifically to develop our understanding of the mechanisms that make this modality of classroom interaction effective.

The second and third studies were designed within a first semester, introductory, calculus-based Modeling Instruction physics course during Fall 2018. To frame the primary researcher's relationship to this course, I was a Teaching Assistant during the period of data collection (and previously); I perceived that I saw firsthand shifts in student attitudes compared to what I had been accustomed to in other physics courses I had taught, consistent with what has been found previously (Brewe, Kramer \& O'Brien, 2009). These experiences formed part of my motivation for studying Modeling Instruction further and to investigate how students cooperate in small groups and construct their physics understanding with one another. To address the former, I used a social interdependence lens; for the latter, I used social metacognition as an interpretive framework. I also tied social interdependence outcomes to conceptual learning and physics identity gains, to examine the effect on those outcomes. 
Thus, in the second study of my dissertation, I collected survey data from students in a first semester, introductory, calculus-based modeling instruction physics course to study their social interdependence outcomes for all six groups students were assigned to participate in during that semester. Having measured aspects of the social interdependence outcomes for every group, I correlated them to pre-semester cooperation beliefs as well as semester-long conceptual understanding and physics identity gains. My analysis found that students who reported more regularly initiating tasks in their groups benefited by experiencing more positive gains in recognition and performance/competence beliefs.

In the third study of my dissertation, I recorded two groups of students in situ while they worked on classroom activities over a period of a week of class (6.5 hours in class). I chose the groups to observe based on their pre-semester cooperation and individualism beliefs (specifically, one group was selected due to its high cooperation and low individualism beliefs and the other group was chosen for low cooperation and high individualism beliefs). For this exploratory observational study, I coded for the social interdependence of the group and the social metacognitive interactions between students during their group activities. The group with high cooperation and low individualism beliefs was observed to be highly interdependent, while the group with low cooperation and high individualism beliefs exhibited more independence (from each other) and dependence (on instructors). Similarities and differences were observed in how 
the groups engaged metacognitively with one another and when instructors were present.

\subsection{Central Theoretical Frameworks}

The primary theoretical frameworks used in my dissertation are Physics Identity theory (PI), Social Interdependence Theory (SIT) and Social Metacognition (SMC). Physics identity was used because of its predictive power for students' career choices and is associated with students' physics interest, recognition beliefs and performance/competence beliefs (Godwin, Potvin, Hazari, \& Lock, 2016; Hazari et al., 2010). Social Interdependence theory provided a framework for understanding how students may interdepend on each other to carry out in-class tasks and generate learning outcomes (Johnson \& Johnson, 2005). Social Metacognition provided a lens for understanding how students structure, analyze, and communicate their ideas between themselves and their peers.

In the theory utilized in this study, a student's physics identity is associated to three related sub-constructs: interest in physics, performance/competence beliefs (beliefs in one's ability to perform and be competent in physics), and, most critically, recognition beliefs (beliefs that one receives recognition from others as a "physics person"). All of these constructs are framed as self-beliefs (rather than the beliefs of others) and provide insight into an individual's perception of physics. Physics identity has been shown to be predictive of students' physics-related career choices which makes it a useful 
framework for trying to address the national demand for STEM majors as well as issues of equity and representation in physics (Hazari, Sonnert, Sadler \& Shanahan, 2010). The PI scale operationalized from this framework is used in the first two studies of my dissertation.

Social interdependence theory provides an interpretive framework for understanding the critical elements and benefits of cooperative learning in an educational context (Johnson \& Johnson, 2002). In general, social interdependence (SI) exists when individuals in a group setting are mutually affected by the actions of others, a situation that is typical in the modeling instruction classroom (Johnson \& Johnson, 2009). There exist four types of social interdependence: positive interdependence, negative interdependence, social dependence and social independence. Positive interdependence occurs when students cooperate in ways that lead to constructive outcomes (ex. students working effectively with other group members to learn a topic). Negative interdependence occurs when students work together, but non-constructively on tasks (ex. students compete against other group members in a way that hinders their learning). Social dependence occurs when the goal achievement of an individual is affected by the actions of another individual, but not the other way around (ex. instructor helping students). Social independence occurs when students do not benefit from any inter-student engagement and are perhaps simply working by themselves. 
There are three constructs that have a reciprocal (e.g., two-way) relationship with SI: quality of relationships, effort to achieve, and social competence. That is, for groups that have positive interdependence, group members develop positive relationships, show greater effort to achieve and develop social competencies (Johnson \& Johnson, 2005). The reverse is also true: when a group has positive relationships, demonstrates greater effort to achieve and exhibits social competence, this is conducive to the development of positive social interdependence. Studying SI provides a lens to help understand why student-centered learning environments tend to lead to higher conceptual and attitudinal gains. Using the SI framework may lead to establishing ways to better implement instructional strategies that promote positive interdependence of students in small groups.

Social metacognition expands metacognition (MC) from an individual setting to a group setting (Jost, Kruglanski \& Nelson, 1998). Metacognition is a way to understand how a learner self-regulates their learning and monitors their own cognition. Social metacognition builds upon Metacognition to include how group members may regulate and monitor each other's cognition. When students cooperate in groups, it may increase the visibility of social metacognition since the interpersonal discourse may help to elucidate elements of cognition and regulation of learning (Dillenbourg \& Traum, 2006).

Social metacognition involves students distributing metacognitive demands, reciprocal scaffolding (e.g., how students build ideas from each other) 
and motivating one another, which in turn can lead to improved individual cognition (Chiu \& Kuo, 2010). Social metacognition aids in the construction of individuals' knowledge as group members motivate each other and help to monitor and regulate cognition. Social metacognition is a theoretical framework that is central to understanding how group members interact with each other's ideas. Studying SMC may lead to finding classroom strategies that promote productive discussions in which students construct their knowledge together.

\subsection{Research Questions}

The three related studies that form my dissertation are presented in Chapters 3,4 , and 5 . The research questions that frame this work are:

1. (Study 1, Quantitative):

1.1. How does the frequency of working in small groups predict students' conceptual learning gains and physics identity gains?

1.2. For students who regularly work in small groups during their physics classes, what instructional strategies are available to them and characterize their class experiences?

2. (Study 2, Quantitative):

2.1. How is social interdependence (particularly task and outcome interdependence) experienced by students in small group learning contexts associated with gains in conceptual understanding and physics identity outcomes? 
3. (Study 3, Qualitative):

3.1. Viewed through the lens of social interdependence and social metacognition, what are possible affordances and limitations to students' learning that are available through small group learning?

\subsection{Structure of the Dissertation}

Chapter 2 provides a comprehensive literature review of the theoretical frameworks used in my dissertation including PI, SI and SMC. In addition, it also presents prior work from which my dissertation builds and a review of the Modeling Instruction pedagogy. Chapter 3 presents the first study, which investigated how working in small groups affects student conceptual and physics identity outcomes using a nationally-representative sample of post-secondary physics students. Chapter 4 presents the second study; in it, I discuss the results of a quantitative study of how social interdependence may be associated with conceptual understanding and physics identity gains. Chapter 5 presents the third study, in which I qualitatively investigated group interactions using the dual lenses of social interdependence and social metacognition theory. All three of these results chapters have their own introductions, methods, results and discussion sections. In the sixth and final chapter of the dissertation, I offer some conclusions that connect the findings and themes of the three interrelated studies, limitations of this collective work, and identify possible future directions. 


\section{LITERATURE REVIEW}

In this chapter I present in detail the central theoretical frameworks introduced in Chapter 1: Physics Identity, Social Interdependence, and Social Metacognition. I also introduce theoretical foundations of group learning and a brief review of three successful, well-known approaches to teaching introductory physics that rely to varying extents on small group learning. Lastly, more details of Modeling Instruction will be provided, as this is the context for the studies presented in Chapters 4 and 5 . This chapter provides a summary of the fundamental theoretical frameworks that form the foundation of my dissertation. In particular sections 2.1 and 2.5 are central to the theme of my dissertation, sections 2.4 is critical to Chapters 3 , and 4 , sections 2.2 is most relevant for Chapters 4 and 5 , while section 2.3 is applied particularly to Chapter 5 .

\subsection{Theoretical Foundations of Student-centered Learning}

The theoretical foundations of small-group learning are rooted in the philosophy of education (e.g., Dewey, 1938), cognitive psychology (Huitt \& Hummel, 2003; Vygotsky, 1997), and social psychology (e.g., Bandura, 2001). Almost a century ago, Dewey argued that education and learning should be a social and interactive process, in which students take an active part in their learning. Some of these ideas have existed even longer than that, going back to the ancient Greeks (e.g., Socratic, Platonic, and Aristotelian schools of thinking). Piagetian and Vygotskian theories of learning and human development form the broad foundation of modern views on how people learn. Social Cognitive Theory 
(SCT) can also provide a particular theoretical lens to understanding how students interact in small groups.

Piaget and Vygotsky separately developed their own unique constructivist approaches to understanding learning but differed substantially in their approaches. Piagetian constructivism is rooted in an understanding that to build knowledge, individuals must construct it in their own minds (Cakir, 2008). Piagetian approaches emphasize how individuals construct their own knowledge based on their personal cognitive experiences (Schunk, 2012) and puts priority on the internal processes and phases of development through which learners pass. Notably for this dissertation, purely Piagetian views do not place significant emphasis on the social elements of learning and, interpreted narrowly, may not have an effective explanation for the role of a teacher in learning (Howe, 1996). Piagetian approaches have led to many modern approaches to supporting individual learners including, for example, the concept of a schema. Schemata informs a person of what to expect in a given situation and is formed from past experiences. In physics, students may come into introductory courses with naive or inconsistent schemata (Redish, 2004). These schemata may be difficult to change but need to be addressed in order for students to gain a deeper, more consistent understanding (Chi, 2005). Through the process of accommodation, learners may change their existing schemata to address inconsistencies or explain new phenomena that could not be understood with existing schemata (Posner et al., 1982). 
Vygotskian approaches, on the other hand, put priority on how knowledge is constructed through social interactions and form the theoretical foundation of modern socio-constructivism (Schunk, 2012). Vygotskian approaches emphasize the important relationship between everyday experiences and scientific concepts taught in school, and that collaboration between students and others (the instructor or other students) are needed to integrate these concepts together (Howe, 1996). The role of an instructor (or, indeed, any person interacting with the learner) can be understood in the context of the zone of proximal development (ZPD), in which an instructor or peer can support an individual to achieve a greater understanding (moving or expanding the ZPD) in comparison to a learner acting purely independently. The ZPD explains how a learner may be able to progress using prior learning and relying on social interactions with others. Whereas in Piagetian development, an individual learner often progresses through predictable, developmental stages, from a Vygotskian perspective, an individual may learn in a unique progression based on their own prior learning, experiences, and the scaffolding afforded by a teacher or other individuals. Since collaboration is essential in this view, providing students with more opportunities to interact and work with others is inherently likely to enhance any learning processes. Small group learning as a particular student-centered practice can be interpreted in a socio-constructivist perspective to be leveraging student-to-student interactions to scaffold students' learning and expand their ZPD. 
Social Cognitive Theory (SCT) provides a theoretical framework for understanding actions that individuals make, including in social settings, from an individual psychological perspective. SCT explains that the behavior, environment, and individual are all intertwined and affect each other in a reciprocal manner (Bandura, 1989). This theory takes into account how social environments and past experiences explain an individual's behavior, particularly related to choices/actions. Personal agency and self-efficacy are core concepts in SCT and help to explain how students make choices, learn and interact with others and their environment (Bandura, 1982, 2010). Agency refers to how much sense of control individuals feel they have over their life experiences and specific activities (Bandura, 2010; Godwin, Potvin, Hazari, \& Lock, 2016). Setting goals, initiating actions and reflecting are all examples of exerting individual agency. The more agency students have over their learning, the more likely they are to feel engaged and retain what they are working on (Zimmerman, 1990). In traditional classroom settings students often do not have significant control over the learning opportunities and hence lack agency. Self-efficacy, on the other hand, refers to self-belief in one's ability to accomplish a particular task effectively. Self-efficacy is related to, but not the same as, performance/competence beliefs, which are a component of students' PI (Bandura, 1982; Potvin \& Hazari, 2013). Self-efficacy has also been repeatedly shown to be predictive of performance in science (Andrew, 1998; Bell \& Kozlowski, 2002; Chemers, Hu \& Garcia, 2001). The relationship between self- 
efficacy and retention in introductory physics has also been well studied (Sawtelle, Brewe \& Kramer, 2012).

These learning theories each have tremendous depth, extremely broad literature bases, and tie together to help describe how and why students may achieve more through student-centered learning practices. The Piagetian approach offers a psychological interpretation to describe learning, while the Vygotskian approach focuses on the sociological elements of learning. A combined understanding of these two approaches offers a holistic explanation for how learning occurs. Students need to construct their own knowledge to create meaning, grasp new concepts, and be able to apply and extend these ideas to new situations. Students may accomplish these feats by scaffolding information within their zone of proximal development to construct their mental schemas. SCT contributes to this picture by considering how the environment, behavior and individual all act together.

\subsection{Foundations of Social Interdependence}

Social Interdependence Theory (SIT) provides a critical framework for understanding cooperative processes of groups (Forsyth, 2018). Social Interdependence $(\mathrm{SI})$ exists when individuals affect and are affected by the actions of others, a situation that is abundant in small groups. Interdependence is one of five characteristics that can be used to describe group dynamics. The next subsection will describe these five characteristics that make up group dynamics. Then, the following subsection will introduce the SI framework by first providing a 
brief historical overview and then describing the key features of the theory used for this dissertation.

\subsubsection{Introduction to Group Dynamics Theory}

The scientific study of group dynamics began in the late nineteenth century, and the uses and applications of this endeavor have a vast history. To define it, a group consists of two or more people connected by social relationships. There are five fundamental characteristics of any group which are: interactions, structure, unity, goals and interdependence (Forsyth, 2018).

- Interactions address the question of what people do when they are in groups (Bales, 2000). Bales summarizes two types of interactions: relationship interactions and task interactions. Relationship interactions pertain to the social or interpersonal interactions between group members. Task interactions are actions primarily focused on a group's work or activities.

- Structure is the norms, roles and member-to-member relations that organize the group.

- Unity is related to how a group holds together; that is, group cohesion.

- Goals are often the reason groups exist. A simple model of group goals can be broken down into 4 parts: generating ideas or plans, choosing a solution, negotiating a solution to a conflict, or performing a task (Straus \& McGrath,1994). 
- Interdependence is related to how group members depend on each other. Social Interdependence is necessary for group cooperation. These five characteristics are not mutually exclusive and often inform one another. These five characteristics are summarized in Table 1.

Table 1: Five characteristics of groups

\begin{tabular}{|l|l|}
\hline Characteristic & Description \\
\hline Interaction & $\begin{array}{l}\text { Groups members create, organize, and sustain relationship and task } \\
\text { interactions with other group members }\end{array}$ \\
\hline Structure & $\begin{array}{l}\text { Groups are often organized, so that meaning there are specific patterns, } \\
\text { roles and norms }\end{array}$ \\
\hline Unity & $\begin{array}{l}\text { Groups members often act cohesively with one another, and in some } \\
\text { cases may be considered a unitone whole }\end{array}$ \\
\hline Goals & $\begin{array}{l}\text { Groups facilitate the achievements or outcomes sought by its group } \\
\text { members }\end{array}$ \\
\hline Interdependence & $\begin{array}{l}\text { Group members are influenced by each other, forming a mutual } \\
\text { dependence between members }\end{array}$ \\
\hline
\end{tabular}

For parts of this dissertation, I focus on studying the interdependence and interactions of students while working on class assignments in small groups. I chose to study social interdependence (SI) because it is essential for effective cooperation. For students to succeed in small groups they need to work together and come to agreements on their assignments. The types of interactions examined in this work will be discussed in Section 2.3.

\subsubsection{Social Interdependence Theory}

The roots of social interdependence theory can be traced back to Koffka and Lewin in the 1930s, though this theory was not formalized until 1949 by Deutsch. At a time that theoretical physics was moving from a mechanistic to a field interpretation, so too was the study of groups. Rather than viewing groups 
from an individualistic and psychological perspective, scientists began to study groups from a cooperative and sociological perspective. Koffka proposed that a group was more than the sum of its parts, and should be viewed as dynamic wholes (Koffka, 1935/2013). Lewin added that the essence of the group is the interdependence among members, making it a dynamic object rather than a static one (Lewin, 1947/2016). Lewin said "Social events depend on the social field as a whole, rather than on a few selected items... it expresses certain general characteristics of interdependence (Lewin, 1947/2016, p. 9)." In other words, any change in the state of any member or subgroup will impact the state of other members or subgroups. Individuals are dynamic, perspectives change over time, and both are influenced by representations of the world as well as by social interactions.

Deutsch extended Lewin's ideas and conceptualized two types of interdependence: positive and negative (Deutsch, 1949/2011). Positive interdependence exists when individuals are linked in a way that they can only attain their goals (or maximize their achievement) through cooperating with others. Negative Interdependence exists when individuals perceive that they can only attain their goals by competing against others. Deutsch created a model of how a group members' social interdependence can lead to specific actions, in turn leading to psychological processes, interactions patterns and, finally, outcomes (see Figure 1). He labeled the action as effective if it contributed to achieving the goals of the group and "Bungling" if otherwise. Actions lead to the 
psychological processes of cathexis, substitutability and inducibility. "Cathexis" (originally labeled as "attitudes" by Deutcsh) "refers to the predisposition to respond evaluatively, favorably or unfavorably to aspects of one's environment or self." (Deutsch, 2001, p. 25) In other terms, it is how much group members value other members (or their efforts) in the group. "Substitutability" is "how a person's actions can satisfy another person's intentions" (Deutsch, 2001, p. 25) and, in the context of this work, it is the extent to which group members fulfill each other's needs for learning. "Inducibility" is "the readiness to accept another's influence to do what he or she wants." (Deutsch, 2001, p. 26) That is, it is the potential to influence and be influenced by others. These psychological processes in turn lead to interaction patterns such as promotive interactions, social skills, and group processing. Promotive interactions are actions that increase the likelihood of the group's success. Group processing is when a group collectively goes through tasks. All of these processes finally lead to the outcomes which are effort to achieve, quality of relationships, and social competence ${ }^{1}$. These outcomes will be further broken down below. This more comprehensive model of SIT, though originally introduced by Deutsch, was later expanded further by Johnson and Johnson (Johnson \& Johnson, 2005).

1 This is also referred to as "Psychological Health" 
Figure 1: Comprehensive model for Social Interdependence

This figure (Deutsch, 1949/2011; Johnson \& Johnson, 2005) provides a comprehensive view of how SI leads to outcomes. This shows that SI leads to actions, which lead to psychological processes, then interaction patterns that lead to more effort to achieve, quality of relationships, and social competence.

\section{Social Interdependence}

$\square$ Positive interdependence

Individual accountability

\begin{tabular}{|ll}
\hline & Actions \\
\hline$\square$ & Effective
\end{tabular}

\begin{tabular}{|c|}
\hline Psychological Processes \\
\hline $\begin{array}{l}\text { Positive cathexis } \\
\text { Substitutability } \\
\text { Inducibility }\end{array}$ \\
\hline Interaction Patterns \\
\hline $\begin{array}{c}\text { Promotive } \\
\text { Social skills } \\
\text { Group processing }\end{array}$ \\
\hline Outcomes \\
\hline $\begin{array}{l}\text { Effort to achieve } \\
\text { Quality of relationships } \\
\text { Social Competence }\end{array}$ \\
\hline
\end{tabular}

Deutsch's work laid the foundation for modern SI but made some limiting assumptions about the nature of groups. First, he assumed that group members only had one goal, but individuals acting in groups may have more than one simultaneous goal. Second, his work was based on the assumption that all group members shared power equally, which is demonstrably not the case. Third, Deutsch claimed that all participants acted in their own self-interests, which may not always be the case. Lastly, Deutsch treated each situation as if it was 
independent of the past and the future, which is not true for persistent (multisession) groups.

Johnson and Johnson $(2002,2005,2009)$ addressed these issues in their modernizing of SIT, as well as providing a simplified but more comprehensive model. In the modern SI framework there are four distinct types of social interdependence: independence, dependence, negative interdependence and positive interdependence (Johnson \& Johnson, 2002). Independence occurs when individuals function without other group members. Dependence occurs when the achievement of one individual is affected by another individual, but not vice versa. An example of dependence may be an instructor-to-student interaction, where the student may benefit from the social interaction but the instructor may not. Negative Interdependence occurs when students work against each other to accomplish their goals and usually involves overly competitive tasks where one individual's performance negatively affects that of another. Positive Interdependence occurs when students' mutual dependence on each other helps each individual to achieve their learning goals.

Positive Interdependence forms the foundation of group cooperation and is associated with three main outcomes: effort to achieve, positive relationships and social competence (Johnson \& Johnson, 2009). Figure 2 (Johnson \& Johnson, 1989) summarizes these outcomes, also described below:

- Positive relationships occur when constructive interactions and relationships exist among group members which can lead to effective 
support structures (e.g., study groups amongst students).

- Improved effort to achieve includes time spent on task, transfer of learned outcomes between one another, willingness to persist in challenging tasks and "higher level" reasoning like metacognition (Gokhale, 1995).

- Social competence includes positive attitudes, improved self-esteem, and improved social skills.

These "outcomes" actually have a reciprocal relationship to positive interdependence, meaning that they can also be considered predictors of positive interdependence.

\section{Figure 2: Simplified model for Social Interdependence}

This diagram gives a simplified visual understanding of SIT. It provides a more in-depth view of SI because of how all the inner-layers (sub-constructs of SIT) and the outer layer of positive interdependence are all reciprocally affected by each other. Taken from Johnson \& Johnson, 1989.

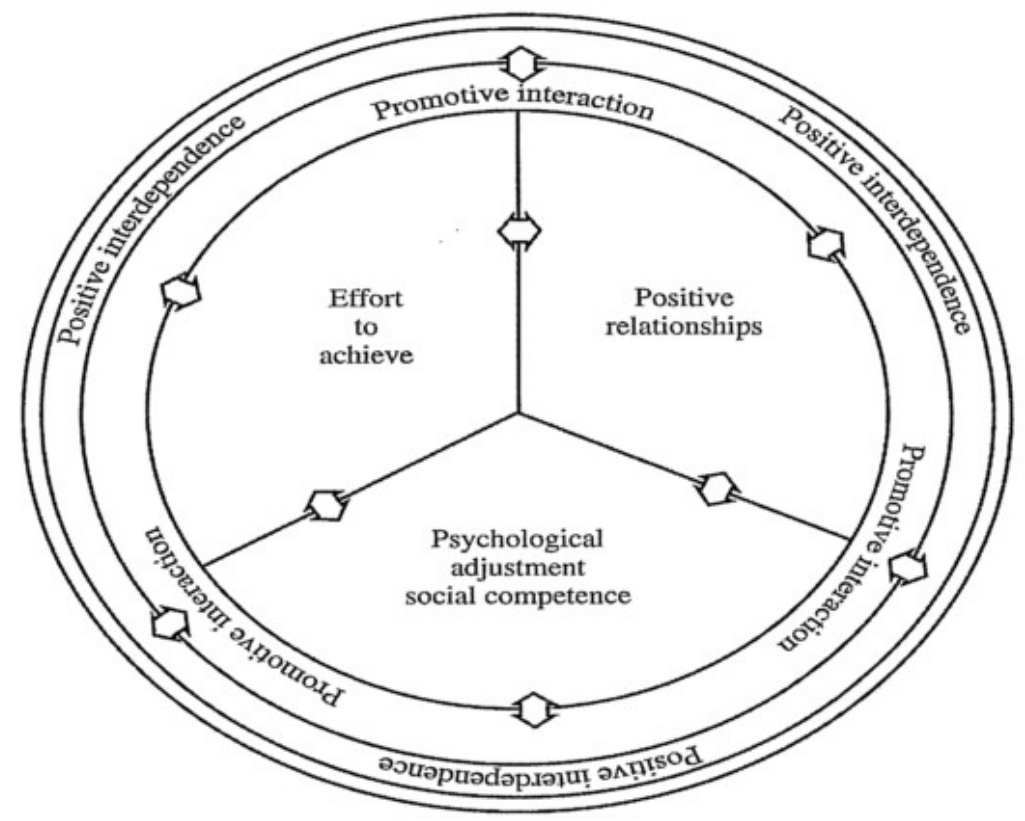


Interdependence can take on multiple forms, including role, resource, task and outcome interdependence. My dissertation particularly studies task and outcome interdependence, because this helps focus the research on how students interact with each other while working on tasks. "Task interdependence" describes how much a task requires the interaction of the entire group (Kiggundu, 1981). Task interdependence can shape the roles students have in a group and the coordination required between individuals (Kozlowski, Gully, Nason, \& Smith, 1999). Low task interdependence occurs when group members contribute to the task without significantly interacting with others. High task interdependence occurs when group members must interact significantly to carry out tasks and individual contributions cannot be easily separated. (Saavedra, Early, \& Van Dyne, 1993). "Outcome interdependence" describes the extent to which an individual's outcomes depended on the group interdependence. High outcome interdependence is characteristic of groups performing better, as each individual's outcome depends on the groups' performance (De Dreu, 2007).

Social Interdependence Theory has been used in an educational context to describe cooperative learning pedagogies (Johnson \& Johnson, 2009; Brewe, 2008; Beichner et al., 2007; Crouch \& Mazur, 2001). Small group learning in particular provides an abundance of opportunities for social interdependence to develop. When students are part of interdependent groups, they build social supports, show greater effort to achieve and improve their social competence (Johnson \& Johnson, 2005). By contrast, in a classroom setting without small 
group learning opportunities, students may be primarily or solely dependent on the instructor or static resources like a textbook. Social Interdependence Theory may also offer an explanatory framework for observed positive effects of collaborative learning environments on students, such as improved student attitudes (Gök \& Sýlay, 2010) and increased attendance rates (Deslauriers, Schelew \& Wieman, 2011) amongst other benefits (Laal \& Ghodsi, 2012).

\subsection{Social Metacognition}

This section outlines the second theoretical framework used to analyze small group interactions in Chapter 5. First, an introduction to metacognition is presented, followed by its expansion into social metacognition. Metacognition forms the foundation of social metacognition both historically and contextually. For the purposes of the current research, social metacognition develops certain features and has several benefits over a focus on individual metacognition, primarily due to the inherently social nature of the student interactions in small group learning.

\subsubsection{Metacognition}

Metacognition (MC) occurs when individuals monitor and self regulate their own thinking (e.g., "thinking about thinking"). A useful way to frame metacognition is through the use of primary and secondary thoughts (Briñol \& DeMarre, 2012). Primary thoughts are cognitive and involve associating some attributes to an object (e.g., "The velocity changes quickly") while secondary thoughts are metacognitive and involve students reflecting on those primary 
ideas (e.g., "Why do I think that the velocity change so fast?") (Briñol \& DeMarre, 2012). Enhancing metacognition should allow students to better regulate their learning, build self-awareness of how they learn, evaluate their personal learning needs, generate a plan to meet those needs and then implement those strategies (Hacker, Dunlosky \& Graesser, 2009).

Metacognition is described as involving various types of metacognitive knowledge, and elements of self-regulation. There are three types of metacognitive knowledge: declarative, procedural and conditional (Schraw \& Moshman, 1995). "Declarative knowledge refers to knowing about things" (Schraw \& Moshman, 1995, p. 352) and may include knowledge about oneself as a learner or what factors may influence performance. An example of a declarative statement is "I know the acceleration is constant because the object is free falling." "Procedural knowledge refers to knowing how to do things" (Schraw \& Moshman, 1995, p. 352) and includes knowledge about how to execute procedures. Procedural statements might be "If we keep working at this pace, it'll take us an hour to finish" or "I don't understand why this experiment is so difficult." "Conditional knowledge refers to knowing the why and when aspects of cognition" (Schraw \& Moshman, 1995, p. 352) and may be thought of as a combination of declarative and procedural knowledge. An example of procedural knowledge is "we know the acceleration but we still have to measure the velocity." 
Metacognition also involves elements of self-regulation including planning, monitoring and evaluating. Planning occurs when students are selecting strategies for allocating resources for accomplishing a task. Self-regulation could, for example, take the form of a student designing an experiment or choosing an approach on how to solve a problem. Monitoring occurs when students are aware of their comprehension and performance of a task. An example of monitoring could be a student asking themselves if an experiment is going as planned. Evaluating refers to appraising the performance and effectiveness of a task.

Metacognition helps students develop self-awareness of what they learn through assessment of their own thought processes. Being metacognitive can allow students to gain an understanding of the learning processes and methods that work best for a given situation (Schunk, 2008), and allows students to selfscaffold when they reframe and evaluate their thinking (Holton \& Clarke, 2006). It can also help students manage their personal experiences which may enhance their motivations (Hacker \& Bol, 2004). Having metacognitive skills may lead to greater academic achievement and success (Young \& Fry, 2008; Coutinho, 2007). Incorporating methods that encourage metacognition have been shown to lead to more effective instruction (Schraw, Crippen \& Hartley, 2006), improved problem solving (Schoenfeld, 1992), better working memory skills (Autin \& Croizet, 2012) and increased task efficiency (Hoffman \& Spatariu, 2008) among other outcomes. 
The benefits to emphasizing metacognition in education are clear. There are various ways to encourage metacognition through instructional practices. Metacognitive instructional strategies include having students set their goals, engage in self-monitoring, and identifying the boundaries of their understanding. Specific activities that encourage metacognition include having students selfquestion, make checklists, create diagrams or concept maps, and engage in reciprocal instruction (Blakey \& Spence, 1990). These strategies can be implemented at an individual or at a group level. However, when students work in groups it may increase the visibility of individual metacognition since group members may be able to regulate and reflect on other students' ideas (Chiu \& Kuo, 2010).

\subsubsection{Social Metacognition}

When students engage in metacognitive thinking in a social setting, it may take the form of social metacognition (SMC). Social metacognition is the process by which group members monitor and regulate each other's thoughts (Chiu \& Kuo, 2010). In this dissertation, a student who responds metacognitively to the ideas of another student is said to be engaged in inter-student SMC. On the other hand, a student metacognitively reflecting on their own thoughts is said to be engaged in individual, or intra-student, metacognition.

Social metacognition involves students engaging in metacognitive processes with one another, either through regulation or using metacognitive knowledge. For example, the regulating activities of planning, monitoring and 
evaluating may be divided up between group members. Working in a group may make students' mental processing more "visible" as they engage in the necessary dialogue to accomplish their learning goals. Such visibility makes it possible to study students' social metacognitive dialogue. Analyzing students in situ using a social metacognitive lens may further our understanding of how students scaffold knowledge and distribute their learning challenges. When students build shared knowledge and expand their understanding they may be engaged in reciprocal scaffolding (Hmelo-Silver \& Barrows, 2008), which also involves group members recognizing each other's consistent and inconsistent ideas (Cobb, 1995, Chiu, 2000). The benefits to students of experiencing social metacognition include: distributing metacognitive demands (Johnson, Johnson, \& Smith, 2007), increased visibility of metacognitive processes (Dillenbourg \& Traum, 2006), improving individual cognition (Salonen et al., 2005), reciprocal scaffolding (Holton \& Clarke, 2006), and greater motivation (Chiu \& Khoo, 2003).

\subsection{Physics Identity}

In this dissertation, I assess the impacts of various classroom experiences on measures of physics affect; specifically, on physics identity (PI). Physics Identity is a theoretical framework that, generally, allows a researcher to understand how students see themselves as a physics person. The particular identity framework used in this dissertation comes from the broader identity literature, anchored by the work of James Gee (Gee, 2000). For this dissertation, $\mathrm{PI}$ is treated (and measured) as a quasi-trait (meaning that attitudes and beliefs 
are semi-stable over time) that is associated to three related sub-constructs (see Figure 3): physics interests, recognition beliefs, and performance/competence beliefs (Godwin, Potvin, Hazari, \& Lock, 2016;Hazari, Sonnert, Sadler, \& Shanahan, 2010; Potvin \& Hazari, 2013). Physics interests have been found to be predictive of students' $\mathrm{PI}$, as have recognition beliefs (beliefs that one is seen as a physics person by others including teachers, peers, and family). The latter is in fact the most important predictor of developing a physics identity, which has been measured and validated in several different contexts (e.g., see Godwin, Potvin, Hazari, \& Lock, 2016; Potvin \& Hazari, 2013). Moreover, recognition beliefs may be directly influenced through social interactions with others, including teachers and peers. Performance/competence beliefs have been found to have a more distant relationship to developing a $\mathrm{PI}$, often mediated through physics interests and recognition beliefs. 
Figure 3: Physics Identity diagram

This diagram (Potvin \& Hazari, 2013) shows the three interrelated sub-constructs that influence an individual's physics identity.

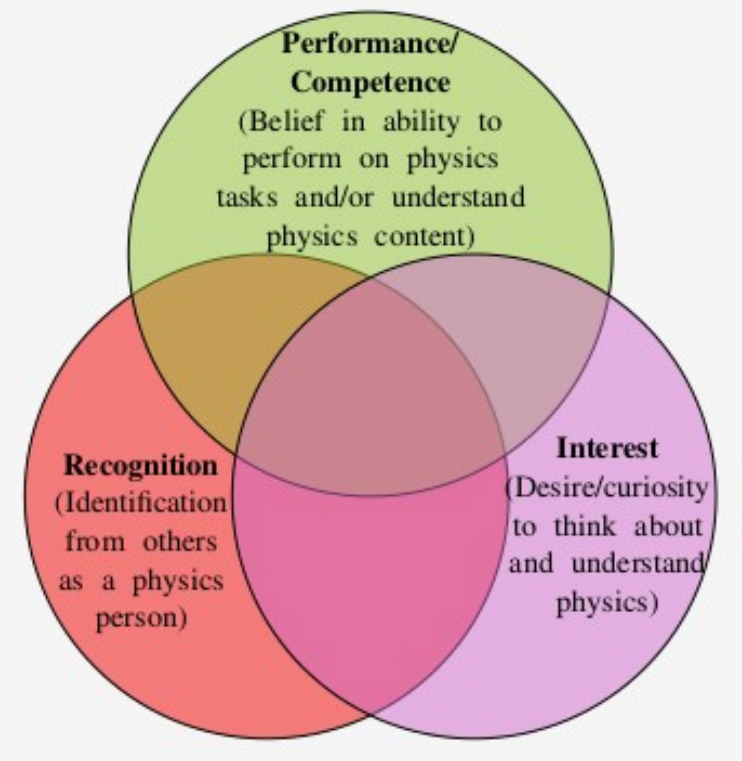

This particular construction of identity is salient because it has been repeatedly found to be predictive of career choice in several STEM disciplines (Cribbs, Hazari, Sonnert \& Sadler, 2015; Godwin, Potvin, Hazari, \& Lock, 2016; Hazari, Potvin, Tai \& Almarode, 2010; Hazari, Sonnert, Sadler, \& Shanahan, 2010). This framework provides a lens to understand why people may choose to pursue physics or physics-related studies. By better understanding which elements of classroom environments may affect $\mathrm{PI}$, instruction that provides support for students' physics-related career choices may be provided.

\subsection{Examples of Student-centered Learning in Introductory Physics}

Improvements in conceptual learning outcomes in student-centered environments across STEM fields, including in introductory physics specifically, have been widely reported (e.g., Freeman et al, 2014; Hake, 1998). There are 
also attitudinal and longitudinal benefits to student-centered learning (OliverHoyo \& Allen, 2005; Sharan, 1980). The basic theoretical foundation of these pedagogies were introduced in section 2.2; here, a more detailed discussion of the implications of these theories for introductory physics is presented. In particular, Modeling Instruction is presented in particular detail since it forms the classroom context in which the studies of Chapters 4 and 5 were conducted.

To be actively involved, "students must engage in such higher-order thinking tasks as analysis, synthesis, and evaluation" (Bonwell \& Eison, 1991 p. 5). In physics classes, such tasks could entail participation in problem solving, building scientific models, performing experiments and collecting data, constructing Gedanken/thought experiments, performing data and/or error analysis. There are many existing research-based pedagogies/curricula in physics that involve many of these tasks, and that are founded on Piagetian and Vygotskian perspectives on constructivism. In this section, three particularly instructive approaches that involve students frequently working in small groups are presented: Modeling Instruction (Halloun \& Hestenes, 1987; Brewe, 2008), Student-Centered Activities for Large Enrollment Undergraduate Programs (formerly "Undergraduate Physics", SCALE-UP) (Beichner et al., 2007), and Peer Instruction (Crouch \& Mazur, 2001). All have been shown to improve student conceptual learning. (Note that in this dissertation I do not directly test or compare these three approaches; rather, I discuss them here because of their reliance on small group work and their relatively widespread use.) 
To measure learning outcomes, a common practice in these and other reform efforts is to use physics concept inventories, including in this dissertation (notably in Chapters 3 and 4). The Force and Motion Conceptual Evaluation (FMCE) (Thornton \& Sokoloff, 1998) in particular is a long-established measure of physics conceptual understanding. The FMCE has been validated and allows an educator, independent of the course of interest, to make a measurement for the conceptual knowledge of students (Ramlo, 2008; Ishimoto, Thornton \& Sokoloff, 2014).

\subsubsection{Modeling Instruction}

Modeling instruction has been used and refined at FIU for over 15 years, builds off widespread implementation of $\mathrm{Ml}$ in high schools and is based on the Modeling Theory of Instruction (Hestenes, 1987; Cabot, 2008; Jackson, Dukerich \& Hestenes, 2008). Modeling Instruction is the classroom context for the studies presented in Chapters 4 and 5. Modeling Instruction is an example of how classroom reform would look from top to bottom, it is a studio-based, integrated instructional method that focuses on building physical models (Brewe, 2008). Typically there are 50-100 students in the course along with the instructor and 34 assistants. Little or no formal lecturing takes place; instead, students communicate in and between their groups to build their understanding of physics while working on well-structured assignments.

In a MI Introductory Physics course, students work in tables of six (two groups of three, assigned by instructors at random for a period of 2-3 weeks) on 
various structured activities (which might involve data collection, interpretation, explication of prior beliefs, making evidence-based extrapolations, solving physics problems, etc.). Then they discuss their work with their peers (often on hand-held white boards or similar) in what are called board meetings where each group creates a white board and talks about what they learned in a large circle consisting of about 24-30 students. Board meetings are unique to $\mathrm{Ml}$ and allow for a couple dozen students to discuss what they learned, as well as what they don't understand. The instructors' (faculty, teaching assistants, or learning assistants) role during class is to mediate discussions and assist the students as they navigate the activities. Students are given complete agency over their learning, and their ideas are fine tuned (if needed) by the instructors and assistants during their board meetings. Another reason that $\mathrm{MI}$ is so unique is because there is a focus on building models using representations. The use of multiple representations give students alternative ways of solving physics problems. Instead of solely relying on math, they are taught to write descriptions, draw diagrams (FBD, circuit diagrams, etc.), energy pie charts, system schemas, and other useful representations that allow them to visualize and solve the problem. Students use these representations to build comprehensive models to explain the physical systems they encounter.

When students work in small groups, they are scaffolded to use several different types of representations that work together to build models. Figure 4 (McPadden, 2018) provides an example of a model consisting of different 
representations, which allow students to express different aspects of a phenomenon. The use of multiple representations allows for students to check for consistency, and communicate their ideas with classmates (Ainsworth, 1999; Hinrichs, 2004). The student-centered nature of the MI course made it ideal for studying students working in small groups.

\section{Figure 4: Example of whiteboard with physics model}

Example of whiteboard summary of a model solution of a physics problem. The problem is that of an accelerating train, and several different representations are shown. Taken from McPadden, 2018.

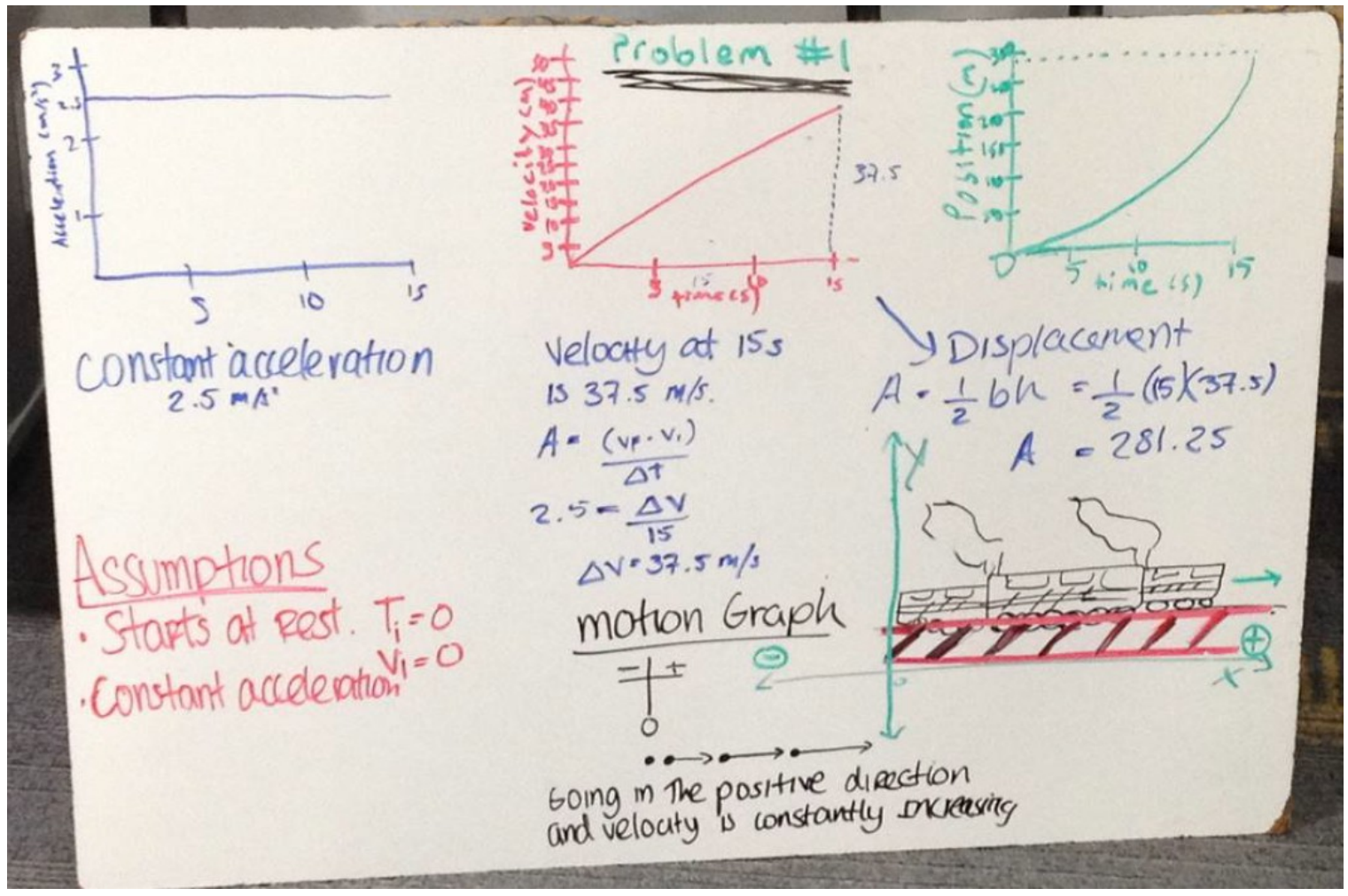

Combined with the group learning structure of the course, the activities in MI are designed to support students' metacognition (particularly, reflecting on assumptions and limitations of naive thinking), thus providing a rich context for studying social metacognitive dialogue (Louca \& Zacharia, 2012). Among the 
metacognitive strategies used in MI are model building, inquiry-driven activities and regular reflection on learning outcomes/models. Building a model in this environment requires coordinating multiple representations that, taken together, are coherent, complete and consistent in representing physical systems. These representations act as metacognitive artifacts, helping students to be aware of what they are thinking in a given situation and communicate them with others. Many $\mathrm{Ml}$ activities are designed to be inquiry-based and instructors also apply metacognitive techniques to support students to build coherent approaches to understanding physical systems. Regular reflection at the end of every activity (in the form of the whiteboard presentations to other students) allows students to recognize what they have learned and still do not feel comfortable with.

There is strong evidence for the effectiveness of increasing learning gains of students who experience a MI course. A study of 3394 high school students with teachers who were expert modelers saw normalized learning gains that were twice as big as traditionally taught students, as measured by the Force Concept Inventory (FCI) (Jackson, Dukerich \& Hestenes, 2008). Further, there is evidence of improved physics-related attitudes (Brewe, Kramer \& O'Brien, 2009; Sawtelle, 2011) and positive impacts on women and underrepresented students (Brewe, 2010). Further, the use of MI has led to a substantial increase in the number of declared physics majors at FIU (Kramer, 2018). Modeling Instruction is the oldest of the three reformed curriculum discussed here and offers a complete alternative to lecturing, as presently there is none. It is also unique in 
that it changes the way students solve physics problems, by placing an emphasis on building models that are coherent, consistent, and complete.

\subsubsection{SCALE-UP}

Student-Centered Activities for Large Enrollment Undergraduate Programs (SCALE-UP) is another studio-based instructional method. Students experience reduced lecturing (10-15 minutes per hour of class) and instead spend significant class time working in small groups on pre-assigned activities or labs which may incorporate computer-based learning or simulations (Beichner et al., 2000). SCALE-UP was designed for 25-100 students only having 2-4 instructors (Professor and TA's). It also integrates the course and lab into one, and is designed to run from 4-6 hours a week in 2 hour blocks. Online reading quizzes are due before the material is covered, and there is sometimes a brief lecture of $10-15$ minutes in the beginning of class. Technology is built into every class experience allowing students to collect data, set up experiments, model mathematics, and view virtual simulations and demonstrations. The dialogue between professor and student is semi-Socratic, in order to make the students think and try to come up with the answer given the tools provided. There are a wide variety of activities in SCALE-UP, as well as other instructional designs which are described in Beichner et al., 2000.

SCALE-UP has had great success in their students' performances especially compared to traditional physics courses. Research has found positive improvements in students' conceptual gains and overall satisfaction (Beichner et 
al., 2007). A study including 15,954 university students found there was a much larger normalized gain in physics conceptual knowledge for SCALE-UP students (.483) than lecture students (.204), again as measured by the $\mathrm{FCl}$ (Beichner et al., 2007). Further, the failure rate in SCALE-UP courses was reduced significantly especially for women and minorities, class attendance was higher and there were improvements in student attitudes about the course (Beichner et al., 2007). Now over 250 institutions implement SCALE-UP and it has been successful in providing highly interactive, computer-rich, learning environments for students.

\subsubsection{Peer Instruction}

The last example of successful implementation of student-centered pedagogies used in Introductory Physics to be discussed is the instructional method known as Peer Instruction (Crouch \& Mazur, 2001). Peer Instruction is designed to fit into the standard lecture and discussion style format and involves class clicker questions, called ConceptTests, that require the students to work together with the people around them to answer them. These ConceptTests also make up part of the exams to encourage student involvement. Peer Instruction uses a mechanics based text and required the students to take quizzes, testing their comprehension of the material, prior to the class in which the material was covered. About a third or half of a class is spent solving ConceptTests, and the rest is spent lecturing. The discussions are made up of cooperative learning activities, in which the TA assists the students. Peer Instruction is used in over 
100 institutions and fits easily into most current University systems. It still requires effort and time to change up the curriculum but at the end the students learn more (Turpen \& Finkelstein, 2009).

Peer Instruction has evolved over time but overall has led to higher student conceptual gains (Crouch \& Mazur, 2001). Research has found improvements in conceptual understanding using the $\mathrm{FCl}$ and the mechanics baseline test, after implementing Peer Instruction, across many different institutions (Fagen, Crouch \& Mazur, 2002). Research on Peer Instruction has also reported a reduction in the "gender gap" in conceptual understanding (Lorenzo, Crouch \& Mazur, 2006). However, this study has not been reproducible and there is strong evidence that shows these gender gaps continue to persist in reformed physics courses (Kost, Pollock \& Finkelstein 2009). With all this considered it is practical to talk about PI because of how well it fits into any course, even a 300 student course. In this sense PI is an economical approach which does not require a studio style classroom as MI and SCALE-UP do while at least providing some daily small group interactions.

\subsubsection{International Success of Student-centered Pedagogies}

These three and similar pedagogies have also been found to be successful in differing nations cultural contexts. In France, the introduction of Peer Instruction and similar strategies led to improvements on the $\mathrm{FCl}$, the Conceptual Survey of Electricity and Magnetism (CSEM, Maloney et al., 2001), final exam grades and overall course satisfaction (Rudolph et al., 2014). In the 
UK, researchers observed conceptual improvements after the adoption of an inverted classroom approach (Bates \& Galloway, 2012). A study in China found improved student attitudes, as measured by the C-LASS (Adams et al, 2006), and the development of more expert-like views after implementing Peer Instruction (Zhang, Ding \& Mazur, 2017). These findings illustrate that the benefits of these classroom strategies are not confined to U.S. contexts. 


\section{FREQUENT SMALL GROUP INTERACTIONS IMPROVE STUDENT LEARNING GAINS IN COLLEGE PHYSICS: RESULTS FROM A NATIONALLY REPRESENTATIVE PRE-POST STUDY}

\subsection{Introduction}

In the past decade, the President's Council of Advisors on Science and Technology has called for a 33\% increase in bachelors degrees in STEM disciplines (Gates et al., 2012). Physics is an important topic for many science and engineering majors, and can often serve as a gatekeeper for those students (Gainen, 1995). In the past 20 years physicists and physics educators have found that students taught in traditional lecture physics courses often lack conceptual understanding of physical principles, even when they can solve many standard problems (Byun \& Lee, 2014). There is a clear need to support students' conceptual understanding of physics. Besides the effort to improve student learning, there is also a need to increase the number of physics majors in the United States. Compared to biology and chemistry, for example, physics has seen significantly less growth in terms of the number of students majoring in physics (NCES, 2020). The fraction of incoming freshmen who choose physics as a major is less than forty years ago, although the raw number of majors has rebounded in recent years from an historic low in the late 1990s (AIP, 2020). Also, there is a stark dearth of participation of women and students identifying with traditionally-marginalized racial/ethnic identities in physics (Merner \& Tyler, 2017; NCES, 2019; Porter \& Irvie, 2019). It has been variously argued (Brewe et al., 2010; Lorenzo, Crouch \& Mazur, 2006; Moriarty, 2007) that all of these 
problems are solvable through reformed physics instruction such as the use of student-centered approaches that create more inclusive learning environments, by giving students more opportunities to co-construct their understanding of physical systems.

In the United States, educators, policy-makers, and education researchers have promoted instructional methods that incorporate more active learning approaches in classrooms of all subjects at the K-12 and post-secondary levels since at least the 1980's (Cross, 1987). Ideas of "active" learning pre-exist such initiatives and, since the initiation of these efforts, many studies indicate that active learning experiences in STEM lead to improved student outcomes. One recent meta analysis that considered results from over 225 separate studies (including 29 in physics specifically) found that for STEM courses,"students in classes with traditional lecturing were 1.5 times more likely to fail than were students in classes with active learning" (Freeman et al., 2014). In another, earlier study, it was reported that students in introductory physics courses taught with "interactive engagement" methods experienced conceptual, normalized gains two standard deviations higher than students taught with traditional methods (Hake, 1998). The definitions used in these works for active learning and interactive engagement are broad, somewhat non-specific, and could include many different classroom practices and teaching methods that are rooted in different theoretical traditions and with different goals in mind. While the earlier work provides strong evidence for the generic benefits of "active learning," it is 
not clear which elements of these approaches are particularly beneficial. Further investigation is needed on what specific aspects of active learning are effective for introductory physics instruction. Many different approaches that might all be characterized as "active learning" may not be directly comparable or commensurate.

Collaborative learning, a subset of practices that might be captured under the broad umbrella of active learning, occurs when students work together on a shared learning activity or towards a common objective (Dillenbourg, 1999). In particular, small group collaborative learning, as a particular instantiation of collaborative learning generally, has been shown to be an effective instructional strategy which leads to greater academic achievement, improved attitudes toward learning, and increased persistence across STEM fields (Springer, Stanne \& Donovan, 1999). Of the studies that have explored the effectiveness of small group learning, relatively few have delved into the particular facets of what students do in small groups and what makes them effective. Much work in this space has been conducted in the context of single institutions and/or have focused on specific pedagogies, such as the use of Modeling Instruction (Brewe, 2008), Peer Instruction (Crouch \& Mazur, 2001), or SCALE-UP (Beichner et al., 2007), etc.. Thus, a limitation of the existing literature on small group learning is that the cross-classroom (or cross-contextual) features of these practices have not been well understood or subjected to comparable analyses. Furthermore, the impacts of various methods on students' attitudes, including their physics 
identities (Hazari, Cass \& Beattie, 2015; Lock et al., 2015; Wang \& Hazari, 2018) have not been studied in as great a detail as students' conceptual learning. Several reformed pedagogies (e.g., see Crouch et al., 2007) continue to find that students suffer declines in their physics-related attitudes despite improved learning gains, which limits the possibilities of recruiting and retaining a larger, more diverse population of physics students, as attitudinal constructs such as physics identity (Hazari et al., 2010) have been shown to predict future physicsrelated career choices more than solely past performance.

Thus, the current study sets out to answer the following two questions, in the context of a nationally-representative sample of students enrolled in introductory university-level physics (both calculus- and algebra-based):

- How does the frequency of working in small groups predict students' conceptual learning gains and physics identity gains?

- For students who regularly work in small groups during their physics classes, what instructional strategies are available to them and characterize their class experiences?

\subsection{Survey Data}

The data analyzed in this chapter were drawn from the Conceptual Understanding and Physics Identity Development (CUPID) survey (see Appendix 1). The CUPID instrument was developed in 2014-2015, drawing on earlier work (e.g., the Sustainability and Gender in Engineering (SAGE) instrument, see Godwin, Potvin, Hazari \& Lock, 2016). In fact, two separate instruments were 
developed, one for use as a pre-course instrument and one for use as a postcourse measure. Both instruments contained the same questions to measure conceptual understanding and physics identity $(\mathrm{PI})$, so pre-to-post results may be reported, but the two surveys varied on the other questions. The pre-survey included a total of 44 multi-part questions and probed students about their career intentions, previous science learning, demographics, family support for science, and prior academic performances. The post-survey also included 44 questions, but instead asked students to detail the physics course they had just taken, in addition to the common constructs indicated. Primarily, these latter items were structured to offer frequency response options (e.g., "every class," "once per week," "once per month," "1-2 times a semester," "never"). A preliminary draft of each survey was distributed to a selection of students and faculty, who provided feedback for improvement and evidence in support of content validity of the various items. The complete, final version of both surveys is attached in the appendices. Further details of relevant items relevant are presented below.

The CUPID survey data used in this chapter were collected from students enrolled in first semester, introductory physics (both algebra- and calculusbased) recruited from a stratified random sample of colleges and universities nationwide. Initially, a list of all colleges and universities in the U.S. (maintained by the National Center for Education Statistics) was acquired. It was then stratified to account for two considerations: institution size and course type. For institution size, the sample was divided into small, medium, and large institutions 
to ensure the sample fairly represented the substantial number of small institutions in comparison to the much sparser, and much larger, state institutions in the U.S. The course type was also considered so that the ratio of algebra- and calculus-based introductory physics was roughly the same as that ratio nationally. Once this stratification was complete, 32 institutions in total were recruited to deploy two surveys near the beginning and end of their regular stream, introductory physics I (e.g., mechanics) classes.

In the end, 1,704 responses were received for the pre CUPID survey and 621 students in the post CUPID survey spread across 22 institutions in the fall of 2015. Students were given the surveys in their classrooms as paper and pencil instruments. Using students' self-reported identifiers (primarily, unique student numbers), the pre and post surveys were matched giving a sample of 371 individual students enrolled at 19 different institutions. Even though the matched data were only a subset of the originally recruited sample, the matched sample had a distribution similar to the national average of students in the algebra- and calculus-based introductory physics courses. In the sample there were 138 students in algebra- and 201 in calculus-based physics courses (with 32 NA's), as compared to the $\sim 153,000$ algebra- and 179,000 calculus-based physics taught nationwide (Porter \& Irvie, 2019).

\subsubsection{Assessing Physics Conceptual Knowledge}

Portions of the FMCE were used to measure students' physics conceptual knowledge (Thornton \& Sokoloff, 1998). Since these items were part of a longer 
survey, for time, they needed to be trimmed so that the entire survey took approximately 20-25 minutes. With the time length in mind, only 17 questions out of the 43 that appeared in the original FMCE were adopted into the surveys. The items with strongest validity and reliability according to prior work (Ramlo, 2008) were prioritized. The questions chosen tested key concepts such as Newton's three laws and momentum. The following problems from the FMCE were selected (in the order that they appear on the CUPID survey): the sled (questions 1-7), office chair (question 39), collision (questions 35-37) and force vs. time graph (questions 14,16-19, 21). On the CUPID survey (Appendix 1) they are questions $9-25$ on the pre survey and questions $25-41$ on the post survey.

The Force Concept Inventory ( $\mathrm{FCl}$ ) and FMCE are both widely used for measuring conceptual understanding in general physics 1 , but they target slightly different topics (Thornton, Kuhl, Cummings, \& Marx, 2009). There are a few reasons the FMCE was used over the $\mathrm{FCl}$. The first and most important reason is that the FMCE has been shown to have better validity than the FCl (Thornton, Kuhl, Cummings, \& Marx, 2009). Also the FMCE covers Kinematics and Newtonian concepts in 1-D, whereas the $\mathrm{FCl}$ explores these concepts in more than 1-D. This means that the FMCE has questions that require less time than the $\mathrm{FCl}$ and the CUPID survey used in this study could not be more than $20-25$ minutes long. This time restriction was important because the surveys were participatory and designing a survey too long may have led to less student participation. 


\subsection{Analysis}

Linear regression analysis was used to determine which classroom experiences are associated with learning and PI gains. Since the sample includes students who had a matching pre-to-post survey, the raw change in both FMCE responses and PI could be calculated. The items that had "frequency" (of various classroom experiences) responses were treated as categorical variables, using the 'never' responses as the basis of comparison to all the other response options.

Before the modeling building phase, the R package Amelia was first used to perform multiple imputation on the data set to maximize the statistical power and reduce statistical biasing due to non-response, which was about $2 \%$ in the items used in the current analysis (Honaker, King, \& Blackwell, 2015). Multiple imputation is a best practices approach to preserve statistical power and handle missing data, and is much more robust than the common practice of listwise deletion (e.g., deleting any individual with any missing responses), amongst other approaches. Multiple Imputation takes the distribution of the observed data collected to iteratively estimate the missing values. The imputation process is numerical and incorporates the extent to which other observed variables in the imputation model can predict its true values (Johnson \& Young, 2011). Thus, a new source of variance, reflecting the uncertainty of the missingness, is introduced into the process, which is the reason to carry out the imputation process multiple times. In this case, twenty imputations were generated. The 
Amelia algorithm uses a bootstrap-based expectation-maximization algorithm that efficiently handles the missingness and random error. A ridge prior was added to account for the collinearity among the variables in the imputed model by setting the empri setting to $10 \%$. (A ridge prior shrinks covariances but keeps the variances and means the same.)

After the imputing stage, the now complete, multiple data sets are analyzed in parallel using the statistical method of choice (in this case, linear regression) and then the analysis on the individual imputed datasets are pooled together, to give a combined result. The package Zelig was used for these last two stages with the Amelia-generated data (Choirat, Honaker, Imai, King, \& Lau, 2016). Zelig is intended to be used with Amelia-generated data files and appropriately handles the within- and between-imputation variance in generating estimates using Rubin's rule (Royston, 2004). After identifying significant effects in the linear regressions, the effect size of various factors was calculated to understand the practical importance of the findings using the package effsize in R (Torchiano, 2016). Descriptive statistics were also used to explore what the students reported happening in their classroom. The descriptive analysis was used to generate a picture of what the students experienced in their courses, specifically to compare between those people who reported working in groups everyday (which, as will be reported below, was found to be a significant predictor of learning gain) versus those that did not. 


\section{$3.4 \quad$ Results}

\subsubsection{Modeling FMCE gain}

In the regression model appearing in Table 2, it is evident that students who reported working in small group activities every class had significant $(p<0.001)$ improvements in their normalized FMCE gain, as seen in Model 1. Translated to the 17 FMCE items asked on the survey, students who reported working in small group activities every class had an improved gain of nearly 2.6 points (or $15 \%$ of the response scale), compared to the rest of the sample. To illustrate this difference, Figure 5 presents the histogram of FMCE gain (post minus pre) for the group of students who reported small group work every day (Group A) versus those that had small groups less frequently (Group B). There were 41 students in Group A, 318 in Group B and 12 students that were not categorized due to leaving the question empty. To correct for this missingness, the data were imputed 20 times. Then all the imputations were combined to include all 371 students and perform the subsequent analysis. The gain of Group A is clearly spread across positive gain (mean gain 3.2 , median of 2 ) while that of Group B is clearly centered around zero (e.g., mean gain of 0.63 , median of 0 ). Also, there is a notably greater fraction of students in Group A whose scores skew particularly high.

The effect size of the difference in gain between these two groups was also calculated and found to be "large" (according to Cohen's categorization, Rosenthal, Cooper \& Hedges, 1994), at 0.86 (95\% confidence interval: 0.77 to 
$0.92, p<0.05)$. This large effect size underscores the real-world importance of these results, providing evidence that regular engagement in small group learning is beneficial to learning physics concepts. These results are consistent with other literature that has argued in favor of the benefits of this type of collaborative learning (Dolmans \& Schmidt, 2006; Michaelsen, Knight \& Fink, 2004).

Figure 5: Comparison of FMCE scores by density

This figure illustrates the comparison of the pre-to-post FMCE gains for students that worked in small groups every class (Group A) and students that did not (Group B).

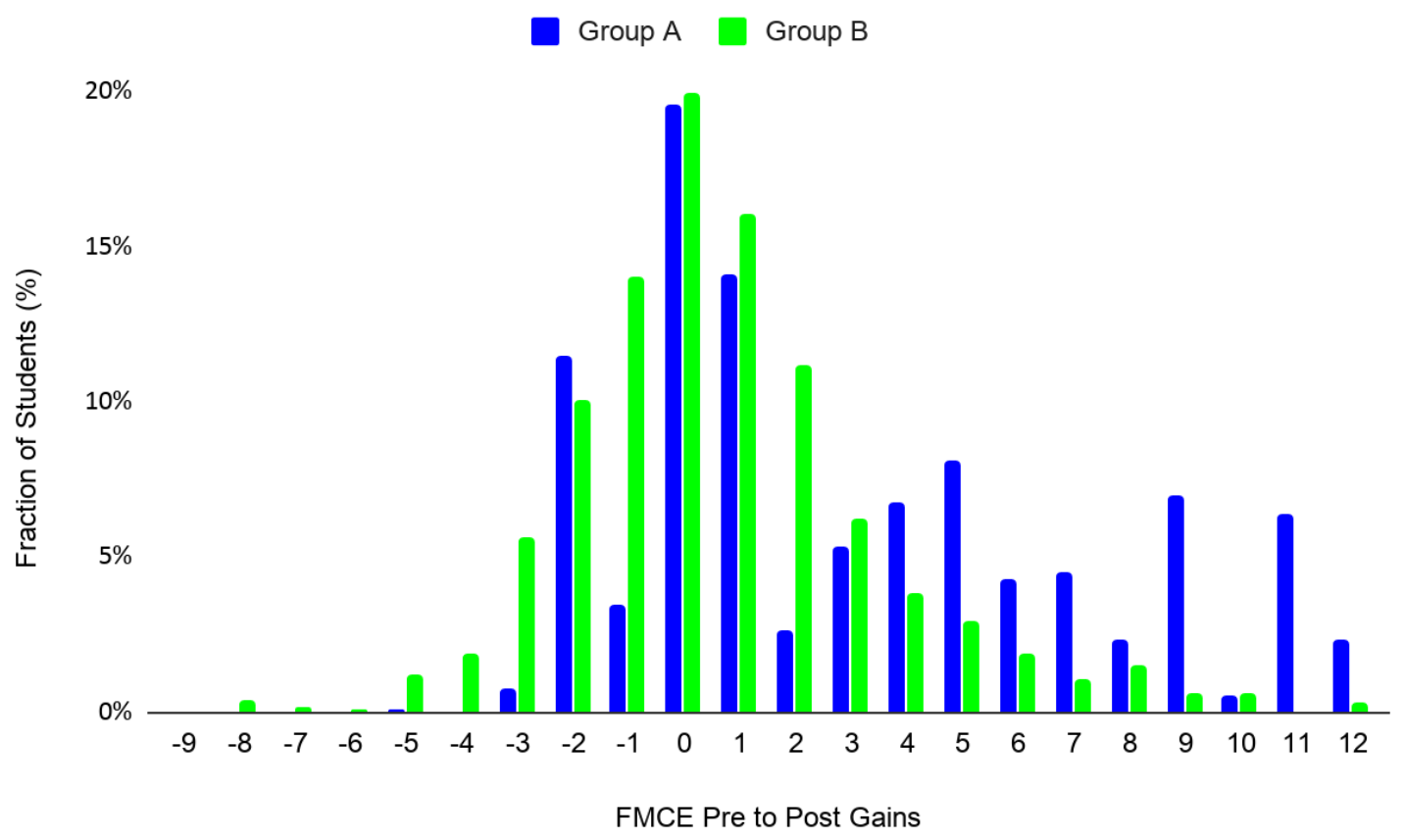


Table 2: Linear model for FMCE and frequency of small group activities

This table presents the first model where a strong correlation between students doing small group activities every class and conceptual gains was found.

\begin{tabular}{|c|c|c|c|c|}
\hline Model & Linear Model & Factors & B & SE for $B$ \\
\hline \multirow{4}{*}{1} & \multirow{4}{*}{$\begin{array}{l}\text { FMCE Gain } \sim \text { Did } \\
\text { small group activities }\end{array}$} & 1-2 times per semester & 0.1364 & 0.2088 \\
\hline & & Once a month & -0.3141 & 0.2677 \\
\hline & & Once a week & 0.1815 & 0.1304 \\
\hline & & Every class & 0.8546 & $0.1654^{* * *}$ \\
\hline
\end{tabular}

${ }^{* * *} p<0.001,{ }^{* *} p<0.01,{ }^{*} p<0.05 \quad$ Adjusted $R^{2}: 0.06987$

In addition to the item appearing in Table 2, students were also asked details of the nature of their experiences in order to more deeply understand the opportunities available to learn. Note that these response items were too highly correlated with the group work item in Model 1 and with each other to simply add them to the original model; doing so would violate basic model assumptions (mutual independence of predictors). Instead, the effect of these variables are presented as independent models instead. Thus, there are four further models, presented in Table 3, which summarize significant associations between other classroom experiences and FMCE gain. In model 2, it was found that students who reported using equipment every class had a significant gain (as opposed to those that reported never using equipment), $p<0.05$. Model 3 shows that students who reported that their groups collaborated with other groups had improved gains, $p<0.01$. In Model 4 , the students who reported using computer simulations once a week $(p<0.05)$ or every class $(p<0.01)$ had improved FMCE gain. Lastly, model 5 shows significant improvement for students who reported working on labs or projects every class. 
Table 3: Linear model for FMCE and classroom practices

Here the other models are presented. The analysis below correlates conceptual gains with how often students engaged in using equipment, collaborating with peers, using computer simulations and working on labs.

\begin{tabular}{|c|c|c|c|c|}
\hline Model & Linear Model & Factors & B & SE for $B$ \\
\hline \multirow{4}{*}{2} & \multirow{4}{*}{$\begin{array}{l}\text { FMCE Gain } \sim \text { Your } \\
\text { group used equipment } \\
\left(R^{2}=0.02192\right)\end{array}$} & 1-2 times per semester & -0.1568 & 0.4330 \\
\hline & & Once a month & 0.1692 & 0.3400 \\
\hline & & Once a week & 0.1872 & 0.1217 \\
\hline & & Every class & 0.4784 & 0.1554 * \\
\hline \multirow{4}{*}{3} & \multirow{4}{*}{$\begin{array}{l}\text { FMCE Gain } \sim \text { Your } \\
\text { group collaborated with } \\
\text { other groups }\left(R^{2}=\right. \\
0.03254)\end{array}$} & 1-2 times per semester & 0.0797 & 0.1705 \\
\hline & & Once a month & 0.3301 & 0.1778 \\
\hline & & Once a week & 0.0645 & 0.1419 \\
\hline & & Every class & 0.6924 & 0.1980 ** \\
\hline \multirow{4}{*}{4} & \multirow{4}{*}{$\begin{array}{l}\text { FMCE Gain Your } \\
\text { group used computer } \\
\text { simulations } \\
\left(\mathrm{R}^{2}=0.04799\right)\end{array}$} & 1-2 times per semester & 0.2581 & 0.1864 \\
\hline & & Once a month & 0.2410 & 0.1899 \\
\hline & & Once a week & 0.4454 & 0.1489 * \\
\hline & & Every class & 0.7875 & $0.2101 *$ \\
\hline \multirow{4}{*}{5} & \multirow{4}{*}{$\begin{array}{l}\text { FMCE Gain } \sim \text { You } \\
\text { worked on labs or } \\
\text { projects }\left(R^{2}=0.03534\right)\end{array}$} & 1-2 times per semester & 0.1148 & 0.4724 \\
\hline & & Once a month & -0.1103 & 0.3429 \\
\hline & & Once a week & 0.1711 & 0.1220 \\
\hline & & Every class & 0.5983 & 0.1601 * \\
\hline
\end{tabular}

\subsubsection{Modeling Physics Identity Gains}

One of the primary goals of the broader CUPID study was to investigate how students' physics identities change from the beginning to the end of a first semester introductory physics course. To this end, regression models analogous to those in the previous section were constructed, regressing PI gain (postminus pre-) on the same classroom experiences discussed above. In the end, no significant associations between classroom practices and PI gains were found. While unfortunate for the overall goal of this study, this finding is not entirely unexpected, since students' physics identities have been argued to be wellformed by the end of secondary education (Godwin, Potvin, Hazari, \& Lock, 2016; Hazari et al., 2010) and university physics curricula have not traditionally 
paid significant attention to affective outcomes in their construction, even amongst reformed classes (see Crouch et al., etc.).

\subsubsection{Comparison of Groups A and B}

It is interesting to understand how the students who reported working in small groups every day (Group A) experienced these other learning opportunities differently than Group B. To avoid the collinearity problems mentioned previously, a descriptive analysis was constructed to compare Groups A and B on the factors appearing in Table 3 as well as several other factors that were not, on their own, predictive of FMCE gain (and, hence, did not appear in separate models in Table 3). Figure 6 presents the proportion of responses for these two groups on a total of nine different items characterizing classroom experiences; the responses of Group A are significantly different than Group B on seven items. 
Figure 6: Histograms of group work details

Question 16 probed students on their group work and asked the frequency of different types of classroom practices throughout their first semester of introductory physics.
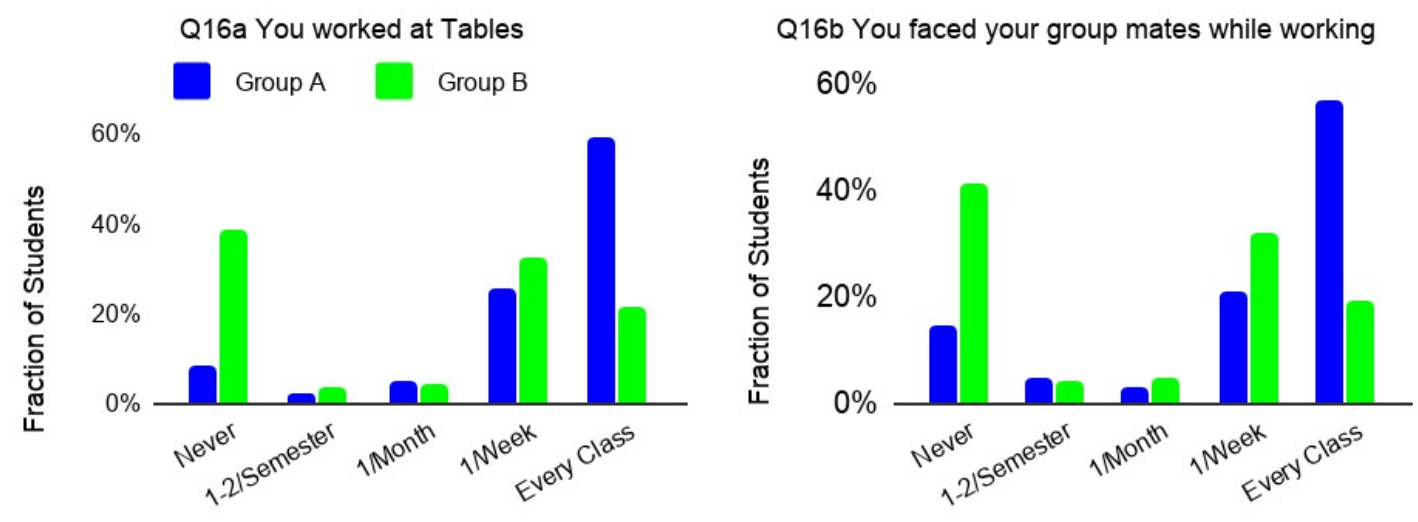

Q16c Your group used equipment
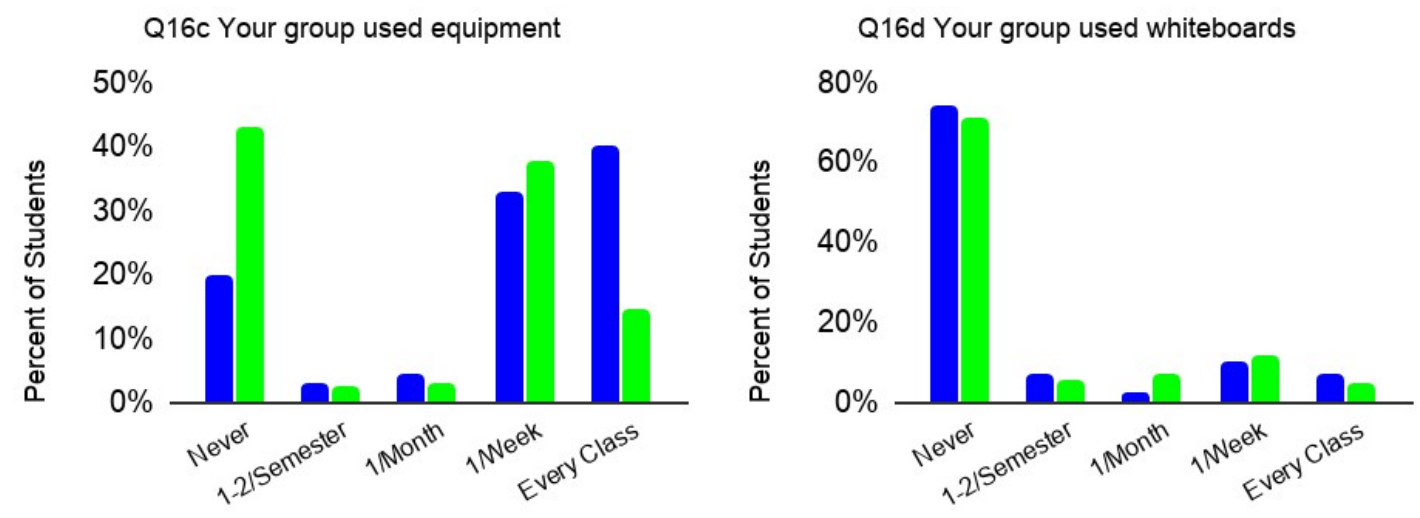

Q16e Your group collaborated with other groups $60 \%$
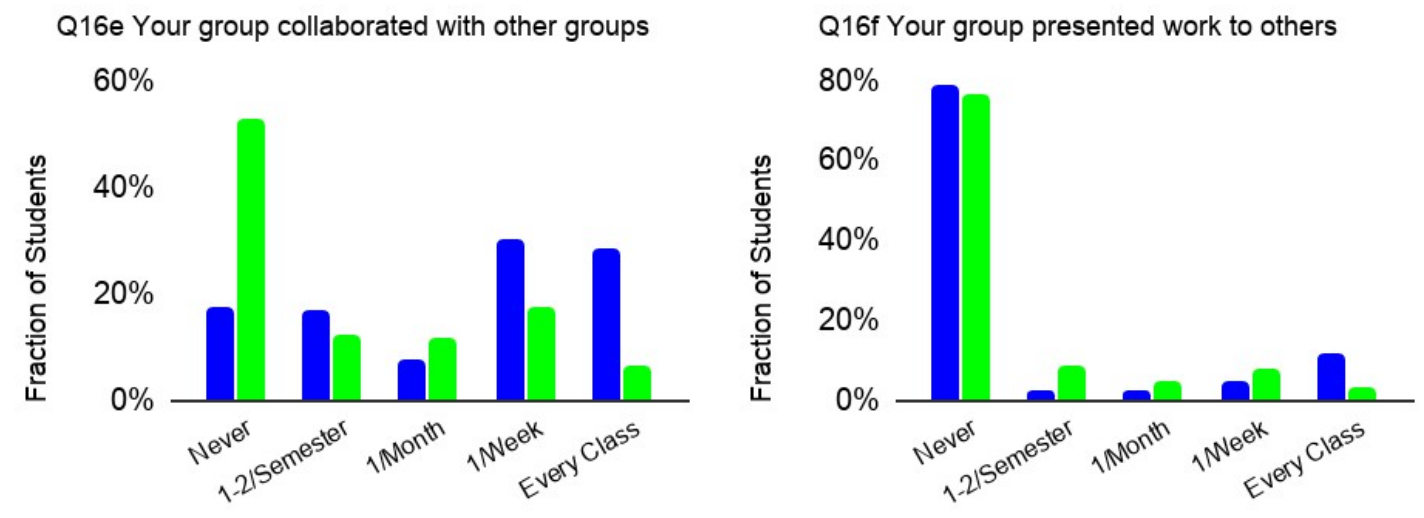
Figure 6, continued

Q16g You simultaneously used numbers, formulas,
graphs, and words when solving a physics problem

Group A Group B

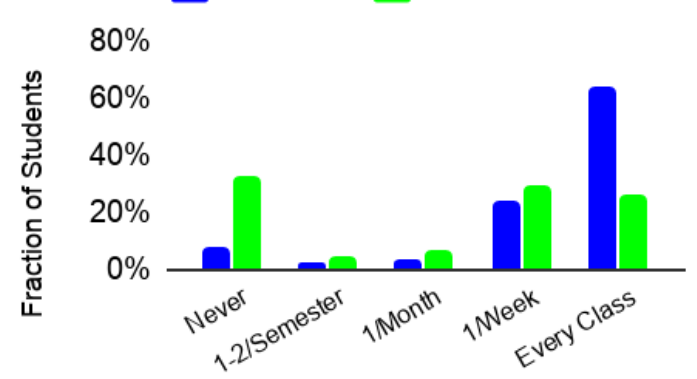

Q16i You worked on labs or projects

$50 \%$

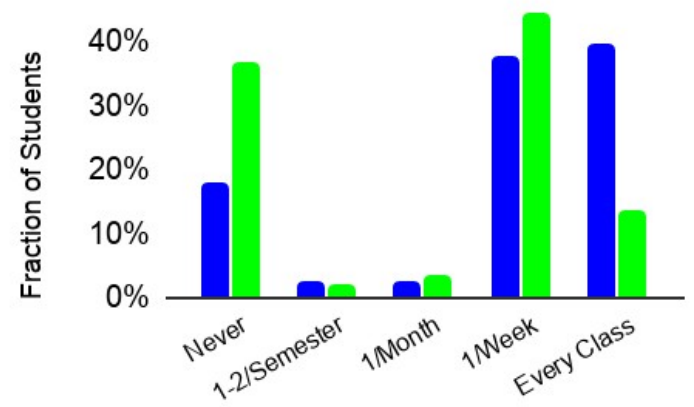

Q16h Your group used computer simulations

$80 \%$

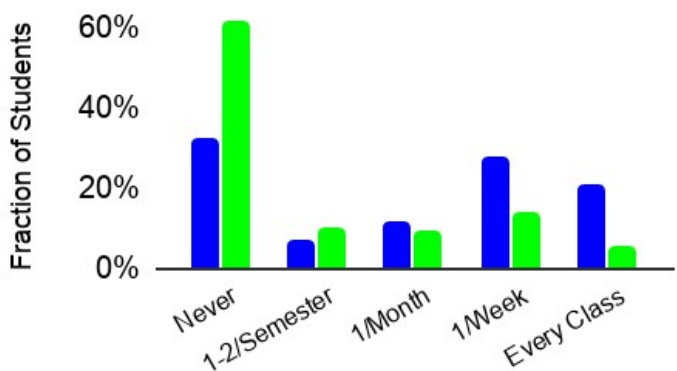

Several of these results help to characterize Group A (those who reported small group work every class). To test whether the apparent differences appearing in Figure 6 were significant, Wilcoxon rank-sum tests were performed on these items. For example, $61 \%$ of those students reported working at tables every class (Q16a) compared to only $21 \%$ in Group B $(p<0.001)$. Similarly, Group A students reported "facing their group mates" (Q16b) much more regularly than Group B $(p<0.001)$. Over $75 \%$ of students in Group A reported using equipment at least once per week (Q16c), whereas only 55\% of Group B did $(p<0.001)$. Nearly $60 \%$ of students in Group A responded that they collaborated with other 
groups (Q16e) at least once per week, which was significant $(p<0.001)$. Students were asked how often they were expected to simultaneously use numbers, formulas, graphs, and words to solve a physics problem (Q16g) which was also found to be significantly different between the two groups $(p<0.001) .66 \%$ of the students in Group A said they had to do this every class, $24 \%$ said they had to do this weekly, meaning that $90 \%$ of this group reported this practice at least weekly. By contrast, only $58 \%$ of Group B responded at least once per week, with 33\% reporting to never have been expected to engage in this type of work in class. The students in Group A reported much more exposure to computer simulations (Q16h); only 32\% of Group A students never had this experience in class compared to $62 \%$ of Group B students $(p<0.001)$. Group A students also reported more regularly working on labs or projects (Q16i, $\mathrm{p}<0.001)$. Finally, on two items, Q16d (use of whiteboards) and Q16f (group presenting work to others), no significant differences were seen between Groups A and B.

As reported in the previous section, no correlations between $\mathrm{PI}$ gains and classroom practices were found but there was one salient difference of interest in the comparison between Groups A and B. Students were asked how interested they were in the content and topic and found a small effect size difference of 0.23 ( $95 \%$ Confidence interval: -0.035 to $0.50, p<0.05$ ) between groups. Though small, it shows a somewhat higher level of interest amongst students who worked on small group activities every class, and interest is one of the important sub-constructs associated with PI. Creating classrooms that generate student 
interest is important for enhancing student affect for physics and the chances of students pursuing physics-related careers (Godwin et al., 2016; Hazari et al., 2010). This is reinforced by other work that suggests interest in science classes is "contagious" (Hazari, Potvin et al., 2017).

\subsection{Discussion and Conclusion}

\subsubsection{Importance of Small-group Learning, Connections with Other Work}

There are several reasons why small group learning may make for more effective learning environments. When students work in small groups, complex social interactions take place. Students may want to do well in front of their peers (performance-approach motivation) and may also want to avoid looking bad (performance-avoidance motivation) (Murayama, Elliot \& Yamagata, 2011; Wolters, 2004). This dynamic may make students take tasks more seriously, as there are only typically three to six people in a small group and there is a greater sense of shared responsibility among students. Also, students who are not normally actively engaged in a traditional course are put in situations where they can participate, as there is more opportunity to speak. Working in small groups creates an environment rich for student agency (Jackson, Dukerich \& Hestenes, 2008; Klemenčič, 2017). Agency is one's capacity to act independently and make one's own choices and decisions. Agency is necessary for building Self Efficacy which is an important factor in how students feel they will perform. Agency and Self Efficacy are essential elements for student motivation as well as confidence building (Dennis, 1999; Pollack \& Lilly, 2008; Schunk, 1991). 
Working in groups also presents students with the opportunity to learn from each other. This allows students to construct and re-construct their knowledge in tandem with their peers; thereby, clarifying any confusion students may have in the process. These group discussions help students build more confidence (Brooks \& Koretsky, 2011). When a student falls behind, they may benefit by having extra help from their peers, whereas during a lecture, students may be primarily dependent on the instructor in order to learn, making it difficult to catch up. In small group learning, students can keep up with each other since they are each actively involved in the learning process. Besides teaching and learning from each other, students may also build on each other's ideas while in a group, which makes for effective brainstorming and development of problem solving skills (Harskamp \& Ding, 2006). In this way students may be more interdependent on one another; interdependence has been found to lead to greater effort to achieve and group effectiveness (Wageman, 1995).

One last reason may be that students form support networks with other students due to increased social integration, which then leads to them being resources for each other such as forming study groups outside of class.

Research on social networks finds that students with broader networks perform better than their peers (Williams et al., 2015). When students work collaboratively they gain the opportunity to build networks within their classes. This collaboration can lead to students having more support overall such as forming study groups, 
exchanging contact information, sharing notes, which are strategies proven to lead to more student success (Yazedijan et al., 2008).

In the previous few paragraphs speculations were drawn on the possibile reasons why the daily use of small-group activities leads to improved conceptual learning gains. In order to further investigate how all of these mechanisms may underly the finding that small group interactions lead to improved conceptual learning gains, we designed specific follow-up studies, to be presented in Chapters 4 and 5 . This work will examine the cooperative aspects of small-group learning in particular, through the lens of Social Interdependence, and their associations with both affective and cognitive outcomes.

Separately, It is worth reflecting on how these results speak to classroom pedagogies that intentionally use small group learning activities daily. As discussed in the literature review, Modeling Instruction (MI) (Halloun, 1987, Brewe, 2008), Student-Centered Activities for Large Enrollment Undergraduate Programs (SCALE-UP) (Beichner et al., 2007), and Peer Instruction (Crouch \& Mazur, 2001) are three such highly research-driven pedagogies for introductory physics that have adopted regular small group activities. Some of the strategies students were asked about their group work (see Figure 6) are varingly implemented among these three pedagogies.

In $\mathrm{Ml}$, for example, students may spend time every class: working on tables, facing their group mates, using equipment, using whiteboards, collaborating with other groups and simultaneously using numbers, formulas, 
graphs, and words for solving physics problems. Modeling Instruction students conduct various labs/experiments frequently but not every class and less frequently make use of computer simulations. Modeling Instruction is the only one of these three example pedagogies discussed here that emphasizes summarizing models on their whiteboards to compare with other groups after every activity and has virtually no lecturing.

In a SCALE-UP classroom, students regularly: work at tables, face their group mates, use equipment, and run computer simulations. There are frequent labs as well but not necessarily the use of whiteboards and groups may not collaborate with other groups on a daily basis. There may be up to 15 minutes of lecturing in the beginning of class and the students may have regular opportunities to simultaneously use numbers, formulas, graphs, and words for solving physics problems.

Peer instruction involves the most reliance on lecturing as compared to the other two pedagogies explored. About a third or half of a class is spent solving ConceptTests, and the rest may be spent lecturing. During these ConceptTests students may face each other and present their work to each other but students are less likely to work at tables, use equipment, run computer simulations, or conduct labs during class. Due to the lack of reform in class structure, Peer Instruction does not include the strategies noted in this paper as much as Modeling Instruction and SCALE-UP and hence may be a less effective approach. 
In summary, then, MI and SCALE-UP may offer more frequent and varied opportunities to engage in the practices identified as important for conceptual gains in this study. Peer Instruction was designed to apply some studentcentered instruction while keeping many of the features of a lecture course intact.

\subsubsection{Literature Support for Other Factors Found to Improve Learning}

From model 2 (see Table 3) the use of equipment was found to be beneficial to learning. The use of equipment may allow students to actively be involved in modeling a phenomena. This result goes hand in hand with model 5 , where students who worked on labs or projects frequently saw higher learning gains. Labs have been found to be important for students' conceptual understanding (Wieman \& Holmes, 2015). There is evidence for the benefits of the use of physics laboratory equipment in secondary education (Olufunke, 2012). In model 4 , the positive effects of frequently using computer simulations were seen and is supported by other research that compares teacher-centered instruction to the use of computer-assisted instruction (Bayrak, 2008). The Physics Education Technology Project (PhET) simulations have also been found to be effective as well (Keller et al., 2007; Wieman, Adams \& Perkins, 2008). Some reasons why using computer simulations may be helpful to students are that it allows them to see phenomena not otherwise visible, learn at their own pace, conduct experiments (perhaps not physically feasible) and gain instant feedback. Computer simulations may also be used to replace physical labs and 
equipment which may lead to more access and availability for students (Finkelstein, et al., 2005).

\subsubsection{Physics Identity \& Research on Affective Outcomes in Physics}

One of the results from this chapter was finding no correlations between students' overall physics identity gain and the selected classroom practices. This finding was somewhat expected at the university level since prior research has found that physics identity on average is fairly stable by this time in a student's life. The reason why so much importance is given to physics identity is because it is shown to predict student career choice (Hazari et al., 2010). The average identity gain over the semester was zero in this study, but there was variance, with some students gaining and others dropping in their identity measures. This study hypothesized that certain classroom practices may impact PI but I did not find evidence of widespread identity-building practices as measured in this study. Even though identity as a whole did not improve for the sample, there was a small significant increase in interest for students that worked in groups every class, as mentioned. Interest is one of the sub-constructs of PI so this was a possibly promising result (Hazari et al., 2010) and is consistent with other work (Hazari, Potvin, et al,, 2017).

Further, these null findings with respect to identity emphasize that there is a pressing need to simultaneously study cognitive and affective domains to understand why reformed classes lead to positive shifts in cognitive outcomes but sometimes negative shifts in affective outcomes (Crouch \& Mazur, 2001) and 
to further promote classroom practices that do generally improve students' attitudes towards physics. This study collected the data to examine elements of both, but the results show that such practices are not widespread enough to be systematically supporting students' identity growth. More research is needed to simultaneously study the cognitive and affective domains to identify strategies that improve both. Such research also promises to address persistent representation issues in physics.

\subsubsection{Low Use of Physics Education Reform}

Only a small number of students, compared to the sample size, reported having the experiences identified as significantly impacting FMCE gain in their physics courses. Many of the respondents were taught in classes that lacked the instructional strategies found to be significant in this study. For example, $40 \%$ of students reported never using equipment, $59 \%$ never used computer simulations, $34 \%$ never worked on labs or projects and $30 \%$ never made use of numbers, formulas, graphs, and words when solving physics problems. Also, the majority of students reported having some form of lecturing every class. This is important to note, as it indicates the relative lack of knowledge and/or adoption of effective teaching strategies. That is, this work provides evidence that effective practices are not widespread. This is a barrier to improving educational outcomes including the production of STEM majors. Other research seeks to understand how to encourage more widespread adoption of evidence-based research. Further discussion of this issue appears in Chapter 6. 


\subsubsection{Limitations}

There are several limitations to this study. One limitation was the inherently discrete scales used to measure these classroom practices so students who had experienced practices with frequencies between the ones provided would have to pick the closest choice which could lead to measurement error. Another limitation is that observations of these classrooms could not be performed to compare student responses to what an observer would identify in the classroom practices. Further, students were not asked to identify if they were part of a particularly identifiable pedagogical style (e.g., were they part of a SCALE-UP) classroom, so this data does not directly assess the implementation or effectiveness of these approaches. This data only sampled 4-year colleges and universities so these results cannot necessarily be generalized to two-year colleges or high schools. Another limitation was only being able to match 371 students pre and post surveys. It was only possible to match 371 students because unique identification markers were relied upon and were not always filled out consistently for both the pre and post surveys. Even though a sample size of 371 was adequate for the purposes of this study, this constraint in matching students led to a loss of statistical power. Lastly, quantitative data limits the ability to understand nuance about classroom practices, especially questions of implementation, framing, and outcomes. Thus, there is a continued need for future work to delve more deeply into the precise underlying mechanisms of 
these findings by digging into the nuances of introductory classroom experiences. 


\section{THE ASSOCIATIONS BETWEEN CONCEPTUAL LEARNING, PHYSICS IDENTITY GAINS AND SOCIAL INTERDEPENDENCE}

\subsection{Introduction}

As discussed in Chapter 2, there is a growing demand for STEM majors in the United States as technology continues to be integrated into ever more facets of society, and to maintain a globally-competitive high tech economy (Xue \& Larson, 2015). Low quality early STEM courses are a leading cause for students to switch out of science majors (Seymour \& Hewitt, 1997). Academic engagement in STEM courses has been shown to lead to more student success and retention of science majors (Gasiewski et al., 2012). Student-centered instruction, such as that embodied through classrooms that rely on learning in small groups, has been repeatedly found to support students' learning more effectively than teacher-centered instructional methods (Freeman et al., 2014). Another well-established approach to considering how to solve the problem of the low production of STEM majors is via the lens of science identity, which has been found to predict students' science-related career choices (Hazari, Sadler \&

Sonnert, 2013). It would be desirable to be able to identify particular classroom practices that support students' identity development, which has been relatively understudied by comparison to studies of practices that impact students' conceptual learning (Laws, Sokoloff \& Thornton, 1999; Smith et al., 2005).

Small group learning offers many benefits to students but concerns have been raised earlier, such as “social loafing” (Latane, Williams \& Harkins, 1979). Social loafing is characterized as the reduction of motivation and effort students 
make in group contexts, compared to what they would have made while working individually. There are three domains that may influence degrees of social loafing: task structure, student evaluation and group structure (Meyers, 1997). Firstly, task structures include how activities are organized and tasks are defined. Student integration, negotiation, participation and even competence are dependent on task structures (Beersma \& De Dreu, 2002; Tammivaaara, 1982). Idea-generating tasks, in which students are tasked with open ended activities (no solution, exploratory), lead to more interdependence than intellective tasks (single fixed solution), in which students are given closed-ended activities (attaining a solution to a problem) (Straus \& McGrath, 1994). Secondly, student evaluations involve identifying or assessing individual student contributions to increase accountability (Voyles, Bailey \& Durik, 2015). Thirdly, group structure refers to the roles and norms in a group and how students view each other (Schellens et al., 2007).

While social loafing is raised as a concern related to student participation in learning, it does not take into account cultural contexts of physics and important considerations of the status quo in physics classrooms. There are issues specific to physics such as a deteriorations in student expectations over a semester of study (Redish, Saul \& Steinberg, 1998), students perceiving physics as being more difficult than other courses, being associated to performed masculinities, and being unpleasant (Kessels, Rau, \& Hannover, 2006), and the low percentage of women and underrepresented minorities who participate in 
physics (Hazari, Cass \& Beattie, 2015). Lastly, there are existing structures in introductory physics that may limit students from taking risks and engaging in the learning process (Hazari, Cass, \& Beattie, 2015), and small group interactions may be a technique that helps overcome all of these problems, and negate the risks raised in discussions of social loafing. Particularly, it has been argued that informal/interpersonal interactions ("side talk") in a physics classroom may help students to overcome their anxieties about physics (Hazari, Cass, \& Beattie, 2015).

In the previous chapter, a positive association between certain classroom practices (notably, daily work in small groups) and conceptual learning gains was found but little was found to be similarly associated with physics identity gains. In the current chapter, detailed data were collected from a first semester, modeling instruction introductory physics I (mechanics) class (which relies on frequent small group activities), in order to model how student engagement in groups viewed through the lens of social interdependence (SI) theory - affects both conceptual learning and physics identity gains. The implementation of frequent small group work in modeling instruction provides an opportunity to study the interdependence of group members and their dependence on instructors. The use of social interdependence theory in this study is based on prior research that shows this theory lends itself to understanding successful group cooperation. As previously discussed in detail in Chapter 2, positive social interdependence is associated to, and has a reciprocal relationship with: positive relationships, 
improved effort to achieve and improved social competence (Johnson \& Johnson, 2009).

There are various types of interdependence like "task," "outcome," "role" and "resource" interdependencies. Task interdependence assesses how much cooperation within the group is needed to perform a task (Gully, Devine \& Whitney, 1995). Task interdependence shapes the roles students play in a group and how they coordinate requirements between group members (Kozlowski, Gully, Nason, \& Smith, 1999). Outcome interdependence assesses how much students' learning outcomes depended on their cooperation. When outcome interdependence is strong, groups perform better, as each group member's outcome depends on the groups' performance (De Dreu, 2007). Role interdependence has to do with how the work is divided by the group members or how they rely on each other to accomplish their goal (Thomas, 1957). Resource interdependence is how the group members share their resources to achieve their goal (Buchs, Butera \& Mugny, 2004).

For this study task and outcome social interdependence were measured, because the focus is on how students interdepend on each other to perform the learning tasks they are given in class and how this leads to group outcomes. Conceptual learning and physics identity gains were also quantitatively assessed. Conceptual gains provide a measure of how well students learned mechanics during the semester, while physics identity gains inform if a student gained more recognition beliefs in physics, interest in physics, and/or 
performance/competence beliefs. Previously, progress has been made in understanding students through the lens of physics identity. It has been found that having a strong physics identity is associated with a greater chance of choosing a physics-related career path (Harazi et al., 2010). The physics identity construct used in this work is built of the three, related sub-constructs mentioned previously: interests in physics, performance/competence beliefs (beliefs in one's ability to perform and be competent in physics), and recognition beliefs (beliefs that one receives recognition from others as a "physics person") (Potvin \& Hazari, 2013). Students' physics identities tend to be formed in high school and be more concrete at the university level (Dabney, Chakraverty \& Tai, 2012; Hazari et al., 2017). However, there is a relative dearth of research on what classroom practices, if any, may affect students' physics identity development.

In this study, an analysis was conducted on multiple measures of students' social interdependence, physics identities, and conceptual learning taken though several surveys collected during a first semester, introductory, calculus-based modeling instruction physics course. Modeling instruction (MI) is a well-established curriculum and pedagogy that relies on regular small group learning in which students build consistent scientific models utilizing several different representations (e.g., velocity graphs, force body diagrams, energy representations, etc.) to explain a wide class of physical phenomena (Brewe, 2008). The daily and constant use of group work makes Modeling Instruction an ideal course to study task and outcome interdependence. The data collected 
included pre- and post-measures of the Force and Motion Conceptual Evaluation (FMCE, Thornton \& Sokoloff, 1998) and physics identity (Potvin \& Hazari, 2013). Data were also collected on students' pre-semester cooperation and individualism attitudes, which have been shown to be predictive of social interdependence (Johnson \& Norem-Hebeisen, 1979). Students were also surveyed about their task and outcome interdependence for each of the six students' groups they were assigned to during the semester. There were 90 students enrolled in the course and at any given time 15 groups of 6 students were arranged. In total, data were collected on eight separate occasions. The research question driving this chapter is:

- How is social interdependence (particularly task and outcome interdependence) experienced by students in small group learning contexts associated with gains in conceptual understanding and physics identity outcomes?

\subsection{Survey Data and Analysis}

The timeline for data collection in this study is summarized in Figure 7. Surveys $1 \& 8$ included the FMCE, physics identity, social interdependence and collective orientation scales. Some questions were also added in survey 8 relating to the outcomes of social interdependence like positive relationships and effort made during the entire semester. The other set of surveys (surveys 2-7) were collected from each student immediately after the end of their previous

group assignment. Over the semester, students were assigned to be part of six 
different groups (e.g., spending 2-3 weeks with each group). Task and outcome interdependence were measured for students for every group they were a part of during the semester. All instruments used had been developed separately and there existed validity evidence for each (Johnson \& Norem-Hebeisen, 1979;

Driskell, Salas \& Hughes, 2010;Van Der Vegt, Emans \& Van De Vliert, 1998), but exploratory factor analyses were performed in some cases to assess elements of construct validity.

\section{Figure 7: Timeline for data collection for quantitative SI study}

This diagram shows the timeline of when the different surveys were collected for this study during the semester of data collection. Survey 1 was handed out in the beginning of the course. Surveys 2-6 were handed out throughout the semester. Surveys 7 and 8 were handed out at the end of the semester. The colors correspond to the type of survey administered and the arrows indicate the time between the surveys was every 2-3 weeks.

Survey 1: Pre- FMCE, PI, Cooperation and Individualism Beliefs

Survey 2: Task and Outcome SI for first selection of groups

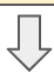

Survey 3: Task and Outcome SI for second selection of groups

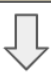

Survey 4: Task and Outcome SI for third selection of groups

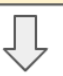

Survey 5: Task and Outcome SI for fourth selection of groups

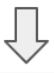

Survey 6: Task and Outcome SI for fifth selection of groups

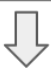

Survey 7: Task and Outcome SI for sixth selection of groups

Survey 8: Post- FMCE, PI, Cooperation and Individualism Beliefs 
Surveys $1 \& 8$ utilized the Social Interdependence (SI) scale (first set of questions in Appendix 2) (Johnson \& Norem-Hebeisen, 1979) and the collective orientation scale (second set of questions in Appendix 2) (Driskell, Salas \& Hughes, 2010) to predict the SI of students. Although the scale of Johnson \& Norem-Hebeisen was validated, the work was published in 1979. To complement this scale a collective orientation scale was also used, to provide a more recently-validated scale that also has been found to correlate positively with SI while predicting team performance. An exploratory factor analysis (EFA) was conducted on both these scales, which resulted in combining items from both. This EFA helped establish the relationship between both of these prior instruments, and to generate a prediction of the pre-semester propensity for interdependence of each student. Only the factor analysis for the cooperation and individualism factors for Survey 1 is shown since these prior beliefs influence social interdependence during class. The best fit for the EFA was found to be a two-factor solution. The items that did not load strongly to either factor were cut, and then the final EFA (Table 4) was constructed. The resulting factors were labeled "cooperation" and "individualism" beliefs due to the nature of the questions (the questions are listed in Table 4) and explained $57.5 \%$ of the total variance. An important thing to note here is that cooperation and individualism beliefs were loaded as two independent factors, as opposed to appearing as opposite extremes of each other. Instead, these beliefs exist independently of one another. Since cooperation is similar to collectivism, this is reminiscent to 
prior findings on individualism and collectivism beliefs (Wagner, 1995). In the end, these factors were used to generate a score measuring students' presemester cooperation and individualism beliefs. 
Table 4: EFA of Survey 1 final items for Cooperation \& Individualism beliefs

This table summarizes the result of the factor analysis done on the final items used, after trimming items that did not load well into the cooperation and individualism beliefs factors.

\section{Factors}

\section{Survey Item}

I like to help other students

I like to share my ideas and materials with other students

I like to cooperate with other students

I can learn important things from other students

I try to share my ideas and materials with other students when I think it will help them

Students learn lots of important things from each other

It is a good idea for students to help each other learn.

0.759

I do better work when I work alone

0.768

I like work better when I do it by myself

0.886

I would rather work on school work alone than with other students

I would rather take action on my own than to wait around for others' input.

I prefer to complete a task from beginning to end with no assistance from others.

For most tasks, I would rather work alone than as part of a group.

I can usually perform better when I work on my own.

I find that it is often more productive to work on my own than with others.

When solving a problem, it is very important to make your own decision and stick by it.

When I have a different opinion than another group member, I usually try to stick with my own opinion. 
Surveys $1 \& 8$ also included the FMCE (Thornton \& Sokoloff, 1998) and Physics Identity surveys (Potvin \& Hazari, 2013). The FMCE is a well validated concept inventory that measures a proxy for students' conceptual understanding of introductory mechanics concepts, including Newton's laws, momentum, and kinematics. Scores were created for students' conceptual understanding using the FMCE and for students' physics recognition beliefs, interests and performance/competence beliefs.

In Surveys 2-7, students were asked to self-report on their task and outcome interdependence (survey appears in Appendix 3) for the student groups they had been a part of during each 2-3 week period in the semester, for six in total. To assess these constructs, items developed in prior research were used to measure task and outcome interdependence (Van Der Vegt, Emans \& Van De Vliert, 1998). This earlier research originally intended to measure these outcomes in a work setting so for the current study the items were adapted for an academic setting by changing "colleagues" to "group" to fit into the context. Van Der Vegt et al. (1998) split the questions measuring task interdependence into two: initiated and received task interdependence. Splitting task interdependence allows for gauging the degree at which each student initiated tasks and/or whether the tasks were initiated by other group members (received task interdependence). Initiated task interdependence is a measure of how much the groups of a particular respondent needed information, help and work done from them. Received task interdependence, on the other hand, asked individual 
students how much they depended on their group for information, help and work. The task interdependence measures used 7 point anchored scales ranging from "Not at all" to "Very much." Next, outcome interdependence measures how students felt their groups impacted their success. This included asking: if their group benefited or hindered them, whether they felt the group to be compatible or incompatible to them, if the group's success led to their own success and if the group's concerns matched their own. Outcome interdependence was also measured using 7 point anchored scales but each item had unique verbiage.

Thus, there were three dimensions of interdependence assessed in Surveys 2 through 7: initiated task, received task and outcome interdependence. The items were assessed for construct validity by again using EFA, to test that items loaded as intended (see Tables 5-10). The final EFA found consistent loadings onto these three factors. Following the EFA, scores were created for the three factors for each of the six rounds of survey. Then, the mean for each student (and each construct) was calculated to establish an average for students' reported initiated task, received task and outcome interdependence. 
Table 5: EFA of Task \& Outcome Interdependence scales for $\mathbf{1}^{\text {st }}$ grouping

In this set of group arrangements it can be seen that task interdependence loaded into two factors while outcome interdependence loaded into one factor. This EFA represents responses for the first of six groups.

\section{Factors}

$\begin{array}{lllll} & \text { Initiated } & \text { Received } & \text { Variance } \\ \text { Survey Item } & \text { Task } & \text { Task } & \text { Outcome } & \text { Explained }\end{array}$

To what extent did your last group depend on you for information or advice?

To what extent did your last group depend on your presence, help, and support?

To what extent did your last group depend on you for doing their work well?

To what extent did you depend on your last group for information or advice? 0.804

To what extent did you depend on the presence, help, and support of your last group?

To what extent did you depend on your last group for doing your work well?

It hinders/benefits me when my last group attained their goals.

The things my last group wanted to accomplish and the things I wanted to accomplish were incompatible/compatible.

It is disadvantageous/advantageous for me when my last group succeeded in their tasks.

When my last group succeeded in their tasks, it was at my expense/benefit.

My concerns and those of my last group were clashing/harmonious.

When my last group succeeded in their tasks, it worked out negatively/positively for me. 
Table 6: EFA of Task \& Outcome Interdependence scales for $2^{\text {nd }}$ grouping

This represents responses for the second of six groups.

\section{Factors}

$\begin{array}{lllll} & \text { Initiated } & \text { Received } & \text { Variance } \\ \text { Survey Item } & \text { Task } & \text { Task } & \text { Outcome } & \text { Explained }\end{array}$

To what extent did your last group depend on you for information or advice?

To what extent did your last group depend on your presence, help, and support?

To what extent did your last group depend on you for doing their work well?

To what extent did you depend on your last group for information or advice?

0.804

To what extent did you depend on the presence, help, and support of your last group?

To what extent did you depend on your last group for doing your work well?

It hinders/benefits me when my last group attained their goals.

The things my last group wanted to accomplish and the things I wanted to accomplish were incompatible/compatible.

0.819

It is disadvantageous/advantageous for me when my last group succeeded in their tasks.

When my last group succeeded in their tasks, it was at my expense/benefit.

My concerns and those of my last group were clashing/harmonious.

When my last group succeeded in their tasks, it worked out negatively/positively for me. 
Table 7: EFA of Task \& Outcome Interdependence scales for $3^{\text {rd }}$ grouping

This represents responses for the third of six groups.

\section{Factors}

$\begin{array}{lllll} & \text { Initiated } & \text { Received } & & \text { Variance } \\ \text { Survey Item } & \text { Task } & \text { Task } & \text { Outcome } & \text { Explained }\end{array}$

To what extent did your last group depend on you for information or advice? 0.948

To what extent did your last group depend on your presence, help, and support?

To what extent did your last group depend on you for doing their work well?

To what extent did you depend on your last group for information or advice?

1.034

To what extent did you depend on the presence, help, and support of your last group?

0.794

$22.6 \%$

To what extent did you depend on your last group for doing your work well?

It hinders/benefits me when my last group attained their goals.

0.678

The things my last group wanted to accomplish and the things I wanted to accomplish were incompatible/compatible.

0.622

It is disadvantageous/advantageous for me when my last group succeeded in their tasks.

When my last group succeeded in their tasks, it was at my expense/benefit.

My concerns and those of my last group were clashing/harmonious.

When my last group succeeded in their tasks, it worked out negatively/positively for me. 
Table 8: EFA of Task \& Outcome Interdependence scales for $4^{\text {th }}$ grouping

This represents responses for the fourth of six groups.

\section{Factors}

$\begin{array}{lllll} & \text { Initiated } & \text { Received } & & \text { Variance } \\ \text { Survey Item } & \text { Task } & \text { Task } & \text { Outcome } & \text { Explained }\end{array}$

To what extent did your last group depend on you for information or advice?

To what extent did your last group depend on your presence, help, and support?

To what extent did your last group depend on you for doing their work well?

To what extent did you depend on your last group for information or advice?

0.566

To what extent did you depend on the presence, help, and support of your last group?

To what extent did you depend on your last group for doing your work well?

It hinders/benefits me when my last group attained their goals.

The things my last group wanted to accomplish and the things I wanted to accomplish were incompatible/compatible.

0.920

It is disadvantageous/advantageous for me when my last group succeeded in their tasks.

When my last group succeeded in their tasks, it was at my expense/benefit.

My concerns and those of my last group were clashing/harmonious.

When my last group succeeded in their tasks, it worked out negatively/positively for me. 
Table 9: EFA of Task \& Outcome Interdependence scales for $5^{\text {th }}$ grouping

This represents responses for the fifth of six groups.

\section{Factors}

$\begin{array}{lllll} & \text { Initiated } & \text { Received } & & \text { Variance } \\ \text { Survey Item } & \text { Task } & \text { Task } & \text { Outcome } & \text { Explained }\end{array}$

To what extent did your last group depend on you for information or advice?

To what extent did your last group depend on your presence, help, and support?

To what extent did your last group depend on you for doing their work well?

\subsection{4}

To what extent did you depend on your last group for information or advice?

0.898

To what extent did you depend on the presence, help, and support of your last group?

$22.4 \%$

To what extent did you depend on your last group for doing your work well?

It hinders/benefits me when my last group attained their goals.

The things my last group wanted to accomplish and the things I wanted to accomplish were incompatible/compatible.

It is disadvantageous/advantageous for me when my last group succeeded in their tasks.

When my last group succeeded in their tasks, it was at my expense/benefit.

My concerns and those of my last group were clashing/harmonious.

When my last group succeeded in their tasks, it worked out negatively/positively for me. 
Table 10: EFA of Task \& Outcome Interdependence scales for $\mathbf{6}^{\text {th }}$ grouping

This represents responses for the sixth and final group during the semester.

Factors

$\begin{array}{lllll} & \text { Initiated } & \text { Received } & & \text { Variance } \\ \text { Survey Item } & \text { Task } & \text { Task } & \text { Outcome } & \text { Explained }\end{array}$

To what extent did your last group depend on you for information or advice?

To what extent did your last group depend on your presence, help, and support?

To what extent did your last group depend on you for doing their work well?

To what extent did you depend on your last group for information or advice?

0.927

To what extent did you depend on the presence, help, and support of your last group?

To what extent did you depend on your last group for doing your work well?

It hinders/benefits me when my last group attained their goals.

0.919

The things my last group wanted to accomplish and the things I wanted to accomplish were incompatible/compatible.

0.893

It is disadvantageous/advantageous for me when my last group succeeded in their tasks.

When my last group succeeded in their tasks, it was at my expense/benefit.

My concerns and those of my last group were clashing/harmonious.

When my last group succeeded in their tasks, it worked out negatively/positively for me.

Total Variance Explained

Further validation of the surveys was conducted by relating the cooperation and individualism beliefs from Survey 1 to the outcome and task interdependence from Surveys 2-7, since a priori these measures should be 
correlated. It was found that pre-semester cooperation beliefs were predictive of the outcome interdependence of groups. Table 11 shows the result of regressing outcome interdependence on pre-semester cooperation beliefs. This association was found to be significant $(p<0.01)$, meaning that students with higher presemester cooperation beliefs reported that being in groups was more beneficial, on average, to succeeding in learning tasks. This is a confirmatory validation; it should be noted that these separate measures are from different literature bases and had not been previously cross validated. No significant correlations between pre-semester individualism beliefs to outcome interdependence were found.

There was also no significant correlation found between pre-semester cooperation and individualism beliefs to task interdependence.

Table 11 : Linear model for outcome interdependence and cooperation beliefs

This table shows the correlation between students self-reported cooperation attitudes and their outcome interdependence throughout their semester.

\begin{tabular}{|l|r|r|r|r|}
\hline & Estimate & Std. Error & \multicolumn{1}{c|}{ Z value } & $\operatorname{Pr}(>|z|)$ \\
\hline (Intercept) & 0.609 & 0.094 & $6.48^{* * *}$ \\
\hline Cooperation beliefs $(\mathrm{N}=90)$ & 0.321 & 0.111 & $2.899^{* *}$ \\
\hline
\end{tabular}

${ }^{* * *} \mathrm{p}<0.001,{ }^{* *} \mathrm{p}<0.01,{ }^{*} \mathrm{p}<0.05 \quad$ Adjusted $\mathrm{R}^{2}=.08536$

Thus, using the interdependence, FMCE, physics identity, and presemester cooperation and individualism beliefs measures, linear regression models were (separately) constructed to test for associations between task/outcome interdependence and gains in conceptual understanding or physics identity. By matching students' pre-to-post semester surveys, the raw change in both FMCE responses and PI could be calculated. To account for non-responses (particularly since the same students were being surveyed on eight different 
instances), multiple imputation was conducted using the R package Amelia. Multiple imputation is a best-practices approach to maximize statistical power and reduce statistical biasing due to non-response, which was about $16 \%$ in the current data (Honaker, King, \& Blackwell, 2015). Multiple imputation allows the researcher to preserve statistical power by accounting for missing responses, and is significantly favored over the common practice of listwise deletion (e.g., deleting individuals with any missing responses entirely from subsequent analysis), amongst other possible approaches. The Amelia algorithm uses a bootstrap-based expectation-maximization algorithm that efficiently handles the missingness and random error. In the current analysis, one hundred imputations were conducted (e.g., one hundred separate imputed data sets were constructed using the algorithm). After imputation, the package Zelig was used to run parallel linear regression analysis (Choirat, Honaker, Imai, King, \& Lau, 2016). Zelig can be used with Amelia-generated data files and appropriately handles the withinand between-imputation variance in generating estimates using Rubin's rule (Royston, 2004).

\subsection{Results}

\subsubsection{Associations between Task Interdependence and Physics Identity}

The results of the regression models predicting identity constructs are summarized in Tables 12 and 13. The average initiated task interdependence positively predicts semester-long standardized gains in physics recognition beliefs and performance/competence beliefs. Other interdependence measures 
were not found to be predictive of physics identity gains. That is, the model appearing in Table 12 shows that students who reported that their groups were more dependent on them for support, on average, over the semester had higher gains in recognition beliefs, a critical component of physics identity development $(p<0.01)$. The effect size is large since these are standardized gains in recognition beliefs; a student reporting at the high end of the initiated task interdependence had a 0.509 (standardized to be out of a maximum of 1.000) greater gain in recognition beliefs than those at the low end of the interdependence scale. It seems plausible that if students feel their groups relied on them during the learning physics topics, they had more opportunities to develop their feelings of recognition in physics contexts.

Table 12: Linear model of initiated task interdependence on gains in recognition beliefs

\begin{tabular}{|l|r|r|r|r|}
\hline & Estimate & Std. Error & Z value & $\operatorname{Pr}(>|z|)$ \\
\hline $\begin{array}{l}\text { (Intercept) } \\
\text { Initialized Task Interdependence } \\
(\mathrm{N}=90)\end{array}$ & -0.279 & 0.12 & -2.32 & ${ }^{*}$ \\
\hline${ }^{* * *} \mathrm{p}<0.001,{ }^{* *} \mathrm{p}<0.01,{ }^{*} \mathrm{p}<0.05$ & 0.509 & 0.176 & 2.89 \\
\hline
\end{tabular}

Similarly, there is a positive association between initiated task interdependence and gains in students' performance/competence beliefs (Table 13). Again, students who reported they were the source of task initiation had greater gains in performance/competence beliefs $(p<0.01$, coefficient estimate is 0.36). Students who have greater experience developing their ideas within their groups may have greater opportunity to build their performance/competence beliefs. 
Table 13: Regression model of initiated task interdependence on gains in performance/competence beliefs

This table shows the significant association between students self reported initiated task interdependence and gain in competence/performance beliefs throughout their semester.

\begin{tabular}{|l|r|r|r|r|}
\hline & Estimate & \multicolumn{1}{c|}{ Std.Error } & \multicolumn{1}{c|}{ Z value } & $\operatorname{Pr}(>|z|)$ \\
\hline Intercept) & -0.1877 & 0.0826 & -2.27 \\
\hline $\begin{array}{l}\text { Initialized Task Interdependence } \\
(\mathrm{N}=90)\end{array}$ & 0.3581 & 0.1214 & 2.95 & \multirow{2}{**}{} \\
\hline
\end{tabular}

${ }^{* * *} p<0.001,{ }^{* *} p<0.01,{ }^{*} p<0.05 \quad$ Adjusted $R^{2}=0.09011$

These simple linear regression models were expanded to multivariate regression models by including pre-semester cooperation beliefs as a second predictor. This was done to check the alternative hypothesis that students who initially showed greater cooperation beliefs were simply reporting higher task interdependence and experienced greater gains in physics identity. In fact, adding cooperation beliefs to each model was not significant and so it did not confound the main finding of each model. In other words, incorporating cooperation beliefs did not qualitatively change the effect size nor the statistical significance of the association between initiated task interdependence and physics identity gains.

Also, no significant association between physics interests and task interdependence (initiated or received) or outcome interdependence were found. Received task interdependence and outcome interdependence were not significant in any identity regression model.

\subsubsection{Associations between Interdependence and Conceptual Gains}

Similarly, regression models predicting conceptual learning gains (postFMCE minus pre-FMCE) were constructed using task/outcome interdependence 
as predictor variables. It was hypothesized, similar to other research (Wageman, 1995; De Deru, 2007), that students who reported higher levels of task or outcome interdependence would also display greater gains in learning gain. In fact, no significant associations were found. A borderline significant association was identified between learning gains and received task interdependence (and it was, in fact, a negative association); however, the significance was slightly above our alpha cutoff (of $5 \%$ ) and so is not considered a statistically significant finding. This non result may be due to the inherent complexity in the learning environment and in performing the physics tasks on the FMCE.

\subsubsection{Change of Cooperation Beliefs over the Semester}

Having measures for cooperation and individualism beliefs made it possible to assess how these attitudes changed over the semester. Comparisons of the pre- to post-semester cooperation and individualism beliefs were conducted. For the former, there was a small effect size of 0.25 (95\% confidence interval: 0.07 to $0.59, p<0.05)$ and, for the latter, a negligible effect size of 0.17 ( $95 \%$ confidence interval: -0.17 to $0.52, p<0.05)$. That is, students' pre-to-post cooperation beliefs improved over the semester, while individualism beliefs were not significantly affected. This finding may imply that the group experiences students had during class somewhat increased their attitudes towards working cooperatively. On the other hand, the semester did not increase or decrease their beliefs in working individually. 


\subsection{Discussion}

\subsubsection{Importance of Main Results}

The findings of this study suggest that students who initiate tasks with other group members more often have improved gain in their physics recognition and performance/competence beliefs. Thus, student participation in a smallgroup setting may be an essential way to support physics identity growth since students in this learning environment get frequent opportunities to initiate tasks. Through group work, students may come to see themselves and feel others see them as physics people, and also build their beliefs in their ability to be successful in physics (performance/competence beliefs). For those interested in addressing the problem of low physics participation, engagement, and production of STEM professionals, these findings lend weight to those who would advocate for student-centered instruction based around small group work; for example, modeling instruction. Other well developed pedagogies, discussed in Chapter 2, such as Peer Instruction and SCALE-UP may also show similar student benefits due to their regular reliance on small group learning.

These results resonate with other research, such as earlier work which identified that self-efficacy beliefs, somewhat associated to performance/competence beliefs, improves more in a MI context compared to traditional instruction (Sawtelle, Brewe \& Kramer, 2012). There is separate evidence that self-efficacy is predictive of academic achievement (Zimmerman, 2000). Out of the three sub-constructs of physics identity, recognition beliefs 
have been shown to be the largest and most important predictor of physics identity (Godwin, Potvin, Hazari, \& Lock, 2016; Wang \& Hazari, 2018). Regularly initiating group tasks may allow students to be seen as good physics students by their peers and be associated with understanding and performing physics well.

The final finding was that there are changes in students' cooperation beliefs over the semester. This suggests that students' preferences towards working in groups increased because of their experiences during the semester. This finding is significant because cooperation beliefs may be beneficial to students' professional careers. As disciplines develop and branch out due to the advancement of technology, interdisciplinary collaborations are becoming more regular features in science and engineering. The importance and prevalence of collaboration in the workfield has led to employers seeking out individuals who have the ability to work in a team, making it a valuable asset (Senior et al., 2010). Also as globalization increases, global collaboration is becoming more common, emphasizing the value of this disposition even more (Shappard, Dominick \& Aronson, 2003). Besides enhancing professional cooperation, there is evidence that collectivist ideas are correlated to good citizenship behavior (Moorman \& Blakely, 1995), environmental beliefs (McCarty \& Shrum, 2001) and more innovation in businesses (Najib \& Kiminami, 2011) among other broader outcomes beyond the scope of this work.

The non-significant findings in this study are also worthy of reflection. For example, cooperation beliefs are predictive of the outcome interdependence 
students reported having in their groups. However, cooperation beliefs did not correlate with initiated task interdependence, meaning that students' participation was not determined (at least in this respect) by these pre-semester beliefs. This means there is a real opportunity for instructors and educators to scaffold/stimulate this type of activity in their classroom which, as seen in the results, is of benefit to students' developing physics identities. Also no significant association between cooperation or individualism beliefs and conceptual gains were found. This lack of association is consistent with the lack of other literature tying communal beliefs to academic performance and may mean that students have an equal chance to increase their conceptual gains in modeling instruction regardless of their incoming attitudes on cooperation and individualism.

\subsubsection{Implications for Student-centered Classrooms}

These results suggest that having students regularly initiate tasks supports their identity development, so it is of interest to ask how these forms of student engagement can be promoted in the classroom. Instructors may use considerations raised in the social loafing literature to effectively design their curriculum to encourage productive student participation. Having students work on assignments that scaffold students to generate ideas is one approach (Straus \& McGrath, 1994) and may include designing experiments, brainstorming ideas, exploring a new topic, producing a particular outcome or activities involving critically thinking about physical systems. A second way to increase class participation is to use student evaluations. There are some challenges to 
conducting these evaluations, for example, the difficulty in simultaneously evaluating each student. Peer evaluations, where students assess each other, may be used to increase the individual accountability of students (Chen \& Lou, 2004; Gueldensoph \& May, 2002). However there may be challenges in how these assessments are incorporated into students' grades. Assigning roles to students so that each group has a particular structure is the third way that Meyers (1997) suggests that student participation may be enhanced and consists of designating roles to particular students, with the roles depending on the task at hand. A challenge to assigning roles in an introductory physics context is that there may not be enough distinct roles for every type of task. Another drawback of assigning roles is that students may not want the role to which they are assigned, which may lead to less participation from those students.

In the modeling instruction course in which the current study took place, there are regular idea-generating and intellective tasks, often structured with the former followed by the latter. Idea-generating tasks used in Modeling Instruction include regular exploration activities to introduce new phenomena and elements of physical systems. Some of the follow-up activities that include applying new principles learned are also idea-generating, as students have to figure out how to use the new tools provided to them. Problem solving activities are often closedended and result in the construction of a complete, consistent solution (which depend on the assumptions made by students). There are no individualized evaluations of students' participation (in the spirit of the social loafing literature) 
nor defined roles in the modeling instruction course in which this study took place. Although these last two strategies highlighted above could be adopted into modeling instruction to better support student engagement, there may be other elements of the course that are sacrificed. For example, the risks of social loafing may be reduced if students know that they would be evaluated for their group participation by their peers. Peer evaluations may make students more accountable for their actions and lead to more participation. However, practically speaking, students may feel uncomfortable knowing that part of their grade comes from their peers' assessment of them, possibly negating the positive effects. The use of roles is harder to implement in modeling due to the various types of activities that exist and may lead to students competing for the same roles which goes against the principle of increasing their cooperation.

\subsection{Conclusions}

This study analyzed the associations between social interdependence (specifically, task and outcome interdependence) and conceptual and physics identity gains. Initiated task interdependence was found to be a significant predictor of physics recognition and performance/competence gains. No associations between task and outcome interdependence and conceptual gains were found. Lastly, cooperation beliefs were found to have slightly shifted towards preferring cooperation from the beginning to the end of the semester.

A limitation in this study is the statistical power and limited representativeness of the sample. The data used in this study were collected 
from a single course of 90 students, which was both a technical limitation (restricting the complexity of models that could be constructed) and a conceptual limitation (there is no comparison to other classroom environments). The analytical methods used in this study did not take full advantage of all of the structure available in the data. To wit: the data collection involved collecting surveys at eight different time points, so more sophisticated time-dependent models such as a linear growth mixed model or structural equation model may have helped elucidate more nuance for each student and each group assignment. The dataset used in this study was sufficient for finding the associations sought out, but collecting a larger, more diverse data set would help ameliorate both of these limitations in the future. Though unlikely, another possible limitation for the result that students' cooperation beliefs increased over the semester is that students' cooperation experiences may go beyond the context of where this study took place. Students may have been enrolled in other classrooms that involved heavy cooperation, or may have had other experiences that led them to increasingly value cooperation over the semester.

Future work that builds on these findings may include more sophisticated models and/or using a larger data set which would take better advantage of the structure of the data or have broader generalizability. Of course, this approach would involve very intensive data collection from multiple classrooms, so the practical challenges should not be ignored. These types of analysis might make it possible to evaluate how social interdependence changes over time in a 
classroom as well as how each group assignment may have particularly impacted pre to post differences in conceptual knowledge and physics identity. 


\section{USING SOCIAL INTERDEPENDENCE AND SOCIAL METACOGNITION LENSES TO STUDY SMALL GROUP INTERACTIONS}

\subsection{Motivation}

As discussed in Chapters 3 and 4, small group learning has been shown to produce greater academic achievement, more favorable attitudinal outcomes and increased persistence in STEM courses (Springer,Stanne \& Donovan, 1999). The results presented in Chapter 3 added to the evidence in favor of the effectiveness of small group learning in introductory physics. Students who reported working in small groups every class gained more conceptually than students who did not. Further, Chapter 4 quantitatively studied how social interdependence affects students' semester-long conceptual learning and physics identity gains in a small group learning environment, finding that students who reported initiating tasks more often had higher physics identity gains. Although these results generally support the use of small group learning in physics classrooms, the underlying causal mechanism of these results still need to be understood deeply. To examine the process by which students cooperated and built ideas with other group members, two theoretical frameworks were leveraged: Social Interdependence (SI) theory and social metacognition (SMC). Social Interdependence is fundamental for successful cooperation within small group learning environments (Johnson and Johnson, 2002). It is also understood that metacognition $(\mathrm{MC})$ is an essential part of learning and that metacognitive strategies can support learning (Schunk, 2008). Through metacognitive dialogue, 
students can construct their mental models in tandem with their peers, generating a shared understanding. In this chapter, these two frameworks are used in parallel to qualitatively analyze the classroom learning of small groups of students, to understand how students can cooperate in learning and build a shared understanding of physics concepts. The research question for this chapter is:

- Viewed through the lens of social interdependence and social metacognition, what are possible affordances and limitations to students' learning that are available through small group learning?

\subsection{Theoretical Perspective on Small-group Learning}

As explained in Chapter 2, SI provides an interpretive framework for understanding the critical elements and benefits of cooperative learning in an educational context (Johnson \& Johnson, 2002). In general, SI occurs when individuals in a group setting are mutually affected by the actions of others (Johnson \& Johnson, 2009), a scenario that is abundant in the Modeling Instruction (MI) classroom. Social Interdependence can be positive (students constructively cooperate on tasks to the benefit of all) or negative (students interact on tasks in a way that hinders students' learning). An element of positive interdependence is that students are mutually supportive of each other. Besides social interdependence, there can be social independence and dependence. Social independence occurs when students act independently of one another, not affecting each other's actions. Student dependence occurs when only one 
subset of student(s) in a group benefits from the group interactions. There are three related sub-constructs associated with positive SI: positive relationships between group members, increased effort to succeed, and psychological adjustment (Johnson \& Johnson, 2005). In the context of classrooms, "effort to succeed" is related to students engaging and trying to achieve the learning goals of the given activity, positive relationships occur when students have constructive and supportive personal interactions with each other and with instructors, and psychological adjustment encompases students' attitudes towards the activities, their interpretation of what they are going through in the classroom, and associated social skills. It is important to note that these sub-constructs have a bi-directional relationship with SI, hence SI leads to more student engagement, positive personal interactions, and social skills and vice versa (as seen in Figure 2).

Social Metacognition (SMC) expands the concepts of metacognition to social settings. Metacognition is the process by which individuals monitor and self regulate their own thoughts (Dinsmore, Alexander \& Loughlin, 2008; Hacker, Dunlosky \& Graesser, 2009; Livingston, 2003; Veenman, Van Hout-Wolters \& Afflerbach, 2006). There are three types of metacognitive knowledge and three components of self regulation. The three types of metacognitive knowledge are: declarative, procedural and conditional metacognitive knowledge. The three components of self regulation are: planning, monitoring, and evaluating. Metacognition has also been shown to increase in self-confidence (Kleitman \& 
Stankov, 2007) and to foster self-reflection and foresight (Desautel, 2009).

Social Metacognition provides a lens for understanding how students share and distribute the metacognitive aspects of learning with others. Social Metacognition provides a framework to understand the ways in which group members may monitor and regulate each other's thoughts (Chiu \& Kuo, 2010). This monitoring and regulating can involve detecting consistent or inconsistent ideas (e.g., students compare what group members say with their own mental models to agree or disagree), building shared knowledge (e.g., group members negotiate their understanding and build on each other's ideas), distributing metacognitive demands (e.g., when students are uncertain about their thinking and ask other group members feedback on those thoughts), reducing mistakes or distractions (e.g., student detects when another group member diverges into irrelevant topics), and motivating one another (e.g., students may increase the groups' morale or effort).

This framework was chosen because of the prior research exploring how improved metacognition (MC) can facilitate learning and improve the performance of tasks and help groups solve problems more effectively (Goos, Galbraith \& Renshaw, 2002; McCrindle \& Christensen, 1995; Schoenfeld, 1992). Social Metacognition involves multiple people communicating with each other which can make MC more conscious as group members explicitly share their ideas with one another. To operationalize SMC for coding, two modalities of SMC were distinguished based on the definition above. The first, "inter-student SMC," 
occurs when students provide metacognitive analysis or insight on other students' thoughts, meaning it requires inter-student dialogue. The second, "intrastudent SMC," occurs when students provide metacognitive analysis of their own ideas but, importantly, share it with their group. The focus of the analysis in this chapter is inter-student SMC as it necessarily involves multiple members of a group but both types of SMC were coded.

In this study, a qualitative analysis was conducted on video data of students working in small groups on class activities in a first semester, introductory, calculus-based modeling instruction physics course. These observations were collected from the same course as the study reported in Chapter 4, and the subjects of the current analysis are part of the whole-class data set analyzed there. MI was chosen due to being a well-studied example of a classroom using a small group learning approach to physics instruction which relies on students building consistent scientific models using several different representations (e.g., mathematics, force diagrams, energy diagrams, motion maps, etc.) that help to explain a wide class of physical phenomena (Brewe, 2008). Both theoretical frameworks of SI and SMC were used to analyze how students cooperate in groups and scaffold shared knowledge with one another.

\subsection{Methods and Analysis}

Survey data and video recordings were taken in a first semester MI Introductory Physics course during the Fall semester of 2018. The video recordings were made by setting up a video camera focused on each group and 
placing audio recorders in the center of each of the groups' tables. The separate collection of audio and video gave the researcher the best of both visual and sound and the video and audio sources were then synced together for the analysis. Two groups of six students were observed, chosen based on their responses of the same pre-semester survey used in chapter 4 (Appendix 2) probing their attitudes towards cooperation and individualism (Johnson \& NoremHebeisen, 1979; Driskell, Salas \& Hughes, 2010). The course in question was co-taught by the author (as a teaching assistant) although the author does not frequently appear in the video data collected. A survey was distributed to all students at the beginning of the semester (see detailed description in Chapter 4 and below) and from those responses two different groups of six students each were selected to be observed for two days in Week 4 of the semester. At this point in the semester, students were just beginning to learn about energy and energy conservation which, in the Modeling curriculum, occurs before learning about forces and momentum. This topic is a critical sequence of learning activities in the Modeling curriculum, because these topics significantly expand the representations that students use daily, and also provide the first set of tools that allow students to understand "why" physical systems evolve in time and why motion occurs. Previous topics involved kinematics and related ideas, which allow students to describe and predict motion, but without a causal understanding. Class was scheduled for 3 hours, 15 minutes twice per week, so this gave 6.5 hours of video data to observe and analyze for each group. Note 
that the groups of 6 are nominally delineated as two groups of 3 students each (assigned by the instructor at random, and persisting for approximately two to three weeks before rotation), but these two groups sit at the same table and interact as a one larger group (hence the reason all six students were treated as a single group in this study). To analyze the video recordings of these classes, first observational notes and coded student dialogue were created in a spreadsheet (a sample of these notes for both groups appears in Appendix 6). The following paragraph explains in detail the pre-semester survey used for choosing which groups to observe and then discusses the two layers of coding used to analyze the student activities and group interactions.

The pre-semester survey utilized previously developed and validated social interdependence (Johnson \& Norem-Hebeisen, 1979) and collective orientation scales (Driskell, Salas \& Hughes, 2010) to predict the expected social interdependence of small groups (See Appendix 2). Although the SI scale is a validated measure, it was developed and validated 41 years ago. Since the Modeling Instruction pedagogy was developed more recently than this scale, and the scale was initially validated with very different populations, the collective orientation scale was chosen to complement the SI scale since it is more modern and has been found to correlate positively with SI, while predicting team performance. Exploratory factor analysis was conducted to understand the factor structure of the items from both surveys and found that they best loaded into two factors, which were identified as "cooperation" and "individualism" beliefs (See 
Table 4 from last chapter). This factor analysis helped to validate the correlation between the two different surveys used. For the purposes of the current analysis, a score was generated to predict the interdependence of the randomly-assigned student groups. Using the results of the EFA some items that did not load well on either of the surviving two factors were dropped and then standardized scores were created for students' cooperation and individualism beliefs. (Further explanation of this validation is presented in Chapter 4.) Group scores were then assigned by averaging students' cooperation and individualism beliefs within each group.

Two groups were chosen to be observed based on these data. The first group had high average cooperation and low average individualism beliefs compared to the class average (Group A) while the second group had low average cooperation and high average individualism beliefs (Group B). These groups were selected because they were expected to provide a contrast in their interactions, which would help validate the pre-semester survey prediction and to understand the SMC of two contrasting group situations. These groups were video recorded for one week, consisting of two days and six hours, thirty minutes total observation time.

An exploratory observational study was conducted to interpret students' small group interactions through the lenses of SI and SMC (Huberman \& Miles, 2002). Each of these constructs were coded independently of one another, first coding the SI minute by minute and then later separately coding for SMC of all 
student transcripts. The analysis was conducted in this order because SI characterizes the cooperation of the groups and then, to further investigate this cooperation, SMC is used to describe the learning the groups are engaged in during their discussions. Once the observations were coded for these constructs, a non grounded theory Constant Comparison Analysis (Fram, 2013) of both groups provided similarities and differences. A Constant Comparative Analysis is an iterative and inductive process that allows the researcher to compare data or incidents to other data or incidents during the coding process (Glaser, 1965). These exploratory results lead to hypotheses on how types of activities, instructor assistance, and individual factors inform SI and SMC outcomes.

In the first layer of analysis, social interdependence was coded for the groups' activities. Codes were created a priori to identify when groups demonstrated interdependence, dependence and/or independence. The operational definition used to code for interdependence was: when two or more students were actively discussing, interacting, and influencing each other while working on an activity or performing a lab/experiment. A critical feature of the interdependence code is that student participation is distributed among students and that each student participating influences the group's direction.

While observing the data, Interdependence events were further broken down into sub-codes to distinguish when students cooperated through discussions while on task ("I-OT"), performed experiments ("I-EX"), discussed other physics tasks ("I-OP”), or built positive relationships (“I-RB"). These 
distinctions allowed for an understanding of different dynamics of interdependence. The most common codes were students discussing activities (I-OT) and collaborating on experiments (I-EX). All interactions with an instructor (including LAs and TAs) were coded as dependent (D) since the instructors help students with their activities but do not benefit directly from those interactions and .When group members worked individually and had little to no interaction with one another they were coded as independent $(\mathrm{N})$. The SI codes were labeled minute by minute since these codes were created based on observations of the entire group. When more than one type of interdependence was possibly identified in the same minute, the type of interdependence that took the longest during that minute was prioritized. However, note that within the interdependence codes there could be double codes such as I-RB and I-OT, resulting in a combined code of I-OT, RB. The SI codes used in this layer of analysis can be found in Table 14. 


\section{Table 14: SI codes and examples}

These codes were used for the first layer of this analysis to code for the SI of the groups in the observational video data collected. Included below are examples of situations where these codes would be used.

\begin{tabular}{|l|l|l|}
\hline Code & \multicolumn{1}{|c|}{ Brief Description } & \multicolumn{1}{c|}{ Examples } \\
\hline I-OT & $\begin{array}{l}\text { Interdependent - } \\
\text { Discussions on task }\end{array}$ & $\begin{array}{l}\text { Students are on task, discussing their current activity } \\
\text { with each other. They can be brainstorming or talking } \\
\text { about the features of a problem or results from an } \\
\text { experiment. }\end{array}$ \\
\hline I-EX & $\begin{array}{l}\text { Interdependent - } \\
\text { Experimenting }\end{array}$ & $\begin{array}{l}\text { Students collaborating to perform an experiment or } \\
\text { collect data. Students often divide into roles to perform } \\
\text { experiments. E.g., one student is on the computer, } \\
\text { another is holding a sensor, another is holding the } \\
\text { ball, etc.. }\end{array}$ \\
\hline I-OP & $\begin{array}{l}\text { Interdependent - Other } \\
\text { Task }\end{array}$ & $\begin{array}{l}\text { Students help each other with physics tasks unrelated } \\
\text { to the current activity they are working on, for example } \\
\text { homework from physics or other course. }\end{array}$ \\
\hline I-RB & $\begin{array}{l}\text { Interdependent - } \\
\text { Positive relationship } \\
\text { building }\end{array}$ & $\begin{array}{l}\text { When the students are talking about side things about } \\
\text { each other. When they are joking around and } \\
\text { laughing, or commenting positive things to each other. }\end{array}$ \\
\hline D & Dependent & $\begin{array}{l}\text { Dependence occurs between the group and } \\
\text { instructors. Students depend on instructors to check } \\
\text { and guide the group's ideas. }\end{array}$ \\
\hline N & Independent & $\begin{array}{l}\text { When all the students are working on their own } \\
\text { without interacting with other group members. }\end{array}$ \\
\hline
\end{tabular}

The second, parallel layer of analysis explores how students built and shared ideas during their interactions. The students' dialogue were coded in their groups directly using the lens of social metacognition. These codes were created independent of the passage of time and instead categorized students' discussions during group activities. The initial codes for this layer were based on prior research, which identified the benefits of SMC such as reciprocal 
scaffolding (students scaffold ideas in parallel with others, within a shared zone of proximal development) (Holton \& Clarke, 2006), motivating one another (students encourage each other to keep performing tasks) (Johnson et al., 2007), distributing metacognitive demands (a student asking about the ideas of another group member or of their own) (Johnson, Johnson, \& Smith, 2007) and increased metacognitive visibility (students working in small groups allows each to see how each other are thinking) (Dillenbourg \& Traum, 2006).

After coding half the observational data with this original coding scheme, the SMC codes were assessed for inter-rater reliability (Hallgren, 2012) with another researcher (graduate student colleague) for 8 minutes of the observations. The result of this initial inter-rater reliability was to trim redundant codes and update the working definitions of the remaining codes, which resulted in the finalized codebook (Table 15). The final codebook includes the following codes: students recognized other group members' ideas as consistent (R-C), students recognized other group members' ideas as inconsistent (R-F), students built shared knowledge (R-B), students expanded on others' ideas (R-E), students distributed metacognitive demands (D-B), students focused on a subset of the problem at hand (S-F), students reduced the distractions of others (S-D) and students reduced mistakes (S-M). These codes are largely based on interstudent SMC, a modality explained above. In addition, there was a code for intrastudent SMC, which is referred to as other metacognitive (MC). Importantly, 
these codes are not necessarily mutually exclusive, so when a statement or

discussion was identified with multiple codes, this was permitted.

\section{Table 15: SMC codebook}

This code book was used for the second layer of this analysis to categorize the social metacognition between group members in the observational video data collected. In the details are what was looked for during student dialogue when labeling for each specific code used. The codes were non exclusive, meaning that dialogue could be recorded for more than one code at a time.

\begin{tabular}{|l|l|l|}
\hline Code & \multicolumn{1}{|c|}{ Brief Description } & \multicolumn{1}{|c|}{ Coding Details } \\
\hline R-C & $\begin{array}{l}\text { Recognize ideas as } \\
\text { consistent }\end{array}$ & $\begin{array}{l}\text { A student explicitly recognizes another student's idea(s) as } \\
\text { consistent }\end{array}$ \\
\hline R-F & $\begin{array}{l}\text { Detect inconsistent } \\
\text { ideas }\end{array}$ & $\begin{array}{l}\text { A student explicitly recognizes another student's idea(s) as } \\
\text { inconsistent }\end{array}$ \\
\hline R-B & $\begin{array}{l}\text { Building shared } \\
\text { knowledge }\end{array}$ & $\begin{array}{l}\text { Students, in discussion of each other's ideas, come to a } \\
\text { (working/formative) consensus (can be tentative) about a } \\
\text { particular idea/principle. }\end{array}$ \\
\hline R-E & $\begin{array}{l}\text { Expanding others } \\
\text { ideas }\end{array}$ & $\begin{array}{l}\text { A student explicitly expands on an idea/concept the group } \\
\text { (or another student) is discussing, bringing new ideas into } \\
\text { the conversation. }\end{array}$ \\
\hline D-B & $\begin{array}{l}\text { Distribute MC } \\
\text { resources }\end{array}$ & $\begin{array}{l}\text { A student (or instructor) explicitly asks questions about } \\
\text { their own or another student's (or instructor) idea. These } \\
\text { questions often probe why or how someone else said } \\
\text { something. }\end{array}$ \\
\hline M-F & $\begin{array}{l}\text { Focus on subset of } \\
\text { problem }\end{array}$ & $\begin{array}{l}\text { A student explicitly focuses on a subset of the problem/task } \\
\text { that is currently under discussion. }\end{array}$ \\
\hline S-D & Reduce distractions & $\begin{array}{l}\text { A student refocuses the group to the task at hand or a } \\
\text { more relevant idea. }\end{array}$ \\
\hline S-M & Reduce mistakes & $\begin{array}{l}\text { When a student doesn't necessarily detect an error but } \\
\text { says something to prevent someone else from making a } \\
\text { mistake. (This code is similar to R-F but is distinct because } \\
\text { it happens proactively.) }\end{array}$ \\
\hline $\begin{array}{l}\text { A student expresses metacognitive discourse on their own } \\
\text { ideas to the group. This code is the only code involving } \\
\text { intra-student SMC. }\end{array}$ \\
\hline Stacognition
\end{tabular}


Once the codebook was finalized, all the videos were analyzed multiple times to capture multiple interpretations of students working in their groups. To validate the resulting SMC codes, an inter-rater reliability assessment was again conducted using sample clips from the video recordings with two other researchers. With the first graduate student colleague, separate coding was conducted on three separate occasions on about 20 total minutes of video samples. The SMC codes were compared and discussed, and consensus for each coding instance was reached. Another colleague coded a different set of video samples (totaling about 8 minutes of class time), again discussing and coming to a consensus on each coding instance. After finishing the coding and inter-rater reliability testing, the resulting codes were then organized and analyzed in more detail to produce the results that are presented in this chapter.

\section{$5.4 \quad$ Results}

The first subsection presents a summary of the overall findings from the

first layer of coding (social interdependence). As a reminder, Group A had high cooperation and low individualism beliefs (on average, compared to the entire class) while Group B had low cooperation and high individualism attitudes (on average, compared to the entire class). Then the similarities and differences between the SI codes for groups A and B are explored. The fourth subsection presents a summary of the overall findings for the second layer of coding (social metacognition). Then similarities and differences between the SMC codes for groups $A$ and $B$ are broken down, first highlighting patterns (modalities) 
commonly observed for both groups and then presenting the contrasting SMC codes. For both layers of code, the coding results are presented at the macro level (e.g., reporting frequency of codes) to frame both groups and then detailed examples from the transcripts are provided. Lastly the seventh subsection explains how the two layers of SI and SMC may connect and inform one another, specifically how positive social interdependence may be necessary for more frequent social metacognition.

\subsubsection{Overall Results of Social Interdependence Coding}

Figure 8 summarizes the total time identified for social interdependence events for groups A and B. Both groups were observed for the same length of class time (262 minutes/codes for Group A and 261 minutes/codes for Group B) and were coded for SI minute by minute as described previously. Group A, which was predicted to have more positive SI, was more frequently coded for interdependence events than Group B. This result is consistent with the fact that previously-validated surveys were used (Johnson \& Norem-Hebeisen, 1979; Driskell, Salas \& Hughes, 2010) to predict the SI of the randomly-assigned groups. However, the coding scheme and observational analysis provide more detailed insight into how SI plays out in this studio physics classroom. In addition to interdependence events, Group A was observed to spend less time in dependent activities with an instructor than did Group B. Group B spent more time acting in ways that were independent (of each other, as well as instructors),

whereas in Group A this type of activity was more rare. This high-level summary 
clearly identifies the gross differences in the activities of the two groups;

however, it lacks the richness available in the observational data. Next, a detailed comparison - similarities and differences - between the social interdependence of groups $A$ and $B$ is provided.

Figure 8: Comparison of SI codes for groups A and B

This figure compares the number of times I coded for social interdependence for groups $A$ and $B$ during the course of 2 days of observation.

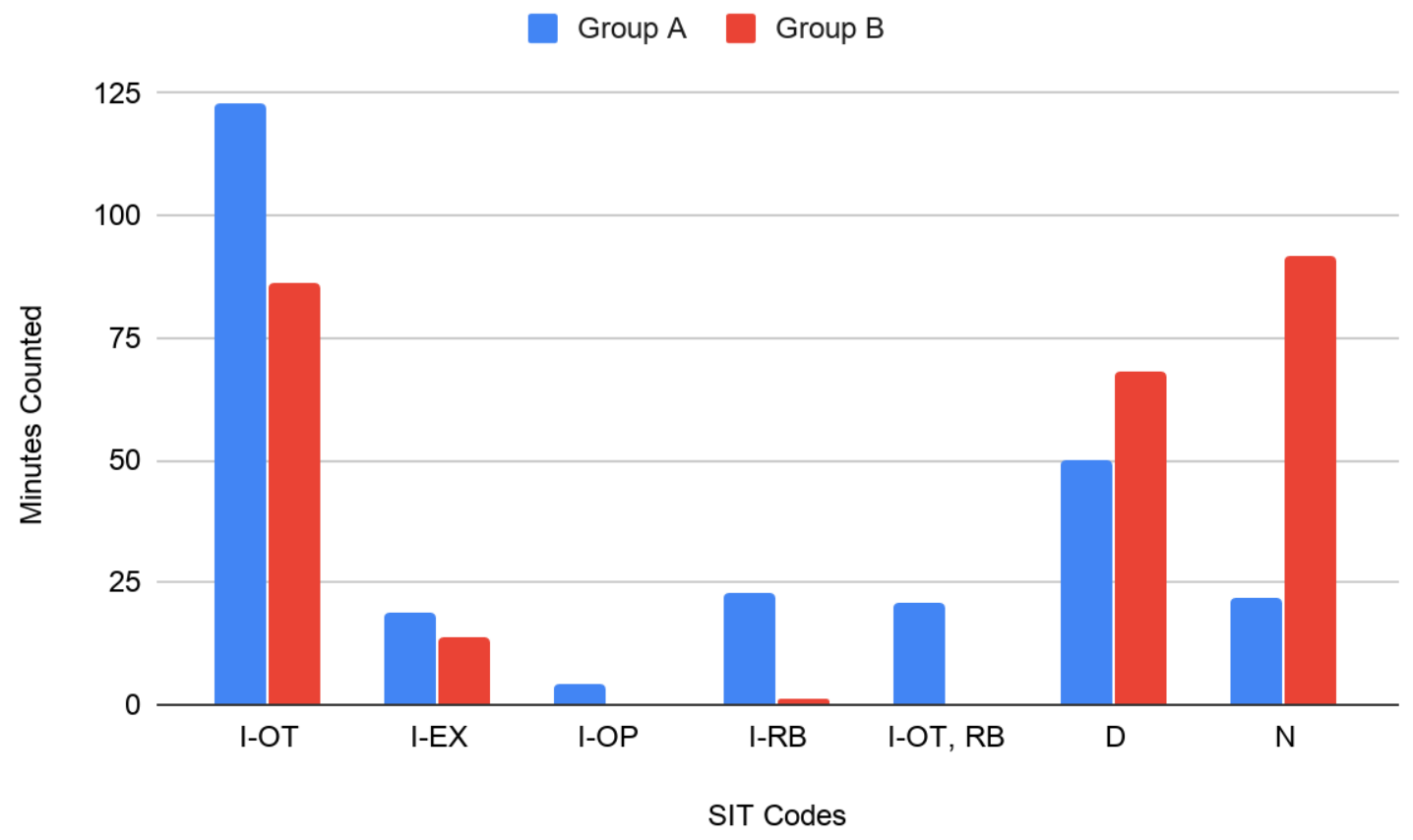

\section{Legend for Codes}

\begin{tabular}{|l|l|}
\hline I-OT & Interdependent - Discussions on task \\
\hline I-EX & Interdependent - Experimenting \\
\hline I-OP & Interdependent - Other Task \\
\hline I-RB & Interdependent - Positive relationship building \\
\hline D & Dependent \\
\hline N & Independent \\
\hline
\end{tabular}




\subsubsection{Commonalities in Social Interdependence}

Though the time spent in different types of social interdependence were observed to be different for both groups (see Figure 8), there were shared features observed while engaged interdependently (specifically, interactions identified with the code I-OT, in these examples). For example, one commonality observed for both groups was how students depended on one another for assistance on individual weaknesses. A vignette from Group B which occurred while they worked on solving for velocity using energy conservation (Day 2, $2: 16: 27-2: 16: 45):$

A: "Okay so then all you have to do is divide both sides by $0.5 \mathrm{~kg}$ to bring everything over to isolate $v^{2}$. Okay and this is the part that trips me up because I suck in algebra, because now we have a three tier fraction, so how would these numbers combine?"

J: "The way I write it is one half, and then the bottom of the fraction moves to the other side by multiplying."

A: "You said one half, what do you mean?"

L: "One over two."

J: "One over two and you just multiply this by 2."

L: "So you can cancel out a fraction."

Student A recognizes her difficulty solving for the velocity in the equation they were working on and was able to rely on other group members for understanding how to isolate velocity. This is one of the direct benefits of student-centered 
learning since students can seek out the help they may need when they need it from their peers. While students were interdependent, they mutually benefited from the group by relying on each other's strengths and making up for their weaknesses.

These conceptual benefits during interdependent events were also observed (and more commonly so) in Group A. Here is an interaction when the group was working on velocity vs. time graphs for the motion of a bouncing ball (Day 1, 0:17:52 0:19:37):

R: "But it is decreasing right because as you go up you decrease and that's why you come back down. When it bounces its going up but its decreasing that's why it comes back again."

A: "Yeah but when it bounces, it changes directions"

$R:$ "It does but it also decreases velocity, which is what this is saying right?

So what you are saying is that this should be a vertical line?"

A: "I think it would look like this [grabs ball to use as demo]. Here is your reference point so if you are dropping it, its going away so its positive, once it hits here [puts ball on table] it bounces back and goes to a negative direction"

R: "And its decreasing velocity"

A: "Okay but you're saying that you are decreasing velocity in the positive direction"

R: "Yeah I see what you mean, there should be a vertical line there" 
Here a conversation is seen taking place between Student A and Student R. Student $A$ is trying to get Student $R$ to recognize his mistake (which could also be seen as SMC) drawing the direction of the velocity vs. time graphs. This example also displays the back and forth nature of dialogue when groups are behaving interdependently, negotiating their ideas with one another.

Another shared commonality observed during social interdependent interactions is the frequent use of representations to communicate with each other. Due to the modeling nature of the course, both groups made regular use of various representations to build their physical models and share their ideas with one another. As discussed in Chapter 2, the use of representations allow students to negotiate their thoughts while also checking the consistency of their models. Here is an example of Group A using the system schema representation after initially learning about it (Day 1, 2:02:37 - 2:03:11):

A: "Do you know there is contact between the hill and the ground?" R: "Yes."

A: "Did you put it permanent or temporary?"

$R:$ "I did temporary, because it's not always in contact all the time, only when you go from hill to ground."

K: "Oh that makes sense because it's not like the hill and the ground are on top of each other, you have the hill and then you have the ground and at some point they touch." 

A: "Right and it's always touching, no?"
K: "I don't know."

Group A is discussing whether the contact between the hill and the ground is permanent or temporary so that they may draw the system schema appropriately. When there is permanent contact, the line representing the contact is solid and when there is temporary contact the line is dashed. The frequent use of these representations is seen in several of the quotes that appear throughout the rest of the results section.

A third commonality observed was how the particular use of whiteboards led to on-task interdependence. Whiteboards played a significant role in compelling students to come together and form a consensus on their ideas. Just before multi-group discussions were held, each group was required to summarize their work on a whiteboard, to present to other groups. In this task, both groups A and B were seen to be highly interdependent. Here, Group B is wrapping up their consensus solution (Day 2, 1:35:05 - 1:36:09):

P: "What was the final velocity for 1.5 meters?"

E: "The final velocity was 6 meters per second."
A: "What was it at 1 ?"
E: "It was 3.7."
J: "So what was the equation you guys came up with?"
E: " $n$ times velocity squared and then in the end we would find whatever its supposed to be, the 0.5." 
$\mathrm{J}$ : "What is $n$ ?"

E: "The 0.5."

A: "But where does that 0.5 come from?"

E: "It comes from the slope of this line [points at white board]."

Here Student $E$ is central to the conversation since she initially wrote down the summary for the groups' results on the whiteboard. In this example, Group B was highly collaborative as they only had a few minutes to finish summarizing their findings on their whiteboard before presenting it to other groups. This quote provides one of the rare occasions four or more students simultaneously participated in Group B.

Whiteboards compelled students to work together and negotiate their understanding more carefully. Both groups showed more interdependence as they needed to negotiate their solutions during these times. In the following vignette, Group A is discussing their final ideas after an instructor assigned them problems 1 and 2 to write up on their whiteboard (Day 1, 2:21:20 - 2:22:08):

R: "Are we doing one and two [on the whiteboard]?"

D: "Yeah we are doing one and two."

K: "Yes, do you want [me to do the whiteboard]"

D: "I'Il do [the whiteboard] don't worry"

K: "Are you sure, I can draw one and you do the other if you want."

D: "Okay"

A: "Wait $R$, how do you do it, for the energy?" 
$R:$ "You start with $E^{k}$ because you are sliding across the surface there is no gravity"

A: "Yeah but as you are moving across the table aren't you losing energy as you slide"

$R$ : "Yeah that's why the first one is $E^{k}$, your internal increases as you go"

A: "You can't just start with kinetic energy though can you?"

K: "We are assuming that we are looking at the problem after the force that acted on the book caused the book to slide."

In the beginning of this quote, Student $\mathrm{K}$ and $\mathrm{D}$ express sharing the responsibility for writing up the whiteboard. Then Student A asks Student R what he got for the energy pie charts, and Student $\mathrm{K}$ gets involved too and highlights some of the assumptions that were made. Students typically finish their whiteboards at the end of activities, so they serve as tools to negotiate shared meaning and finalize results agreed upon by group members so they can present during the whiteboard meeting.

These three commonalities emerged from the observed interdependence events of both groups. The first presented examples of how students benefited through negotiating their understanding with their peers. The second connected how interdependent communication depended on the curriculum, particularly the use of representations in Modeling Instruction. The third identified a classroom feature that provided a clear affordance to encourage socially interdependent 
interactions for both groups. Next, the differences found in the social interdependence of each group will be highlighted.

\subsubsection{Contrasts in Social Interdependence}

From Figure 8, clear differences in the way the groups spent their time can be immediately identified. Group A was coded as having interdependent activities more frequently and expressed more relationship building than Group B. Group B spent a significant amount of time acting independently. This means that Group

B had less intra-group communication overall and there were fewer opportunities for students to mutually negotiate their ideas. Both groups sometimes depended on instructors, but the way in which the groups interacted with the instructors varied.

Group A was more often observed using the strategy of working on every facet of each activity together, thereby expressing more group processing (e.g., collective actions towards accomplishing tasks). Their discourse was open and highly substitutable (e.g., group members substitute for the actions/ideas of each other) since students in this group often explicitly worked through problems step by step. Substitutability is the ability to build a shared idea. For example, while modeling the motion of a bouncing ball and discussing the plot of the acceleration of the ball over time (Day 1, 0:44:52 - 0:45:57):

D: "What do you guys think?" P: "How about this [shows $D$ his paper], because it's not constant but it's still similar 
D: "I don't know..."

D: "What do you think for [the] acceleration [graph]? Do you think it's constant?"

R: "Acceleration should be constant right, it's gravity."

A: "But we are not talking about gravity, we are talking about the ball."

K: "Yeah, but our original graph made sense to me."

Four of the five students present at the table that day were engaging with one another while negotiating what the acceleration graph should look like. These types of interactions involving most of the group were common in Group A's activities.

On the other hand, Group B tended to work more independently (of each other) and dependently (on instructors). The students in Group B often talked to each other only to verify their individual work, instead tending to work by themselves or ask an instructor nearby when confused. Group B was observed working interdependently most often when they needed to verify their solutions or when compelled (by the instructors) to reach a consensus on their white board. Less substitutability was observed in Group B, since they did not explicitly build on each other's ideas like Group A. An example of this latter type of discussion, occuring while students were working on the same activity as the previous vignette for Group A but focused on the motion map representation, is (Day 1, $0: 43: 08-0: 43: 48):$ 
P: “For the motion map, wouldn't the arrows be under the curve? Let's say at this point the horizontal is the same but is getting vertically farther?" E: "I think it's this way because..."

P: "Oh yeah that makes sense and do you know at the top when it stops moving, would it be straight or no?"

E: "Yea I think so."

This short discourse, between only two students of the six present, takes the form of a confirmation-based dialogue of solutions already independently generated. There were relatively few interactions that included more than two students working together and four of the six group members accounted for most of the discussions observed (e.g., two group members contributed very infrequently to any group discussion).

More positive relationship-building was observed within Group A. This group was visibly more relaxed and engaged (laughter, etc.) and also more frequently mentioned personal topics during tasks (I-OT, RB in Figure 8). Here, Group A is working on an energy conservation problem (whether a person going up 100 flights of stairs burns enough calories to eat a chocolate fondue) but is simultaneously developing positive relationships (Day 2, 1:53:27 - 1:55:08):

R: "Why would that entitle you to eat the entire chocolate fondue?" D: "I'm going to get technical. When I do my stairmaster I do about 50 floors and that is barely 200 calories. So if you multiply... you know what I'm saying?" 
K: "I'm impressed you do 50 floors on the stairmaster [laughs]"

D: "[laughs] Barely, no but really think of it, if you do that's not even going to be the amount of calories of this whole thing. You are not entitled." K: "I feel like I would just eat the fondue regardless" D: "Exactly"

\section{A: "What is going on?"}

R: "Maybe we are over complicating this. Entitles are an objective thing. A: "This is a lot of assumptions [laughs] " $R:$ "Yes because if we take the stairs we waste energy and I wasn't meant to take the stairs because I'm not paying a hundred thousand dollars a night in this hotel on the 100th floor [joking]"

The students here are seen joking while they are working on their activity together. Student $D$ connected their stairmaster experience and how many calories they could burn, and Student $\mathrm{K}$ found this funny and impressive. Then Student $A$ laughs about the assumptions they are making and Student $\mathrm{R}$ tells another joke. The students' attitudes observed here provided evidence of them building positive relationships with their peers, which is an outcome of SI. Group A appeared to enjoy this particular problem overall and did complete it with a consistent solution. Group B did not exhibit the same positive relationships while working on tasks and were rarely observed building positive relationships.

Observations of both groups being dependent on instructors were seen at times, but Group A engaged in this dependence less frequently than Group B. 
When Group A encountered discrepancies in their data or inconsistencies in their models, they conducted experiments over again and continued to discuss things to find a resolution. Not only was Group A less dependent on instructors than Group B, but also more students in Group A participated in talking to instructors when the opportunity arose. Here, Group A is engaged with professor G, trying to explain what they think is happening to the bouncing ball (Day 1, 0:42:15 $0: 42: 55)$

G: "Why does the ball bounce then?"

P: "Because it's bouncy."

G: "Yeah, it's a bouncy ball..."

$K:$ "[P] was talking about force"

D: "Yeah force is exerted on the floor which pushes it to bounce back."

P: "Alright so gravity pushes down, that's some type of force and when it hits and comes back up and whatever it has left, gravity pushes it down." R: "Because every action has an equal and opposite reaction." G: "You're both right but that's not what is relevant here."

From this interaction, it can be seen that four of the five group members engaged with the instructor in this short exchange, which emphasizes the substitutability of the group (finishing off each other's ideas in this case). Even though some of the ideas raised in this example were not relevant to the particular activity as the instructor indicated, this group continued to show a high level of interdependence even while engaged with the instructor. 
Group B had more frequent dependent interactions with instructors and different modes of interactions with instructors than Group A. Often, the instructor dependence was initiated (sought out) by students in Group B, as opposed to initiated by the instructor for Group A. Also, Group B did not display the same substitutability as Group A; these students tended to listen and respond only to the instructor during these encounters (Day 1, 0:32:50 - 0:33:55):

$B$ [learning assistant]: "The energy pie chart represents the energy in your system over time. So you have a pie chart, each pie represents how much energy, the different types of energy that exist any point in time. Do you guys know any types of energy?"

J: "Kinetic."

B: "So we have kinetic, what's that?.. so motion right and then what else?" E: "Potential."

B: "Potential right, so what's potential?."

J: "When it's still."

B: "When it's still right, but why is it called potential?"

P: "It's stored energy"

B: "So when do you think something would have more potential energy?"

P: "When it's higher up."

B: "Right, so you have stored energy and it is dependent on your height." In this exchange the learning assistant does most of the talking while students participate through a confirmatory call-and-response. This is representative of the 
frequent dependent interactions for this group. Even though the students in Group B were attentive and found the help useful, their dependence, in comparison to Group A, was more instructor-centered and rarely involved participation of 3 or more group members.

\subsubsection{Overall Results of Social Metacognition}

To understand better the process of learning in groups, the framework of social metacognition (SMC) described previously was used to compare how groups A and B scaffolded and distributed the learning process with one another, particularly focusing on the social metacognitive elements of student discourse. As described in section 5.3, in this layer of analysis student discourse was coded independently of time. This in part led to a disparity of the number of SMC codes counted for both groups with Group A having 251 and Group B having 153. Figure 9 summarizes the number of times the codes were counted for SMC. A raw count is provided, where a summary of codes for both groups is compared, indicating Group A having more SMC talk overall than Group B. A normalized count is also provided, to take into consideration the difference in the number of codes. There are clear differences in the SMC of both groups, but there were also some similarities. First similarities are reported, specifically modalities found in the observations and then differences are examined to understand the contrast between both groups. 
Figure 9. Comparison of SMC codes for groups A and B

This figure compares the number of times social metacognition was coded for Groups A and B. The raw comparison shows all the codes added up, totaling 251 codes for Group A and 162 codes for Group B. The normalized comparison takes the raw counts and divides it by the total number of SMC codes for that group.

\section{Raw Comparison of SMC codes}

Group A Group B

80

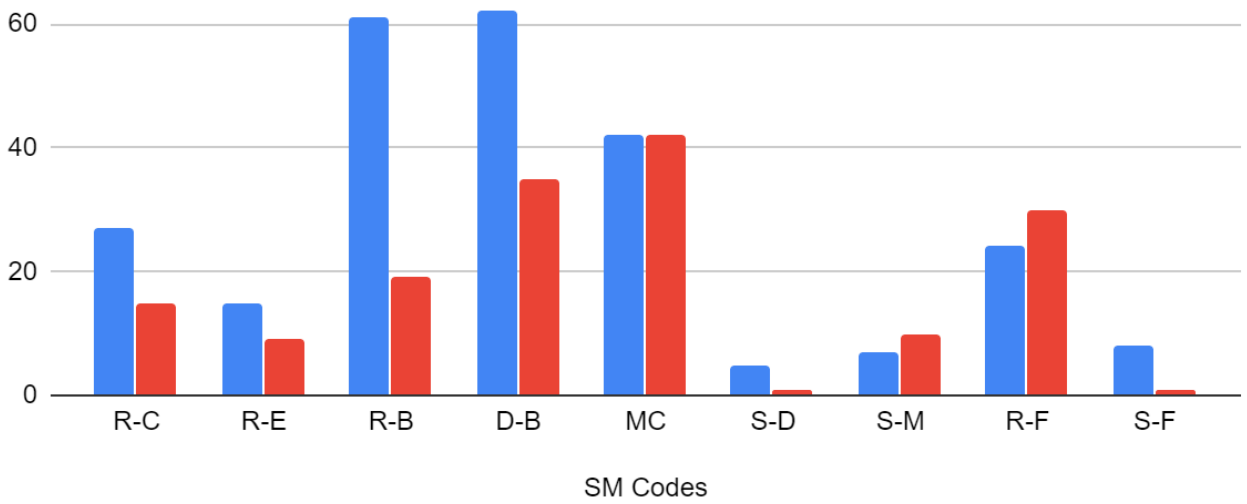

Normalized Comparison of SMC codes

Group A

Group B

$30.00 \%$

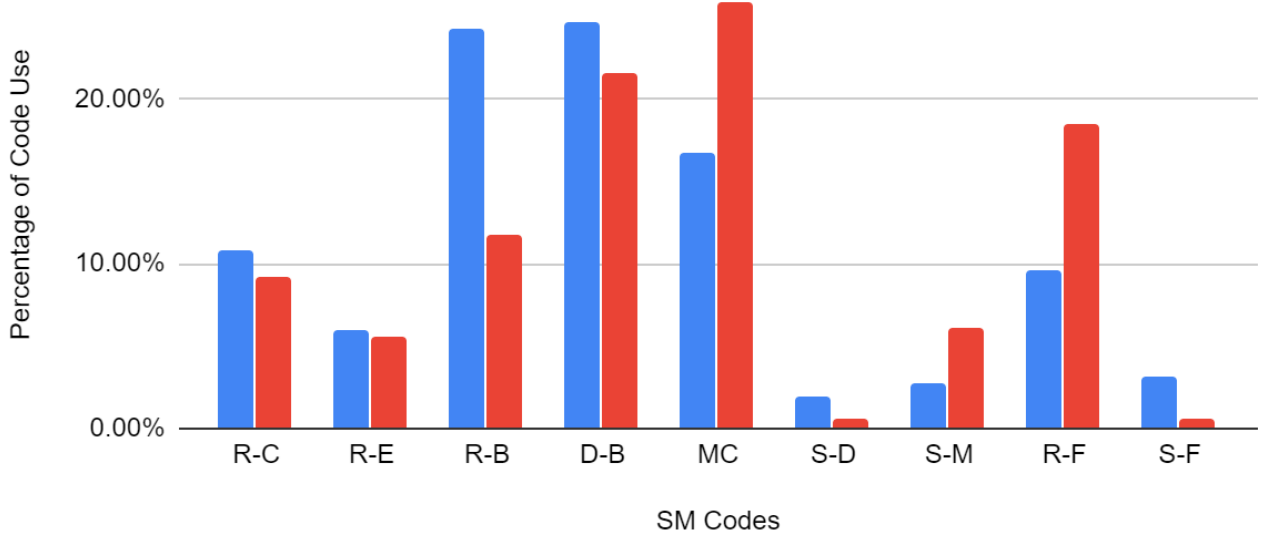

Legend of SMC codes

\begin{tabular}{|l|l|}
\hline $\mathbf{R}-\mathbf{C}$ & Recognize ideas as consistent \\
\hline $\mathbf{R}-\mathbf{E}$ & Expanding others ideas \\
\hline
\end{tabular}


Figure 9, continued

\section{Legend of SMC codes}

\begin{tabular}{|l|l|}
\hline R-B & Building shared knowledge \\
\hline D-B & Distribute MC resources \\
\hline MC & Other MC talk \\
\hline S-D & Reduce distractions \\
\hline S-M & Reduce mistakes \\
\hline R-F & Detect inconsistent ideas \\
\hline S-F & Focus on subset of problem \\
\hline
\end{tabular}

\subsubsection{Modalities of Social Metacognition}

In the initial round of coding for SMC, three distinct modalities were observed, based on the type of activity that students were tasked with completing. The first modality was observed when students were discussing ideas or working on problems/solutions within their group. In this modality, students tended to regularly engage in forms of social metacognition. The second modality occurred while a group was in discussion with an instructor. Here, the instructors tended to use SMC strategies to support and challenge the groups' ideas. The third modality occurred when students ran physical experiments; in this third modality, there was little or no SMC observed amongst the students. These modalities were observed to be heavily dependent on the type of activity the students were currently engaged with. These modalities will be connected to the types of activities that exist in $\mathrm{MI}$ in the discussion. 
In the first modality, students engaged most regularly in social metacognitive actions with each other. For example, in the following vignette, Group B is discussing the energy and system schema for a box sliding down a hill (Day 1, 2:08:33 - 2:10:13):

P: "I don't think we should ignore friction because if we do then theoretically the ball will never stop after it comes down the hill because... $[M C]^{\prime \prime}$

J: "Yeah I put it"

P: "He said to do the System Schema first and then that helps. Would friction be one of the circles? [D-B]"

E: "I think it would be like this [shows her paper]... the box is always in contact."

$P$ : "[reacting to reading her paper] Oh and the friction is from the contact. $[R-C]^{\prime \prime}$

L: "Yeah but it's not dotted right, the contact? [R-B]"

J: "The contact line?"

P: "Yeah it's not dashed because it's always on the floor. [R-B,R-C]"

L: "The arrow, where is it pointing at?"

P: "Yeah it's because the earth's gravity affects the box but the box also affects the earth. "

L: "Okay so it's pointing in both sides."

P: Yeah, arrows are going in both sides." 
Here, Student P expresses that they should include friction and then explains his own thought process, an example of intra-student metacognition (MC). Student $P$ mentions creating a system schema and asks where friction would be included, which was coded as distributing metacognitive demands (D-B) because the student is explicitly and strategically relying on other students to achieve this particular task. Then, Student $E$ shares her ideas with Student $P$, who recognizes her consistent ideas (R-C) and recognizes that friction arises from contact. Then they build a shared understanding (R-B) of how to represent the contact in a system schema.

Group A spent a lot of time in this modality since they often discussed every facet of each problem, as discussed previously. In the following interaction the group is discussing the energy pie charts of an object sliding down a hill (Day 1, 2:07:15 - 2:08:11):

R: So what about the pie charts? The first one is gravity for sure right? K: Yeah so I think.

A: Okay and this is called a pie chart?

D: Yeah, energy pie chart

$R:$ The second one is Kinetic because you are gaining velocity right?

$K$ : Yeah so it would be partial $[R-B, R-C]$

$R$ : Half kinetic and half gravity $[R-B]$

K: Yeah and you get to the point where you have only kinetic energy and... $[R-B]$ 


\section{R: Internal}

K: Why do we have internal? [D-B]

$R$ : When you stop moving.

The dialogue here is mostly between students $\mathrm{K}$ and $\mathrm{R}$ when they were deciding what energy would be drawn in the energy pie charts at different times in their model. They agreed upon the object having all gravitational energy at the top of the hill, and then there is a moment when they come to a consensus of what the energy should be half way down the hill. When discussing the energy at the bottom of the ramp, Student $\mathrm{R}$ mentions including internal energy prompting Student $\mathrm{K}$ to ask why he thinks so. Student $\mathrm{R}$ then explains that the internal energy the ball gains from friction is what causes the ball to stop. The differences between groups $A$ and $B$ in this mode will be expanded upon in the next section.

In the second modality (occurring when students are engaged with an instructor), instructors were observed to deliberately distribute metacognitive demands, recognize consistent ideas, and reduce distractions of the group. Both groups experienced similar SMC interactions during this modality. Here, learning assistant $Y$ is interacting with Group A (Day 2, 0:19:31 - 0:20:34):

$R$ : "When things fall they are weightless so it shouldn't matter..."

LA Y: "Are they weightless? [S-D,D-B]"

D: "I think the difference isn't substantial between [example] two and [example] three, but doesnt three fall a little faster?"

LA Y: "What do you mean? [D-B]" 
D: "Because two is significantly heavier."

LA Y: "Are you thinking between [example] one and [example] two, or [example] one and [example] three?"

M: "Mass is not going to affect the speed that it falls, because gravity is constant."

LA Y: "Yeah that's true, if they are falling the same distance they should end up falling at the same speed. But is the energy the same?"

M: "Well the energy is equal to the mass times the acceleration, mass times acceleration is a force"

LA Y: "Who told you that? What are forces? [R-F,S-D]"

Here the learning assistant $Y$ listens to the group and provides direct feedback in the form of probing questions to distribute metacognitive demands (D-B). The LA is also seen reducing distractions (S-D) and detecting inconsistent ideas (R-F) to move students forward.

Instructors act as multi-dimensional guides for students, as they have authority and are seen as the source of knowledge. Another example of SMCoriented actions from Group B in this modality involves learning assistant $\mathrm{M}$ probing the group to see what solutions they have generated (Day 2, 0:41:27 0:43:07):

LA M: "What did you guys get for $E^{g}$ ?"

P: "Mass times height times gravity"

E: "Is that right? [D-B]" 
LA M: "Yeah, that's the equation for gravitational energy [R-C]. Now try to figure out how $E^{k}$ is related to $E^{g} . "$

P: "What I thought was that, if you are dropping a book, before you drop it you have $E^{g}$ and then the moment it hits the ground it's all $E^{k}$. They will be the same in those two instances."

E: "Not necessarily because if you are throwing something in the air $E^{g}$ will increase and so will $E^{k}$."

P: "Well if you throw something up $E^{g}$ would go up and then $E^{k}$ would be going down."

LA M: "[interrupts them] Don't think about when you are throwing it because you are putting energy into the system [S-D]. Just drop it and then what happens."

E: "They have an inverse relationship."

M: "Why would you say they have an inverse relationship? [D-B]"

The group and LA M distributed the metacognitive demands (D-B) between students and LA M confirms their equation is correct (R-C). Then, asking about the kinetic energy, Student P and E start changing the problem (throwing something rather than dropping it) so LA M reduces the distraction (S-D) by restating they should think about only dropping the books.

From the last two vignettes it should be noted that in this modality, for both groups, the instructors acted as the primary mediators of SMC. The instructors' intentions were to facilitate student discussions and use SMC-supporting 
techniques. Since the instructors are generally more expert-like than students, they rarely (none in these observations) build shared knowledge with students. The role of instructors is important for both groups observed as they are key players in facilitating the cognitive and metacognitive demands put on the students.

In the third modality (students working on experiments and/or data collection), very few SMC events were observed. Instead, students appeared more focused on putting equipment together and conducting experiments. There is more demand for narrow attention as students are engaged with real equipment. For example, in one case for Group A, Student R was on the computer running the Logger Pro software, student $\mathrm{K}$ was dropping a ball from a chair, Student A was holding the meter stick and Student D was holding the chair still. A similar division of labor was happening in Group B during the same experiments. Though there was little or no SMC actions during experimentation, there is socially metacognitive discussion afterwards, when they interpret results (and go back to the first modality of engagement).

The modalities of SMC were to some extent determined by the types of activities available to the groups, as determined by the course curriculum/instructor. Activities in Modeling Instruction (MI) can be roughly divided into four types. The first type are Explorative activities which are designed for students to investigate a new concept or phenomena. The second type of activities are Experiments or Labs. The labs or experiments may involve 
students exploring a new topic, testing a known theory, designing an experiment or predicting an outcome. The third type of activities are the initial practice problems after learning a new concept. These problems tend to be simpler and make use of newly-introduced representations or concepts. The fourth type of activities are extended practice problems to provide more examples for students and model more complex problems.

When students were engaged in exploration activities in these observations they tended to regularly exhibit social metacognition. In exploration activities, students are typically introduced to a new phenomena and are often engaged in discussions and sometimes experimentation. Both groups were observed to be engaged in SMC talk during exploratory activities since these activities often lead to expanding their models and adjusting their ideas to new concepts. All three modalities of social metacognition (SMC) may be present during this type of activity. Here, Group B is exploring gravitational potential energy for the first time and trying to determine how mass affects gravitational potential energy (Day 2, 19:12 - 19:57):

G: What would you rather have dropped on your head? (D-B)

$P$ : The smaller one.

G: Why? [then walks away]

P: Because it's lighter, I don't know if it's slower.

$\mathrm{J}$ : Well it would fall at the same time if there is no wind resistance (R-E, $R-B)$ 
P: Yeah, that's true

A: Well I don't think it has anything to do with it because I would rather have something smaller fall on me from what ever height $(R-B)$

P: Would the second one have more energy, because it's heavier? (D-B)

E: [looking at computer] yeah mass affects Eg [then reads off computer]

Professor G had come by to help them briefly and redirected their thinking by asking which object they would rather hit their head, then the group continued the discussion after he left. Student $P$ answers his questions but is uncertain about how the final velocities of the object relates to their masses, so Student $\mathrm{J}$ explains that without air resistance both objects would fall at the same rate, from the same height. The discussion continues productively until student $E$ uses the internet to find the final equation for potential energy. The group continued to discuss what Student $E$ found after this vignette. This vignette also provides an example of how instructors' use of SMC helped propagate student discussions after the instructor leaves.

Another example of students being metacognitive during the exploration activities is the following, where Group $A$ is deducing their experimental results on the kinetic energy of a ball drop (Day 2: 1:17:53 - 1:18:53)

K: Remember how we talked about the day before yesterday, when you throw something it has Ek to begin with whereas if you drop something it only has Eg.

A: So your final velocity is your Ek $(R-E, R-B)$. 
$K:$ That's it, that's like the whole thing?

R: I don't know but it sounds right .

$D$ : Actually that would make sense because Ek is movement (R-B, $R-C)$.

A: Exactly so if you start with zero, your Ek would increase as you keep going $(R-B)$

$R$ : I think our numbers are wrong though $(R-F)$

A: Yeah, most definitely

K: You are right, let's test it again [gets up to do more trials]

A: I honestly think it's the sensor.

Group $A$ is processing their noisy results and together arrive at the idea that the results they had gotten must be wrong. After Student $\mathrm{K}$ mentions the differences in throwing and dropping the ball, Student A arrives at the conclusion that the final velocity of a dropped ball must be all the kinetic energy. The group continues to discuss this for a bit and decides to do more experiments. In this vignette the experimental aspects of exploration activities can be seen along with how students have the flexibility of discussing and redoing their results.

When students were purely engaged in experiments or labs they were observed to have the least social metacognitive discourse. The students in these situations were often focused on performing a lab which typically involves primary thoughts (e.g. "What to do?" or "Where to put things?"), which may be why little to no SMC was observed. This type of activity perfectly matches up with the third SMC modality. Although students were less socially metacognitive 
during these activities, they were highly interdependent since labs often require students to work together to use the equipment and properly perform the experiment.

The initial practice activities were also interesting from this perspective, due to the qualitatively rich moments of SI and SMC. The students were observed to be the most frequently socially metacognitive during these activities. When students are working on these activities, they have to come to an agreement on a solution which may compel them to engage in more socially interdependent, and socially metacognitive, interactions. On top of this, when students need to apply what they are learning, they have a chance to share and compare their ideas, which leads them to refining and clarifying inconsistencies as they distribute metacognitive demands. The first two quotes of this subsection (on pages 126-128) for the first modality of SMC occur during these types of activities, but one further example below is provided. Here is Group B working on an initial practice problem involving two different masses hanging on the opposite sides of a pulley (Day 2, 2:211:53 - 2:12:53):

A: We know for sure that this one is going to go down because this this one is not strong enough to cancel it out so it's going to come down (MC) $\mathrm{J}$ : Yeah, if they were the same weight they would stay in the same spot $(R-B)$

A: But it can't do that because the other one doesn't weight equally (R-B) J: Right, It would pull down (R-C, R-B) 
A: It would have to have something more on the other one to keep it up

J: That's why I think it could move down to get $1 \mathrm{~kg}$

A: What did he say about the height about the second one? (D-B)

E: It could be 1.5 or negative 1.5

P: He [Instructor] is telling us to calculate the height of M2 once they move

A: How does that help us with the height of the other one?.. would the height be zero, that doesn't make sense (D-B)

Students $\mathrm{A}$ and $\mathrm{J}$ are engaged in a dialogue of rationalizing what will happen in the problem and come to an agreement that since the masses are of differing values, the movement will be towards the heavier mass. This dialogue is happening at the same time that Students $\mathrm{P}$ and $\mathrm{E}$ are simultaneously discussing the gravitational energy of the masses (not shown above). Then Student A joins the conversation between Student $E$ and Student $P$, which are then discussing what the height should be for the masses in order to calculate the gravitational energy of the system.

Less SMC was seen when students were working on subsequent extended practice problems (as opposed to initial practice problems). This may be due to the fact that students do more negotiating of how to build their models during the initial problems as opposed to the problems that come later. In this type of activity there was some SMC observed but less than the first and third type of activities presented above. 


\subsubsection{Contrasts in Social Metacognition}

To graphically summarize the SMC codes, a raw and normalized bar chart were created (Figure 9). In the top graph, it is easy to see that Group A was coded more frequently for SMC actions than Group B (251 versus 162 identified SMC statements overall). This is related to the earlier observation that Group A spent more time being interdependent than Group B. Thus, Group A had more opportunity to engage metacognitively with each other. Group A was able to engage in distributing metacognitive demands (D-B) almost twice as much and build shared knowledge (R-B) three times more often than Group $B$. The fact that Group A was able to distribute and share metacognitive knowledge more often reflects their relatively high propensity for collaboration. To better compare the relative distribution of SMC codes (within each group), the counts were normalized (e.g., I calculated the proportion of various codes within each group). In the bottom graph of Figure 9, Group B is seen spending more of its SMC actions being metacognitive on their own thoughts (MC) as opposed to their group member's thoughts (all other SMC codes). Again, this is consistent with the prior measure that Group B had relatively high individualist beliefs. Students in Group B also recognized inconsistent ideas (R-F) relatively more often than students in Group A, which may reflect their practice of double-checking their individual responses as opposed to building them together. These graphs only provide a visual overview of the comparisons between Groups A and B. The next 
vignettes highlight key differences between groups and explore how SMC and SI events overlapped in this analysis.

During the first modality of SMC, students in Group A built shared knowledge more regularly than Group B. Here, Group A is negotiating the creation of energy pie charts for three different examples of a book being dropped from some height, where mass and height vary (Day 2, 0:29:30 $0: 30: 41):$

D: "They are all the same pie charts with different sizes of the circle." $R:$ "Wait, all the pie charts are the same size?"

D: "No, the sizes vary between them but the $E^{g}$ and $E^{k}$ shouldn't differ" $K$ : "Yeah, they are the same [referring to the relationship between $E^{g}$ and $\left.E^{k}\right] \cdot[R-C]^{\prime \prime}$ $R$ : "One and three are the same size, or two and three are the same size." $K$ : "None of them are the same size [R-F], because what she was saying is that you can consider them to be the same thing, the mass and the height have a similar effect on total energy. The mass is the same for one and three but you are multiplying the height by 5 and for one and two the mass is multiplied by 3 but you are not changing your height. [R-B]" $R$ : "Yeah that makes sense, if you drop the 5 one at .1 meter and if you drop the same mass at a higher even more energy. $[R-B]^{\prime \prime}$ A: "So by comparing 2 and 3 to 1 , you can compare 2 and 3. [R-B]" 
K: "Yeah I think so, I guess you could compare two and three but you would use the equation. [R-B,R-E]"

Here students start by discussing how the system's energy pie charts change from the moment the book is dropped to right before it hits the ground. Student K recognizes Student D and Student R's consistent ideas (R-C) and recognizes a subsequently inconsistent idea of Student $R(R-F)$. This leads to building the shared knowledge (R-B) that they could determine which scenarios had more energy based on the relative proportions of the height and mass. At the end of this exchange, Student $\mathrm{K}$ expands on their ideas (R-E) and explicitly mentions they could also use the equation for gravitational energy. This is a common type of interaction in Group A which, again, had high levels of group participation.

Students in Group B tended to spend their metacognitive time engaging in intra-student metacognition (MC) and detecting others' inconsistent ideas (R-F) than Group A. Here, the students are seen negotiating the equation for gravitational energy (Day 2, 0:29:03 - 0:31:25):

J: "If you were to guess the equation?"

L: "Guess the equation?"

P: "I put height time weight times gravity. I'm not sure if it's times gravity or times a constant. [MC]"

E: "I just put mass times height times velocity."

P: "I don't know if you want to keep velocity because you can have an item at zero velocity with gravitational energy [puts his hand like he is about to 
drop something] [R-F]"

A: "But it might not always be gravity."

J: "I put acceleration."

P: "But isn't acceleration the same as gravity."

$J:$ "Yeah but if you are on a ramp... [R-E]"

E: "In this case it's gravity."

$P$ : "If you are on a ramp and not moving then the acceleration is just

gravity. If I let something go [picks up phone to indicate he is talking about dropping something] the acceleration would be gravity but if it's on a ramp it would be different, that's [not] right I don't know [MC]."

Student $\mathrm{J}$ asks for the equation and Student $\mathrm{P}$ tells his version but also explicitly expresses uncertainty (MC). Student E shares that she had used velocity in her equation instead of gravitational acceleration and Student $P$ detects this inconsistency (R-F) while providing an example to make his case. Then they discuss if it's gravitational acceleration (g) or acceleration (a) and Student $\mathrm{J}$ brings up the case of a ramp which expanded their discussion (R-E) leading to Student P making another self-metacognitive statement (MC). Metacognition statements (MC) are beneficial for learning but, consistent with this group's predisposition to individualist attitudes, they reflect a more individualistic approach to learning. 


\subsubsection{Connecting Social Metacognition and Social Interdependence}

The previous sections highlighted the group interactions observed through the lens of social interdependence and social metacognition separately. In this section connections are drawn between the two coding frameworks, to highlight how they may inform one another. Overall, when the groups were coded for engaging in social metacognition, they were also regularly coded as being interdependent and on task (I-OT) or dependent on the instructor (D). This implies that without an instructor, social interdependence is a supportive precursor for social metacognition to occur. This is not guaranteed, however, as students can be socially interdependent without necessarily engaging in social metacognition.

The three modalities of SMC occurred during specific coding events of social interdependence. The first modality of SMC (when students were frequently being metacognitive with each other), essentially always occurred within the I-OT interdependence code (interdependent and on-task). The second modality of SMC, which occurred when an instructor was present lined up with the dependence SMC code for groups (D). Lastly, the third modality of SMC, in which students are conducting experiments, exactly matches the interdependence code for students experimenting (I-EX). When students worked independently they did not engage in metacognitive dialogue (rarely any dialogue at all, for that matter), which meant that Group B was coded less for SMC since they spent significantly more time than Group A acting independently. Both 
groups were seen to be able to distribute metacognitive demands; however, Group A was coded as engaging more frequently in the building of shared knowledge (R-B) while Group B was seen more frequently detecting inconsistent ideas (R-F). It may be that Group A exhibited more shared knowledge building (R-B) because those students had high cooperative and low individualist attitudes. The discussions of Group A were observed to be frequently more complex and involve more students (and exhibiting greater substitutability). On the other hand, Group B more regularly recognized inconsistent ideas of each other (R-F) and exhibited more individual metacognition (MC). Again, it is theorized that this is related to these students having low cooperation and high individualism attitudes. Students in Group B showed more individualized/independent interactions overall, meaning they tended to focus on their own ideas and problem solutions rather than working closely with other group members' ideas.

\subsection{Discussion}

\subsubsection{Modeling Instruction Provides Affordances for SI and SMC}

This study provides the first analysis of the Modeling Instruction curriculum that explicitly uses the dual lenses of social interdependence and social metacognition. However, features related to the SI outcomes of effort to achieve and social competence have been studied including the identification of positive attitudinal shifts (Brewe, 2008), increased participation (Brewe, Sawtelle \& Kramer, 2010) and positive gains in self-efficacy (Sawtelle, Brewe \& Kramer, 
2010). There is also evidence for students building many relationships with their peers, seen through social network analysis, which speaks of the positive relationship sub construct of SI (Willams et al., 2015). Although some of these outcomes are not directly related to SI, they may be association to the highly interdependent nature of the Modeling Instruction classroom. This study does not provide direct evidence that increased SI leads to these particular outcomes, but it does complement these findings.

The MI curriculum was designed to support students thinking metacognitively and in exploration activities students examine new ideas and learn to accommodate them (Louca \& Zacharia, 2012). The representations used in Modeling Instruction can be seen as metacognitve artifacts, as they provide students with tools to express their thoughts and build understanding with one another. There is also research that compares non modeling and modeling students which found that modeling students develop more metacognitive skills compared to their counterparts (Malone, 2006). This means that modeling students not only come out with better conceptual learning outcomes compared to their counterparts, but also develop a more expertlike understandning of physics. In this study, we see clear evidence that certain modeling activities (e.g. exploratory and initial problem-solving activities) afford opportunities for students to engage in socially metacognitive discourse, anchored by peer- and instructureinitiated interdependence. 


\subsubsection{Individual Student Effects on Group Interactions}

Group dynamics are complex and inherently depend on the members that make up the group (Lewin, 1947/2016). How inter-students dynamics can change based on individual students' contributions was seen. One student can make a significant impact on a group's interdependence. For example, on Day 1 , Student A was absent from Group B when low independence was observed, then on Day 2, Student A was present and she often engaged with the group resulting in Group B exhibiting more interdependence on Day 2. There was more silent, independent action when A was not present. When present, Student A asked a lot of questions which stimulated group conversations.

Each group member is an essential part of their group. Two clear examples were seen of how individual students affected Group A. The first example involves Student M who was absent on Day 1 . Then on Day 2 he spent the first half of class cooperating with his group mates but made some inconsistent comments which led to his group recognizing his inconsistent ideas. Then during the second half of class on Day 2, he mostly worked independently of the group. The second example involves Student P on Day 1 where he spent the class distracted and at some point expressed not knowing what was going on. The group did help catch him up by working with him to explain what was going on. He benefited from being in the group, but did not contribute much metacognitively in these observations. 
Individual students were also the drivers (or non-drivers) of SMC for their groups. In Group A, Student K was regularly observed to lead her group into SMC dialogue. Her group members backed her up and provided feedback to her, which led them to building more shared knowledge. This led to group discourse being more balanced among the group members. For Group B, Student $P$ frequently expressed individual metacognition $(\mathrm{MC})$ to drive the SMC of the group. Students $E$ and A provided the most feedback to student $P$, while Student $\mathrm{J}$ sometimes provided feedback and the two remaining group members barely participated in the dialogue during the period of observation.

\subsubsection{Instructors' Effects on Group Interactions}

When an Instructor (Learning Assistant, Teaching Assistant, Professor) approached a group of students, the students often stopped engaging each other to pay attention to the instructor. Students were observed to accept what an instructor says, as opposed to thinking more critically and expressing the level of

doubt they may have shown with a peer. The learning for students during those instances became instructor-centered where students depended on the instructor. Instructors that try to involve the whole group in discussions lead students to re-establish interdependent discourse as opposed to when an instructor was engaged only with one student in the group. Some instructors would use a strategy of asking the same question back to the group in a slightly different way, which also led to the re-emergence of interdependence as well. 
Instructors play key roles for students during class by providing them feedback and facilitating their learning. As seen in the results above, instructors were seen to distribute metacognitive demands and provide a filter for students while they are present. Getting students to think critically about their ideas or their peers' ideas was frequently seen to be a goal of the instructors. When instructors engaged in SMC with a group, the groups were observed to continue to engage interdependently afterwards, leading to more SMC. In these scenarios instructors rely on student ideas to provide them feedback to steer them in particular directions, as opposed to simply providing answers. Learning Assistants, Teaching Assistants, and Professors all have the responsibility to mediate dialogue during their interactions with students. In most instances instructors used SMC, however a few instances were observed where an instructor did not provide SMC feedback but instead their own cognitive feedback (gave them answers or ideas freely). Sometimes this impeded the collaboration of the group and led to students working independently or on another task after the instructor leaves, since their goals for the activity were (apparently) met. When an instructor simply gives an answer they may be reducing the possibility of SMC talk between those students after they leave.

\subsubsection{Implications for Student-centered learning}

The observations from the SI layer of coding may provide a step towards a more systematic approach to selecting groups within the classroom. Assigning students into groups using students' cooperation and individualism attitudes (as 
used in this study) may lead to more productive groups: reducing the variance or simply mixing students with high cooperation and low independence attitudes with students that have low cooperation and high independent attitudes may result in an increase in social interdependence overall. Further research is necessary but the current study may identify a path to assigning groups that lead to greater group social interdependence.

Paying attention to SI could help Instructors implement strategies to promote more cooperation among students, thereby also increasing the possibility of social metacognition between students. At a curricular level, instructors may implement frequent small group learning activities that require students to apply what they are learning while asking metacognitively-rich questions. These activities may include having students predict experiments, set goals, identify what they know and identify what they don't know. Having activities ask students "why" more often may also lead to more social metacognition.

At the classroom level, instructors can help get students to work together when they seek participation from an entire group of students and then ask probing questions back to the group while recognizing consistent and inconsistent ideas. This type of instruction was observed to lead to groups continuing socially interdependent discussion after the instructor leaves, even for the group with lower cooperation beliefs. Having instructors use metacognitive techniques to interact with the students may require some adjustment on the 
instructor's part. The interaction of instructors with students is traditionally framed as the instructor sharing their knowledge with their students (e.g., common framing in lecturing), so this may require a change of perception for instructors less familiar with using metacognition. When Learning Assistants and Teaching Assistants are involved, it may be important to train them how to engage with students using social metacognition. In these observations there were a few instances where learning assistants did not use social metacognition, which led to some groups working independently afterwards.

\subsection{Conclusions}

In this study observations of the interactions of students were analyzed through the lens of SI and SMC. Social Interdependence provided a way of coding for the cooperation of the group, making it possible to analyze the ways in which a group cooperated, relied on instructors, or acted independently. Coding for SMC provided a way to code students when they were engaging with each other's ideas and building shared knowledge (or not). Both of these layers provided a more complete picture of how cooperation may lead to students sharing ideas and how those ideas are propagated. Through the comparison between a high interdependent group (Group A) and low interdependent group (Group B), the higher interdependent group was seen spending more of their time being socially metacognitive. The nature of the social metacognition varied among groups, with Group A building more shared knowledge together. Overall, this study provides an analysis of how these types of interactions impact students 
in class and lays the foundation for studying SI and SMC of students in a student-centered learning environment.

The two layers of code were independent but did inform one another. They describe different aspects of the student's experience; SI explored the cooperation and SMC explored the development and sharing of ideas of the group. There were moments where students were highly interdependent but not socially metacognitive, but when they were socially metacognitive they were essentially always interdependent with one another. It was observed how instructor dependence can be productive if the instructor redirects their conversations in a way that supports social metacognition.Students in both groups often engaged in social metacognition, though the frequency and nature varied. This may reflect the structure of the activities students are asked to engage in in the modeling instruction curriculum and how they require students to question their ideas.

We could not use the pre and post semester surveys to make claims on the affective and cognitive outcomes of the students from our observed groups, due to the students having five other group experiences spread throughout the semester. That is to say: it was not possible to tie the individual learning of each student in the observed groups to the semester-long learning measures, as there were too many intervening experiences that confounded such direct associations. However, the results of this workdo provide in great detail the social interdependence experiences in a Modeling classroom and suggest the 
opportunities afforded by the Modeling curriculum for social metacognition to occur. Using SI and SMC may allow researchers to study more effectively the common basis of classroom experiences that may support cognitive and affective outcomes, and the ways in which the affective side of learning can be supported by the cognitive side, and vice versa.

There are other limitations to this work such as the particular data that were analyzed, the individual nature of the groups, and how instructors affected group interactions. Two days of class for two groups were observed (one full week or 6.5 hours of class time), which limits the claims that can be made from these findings. The individual nature of groups is a limitation, since the dynamics of each group may depend heavily on what was going on in each of the groups as well as its members. There is no simple way to account for this. How instructors affected the groups was also a limitation because their interactions were observed to substantially impact the groups' dynamics. Since the course observed had several instructors, these interactions also varied depending on each instructor's approach to group interactions.

Possible future work includes expanding the social metacognition analysis to extend the analysis for how students built shared knowledge and distributed metacognitive demands, and how this interacted with the social interdependence of students. Extending this analysis to groups that were more "average" in their cooperation and individualism beliefs could lead to better understanding of how these student beliefs lead to interdependent or independent group interactions, 
and the consequent metacognitive engagement. Another interesting possible future study is to collect data specific learning outcomes immediately before/after specific learning activities (e.g. probe students' understanding of specific topics immediately after they are encountered in the lessons), which might facilitate specific claims about which SI or SMC modalities support individual learning more effectively. 


\section{CONCLUSION}

\subsection{Connecting the Three Studies}

In this dissertation, a literature review provided relevant frameworks to understanding student learning in introductory physics as well as frameworks such as: Physics Identity (PI), Social Interdependence Theory (SIT), and Social Metacognition (SMC). In the first study I reported, using a nationally representative sample, found that students reporting daily small group work had significantly higher conceptual gains than students who did not report frequent small group work (while simultaneously identifying no statistically-significant practice as improving physics identity gains). Second, I studied how social interdependence theory during a semester of learning may inform on physics identity and conceptual gains. I showed that students with higher initiated task interdependence were found to have positive gains in their physics recognition and performance/competence beliefs. Further a correlation between presemester cooperation attitudes and outcome interdependence was identified. The third and final study dove deeper into the social interdependence of students and analyzed their classroom interactions using a second lens of social metacognition. Students working in small groups were explored using these two lenses to describe their cooperative learning experiences.

This collected work is internally tied together as all three of these studies inform in different ways on how students benefit in some way from small group learning. For example, in Chapter 3 I found that students who reported frequently 
working in small groups benefited conceptually, but did not find any physics identity gains related to widespread classroom practices. However, using the SI framework in Chapter 4 to analyze students' conceptual and identity gains, I found a relationship between task interdependence and students' recognition and performance/competence beliefs, which furthered the non-significant findings of Chapter 3 by showing there are specific types of interactions that may support students' identity building in physics. Some of the claims made in Chapter 5 also supported the idea that certain classroom activities and instructor practices may be particularly productive for student learning, emphasizing some themes of Chapter 3.

Chapter 3 found associations to congnitive outcomes in a nationallyrepresentative study while Chapter 4 found affective outcomes at a singular classroom level, specifically in a Modeling Instruction classroom. The data in Chapter 3 may not have been sensitive to classroom practices that impact affective outcomes since there were many courses analyzed but few use such practices (highlighting the dearth of uptake of such findings in actual practice). Chapter 4 found that initiated task interdependence did improve affective outcomes, but were not found to be associated with semester-long cognitive gains. This is probably due to the fact that a single Modeling Instruction course was studied, which has previously been found to have overall strong learning outcomes (Brewe, 2008), meaning that there was restricted variance in the range of cognitive outcomes, unlike the broad sample analyzed in Chapter 3. 
The analysis in Chapter 5 qualitatively studied both affective and cognitive domains simultaneously. Through the social interdependence lens, students were observed building positive relationships with other group members while also exerting effort to achieve their learning goals. Adding to this, social metacognition provided insight on how students shared and built their ideas with one another, while exhibiting positive social interdependence. Even though this analysis did not examine students' conceptual gains directly (e.g., through a prepost concept inventory), the outcomes of this analysis made it clear that more interdependence leads to more opportunities for metacognition. Metacognition is associated to greater academic achievement (Young \& Fry, 2008), the ability to self evaluate one's thought (Holton \& Clarke, 2006) and improved problem solving (Schoenfeld, 1992). These findings give an indication that students were developing a better, more coherent understanding of physics through these metacognitive experiences. As previously mentioned, Modeling Instruction was seen to provide specific affordences for students to be interdependent, due to the frequent use of small-groups, while at the same time providing opportunities for social metacognition, due to the course design (e.g., the use of representations, idea generating explorative activities and subsequent initial practice problems). 


\subsection{Overall Implications}

A major ramification of this dissertation is that small group learning may have benefits for students because of social interdependent and metacognitive experiences inherent to this type of learning. The frequent use of lab equipment, computer simulations and small group work are different constructions of active learning that are associated to greater student success. Designing activities that involve such practices may be a highly effective method to support student learning. Working in groups also leads to other outcomes such as those associated to social interdependence theory (e.g. positive relationship building and social competencies) and social metacognition (e.g. building shared knowledge), which may contribute to the reasons why small group learning is effective. From Chapter 4 cooperation beliefs were found to be correlated with outcome interdependence, and in Chapter 5 a broad confirmation of the predictions of social interdependence (students' pre-semester cooperation and individualism beliefs) were observed. This suggests that these beliefs may be measured and used to intentionally choose how to group students to maximize the social interdependence, identity-building, and learning outcomes for each student.

\subsection{Barriers for Improving Physics Education}

This work has implications for understanding what effective strategies and barriers exist for reforming university introductory physics; specifically, pedagogies that utilize small group learning. For decades education researchers 
have pointed out the threat of the U.S. losing its position as a leader in university education (National Research Council Staff, 1999). Thus, it is important to consider strategies for implementing educational changes effectively. Henderson et al categorized four different types of change strategy from a meta-analysis of 191 studies (Henderson, Beach \& Finkelstein, 2011). The four types of change strategy they concluded existed were: disseminating curriculum and pedagogy, developing reflective teachers, enacting policy, and developing shared vision. They further point out that for long-lasting change to happen, a combination of these four need to be enacted. They concluded three things:

First, effective change strategies must be aligned with or seek to change the beliefs of the individuals involved. Second, change strategies need to involve long-term interventions, lasting a semester, a year, and longer. Third, colleges and universities are complex systems. Developing a successful change strategy means first understanding the system and then designing a strategy that is compatible with this system. (Henderson, Beach \& Finkelstein, 2011.

There are barriers to instructors adopting research-based instruction strategies that relate both to faculty beliefs, values and knowledge and to institutional structures/barriers. There is some evidence that familiarity with Physics Education Research is associated with sustaining evidence-based teaching practices (Pollock, 2008). Other barriers include (i) student attitudes towards school, (ii) expectations of content coverage, (iii) lack of instructor time, 
and (iv) departmental norms (Henderson, 2007). Further, classroom size, availability of teacher assistants/learning assistants, and institutional norms may also limit the adoption of evidence-based practices. In the context of SCALE-UP, the key features that helped sustain reform are (i) administrative support, (ii) documenting evidence of local success, (iii) funding and (iv) interaction with outside SCALE-UP users (Foote et al., 2016).

\subsection{Future Directions}

This dissertation emphasizes the need for further work that investigates socially interdependent learning, which may help to identify practices that simultaneously support students' affective and cognitive growth. Other future work may extend the observational studies of students' social interdependence and social metacognition, furthering the objectives and findings of Chapter 5. Some of the specific findings in Chapter 5 may be extended in the future to improve our understanding of specific features of how students build shared knowledge and distribute metacognitive demands. A practical extension of this work is to explore how student groups may be more effectively chosen, to support students' small group interactions and the learning opportunities presented during physics class time. 


\section{LIST OF REFERENCES}

Adams, W. K., Perkins, K. K., Podolefsky, N. S., Dubson, M., Finkelstein, N. D., \& Wieman, C. E. (2006). New instrument for measuring student beliefs about physics and learning physics: The Colorado Learning Attitudes about Science Survey. Physical review special topics-physics education research, 2(1), 010101.

Ainsworth, S. (1999). The functions of multiple representations. Computers \& education, 33(2-3), 131-152.

AIP Statistical Research Center (2020).

Andrew, S. (1998). Self-efficacy as a predictor of academic performance in science. Journal of advanced nursing, 27(3), 596-603.

Autin, F., \& Croizet, J. C. (2012). Improving working memory efficiency by reframing metacognitive interpretation of task difficulty. Journal of Experimental Psychology: General, 141(4), 610.

Beichner, R. J., Saul, J. M., Abbott, D. S., Morse, J. J., Deardorff, D., Allain, R. J., ... \& Risley, J. S. (2007). The student-centered activities for large enrollment undergraduate programs (SCALE-UP) project. Research-based reform of university physics, 1(1), 2-39.

Bales, R. F. (2000). Social Interaction Systems: Theory and Measurement: Book review.

Bandura, A. (1982). Self-efficacy mechanism in human agency. American psychologist, 37(2), 122.

Bandura, A. (1989). Human agency in social cognitive theory. American psychologist, 44(9), 1175.

Bandura, A. (2001). Social cognitive theory: An agentic perspective. Annual review of psychology, 52(1), 1-26.

Bandura, A. (2010). Self-efficacy. The Corsini encyclopedia of psychology, 1-3.

Bates, S., \& Galloway, R. (2012, April). The inverted classroom in a large enrolment introductory physics course: a case study. In Proceedings of the HEA STEM learning and teaching conference (Vol. 1). 
Bayrak, C. (2008). Effects of computer simulations Programs on university students' achievements in physics. Turkish online journal of distance education, 9(4), 53-62.

Beersma, B., \& De Dreu, C. K. (2002). Integrative and distributive negotiation in small groups: Effects of task structure, decision rule, and social motive. Organizational Behavior and Human Decision Processes, 87(2), 227-252.

Bell, B. S., \& Kozlowski, W. J. (2002). Goal orientation and ability: Interactive effects on self-efficacy, performance, and knowledge. Journal of Applied Psychology, 87(3), 497.

Beichner, R. J., Saul, J. M., Allain, R. J., Deardorff, D. L., \& Abbott, D. S. (2000). Introduction to SCALE-UP: Student-Centered Activities for Large Enrollment University Physics.

Beichner, R. J., Saul, J. M., Abbott, D. S., Morse, J. J., Deardorff, D., Allain, R. J., ... \& Risley, J. S. (2007). The student-centered activities for large enrollment undergraduate programs (SCALE-UP) project. Research-based reform of university physics, 1(1), 2-39.

Blakey, E., \& Spence, S. (1990). Developing metacognition. ERIC Clearinghouse on Information and Technology.

Bonwell, C. C., \& Eison, J. A. (1991). Active Learning: Creating Excitement in the Classroom. 1991 ASHE-ERIC Higher Education Reports. ERIC Clearinghouse on Higher Education, The George Washington University, One Dupont Circle, Suite 630, Washington, DC 20036-1183.

Brewe, E. (2008). Modeling theory applied: Modeling Instruction in introductory physics. American Journal of physics, 76(12), 1155-1160.

Brewe, E., Kramer, L., \& O'Brien, G. (2009). Modeling instruction: Positive attitudinal shifts in introductory physics measured with CLASS. Physical Review Special Topics-Physics Education Research, 5(1), 013102.

Brewe, E., Sawtelle, V., Kramer, L. H., O’Brien, G. E., Rodriguez, I., \& Pamelá, P. (2010). Toward equity through participation in Modeling Instruction in introductory university physics. Physical Review Special Topics-Physics Education Research, 6(1), 010106.

Briñol, P., \& DeMarree, K. (2012). Social metacognition. Psychology Press. 
Brooks, B. J., \& Koretsky, M. D. (2011). The influence of group discussion on students' responses and confidence during peer instruction. Journal of Chemical Education, 88(11), 1477-1484.

Buchs, C., Butera*, F., \& Mugny, G. (2004). Resource interdependence, student interactions and performance in cooperative learning. Educational Psychology, 24(3), 291-314.

Byun, T., \& Lee, G. (2014). Why students still can't solve physics problems after solving over 2000 problems. American Journal of Physics, 82(9), 906-913.

Cabot, L. H. (2008). Transforming teacher knowledge: Modeling instruction in physics. University of Washington.

Cakir, M. (2008). Constructivist approaches to learning in science and their implications for science pedagogy: A literature review. International journal of environmental and science education, 3(4), 193-206.

Ceci, S. J., \& Williams, W. M. (2011). Understanding current causes of women's underrepresentation in science. Proceedings of the National Academy of Sciences, 108(8), 3157-3162.

Chemers, M. M., Hu, L. T., \& Garcia, B. F. (2001). Academic self-efficacy and first year college student performance and adjustment. Journal of Educational psychology, 93(1), 55.

Chen, Y., \& Lou, H. (2004). Students' perceptions of peer evaluation: An expectancy perspective. Journal of Education for Business, 79(5), 275-282.

Chi, M. T. (2005). Commonsense conceptions of emergent processes: Why some misconceptions are robust. The journal of the learning sciences, 14(2), 161-199.

Chiu, M. M. (2000). Group Problem-Solving Processes: Social Interactions and Individual Actions. Journal for the theory of social behaviour, 30(1), 26-49.

Chiu, M. M., \& Khoo, L. (2003). Rudeness and status effects during group problem solving: Do they bias evaluations and reduce the likelihood of correct solutions?. Journal of Educational Psychology, 95(3), 506.

Chiu, M. M., \& Kuo, S. W. (2010). From metacognition to social metacognition: Similarities, differences, and learning. Journal of Education Research, 3(4), 321338. 
Choirat, C., Honaker, J., Imai, K., King, G., \& Lau, O. (2016). Zelig: everyone’s statistical software. URL http://zeligproject.org/

Cobb, P. (1995). Mathematical learning and small-group interaction: Four case studies. The emergence of mathematical meaning: Interaction in classroom cultures, 25-129.

Coutinho, S. A. (2007). The relationship between goals, metacognition, and academic success. Educate , 7(1), 39-47.

Cribbs, J. D., Hazari, Z., Sonnert, G., \& Sadler, P. M. (2015). Establishing an explanatory model for mathematics identity. Child development, 86(4), 10481062.

Crouch, C. H., \& Mazur, E. (2001). Peer instruction: Ten years of experience and results. American journal of physics, 69(9), 970-977.

Crouch, C. H., Watkins, J., Fagen, A. P., \& Mazur, E. (2007). Peer instruction: Engaging students one-on-one, all at once. Research-based reform of university physics, 1(1), 40-95.

Cross, K. P. (1987). Teaching for learning. AAHE Bulletin, 39(8), n8.

Dabney, K. P., Chakraverty, D., \& Tai, R. H. (2013). The association of family influence and initial interest in science. Science Education, 97(3), 395-409.

De Dreu, C. K. (2007). Cooperative outcome interdependence, task reflexivity, and team effectiveness: a motivated information processing perspective. Journal of applied psychology, 92(3), 628.

Dennis, C. L. (1999). Theoretical underpinnings of breastfeeding confidence: a self-efficacy framework. Journal of human lactation, 15(3), 195-201.

Desautel, D. (2009). Becoming a Thinking Thinker: Metacognition, SelfReflection, and Classroom Practice. Teachers College Record, 111(8), 19972020.

Deslauriers, L., Schelew, E., \& Wieman, C. (2011). Improved learning in a largeenrollment physics class. science, 332(6031), 862-864.

Deutsch, M. (2011). Cooperation and competition. In Conflict, interdependence, and justice (pp. 23-40). Springer, New York, NY. (Original work published 1949) 
Dewey, John. "Experience and Education. New York: touchstone." Original work published 1997 (1938).

Dillenbourg, P. (1999). What do you mean by collaborative learning?.

Dillenbourg, P., \& Traum, D. (2006). Sharing solutions: Persistence and grounding in multimodal collaborative problem solving. The Journal of the Learning Sciences, 15(1), 121-151.

Dinsmore, D. L., Alexander, P. A., \& Loughlin, S. M. (2008). Focusing the conceptual lens on metacognition, self-regulation, and self-regulated learning. Educational Psychology Review, 20(4), 391-409.

Dolmans, D. H., \& Schmidt, H. G. (2006). What do we know about cognitive and motivational effects of small group tutorials in problem-based learning?.

Advances in Health Sciences Education, 11(4), 321.

Driskell, J. E., Salas, E., \& Hughes, S. (2010). Collective orientation and team performance: Development of an individual differences measure. Human factors, 52(2), 316-328.

Fagen, A. P., Crouch, C. H., \& Mazur, E. (2002). Peer instruction: Results from a range of classrooms. The physics teacher, 40(4), 206-209.

Finkelstein, N. D., Adams, W. K., Keller, C. J., Kohl, P. B., Perkins, K. K., Podolefsky, N. S., ... \& LeMaster, R. (2005). When learning about the real world is better done virtually: A study of substituting computer simulations for laboratory equipment. Physical review special topics-physics education research, 1(1), 010103.

Foote, K., Knaub, A., Henderson, C., Dancy, M., \& Beichner, R. J. (2016). Enabling and challenging factors in institutional reform: The case of SCALE-UP. Physical Review Physics Education Research, 12(1), 010103.

Forsyth, D. R. (2018). Group dynamics. Cengage Learning.

Fram, S. M. (2013). The constant comparative analysis method outside of grounded theory. Qualitative Report, 18, 1.

Freeman, S., Eddy, S. L., McDonough, M., Smith, M. K., Okoroafor, N., Jordt, H., \& Wenderoth, M. P. (2014). Active learning increases student performance in science, engineering, and mathematics. Proceedings of the National Academy of Sciences, 111(23), 8410-8415. 
Gainen, J. (1995). Barriers to success in quantitative gatekeeper courses. New directions for teaching and learning, 1995(61), 5-14.

Gasiewski, J. A., Eagan, M. K., Garcia, G. A., Hurtado, S., \& Chang, M. J. (2012). From gatekeeping to engagement: A multicontextual, mixed method study of student academic engagement in introductory STEM courses. Research in higher education, 53(2), 229-261.

Gee, J. P. (2000). Chapter 3: Identity as an analytic lens for research in education. Review of research in education, 25(1), 99-125.

Glaser, B. G. (1965). The constant comparative method of qualitative analysis. Social problems, 12(4), 436-445.

Godwin, A., Potvin, G., Hazari, Z., \& Lock, R. (2016). Identity, critical agency, and engineering: An affective model for predicting engineering as a career choice. Journal of Engineering Education, 105(2), 312-340.

Gök, T., \& Sýlay, I. (2010). The Effects of Problem Solving Strategies on Students' Achievement, Attitude and Motivation. Latin-American Journal of Physics Education, 4(1), 2.

Goos, M., Galbraith, P., \& Renshaw, P. (2002). Socially mediated metacognition: Creating collaborative zones of proximal development in small group problem solving. Educational studies in Mathematics, 49(2), 193-223.

Gokhale, A. A. (1995). Collaborative learning enhances critical thinking.

Gueldenzoph, L. E., \& May, G. L. (2002). Collaborative peer evaluation: Best practices for group member assessments. Business Communication Quarterly, $65(1), 9-20$.

Gully, S. M., Devine, D. J., \& Whitney, D. J. (1995). A meta-analysis of cohesion and performance: Effects of level of analysis and task interdependence. Small group research, 26(4), 497-520.

Hacker, D. J., \& Bol, L. (2004). Considering the Social-Cognitive Influences. Big theories revisited, 275.

Hacker, D. J., Dunlosky, J., \& Graesser, A. C. (Eds.). (2009). Handbook of metacognition in education. Routledge.

Hallgren, K. A. (2012). Computing inter-rater reliability for observational data: an overview and tutorial. Tutorials in quantitative methods for psychology, 8(1), 23. 
Halloun, I. A., \& Hestenes, D. (1987). Modeling instruction in mechanics. american Journal of Physics, 55(5), 455-462.

Hake, R. R. (1998). Interactive-engagement versus traditional methods: A sixthousand-student survey of mechanics test data for introductory physics courses. American journal of Physics, 66(1), 64-74.

Harskamp, E., \& Ding, N. (2006). Structured collaboration versus individual learning in solving physics problems. International journal of science education, 28(14), 1669-1688.

Hazari, Z., \& Potvin, G. (2005). Views on Female Under-Representation in Physics: Retraining Women or Reinventing Physics?. Electronic Journal of Science Education, 10(1).

Hazari, Z., Potvin, G., Tai, R. H., \& Almarode, J. (2010). For the love of learning science: Connecting learning orientation and career productivity in physics and chemistry. Physical review special topics-physics education research, 6(1), 010107.

Hazari, Z., Sonnert, G., Sadler, P. M., \& Shanahan, M. C. (2010). Connecting high school physics experiences, outcome expectations, physics identity, and physics career choice: A gender study. Journal of research in science teaching, 47(8), 978-1003.

Hazari, Z., Sadler, P. M., \& Sonnert, G. (2013). The science identity of college students: Exploring the intersection of gender, race, and ethnicity. Journal of College Science Teaching, 42(5), 82-91.

Hazari, Z., Cass, C., \& Beattie, C. (2015). Obscuring power structures in the physics classroom: Linking teacher positioning, student engagement, and physics identity development. Journal of Research in Science Teaching, 52(6), 735-762.

Hazari, Z., Potvin, G., Cribbs, J. D., Godwin, A., Scott, T. D., \& Klotz, L. (2017). Interest in STEM is contagious for students in biology, chemistry, and physics classes. Science advances, 3(8), e1700046.

Hazari, Z., Brewe, E., Goertzen, R. M., \& Hodapp, T. (2017). The importance of high school physics teachers for female students' physics identity and persistence. The Physics Teacher, 55(2), 96-99. 
Henderson, C., \& Dancy, M. H. (2007). Barriers to the use of research-based instructional strategies: The influence of both individual and situational characteristics. Physical Review Special Topics-Physics Education Research, 3(2), 020102.

Henderson, C., Beach, A., \& Finkelstein, N. (2011). Facilitating change in undergraduate STEM instructional practices: An analytic review of the literature. Journal of research in science teaching, 48(8), 952-984.

Hestenes, D. (1987). Toward a modeling theory of physics instruction. American journal of physics, 55(5), 440-454.

Hinrichs, B. E. (2005, September). Using the system schema representational tool to promote student understanding of Newton's third law. In AIP Conference Proceedings (Vol. 790, No. 1, pp. 117-120). American Institute of Physics.

Hmelo-Silver, C. E., \& Barrows, H. S. (2008). Facilitating collaborative knowledge building. Cognition and instruction, 26(1), 48-94.

Hoffman, B., \& Spatariu, A. (2008). The influence of self-efficacy and metacognitive prompting on math problem-solving efficiency. Contemporary educational psychology, 33(4), 875-893.

Holton, D., \& Clarke, D. (2006). Scaffolding and metacognition. International journal of mathematical education in science and technology, 37(2), 127-143.

Honaker, J., King, G., \& Blackwell, M. (2015). Package Amelia. A program for missing data.

Howe, A. C. (1996). Development of science concepts within a Vygotskian framework. Science Education, 80(1), 35-51.

Huberman, M., \& Miles, M. B. (2002). The qualitative researcher's companion. Sage.

Huitt, W., \& Hummel, J. (2003). Piaget's theory of cognitive development. Educational psychology interactive, 3(2), 1-5.

Ishimoto, M., Thornton, R. K., \& Sokoloff, D. R. (2014). Validating the Japanese translation of the Force and Motion Conceptual Evaluation and comparing performance levels of American and Japanese students. Physical Review Special Topics-Physics Education Research, 10(2), 020114. 
Jackson, D. B. (2003). Education reform as if student agency mattered: Academic microcultures and student identity. Phi Delta Kappan, 84(8), 579-585.

Jackson, J., Dukerich, L., \& Hestenes, D. (2008). Modeling Instruction: An Effective Model for Science Education. Science Educator, 17(1), 10-17.

Johnson, D. W., \& Norem-Hebeisen, A. A. (1979). A measure of cooperative, competitive, and individualistic attitudes. The Journal of Social Psychology, 109(2), 253-261.

Johnson, D. W., \& Johnson, R. T. (1989). Cooperation and competition: Theory and research. Interaction Book Company.

Johnson, D. W., \& Johnson, R. T. (2002). Cooperative learning and social interdependence theory. In Theory and research on small groups (pp. 9-35). Springer, Boston, MA.

Johnson, D. W., \& Johnson, R. T. (2005). New developments in social interdependence theory. Genetic, social, and general psychology monographs, 131(4), 285-358.

Johnson, D. W., Johnson, R. T., \& Smith, K. (2007). The state of cooperative learning in postsecondary and professional settings. Educational Psychology Review, 19(1), 15-29.

Johnson, D. W., \& Johnson, R. T. (2009). An educational psychology success story: Social interdependence theory and cooperative learning. Educational researcher, 38(5), 365-379.

Johnson, D. R., \& Young, R. (2011). Toward best practices in analyzing datasets with missing data: Comparisons and recommendations. Journal of Marriage and Family, 73(5), 926-945.

Jost, J. T., Kruglanski, A. W., \& Nelson, T. O. (1998). Social metacognition: An expansionist review. Personality and Social Psychology Review, 2(2), 137-154.

Keller, C. J., Finkelstein, N. D., Perkins, K. K., \& Pollock, S. J. (2007, January). Assessing the effectiveness of a computer simulation in introductory undergraduate environments. In AIP Conference Proceedings (Vol. 883, No. 1, pp. 121-124). American Institute of Physics.

Kessels, U., Rau, M., \& Hannover, B. (2006). What goes well with physics? Measuring and altering the image of science. British Journal of Educational Psychology, 76(4), 761-780. 
Kiggundu, M. N. (1981). Task interdependence and the theory of job design. Academy of management Review, 6(3), 499-508.

Kleitman, S., \& Stankov, L. (2007). Self-confidence and metacognitive processes. Learning and individual differences, 17(2), 161-173.

Klemenčič, M. (2017). From student engagement to student agency: Conceptual considerations of European policies on student-centered learning in higher education. Higher Education Policy, 30(1), 69-85.

Koffka, K. (2013). Principles of Gestalt psychology (Vol. 44). Routledge. (Original work published 1935)

Kost, L. E., Pollock, S. J., \& Finkelstein, N. D. (2009). Characterizing the gender gap in introductory physics. Physical Review Special Topics-Physics Education Research, 5(1), 010101.

Kozlowski, S. W., Gully, S. M., Nason, E. R., \& Smith, E. M. (1999). Developing adaptive teams: A theory of compilation and performance across levels and time. Pulakos (Eds.), The changing nature of work performance: Implications for staffing, personnel actions, and development, 240, 292.

Kramer, L. (2018). Case Study: PhysTEC. FIU: A Decade Later A Changed Campus. Bulletin of the American Physical Society, 63.

Laal, M., \& Ghodsi, S. M. (2012). Benefits of collaborative learning. Procediasocial and behavioral sciences, 31, 486-490.

Latané, B., Williams, K., \& Harkins, S. (1979). Many hands make light the work: The causes and consequences of social loafing. Journal of personality and social psychology, 37(6), 822.

Laws, P., Sokoloff, D., \& Thornton, R. (1999). Promoting active learning using the results of physics education research. UniServe Science News, 13, 14-19.

Lewin, K. (2016). Frontiers in group dynamics: Concept, method and reality in social science; social equilibria and social change. Human relations. (Original work published 1947)

Livingston, J. A. (2003). Metacognition: An Overview. 
Lock, R. M., Hazari, Z., \& Potvin, G. (2013, January). Physics career intentions: The effect of physics identity, math identity, and gender. In AIP Conference Proceedings (Vol. 1513, No. 1, pp. 262-265). American Institute of Physics.

Lock, R. M., Castillo, J., Hazari, Z., \& Potvin, G. (2015). Determining strategies that predict physics identity: Emphasizing recognition and interest. In 2015 Physics Education Research Conference Proceedings (pp. 199-202).

Lorenzo, M., Crouch, C. H., \& Mazur, E. (2006). Reducing the gender gap in the physics classroom. American Journal of Physics, 74(2), 118-122.

Louca, L. T., \& Zacharia, Z. C. (2012). Modeling-based learning in science education: cognitive, metacognitive, social, material and epistemological contributions. Educational Review, 64(4), 471-492.

Malone, K. L. (2006). A comparative study of the cognitive and metacognitive differences between modeling and non-modeling high school physics students. In Department of Psychology Center for Innovation in Learning 2006. Carnegie Mellon University.

McCarty, J. A., \& Shrum, L. J. (2001). The influence of individualism, collectivism, and locus of control on environmental beliefs and behavior. Journal of Public Policy \& Marketing, 20(1), 93-104.

McCrindle, A. R., \& Christensen, C. A. (1995). The impact of learning journals on metacognitive and cognitive processes and learning performance. Learning and instruction, 5(2), 167-185.

McPadden, D. (2018). Examining Students' Representation Choices in University Modeling Instruction.

Merner, L. \& Tyler, J. (2017) African American, Hispanic, and Native American Women among Bachelors in Physical Sciences \& Engineering. Retrieved from https://www.aip.org/statistics/reports/african-american-hispanic-and-nativeamerican-women-among-bachelors-physical

Meyers, S. A. (1997). Increasing student participation and productivity in smallgroup activities for psychology classes. Teaching of Psychology, 24(2), 105-115.

Michael, J. (2006). Where's the evidence that active learning works?. Advances in physiology education, 30(4), 159-167.

Michaelsen, L. K., Knight, A. B., \& Fink, L. D. (2004). Team-based learning: A transformative use of small groups in college teaching. 
Moorman, R. H., \& Blakely, G. L. (1995). Individualism-collectivism as an individual difference predictor of organizational citizenship behavior. Journal of organizational behavior, 16(2), 127-142.

Moriarty, M. A. (2007). Inclusive pedagogy: Teaching methodologies to reach diverse learners in science instruction. Equity \& Excellence in Education, 40(3), 252-265.

Murayama, K., Elliot, A. J., \& Yamagata, S. (2011). Separation of performanceapproach and performance-avoidance achievement goals: A broader analysis. Journal of Educational Psychology, 103(1), 238.

Najib, M., \& Kiminami, A. (2011). Innovation, cooperation and business performance. Journal of Agribusiness in Developing and Emerging Economies.

National Center for Education Statistics (2020)

National Science Foundation, National Center for Science and Engineering Statistics. 2019. Women, Minorities, and Persons with Disabilities in Science and Engineering: 2019. Special Report NSF 19-304. Alexandria, VA. Available at https://www.nsf.gov/statistics/wmpd.

Oliver-Hoyo, M. T., \& Allen, D. (2005). Attitudinal effects of a student-centered active learning environment. Journal of Chemical Education, 82(6), 944.

Olufunke, B. T. (2012). Effect of Availability and Utilization of Physics Laboratory Equipment on Students' Academic Achievement in Senior Secondary School Physics. World Journal of Education, 2(5), 1-7.

PCAST STEM Undergraduate Working Group (2012) Engage to Excel: Producing One Million Additional College Graduates with Degrees in Science, Technology, Engineering, and Mathematics, eds Gates SJ, Jr, Handelsman J, Lepage GP, Mirkin C (Office of the President, Washington).

Pollack, B. L., \& Lilly, B. (2008). Gaining confidence and competence through experiential assignments: An exploration of student self-efficacy and spectrum of inquiry. Marketing Education Review, 18(2), 55-66.

Pollock, S. J., \& Finkelstein, N. D. (2008). Sustaining educational reforms in introductory physics. Physical Review Special Topics-Physics Education Research, 4(1), 010110. 
Porter, A. \& Ivie, R. (2019). Women in Physics and Astronomy. Retrieved from https://www.aip.org/statistics/reports/women-physics-and-astronomy-2019\#files

Posner, G., Strike, K., Hewson, P., \& Gertzog, W. (1982). Accommodation of a scientific conception: Toward a theory of conceptual change. Science Education, 66 (2), 211-227

Potvin, G., \& Hazari, Z. (2013). The development and measurement of identity across the physical sciences. In Proceedings of the Physics Education Research Conference (PERC), Portland, OR.

Prince, M. (2004). Does active learning work? A review of the research. Journal of engineering education, 93(3), 223-231.

Ramlo, S. (2008). Validity and reliability of the force and motion conceptual evaluation. American Journal of Physics, 76(9), 882-886.

Redish, E. F., Saul, J. M., \& Steinberg, R. N. (1998). Student expectations in introductory physics. American Journal of Physics, 66(3), 212-224.

Redish, E. F. (2004). A theoretical framework for physics education research: Modeling student thinking. arXiv preprint physics/0411149.

Rifkin, M. (2016). Addressing underrepresentation: Physics teaching for all. The Physics Teacher, 54(2), 72-74.

Rosenthal, R., Cooper, H., \& Hedges, L. (1994). Parametric measures of effect size. The handbook of research synthesis, 621(2), 231-244.

Royston, P. (2004). Multiple imputation of missing values. The Stata Journal, 4(3), 227-241.

Rudolph, A. L., Lamine, B., Joyce, M., Vignolles, H., \& Consiglio, D. (2014). Introduction of interactive learning into French university physics classrooms. Physical review special topics-physics education research, 10(1), 010103.

Saavedra, R., Earley, P. C., \& Van Dyne, L. (1993). Complex interdependence in task-performing groups. Journal of applied psychology, 78(1), 61.

Salonen, P., Vauras, M., \& Efklides, A. (2005). Social interaction-what can it tell us about metacognition and coregulation in learning? European Psychologist, 10(3), 199-208. 
Sawtelle, V. (2011). A gender study investigating physics self-efficacy.

Sawtelle, V., Brewe, E., \& Kramer, L. H. (2012). Exploring the relationship between self-efficacy and retention in introductory physics. Journal of research in science teaching, 49(9), 1096-1121.

Sayre, E. C., Franklin, S. V., Dymek, S., Clark, J., \& Sun, Y. (2012). Learning, retention, and forgetting of Newton's third law throughout university physics. Physical Review Special Topics-Physics Education Research, 8(1), 010116.

Schellens, T., Van Keer, H., De Wever, B., \& Valcke, M. (2007). Scripting by assigning roles: Does it improve knowledge construction in asynchronous discussion groups?. International Journal of Computer-Supported Collaborative Learning, 2(2-3), 225-246.

Schoenfeld, A. H. (1992). Learning to think mathematically: Problem solving, metacognition, and sense making in mathematics. Handbook of research on mathematics teaching and learning, 334370.

Schraw, G., \& Moshman, D. (1995). Metacognitive theories. Educational psychology review, 7(4), 351-371.

Schraw, G., Crippen, K. J., \& Hartley, K. (2006). Promoting self-regulation in science education: Metacognition as part of a broader perspective on learning. Research in science education, 36(1-2), 111-139.

Schunk, D. H. (1991). Self-efficacy and academic motivation. Educational psychologist, 26(3-4), 207-231.

Schunk, D. H. (2008). Metacognition, self-regulation, and self-regulated learning: Research recommendations. Educational psychology review, 20(4), 463-467.

Schunk, D. H. (2012). Learning theories an educational perspective sixth edition. Pearson.

Senior, C., Cubbidge, R., Riebe, L., Roepen, D., Santarelli, B., \& Marchioro, G. (2010). Teamwork: effectively teaching an employability skill. Education+ Training.

Seymour, E. \& Hewitt, N. M. (1997). Talking about leaving. Westview Press, Boulder, CO. 
Sharan, S. (1980). Cooperative learning in small groups: Recent methods and effects on achievement, attitudes, and ethnic relations. Review of educational research, 50(2), 241-271.

Sheppard, K., Dominick, P., \& Aronson, Z. (2003). Preparing engineering students for the new business paradigm of international teamwork and global orientation.

Smith, K. A., Sheppard, S. D., Johnson, D. W., \& Johnson, R. T. (2005).

Pedagogies of engagement: Classroom-based practices. Journal of engineering education, 94(1), 87-101.

Springer, L., Stanne, M. E., \& Donovan, S. S. (1999). Effects of small-group learning on undergraduates in science, mathematics, engineering, and technology: A meta-analysis. Review of educational research, 69(1), 21-51.

Straus, S. G., \& McGrath, J. E. (1994). Does the medium matter? The interaction of task type and technology on group performance and member reactions. Journal of applied psychology, 79(1), 87.

Tammivaara, J. S. (1982). The effects of task structure on beliefs about competence and participation in small groups. Sociology of Education, 212-222.

Thomas, E. J. (1957). Effects of facilitative role interdependence on group functioning. Human relations, 10(4), 347-366.

Thornton, R. K., \& Sokoloff, D. R. (1998). Assessing student learning of Newton's laws: The force and motion conceptual evaluation and the evaluation of active learning laboratory and lecture curricula. American Journal of Physics, 66(4), 338-352.

Thornton, R. K., Kuhl, D., Cummings, K., \& Marx, J. (2009). Comparing the force and motion conceptual evaluation and the force concept inventory. Physical review special topics-Physics education research, 5(1), 010105.

Torchiano, M. (2016). effsize: efficient effect size computation (R package).

Turpen, C., \& Finkelstein, N. D. (2009). Not all interactive engagement is the same: variations in physics professors' implementation of peer instruction. Physical Review Special Topics-Physics Education Research, 5(2), 020101.

Van Der Vegt, G., Emans, B., \& Van De Vliert, E. (1998). Motivating effects of task and outcome interdependence in work teams. Group \& organization management, 23(2), 124-143. 
Veenman, M. V., Van Hout-Wolters, B. H., \& Afflerbach, P. (2006). Metacognition and learning: Conceptual and methodological considerations. Metacognition and learning, 1(1), 3-14.

Voyles, E. C., Bailey, S. F., \& Durik, A. M. (2015). New pieces of the jigsaw classroom: increasing accountability to reduce social loafing in student group projects. The New Shool Psychology Bulletin, 13(1), 11-20.

Vygotsky, L. S. (1997). The collected works of LS Vygotsky: Problems of the theory and history of psychology (Vol. 3). Springer Science \& Business Media.

Wageman, R. (1995). Interdependence and group effectiveness. Administrative science quarterly, 145-180.

Wagner III, J. A. (1995). Studies of individualism-collectivism: Effects on cooperation in groups. Academy of Management journal, 38(1), 152-173.

Wang, J., \& Hazari, Z. (2018). Promoting high school students' physics identity through explicit and implicit recognition. Physical Review Physics Education Research, 14(2), 020111.

Wieman, C. E., Adams, W. K., \& Perkins, K. K. (2008). PhET: Simulations that enhance learning. Science, 322(5902), 682-683.

Wieman, C., \& Holmes, N. G. (2015). Measuring the impact of an instructional laboratory on the learning of introductory physics. American Journal of Physics, 83(11), 972-978.

Williams, E., Brewe, E., Zwolak, J. P., \& Dou, R. (2015). Understanding centrality: Investigating student outcomes within a classroom social network. In 2015 Physics Education Research Conference Proceeding (pp. 375-378).

Wolters, C. A. (2004). Advancing Achievement Goal Theory: Using Goal Structures and Goal Orientations to Predict Students' Motivation, Cognition, and Achievement. Journal of educational psychology, 96(2), 236.

Xue, Y. \& Larson, R., "STEM crisis or STEM surplus? Yes and yes," Monthly Labor Review, U.S. Bureau of Labor Statistics, May 2015, https://doi.org/10.21916/mlr.2015.14. 
Yazedjian, A., Toews, M. L., Sevin, T., \& Purswell, K. E. (2008). " It's a Whole New World": A Qualitative Exploration of College Students' Definitions of and Strategies for College Success. Journal of College Student Development, 49(2), 141-154.

Young, A., \& Fry, J. D. (2008). Metacognitive awareness and academic achievement in college students. Journal of the Scholarship of Teaching and Learning, 8(2), 1-10.

Zhang, P., Ding, L., \& Mazur, E. (2017). Peer Instruction in introductory physics: A method to bring about positive changes in students' attitudes and beliefs. Physical Review Physics Education Research, 13(1), 010104.

Zimmerman, B. J. (1990). Self-regulated learning and academic achievement: An overview. Educational psychologist, 25(1), 3-17.

Zimmerman, B. J. (2000). Self-efficacy: An essential motive to learn. Contemporary educational psychology, 25(1), 82-91. 


\section{APPENDICES}

Appendix 1: The CUPID pre and post survey, page \#

Appendix 2: SI and Collective Orientation scales, page \#

Appendix 3: The Task and Outcome Interdependence survey, page \#

Appendix 4: The $\mathbf{R}$ code for chapter 3 analysis, page \#

Appendix 5: The $\mathbf{R}$ code for chapter 4 analysis, page \#

Appendix 6: Sample of Observation codes for chapter 5, page \# 


\section{Appendix 1: The CUPID pre and post Survey}

\section{STEM Transformation Institute \\ FLORIDA INTERNATIONAL UNIVERSITY}

\section{Conceptual Understanding and Physics Identity Development}

\section{PRE SURVEY}

\section{Information Regarding Your Participation in this Survey}

We are interested in your experiences, attitudes, beliefs, and career expectations with respect to learning physics. Please make your best estimate for each item and answer as many questions as possible. There are no right or wrong answers. Describe yourself as you generally are now, not as you wish to be in the future. Describe yourself as you honestly see yourself.

PLEASE NOTE:

- You must be 18 years or older to participate.

- The survey will take approximately 20 minutes to complete.

- Participation is voluntary. You may withdraw at any time.

- Participation will NOT impact your grade in this course in any way.

- You will be asked for contact information (email) in case we want to follow-up on some of your survey responses. This information is voluntary and will not be shared with any third party.

- If you have any questions or concerns, please contact Geoff Potvin [gpotvin@fiu.edu, (305) 348-7614] or Zahra Hazari [zhazari@fiu.edu, (305) 348-2096].

- Participants may also contact the Florida International University Office of Research Integrity, located in room MARC 270, at (305) 348-8311.

Thank you for your time and insight. 


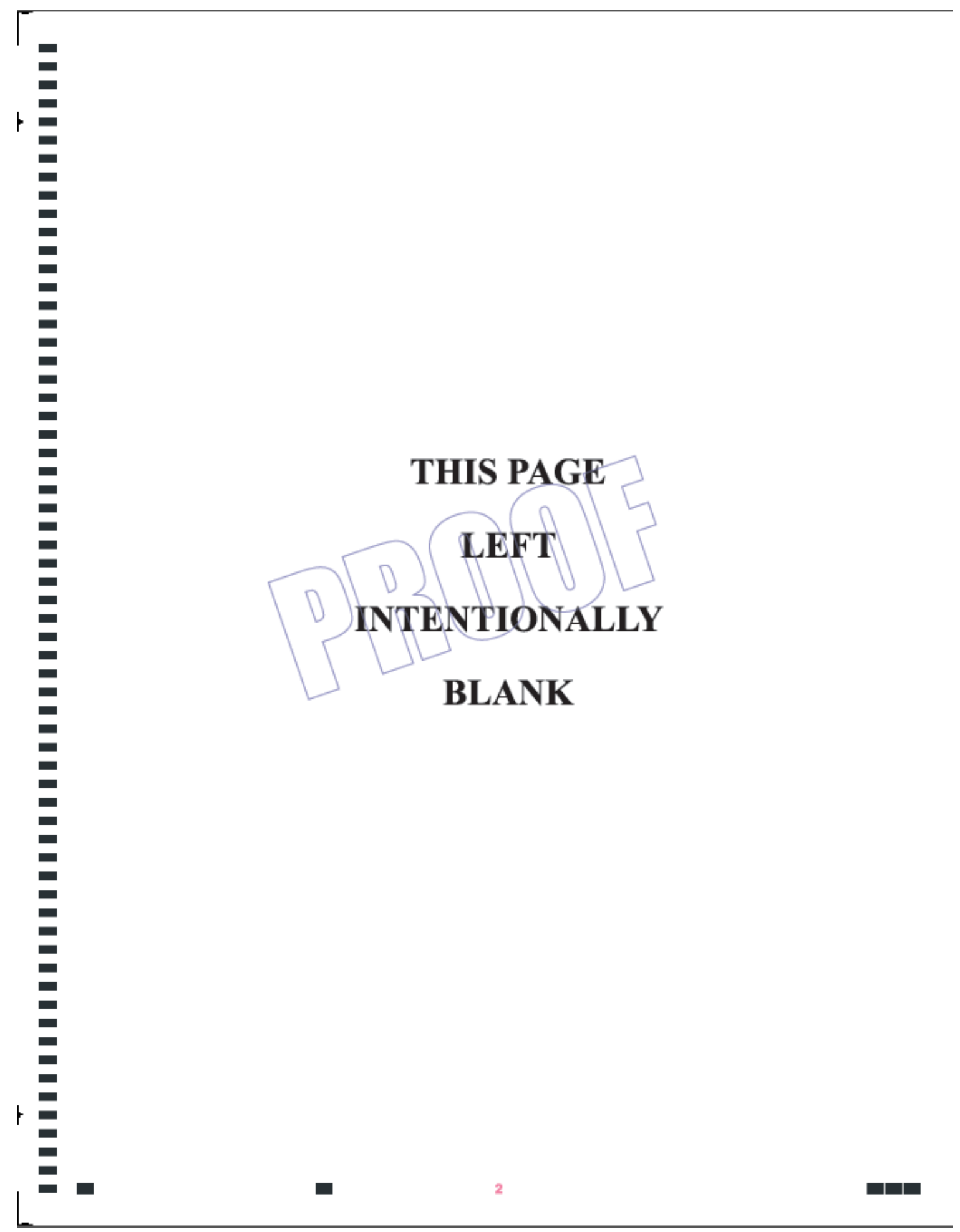


1. Write your student ID in the space provided.

If you have less than 10 digits, leave extra columns blank.

2. Is this an algebra or calculus-based physics course?

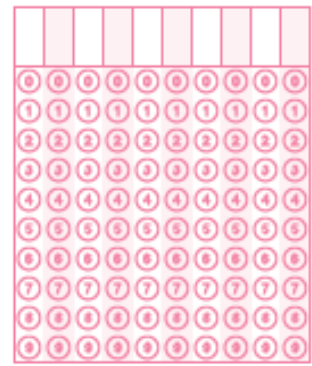

Algebra-based

Calculus-based

๑๐๐๐๐๐๐๐

3. How important are the following factors for your future career satisfaction?

a. Making money

b. Beooming well known

c. Helping other people

d. Having others working under my supervision

e. Having job security and opportunities

f. Working with people rather than objects

g. Inventing/designing new things

h. Having lots of free time outside of my career

i. Having an easy job

j. Solving societal problems

k. Making use of my talents and abilities

L. Doing hands-on work

m. Applying math and science

4. Which options most describe what you want(ed) to be in middle Never school, high school, and college? (Mark fill ther applyt

a. Modical professional (e.g doctor dentist, vet.)

b. Health professional (e.g. nursing, pharmacy)

c. Biologist

d. Engineer

e. Computer scientist/Information technologist

f. Earth/Environmental scientist

g. Astronomer

h. Chemist

i. Physicist

j. Social scientist (e.g. sociologist, anthropologist)

k. Mathematician

1. Science/Math teacher

m. Other scienoe-related career

n. Other non-science related career

5. Please rate the current likelihood of your choosing a career in the following fields:

a. Medicine/Health

b. Biology

c. Engineering

d. Environmental science

e. Chemistry

f. Physics

g. Mathematics

h. Other sciences

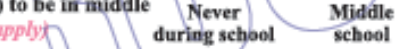

Not at all important
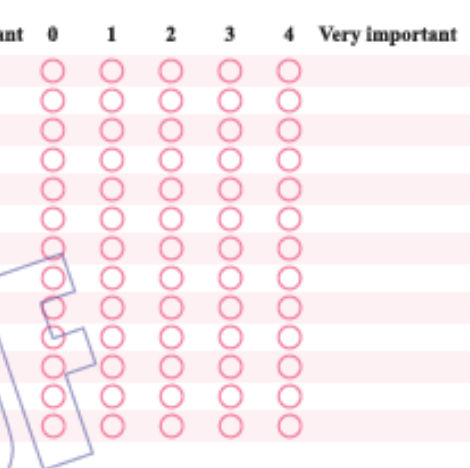

(2)

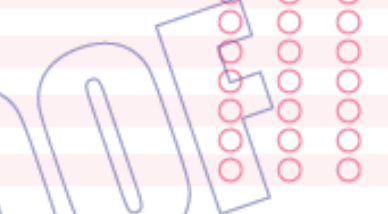
Beginning
of high school

End of school

high school

In college
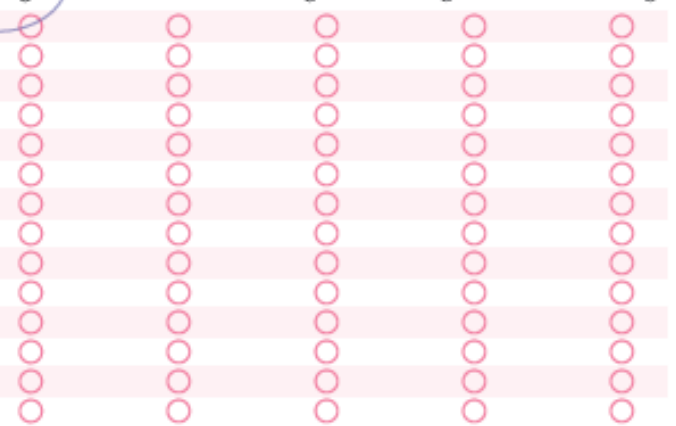

둔

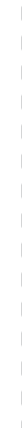

$=$
$=$
$=$
$=$
$\square$
$\square$
$\square$
$\square$

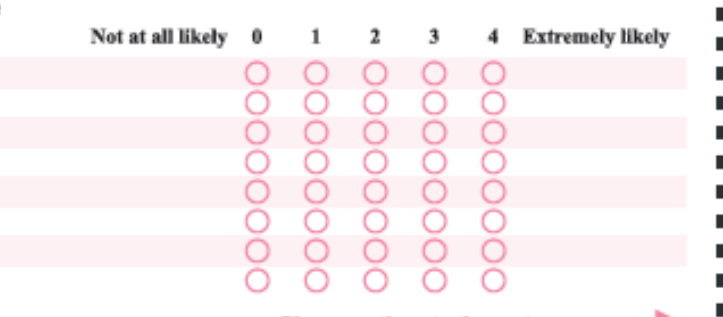

Please continue to the next page

DO NOT WRITE IN THIS AREA

000000000000000000000000

SERIAL \# 


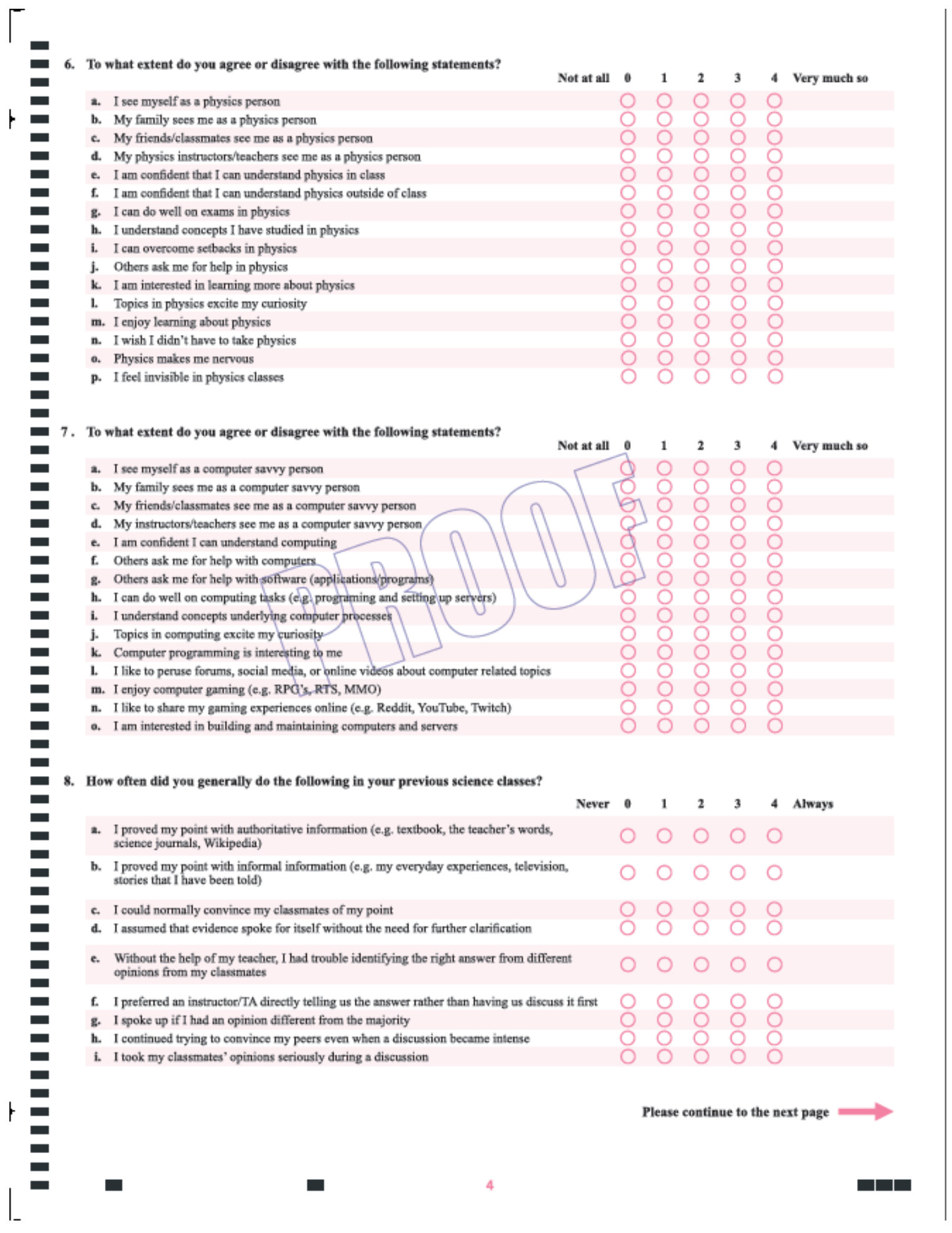


Questions 9-15 refer to a sled on ice. A sled on ice moves the way described in questions $9-15$ below. Friction is so small that it can be ignored. A person wearing spiked shoes standing on the ice can apply a force to the sled and push it along the ice.

Choose the one force (A through G) which would keep the sled moving as described in each statement below.

You may use a choice more than once or not at all but choose only one answer for each blank.

If you think that none is correct, answer choice $\mathbf{J}$.

\begin{tabular}{|c|c|}
\hline Dewita & $\begin{array}{l}\text { A. The force is toward the right and is } \\
\text { increasing in strength (magnitude). } \\
\text { B. The force is toward the right and is of } \\
\text { constant strength (magnitude). } \\
\text { C. The force is toward the right and is } \\
\text { deereasing in strength (magnitude). }\end{array}$ \\
\hline & D. No applied force is needed \\
\hline & $\begin{array}{l}\text { E. The force is toward the left and is } \\
\text { deereasing in strength (magnitude). } \\
\text { F. The force is toward the left and is of } \\
\text { constant strength (magnitude). } \\
\text { G. The force is toward the left and is } \\
\text { increasing in strength (magnitude). }\end{array}$ \\
\hline & J. None of these answers is correct. \\
\hline
\end{tabular}

9. Which force would keep the sled moving to the right and speeding up at a steady rate (constant acceleration)?

10. Which force would keep the sled moving to the right at a steady (constant) velocity?

11. The sled is moving toward the right. Which force would slow it down at a steady rate (constant acceleration)?

12. Which force would keep the sled moving to the left and speeding up at a steady rate (constant acceleration)?

13. The sled was started from rest and pushed until it reached a steady (constant) velocity toward the right. Which force would keep the sled moving at this velocity?

14. The sled is slowing down at a steady rate and has an acceleration to the right Which force would account for this motion?

15. The sled is moving toward the left. Which force would slow it down at a steady rate (constant acceleration)?

16. Two students sit in identical office chairs facing each other. Bob has a mass of $95 \mathrm{~kg}$. while Jim has a mass of $77 \mathrm{~kg}$. Bob places his bare foet on Jim's knees, as shown to the right. Bob then sudderily pushes outward with his feet, causing both chairs to move. In this situation, while Bob's feet are in contact with Jim's knees,

A. Neither stadent exerts a force gn extch other.

B. Bob exerts a force on Jim, but Jim doesn't exert any force on Bob.

C. Fach student exerts a force on the other, but Jim exerts the langer force.

D. Each student exerts a force on the other, but Bob exerts the larger force.

E. Each student exerts the same amount of foroc on each other

J. None of these answers is correct.

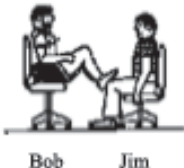

Questions 17-19 refer to collisions between a car and truck. For each description of a collision below, choose the one answer from the possibilitic A through $\mathbf{J}$ that best describes the forces between the car and the truck.

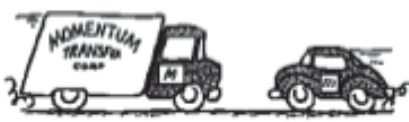

In questions 15 through 17

the truck is much heavier than the car

A. The truck exerts a greater amount of force on the car than the car exerts on the truck.

B. The car exerts a greater amount of force on the truck than the truck exerts on the car

C. Neither exerts a force on the other, the car gets smashed simply bocause it is in the way of the truck

D. The truck exerts a force on the car but the car doesn't exert a force on the truck

E. The truck exerts the same amount of force on the car as the car exerts on the truck.

F. Not enough information is given to pick one of the answers above.

J. None of the answers above describes the situation correctly.

17. They are both moving at the same speed when they collide. Which choice describes the forces?

18. The car is moving much faster than the heavier truck when they collide. Which choice describes the forces?

19. The heavier truck is standing still when the car hits it. Which choice describes the forces?
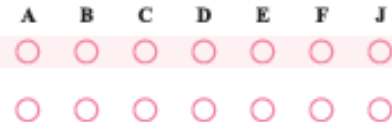

$\begin{array}{llllll}0 & 0 & 0 & 0 & 0 & 0\end{array}$

Please continue to the next page 


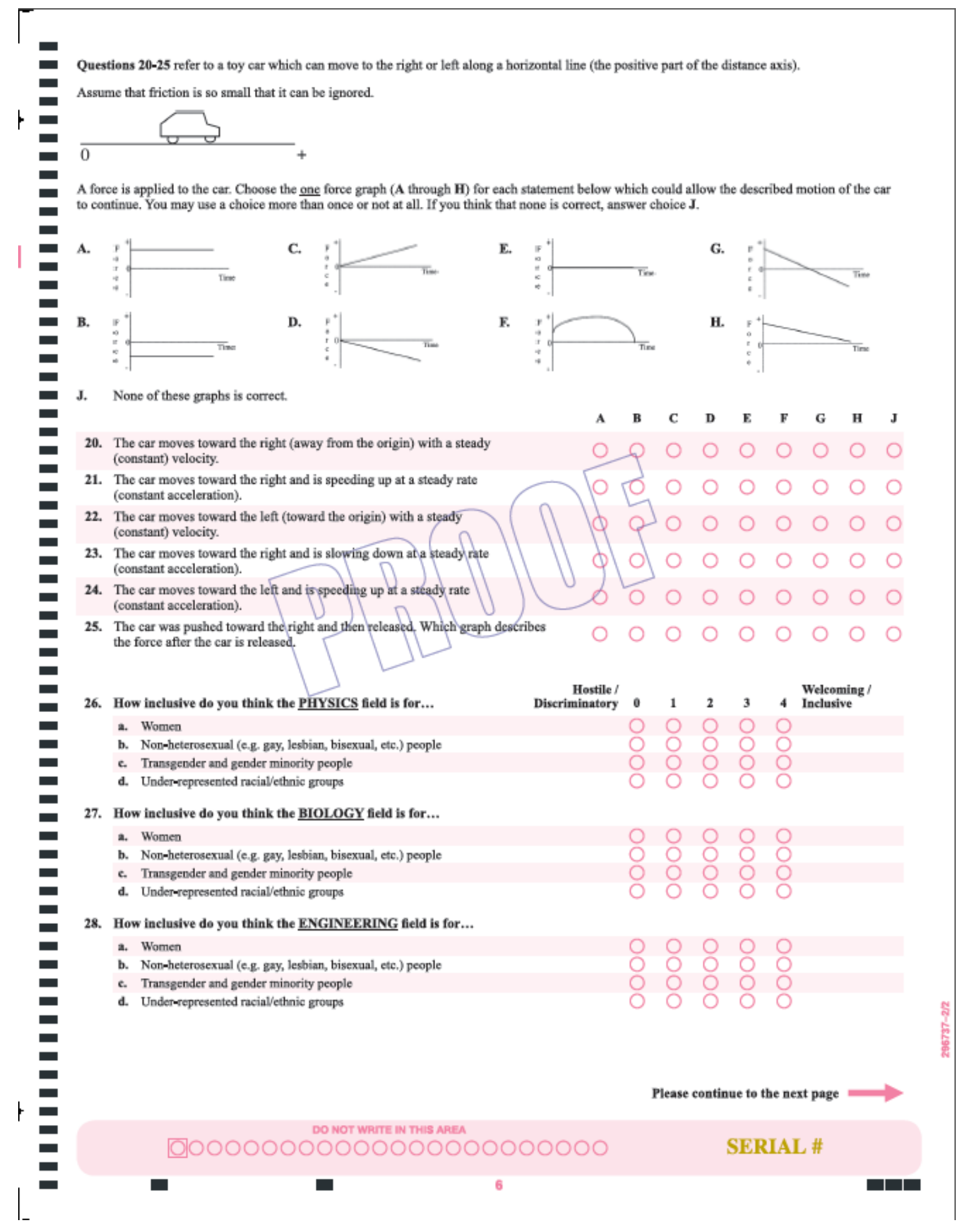


29. How frequently have you done the following activities outside of formal courses? (Mark all that apply)

a. Participated in seience/engineering clubs or competitions

b. Built things (e.g. structures, houses)

c. Tinkered with mechanical devices (e.g. rifle, bow and amow, car jack, pulleys, wheelbarrow, sewing machine)

d. Tinkered with electrical devices (e.g, cars, batteries and bulbs, radio, TV)

e. Mixed chemicals/materials. Engaged with chemistry sets, kitehen chemistry

f. Planted seeds, watched plants grow, watched animal behavior, collected things in nature (e.g. butterflies, rocks)

g. Observed or studied stars and other astronomical objects

h. Read/watched science fiction

i. Did math/logic puzzles

j. Read/watched science/engineering programs or literature

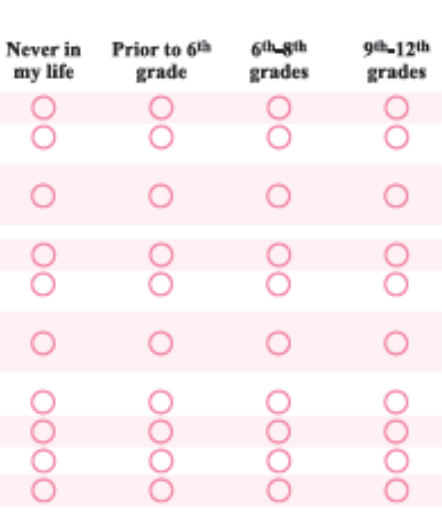

30. Which of the following courses did you take in college or high school? (Mark all that apply)

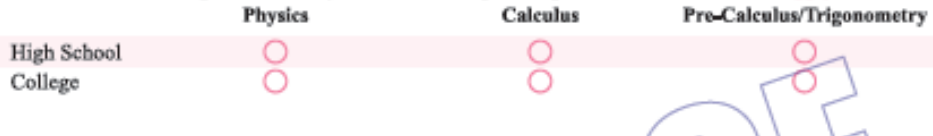

31. For each of the following standardized tests, please indicate the seore you earned on each subtest by marking the appropriate numbers.

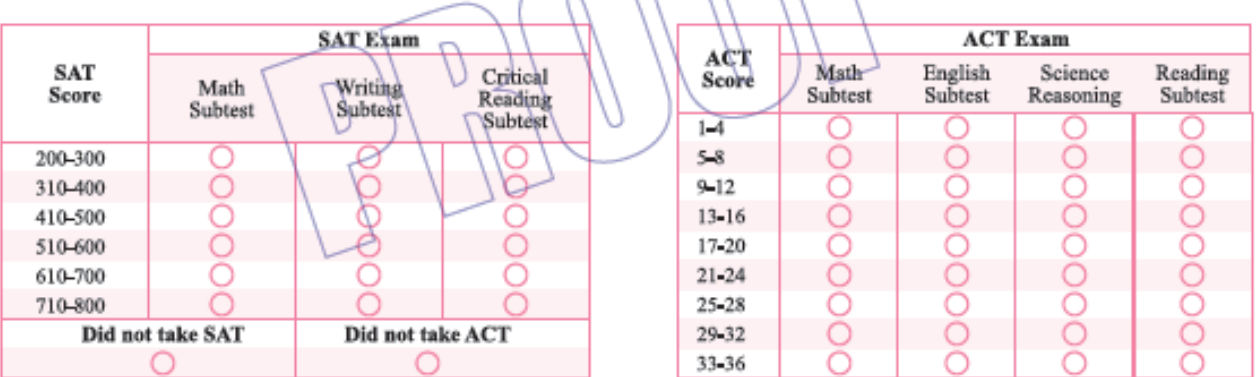

32. What grade did you receive in your last physics and math courses (if any)?

$\begin{array}{lcccccccccc} & \text { A } & \text { A- } & \text { B+ } & \text { B } & \text { B- } & \text { C+ } & \text { c } & \text { c- } & \text { D } & \text { F } \\ \text { Physics } & \bigcirc & \bigcirc & \bigcirc & \bigcirc & \bigcirc & \bigcirc & \bigcirc & \bigcirc & \bigcirc & \bigcirc \\ \text { Math } & \bigcirc & \bigcirc & \bigcirc & \bigcirc & \bigcirc & \bigcirc & \bigcirc & \bigcirc & \bigcirc & \bigcirc\end{array}$
33. What year are you in college? 1 year
$2^{a d}$ year
3rd year
$4^{\text {th }}$ year +

34. How many college eredit hours did you complete before starting college? (e.g. AP credits, IB, dual credit, etc.)
0
$1-6$
$7-12$
13-18
$19-24$
$25-30$
$31+$

35. How do you describe your gender identity? (Mark all that apply)
Female
Male
Genderqueer
Agender
Transgender
Cisgender
A gender not listed

36. With which racial and ethnie group(s) do you identify? (Mark all that apply)
American Indian or Alaska Native
Hispanic, Latino, or Spanish origin
White

Asian

Middle Eastern or North African

Other nace(s) or ethnicity(s)

Black or African American

Native Hawaiian or Other Pacific Islander

Please continue to the next page 
37. Print your specific ethnicities in the space below.

Examples of ethnicities include: German, Korean, Midwesterner (American), Mexican American, Navajo Nation, Samoan, Puerto Rican,

Southerner (American), Chinese, ete. Note, you may report more than one group

Your Specific Ethnicities

38. How would your parent(s)/guardian(s) describe their gender identities? (Mark all that apply)

Parent/Guardian $\# 1$

$\bigcirc$ Female $\bigcirc$ male $\bigcirc$ Genderqueer $\bigcirc$ Agender $\bigcirc$ Transgender $\bigcirc$ Cisgender $\bigcirc$ A gender not listed

Parent/Guardian W2

$\bigcirc$ Female $\bigcirc$ male $\bigcirc$ Genderqueer $\bigcirc$ Agender $\bigcirc$ Transgender $\bigcirc$ Cisgender $\bigcirc$ A gender not listed

39. Which eategory best fits you and your parent(s)'/guardian(s)' background? Born in United States

$\begin{array}{lll}\text { Me } & \text { Yes } & \text { No } \\ \text { Parent/Guardian \#1 } & \text { Yes } & \text { No } \\ \text { Parent/Guardian \#2 } & \bigcirc \text { Yes } & \text { No }\end{array}$

40. What was the highest level of education for your parents/guardians?
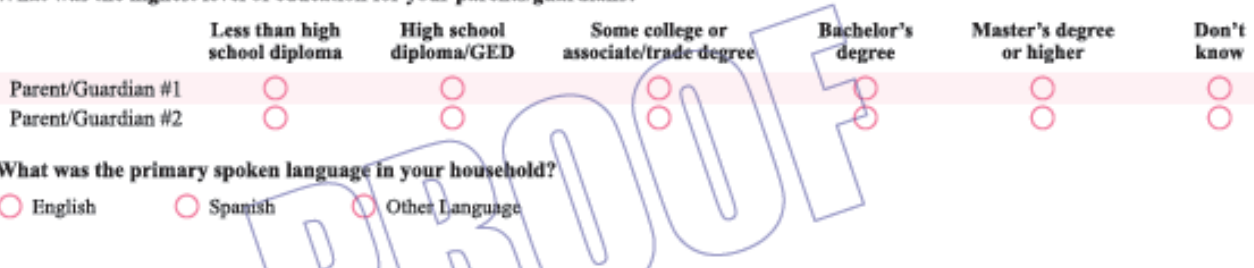

41. What was the primary spoken language in your household? English

Spanish

42. Which of the following statements describes your family's interest in physics and science in general? (Mark all that apply)

a. This topic was a diversion or hobby

b. This topic was a way for me to baved better career

c. My family helped me with my schoolwork in this topic

d. My family arranged for tatoring in this topic

c. This topic was a series of courses that I had to pass

f. This topic was not a family interest

43. Please provide your home ZIP code, to help us estimate the size of the community you come from.

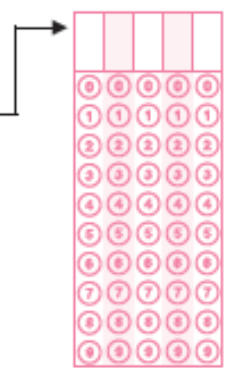

Physics

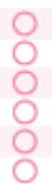

Science in general

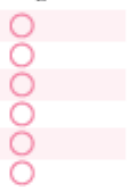

You have reached the end of the survey. Thank you for your time. It is our goal that many science educators will benefit from the insights you have provided. 


\section{FIU $\mid$ sTeM Transomamion hastuto \\ FLORIDA INTERNATIONAL UNIVERSITY}

\section{Conceptual Understanding and Physics Identity Development}

\section{POST SURVEY}

Information Regarding Your Participation in this Survey

We are interested in your experiences, attitudes, beliefs, and career expectations with respect to learning physics. Please make your best estimate for each item and answer as many questions as possible. There are no right or wrong answers. Describe yourself as you generally are now, not as you wish to be in the future. Describe yourself as you honestly see yourself.

PLEASE NOTE:

- You must be 18 years orldider to participate

- The survey will take approximately 20 minutes to complete

- Participation is voluntary Xou may withdraw at any time.

- Participation will NOT impact your grade in this course in any way.

- You will be asked for contact information (email) in case we want to follow-up on some of your survey responses. This information is voluntary and will not be shared with any third party.

- If you have any questions or concerns, please contact Geoff Potvin [gpotvin@fiu.edu, (305) 348-7614] or Zahra Hazari [zhazari@fiu.edu, (305) 348-2096].

- Participants may also contact the Florida International University Office of Research Integrity, located in room MARC 270 , at (305) 348-8311.

Thank you for your time and insight. 


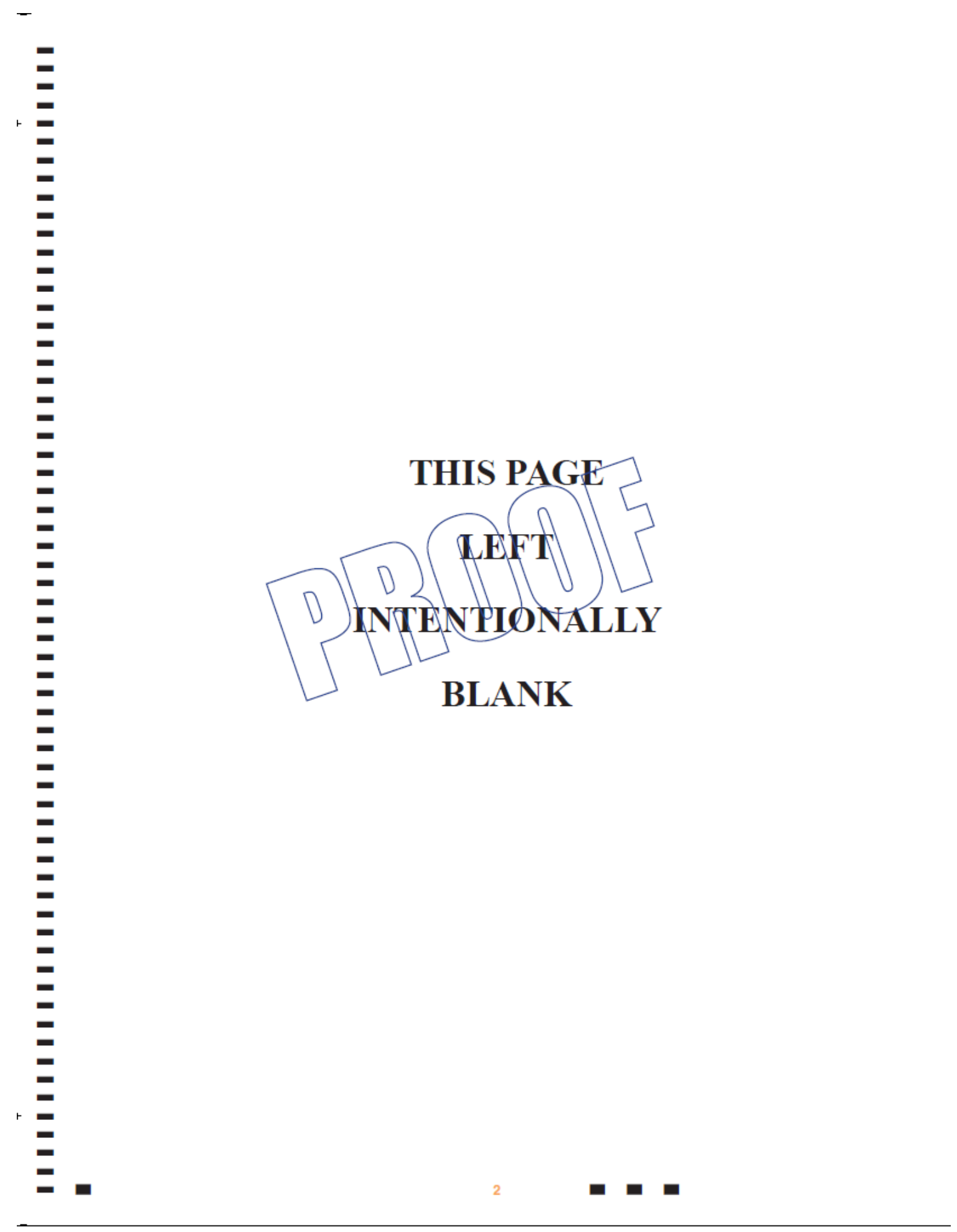


1. Write your student ID in the space provided. If you have less than 10 digits, leave extra columns blank.

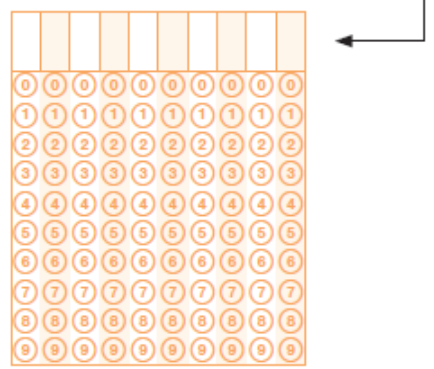

2. Please rate the current likelihood of your choosing a career in the following fields:

a. Biology

b. Engineering

c. Environmental science

d. Chemistry

e. Physics

f. Mathematics

g. Science/Math teacher

h. Other sciences

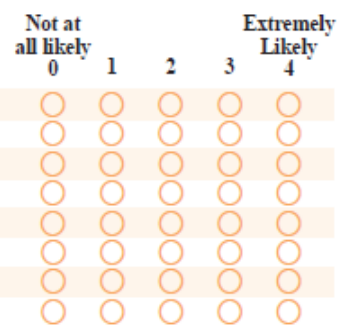

3. To what extent do you agree or disagree with the following statements?

a. I see myself as a physics person

b. My family sees me as a physics person

c. My friends/classmates see me as a physics person

d. My physics instructors/teachers see me as a physics person

e. I am confident that I can understand physics in class

f. I am confident that I can understand physics outside of class

g. I can do well on exams in physics

h. I understand concepts I have studied in physics

i. I can overcome setbacks in physics

j. Others ask me for help in physics

k. I am interested in learning more aboutlphysic

l. Topics in physics excite my curiosity

$\mathrm{m}$. I enjoy leaming about physics

n. I wish I didn't have to take physics

o. Physics makes me nervous

p. I feel invisible in physics classes

\section{About Your Physics Course}

4. Were your physics lecture and lab sections combined? (Mark only one)
Lecture and lab were integrated
Lecture and lab were separate and paced together
Lecture and lab were separate but not paced together

5. How many of each of the following types of instructors taught this course regularly?
a. Professor(s)
b. Graduate student(s)
c. Undergraduate student(s)

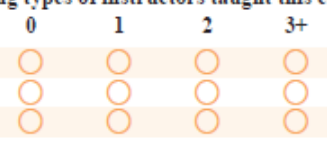

6. In terms of learning the material, your current physics course requires:

Very little memorization
b. Very little conceptual understanding




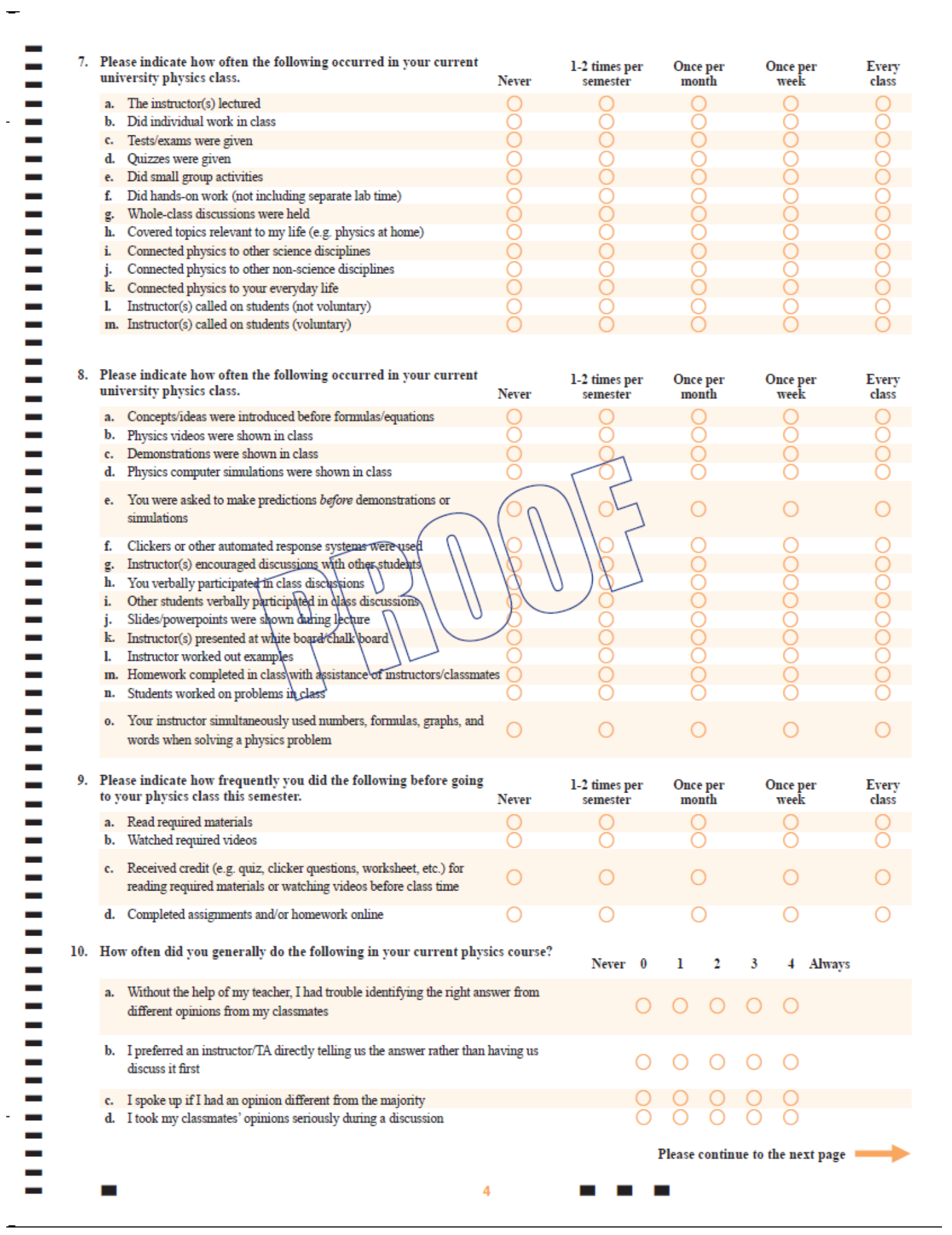


11. What types of questions were you required to answer in your current physics course? (Mark all that apply)
a. Required only one step of calculations
b. Required several steps of calculations
c. Could be solved without math
d. Required written explanations
e. Questions about material covered on previous tests/quizzes
f. Required graphing or plotting
g. Required sketching or drawing (e.g., free-body diagram or other representation)
h. Required memorization of terms or facts
i. Had multiple-choice/true-false format
j. Required analyzing data presented in tables
k. Required new insight and creativity
l. Had more than one correct response

12. To what extent did quizzes/tests match with the course activities/lectures?

$$
\text { Not at all } \bigcirc \bigcirc \bigcirc \quad \bigcirc \text { Very much so }
$$

13. How interested were most students in the content/topics?

$$
\text { Not at all interested } \bigcirc \bigcirc \bigcirc \bigcirc \text { Very interested }
$$

\section{About Group Work}

14. How many total students (including yourself) werefypically in pur groups?

No Group Work

15. How many other students in your gropps were typically fhe spme gender as tou?
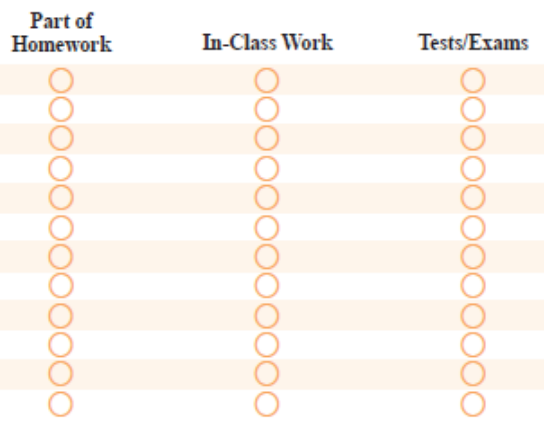

16. Please tell us how frequently the following occurryed durng group work.

a. You worked at tables

b. You faced your group mates while working

c. Your group used equipment

d. Your group used whiteboards or other shared writing surfaces

e. Your group collaborated with other groups

f. Your group presented work to others

g. You were expected to simultaneously use numbers, formulas, graphs, and words when solving a physics problem

h. Your group used computer simulations

i. You worked on labs or projects

j. You led your group's activities

k. You taught your group members

\section{About Out of Class Work}

17. How many MINUTES, on average, did you spend doing work outside of class each day for this physics course?
0
1-15
$16-30$
$31-45$
$46-60$
More than 60
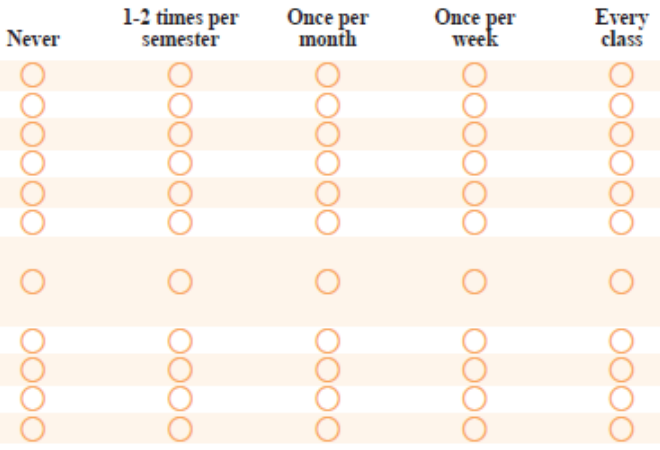
18. Please tell us how often YOU did the following outside of class:

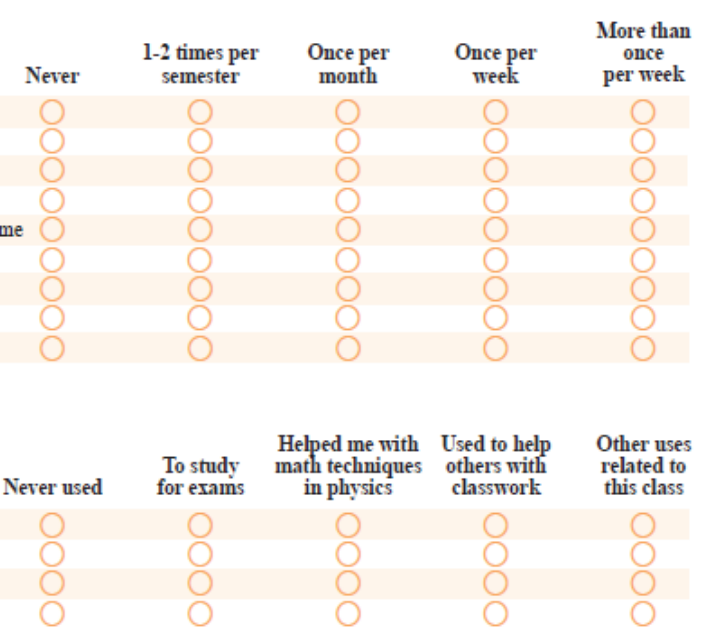

19. How did you use the following online resources?

a. Worked outside of class time with other students from this course

b. Visited a physics help/drop-in center

c. Asked your professor for help outside of class time

d. Asked a graduate teaching assistant for help outside of class time

e. Asked an undergraduate teaching assistant for help outside of class time

f. Visited a private tutor

g. Used your textbook

h. Asked your classmates for help

i. Gave help to classmates outside of class time Mark all that apply)

a. Videos

b. Written resources (Wikipedia, Reddit, fonms, examples/solutions)

c. Physics simulations

d. Interactive social resources (Twitter, Facebook)

amples/solutions)

20. Which of the following online resources, if any, were used for your physics course?
No online resources
Just In Time Teaching
Mastering Physics
Blackboard
Web Assign
Hyperphysics

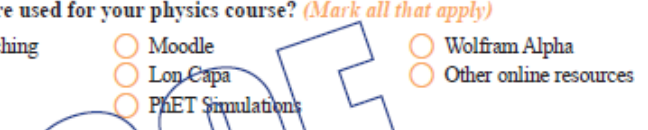

About Instructor(s)

21. How would you rate your physics instructor on the folloting dataracteristics?

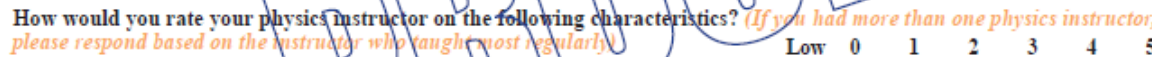

a. Enthusiasm for physics

b. Treated all students with respect

c. Explained ideas clearly

d. Explained problems and answeted equestions in several different ways

e. Was able to organize lessons and classroom activities

f. Was able to handle discipline and manage the classroom

g. Was available to help students outside of class

22. Which class members knew your name?
No one in my class knew my name
Undergraduate teaching assistant(s)
Classmates
Professor(s)
Graduate teaching assistant(s)

23. Please tell us how frequently:

a. Instructor(s) asked for feedback

b. Instructors adjusted their lessons based upon students' needs/understanding

c. Instructors gave you individual feedback

d. Instructors gave the class feedback

e. You adjusted your habits based on professor feedback

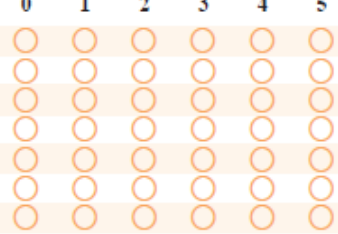

6 High

24. How would you describe your professor(s)' gender(s)? (Please select all that apply: If you had more flian one physics instructor, please respond based on the instructor who tanght most regulariy)
Female
Male
Genderqueer
Agender
A gender not listed

Please continue to the next page 


\section{Physics Concepts}

Questions 25-31 refer to a sled on ice. A sled on ice moves the way described in questions 25-31 below. Friction is so small that it can be ignored. A person wearing spiked shoes standing on the ice can apply a force to the sled and push it along the ice.

Choose the one force (A through $\mathrm{G}$ ) which would keep the sled moving as described in each statement below.

You may use a choice more than once or not at all but choose only one answer for each blank.

If you think that none is correct, answer choice $\mathrm{J}$

A. The force is toward the right and is
increasing in strength (magnitude).
B. The force is toward the right and is of
constant strength (magnitude).
C. The force is toward the right and is
decreasing in strength (magnitude).

A

B C

E G J

25. Which force would keep the sled moving to the right and speeding up at a steady rate (constant acceleration)?

26. Which force would keep the sled moving to the right at a steady (constant) velocity?

27. The sled is moving toward the right. Which force would slow it down at a steady rate (constant acceleration)?

28. Which force would keep the sled moving to the left and speeding up at a steadyrate (constant acceleration)?

29. The sled was started from rest and pushed until it reached a steady (constant) velpcity toward the right. Which force would keep the sled moving at thipvelocity?

30. The sled is slowing down at a steady rate and has an acceleration to the right. Which force would account for thismotion?

31. The sled is moving toward the left. Which fofce world slow it down at a steady rate (constant acceleration)?

Two students sit in identical office charrs facing each pther Bob has a mass of $95 \mathrm{~kg}$, while Jim has a mass of $77 \mathrm{~kg}$. Bob places his bare feet on Jim's knees, as shown to the right. Bop then suddenty pushes outward with his feet, causing both chairs to move. In this situation, while Bob's feet are in contact with Jim's knees,

A. Neither student exerts a force on each other.

B. Bob exerts a force on Jim, but Jim doesn't exert any force on Bob.

C. Each student exerts a force on the other, but Jim exerts the larger force.

D. Each student exerts a force on the other, but Bob exerts the larger force.

E. Each student exerts the same amount of force on each other

J. None of these answers is correct.

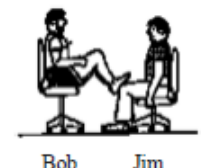

Questions 33-35 refer to collisions between a car and truck. For each description of a collision below, choose the one answer from the possibilities A through $\mathrm{J}$ that best describes the forces between the car and the truck.

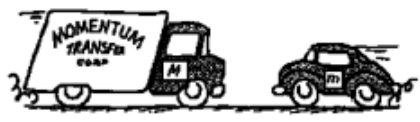

In questions 33 through 35

the truck is much heavier than the car

A. The truck exerts a greater amount of force on the car than the car exerts on the truck.

B. The car exerts a greater amount of force on the truck than the truck exerts on the car

C. Neither exerts a force on the other; the car gets smashed simply because it is in the way of the truck

D. The truck exerts a force on the car but the car doesn't exert a force on the truck.

E. The truck exerts the same amount of force on the car as the car exerts on the truck.

F. Not enough information is given to pick one of the answers above

J. None of the answers above describes the situation correctly.

33. They are both moving at the same speed when they collide. Which choice describes the forces?

34. The car is moving much faster than the heavier truck when they collide. Which choice describes the forces?

35. The heavier truck is standing still when the car hits it. Which choice describes the forces?

C D $\quad$ E $\quad F \quad$ J
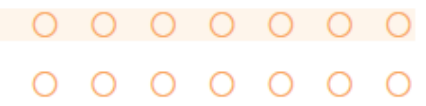

000000

Please continue to the next page 


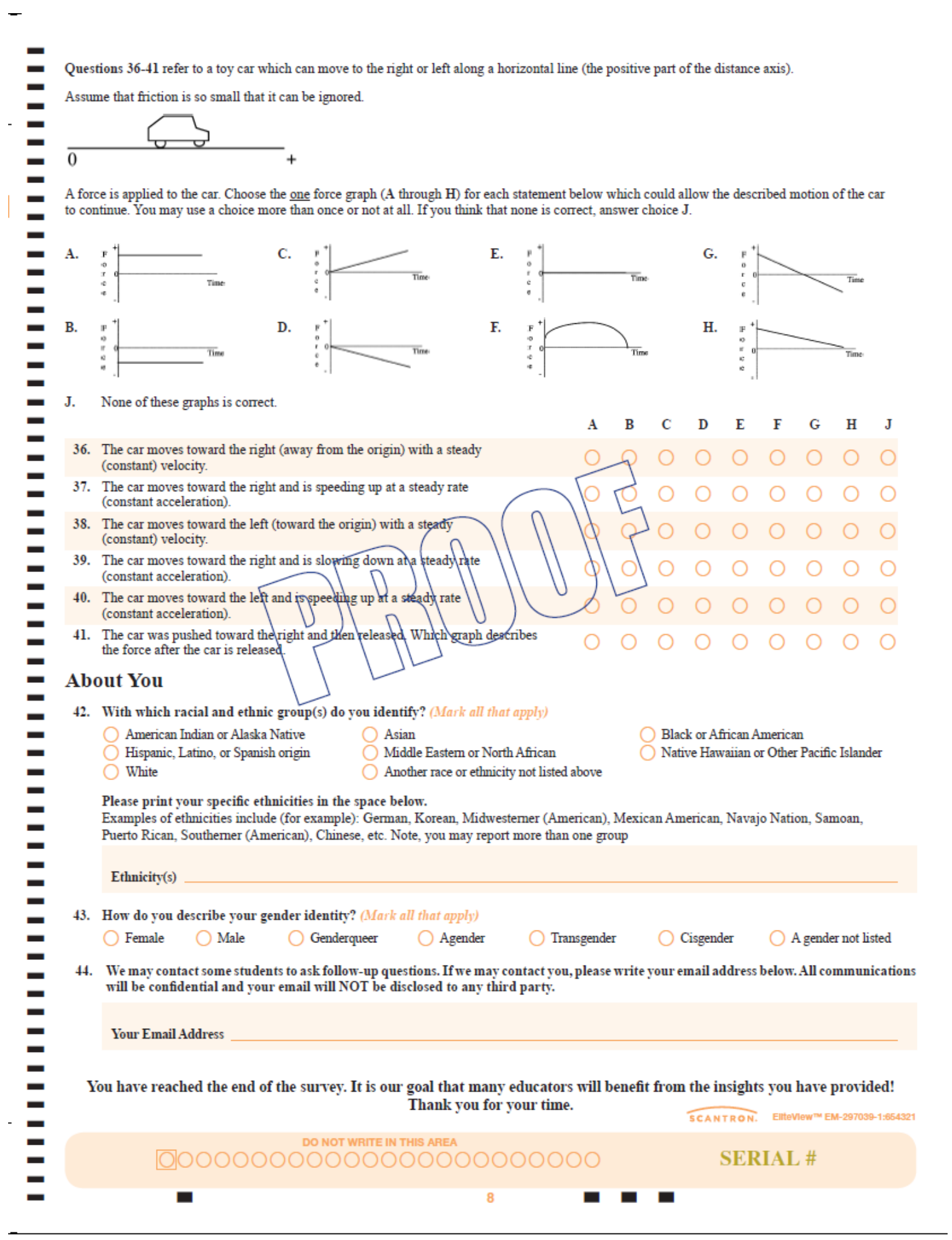




\section{Appendix 2: SI and Collective Orientation scales}

\section{Social Interdependence scale}

Name

Panther ID

1. Please rate your level of agreement with the following statements.

\begin{tabular}{|c|c|c|c|c|c|c|c|c|c|}
\hline & $\begin{array}{l}\text { Strongly } \\
\text { disagree }\end{array}$ & 0 & 1 & 2 & 3 & 4 & 5 & 6 & $\begin{array}{l}\text { Strongly } \\
\text { Agree }\end{array}$ \\
\hline a. I like to help other students & & $\mathrm{O}$ & $\mathrm{O}$ & $\mathrm{O}$ & $\mathrm{O}$ & $\mathrm{O}$ & $\mathrm{O}$ & $\mathrm{O}$ & \\
\hline $\begin{array}{l}\text { b. I like to share my ideas and materials with } \\
\text { other students }\end{array}$ & & $\mathrm{O}$ & $\mathrm{O}$ & $\mathrm{O}$ & $\mathrm{O}$ & $\mathrm{O}$ & $\mathrm{O}$ & $\mathrm{O}$ & \\
\hline c. I like to cooperate with other students & & $\mathrm{O}$ & $\mathrm{O}$ & $\mathrm{O}$ & $\mathrm{O}$ & $\mathrm{O}$ & $\mathrm{O}$ & $\mathrm{O}$ & \\
\hline d. I can learn important things from other students & & $\mathrm{O}$ & $\mathrm{O}$ & $\mathrm{O}$ & $\mathrm{O}$ & $\mathrm{O}$ & $\mathrm{O}$ & $\mathrm{O}$ & \\
\hline $\begin{array}{l}\text { e. I try to share my ideas and materials with other } \\
\text { students when I think it will help them }\end{array}$ & & $\mathrm{O}$ & $\mathrm{O}$ & $\mathrm{O}$ & $\mathrm{O}$ & $\mathrm{O}$ & $\mathrm{O}$ & 0 & \\
\hline $\begin{array}{l}\text { f. Students learn lots of important things from } \\
\text { each other }\end{array}$ & & $\mathrm{O}$ & $\mathrm{O}$ & $\mathrm{O}$ & $\mathrm{O}$ & $\mathrm{O}$ & $\mathrm{O}$ & $\mathrm{O}$ & \\
\hline $\begin{array}{l}\text { g. It is a good idea for students to help each other } \\
\text { learn. }\end{array}$ & & $\mathrm{O}$ & $\mathrm{O}$ & $\mathrm{O}$ & $\mathrm{O}$ & $\mathrm{O}$ & $\mathrm{O}$ & $\mathrm{O}$ & \\
\hline $\begin{array}{l}\text { h. I don't like working with other students in } \\
\text { school }\end{array}$ & & $\mathrm{O}$ & $\mathrm{O}$ & $\mathrm{O}$ & $\mathrm{O}$ & $\mathrm{O}$ & $\mathrm{O}$ & $\mathrm{O}$ & \\
\hline i. I like to work with other students & & $\mathrm{O}$ & $\mathrm{O}$ & $\mathrm{O}$ & $\mathrm{O}$ & $\mathrm{O}$ & $\mathrm{O}$ & $\mathrm{O}$ & \\
\hline $\begin{array}{l}\text { j. It bothers me when I have to work with other } \\
\text { students }\end{array}$ & & $\mathrm{O}$ & $\mathrm{O}$ & $\mathrm{O}$ & $\mathrm{O}$ & $\mathrm{O}$ & $\mathrm{O}$ & $\mathrm{O}$ & \\
\hline k. I do better work when I work alone & & $\mathrm{O}$ & $\mathrm{O}$ & $\mathrm{O}$ & $\mathrm{O}$ & $\mathrm{O}$ & $\mathrm{O}$ & $\mathrm{O}$ & \\
\hline I. I like work better when I do it by myself & & $\mathrm{O}$ & $\mathrm{O}$ & $\mathrm{O}$ & $\mathrm{O}$ & $\mathrm{O}$ & $\mathrm{O}$ & $\mathrm{O}$ & \\
\hline $\begin{array}{l}\mathrm{m} \text {. I would rather work on school work alone than } \\
\text { with other students }\end{array}$ & & $\mathrm{O}$ & $\mathrm{O}$ & $\mathrm{O}$ & $\mathrm{O}$ & $\mathrm{O}$ & $\mathrm{O}$ & $\mathrm{O}$ & \\
\hline $\begin{array}{l}\mathrm{n} \text {. Working in small groups is better than working } \\
\text { alone. }\end{array}$ & & $\mathrm{O}$ & $\mathrm{O}$ & $\mathrm{O}$ & $\mathrm{O}$ & $\mathrm{O}$ & $\mathrm{O}$ & $\mathrm{O}$ & \\
\hline
\end{tabular}




\section{Collective Orientation scale}

2. Please rate your level of agreement with the following statements.

\begin{tabular}{|c|c|c|c|c|c|c|c|c|c|}
\hline & $\begin{array}{l}\text { Strongly } \\
\text { disagree }\end{array}$ & 0 & 1 & 2 & 3 & 4 & 5 & 6 & $\begin{array}{l}\text { Strongly } \\
\text { Agree }\end{array}$ \\
\hline $\begin{array}{l}\text { a. I find working on group activiies to be very } \\
\text { satisfying. }\end{array}$ & & $\mathrm{O}$ & $\mathrm{O}$ & $\mathrm{O}$ & $\mathrm{O}$ & $\mathrm{O}$ & $\mathrm{O}$ & $\mathrm{O}$ & \\
\hline $\begin{array}{l}\text { b. I would rather take action on my own than to } \\
\text { wait around for others' input. }\end{array}$ & & $\mathrm{O}$ & $\mathrm{O}$ & $\mathrm{O}$ & $\mathrm{O}$ & $\mathrm{O}$ & $\mathrm{O}$ & $\mathrm{O}$ & \\
\hline $\begin{array}{l}\text { c. I prefer to complete a task from beginning to } \\
\text { end with no assistance from others. }\end{array}$ & & $\mathrm{O}$ & $\mathrm{O}$ & $\mathrm{O}$ & $\mathrm{O}$ & $\mathrm{O}$ & $\mathrm{O}$ & $\mathrm{O}$ & \\
\hline $\begin{array}{l}\text { d. For most tasks, I would rather work alone than } \\
\text { as part of a group. }\end{array}$ & & $\mathrm{O}$ & $\mathrm{O}$ & $\mathrm{O}$ & $\mathrm{O}$ & $\mathrm{O}$ & $\mathrm{O}$ & $\mathrm{O}$ & \\
\hline $\begin{array}{l}\text { e. I can usually perform better when I work on my } \\
\text { own. }\end{array}$ & & $\mathrm{O}$ & $\mathrm{O}$ & $\mathrm{O}$ & $\mathrm{O}$ & $\mathrm{O}$ & $\mathrm{O}$ & 0 & \\
\hline $\begin{array}{l}\text { f. I find that it is often more productive to work on } \\
\text { my own than with others. }\end{array}$ & & $\mathrm{O}$ & $\mathrm{O}$ & $\mathrm{O}$ & $\mathrm{O}$ & $\mathrm{O}$ & $\mathrm{O}$ & $\mathrm{O}$ & \\
\hline $\begin{array}{l}\text { g. When solving a problem, it is very important to } \\
\text { make your own decision and stick by it. }\end{array}$ & & $\mathrm{O}$ & $\mathrm{O}$ & $\mathrm{O}$ & $\mathrm{O}$ & $\mathrm{O}$ & $\mathrm{O}$ & $\mathrm{O}$ & \\
\hline $\begin{array}{l}\text { h. When I have a different opinion than another } \\
\text { group member, I usually try to stick with my own } \\
\text { opinion. }\end{array}$ & & $\mathrm{O}$ & $\mathrm{O}$ & $\mathrm{O}$ & $\mathrm{O}$ & $\mathrm{O}$ & $\mathrm{O}$ & $\mathrm{O}$ & \\
\hline $\begin{array}{l}\text { i. It is important to stick to your own decisions, } \\
\text { even when others around you are trying to get } \\
\text { you to change. }\end{array}$ & & $\mathrm{O}$ & $\mathrm{O}$ & $\mathrm{O}$ & $\mathrm{O}$ & $\mathrm{O}$ & $\mathrm{O}$ & $\mathrm{O}$ & \\
\hline $\begin{array}{l}\text { j. When others disagree, it is important to hold } \\
\text { one's own ground and not give in. }\end{array}$ & & $\mathrm{O}$ & $\mathrm{O}$ & $\mathrm{O}$ & $\mathrm{O}$ & $\mathrm{O}$ & $\mathrm{O}$ & $\mathrm{O}$ & \\
\hline
\end{tabular}

Please continue to the next page $\longrightarrow$ 


\section{Appendix 3: Task and outcome interdependence survey}

\section{Post Group Questionnaire}

Name

Panther ID

1. Please rate your level of agreement with the following statements.

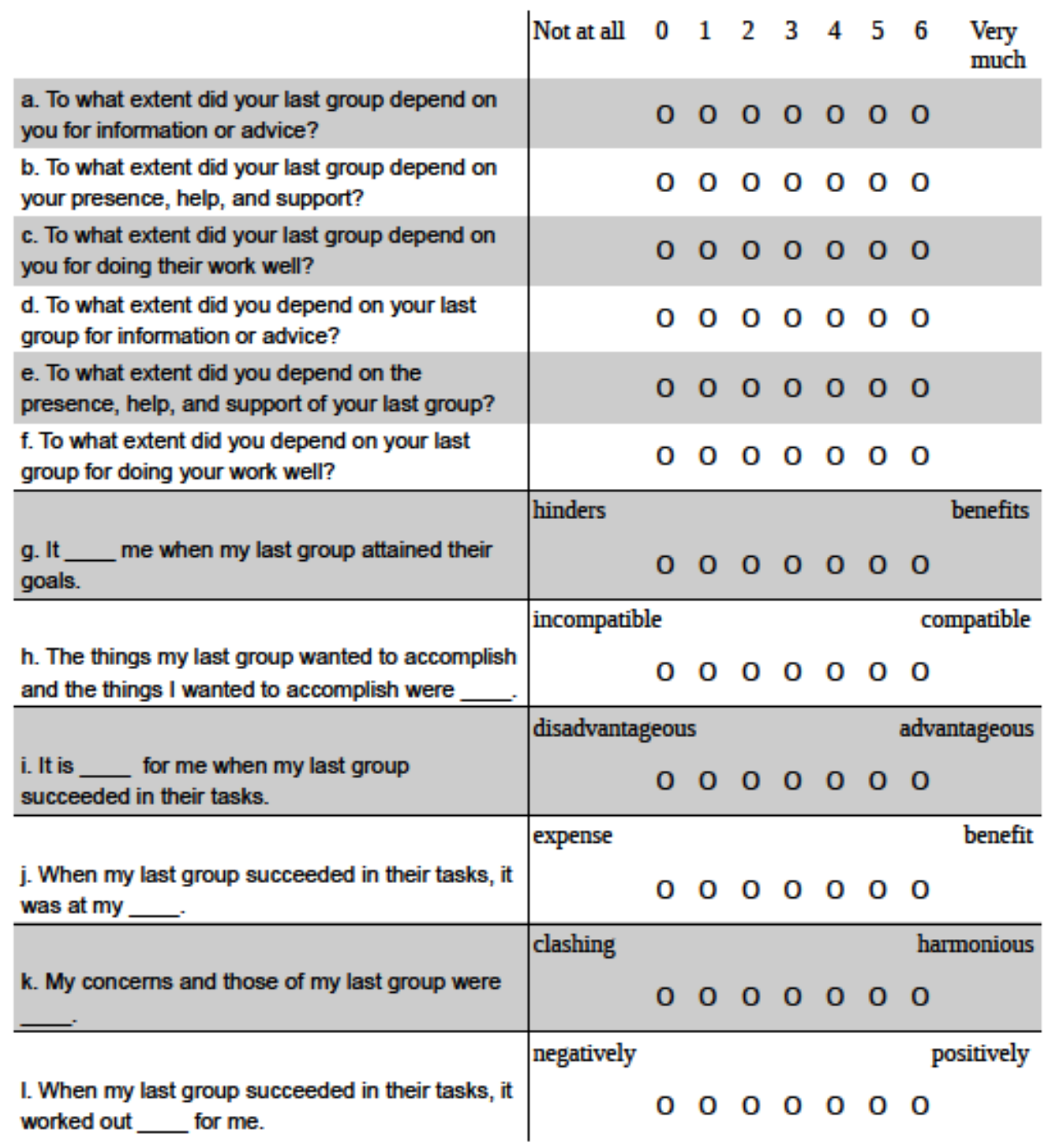

Please continue to the next page 


\section{Appendix 4: The $\mathrm{R}$ code for chapter 3 analysis}

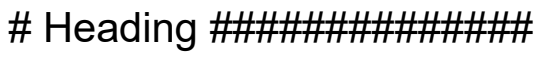

library("ggplot2")

library("Zelig")

library("Amelia")

library("effsize")

load(" /PER/Projects/1- Frequent group learning leads to improved learning/Work on CUPID/Clean_Pre_CUPID.Rdata")

load(" /PER/Projects/1- Frequent group learning leads to improved learning/Work on CUPID/Clean_Post_CUPID.Rdata")

load(" /PER/Projects/1- Frequent group learning leads to improved learning/Work on CUPID/CUPID.Rdata")

\# Creating Subset of data \& imputing \#\#\#\#\#

PI_both <-CUPID[c(96:111,285:300)] \#pre and post PI question

FM̄CE <- CUPID[C(136:152,457:473)] \#pre and post FMCE

freq <- CUPID[c(307:338,383:393,395:403,447:451)] \# postQs:7,8, 9,16,18,23

likert <- CUPID[c(339:342,435:441)] \#postQs:10,21

\#putting it together

Impable <- cbind(PI_both,FMCE,freq,likert)

rm(PI_both,FMCE,freq,likert)

\#ridge set to 10 percent to correct for the high correlation of variables

set.seed(7151) \#\$ to re run code

$\mathrm{mm}<-20$

a.Impable <- Amelia::amelia(Impable, $m=m m$,incheck = FALSE, ords=c(33:123),

empri = 5)

\#_missmap(a.Impable)

\# Adding column of raw and normalized improvement of FMCE Scores \#\#\#\#\#\# kk <- 1:1000; jj <- 1:1000

FMCE_pre <- list(); FMCE_post <- list()

FMCE_raw <- list(); FMCE_norm <- list()

responses $<-$ data.frame()

\#FMCE pre score

for(kk in $1: \mathrm{mm})$

\# Creating a score for FMCE Portion for Pre

responses <- a.Impable\$imputations[[kk]][c(33:49)] 


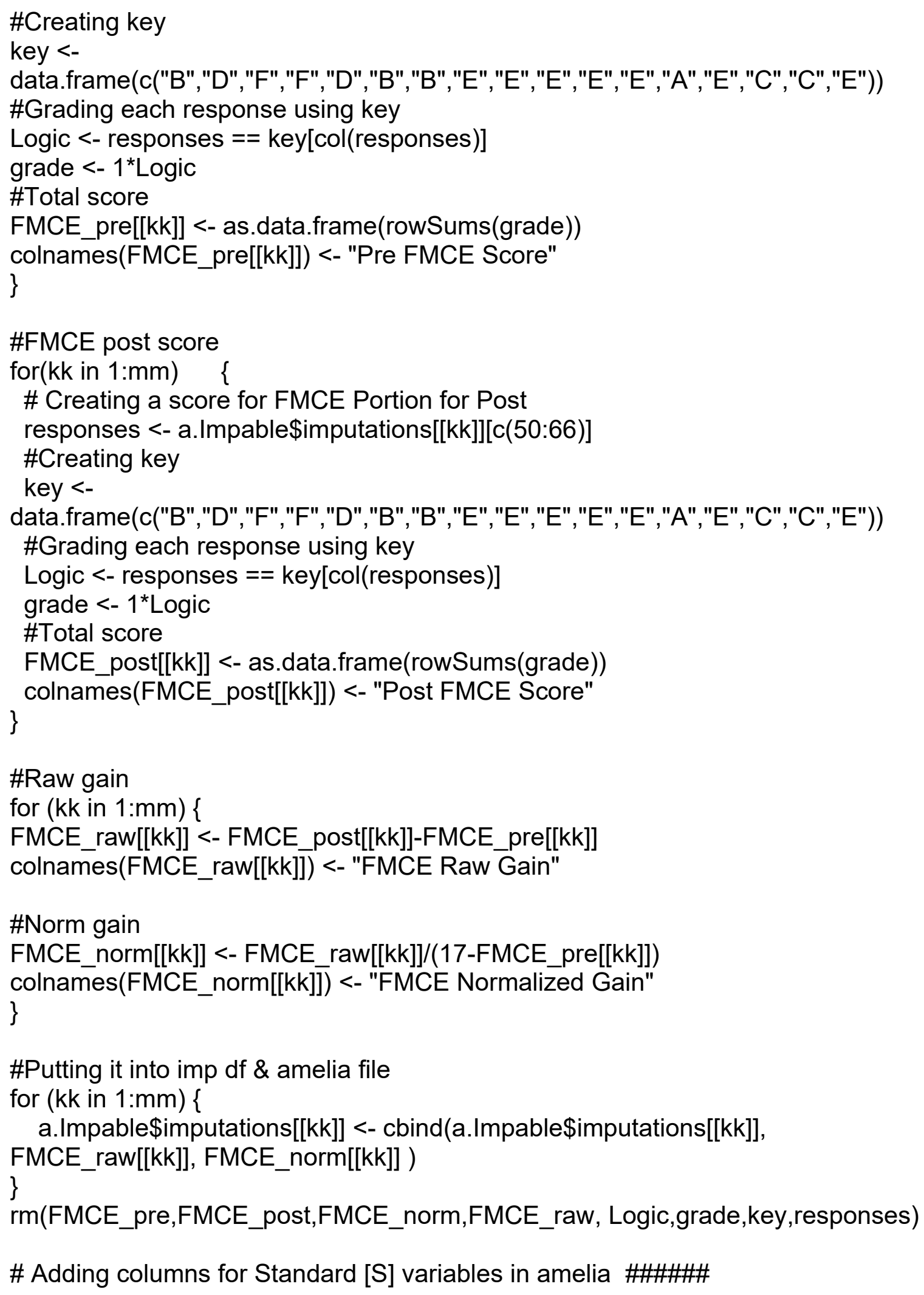


for(kk in 1:mm) \{

a.Impable\$imputations[[kk]]\$ 'S FMCE Raw Gain`<scale(a.Impable\$imputations[[kk]]\$FMCE Raw Gain`)\}

\# Linear regression for model 1 (Table 1) \#\#\#\#\#

\#FMCE Raw Gain` Q7e .86 ***

z7e1.out <- zelig('S FMCE Raw Gain` Q7e.y, model="Is", data=a.Impable) summary(z7e1.out)

\# Other simple LR models (some in Table 2) \#\#\#\#\#

\#FMCE Raw Gain` Q16a [\$\$ 4] ${ }^{\star}$

z16a1.out <- zelig('S FMCE Raw Gain` Q16a, model="Is", data=a.Impable) summary(z16a1.out)

\#FMCE Raw Gain` Q16b [\$ 4]

z16b1.out <- zelig('FMCE Raw Gain` Q16b, model="Is", data=a.Impable)

summary(z16b1.out)

\#FMCE Raw Gain` Q16c [\$ 4]

z16c1.out <- zelig('S FMCE Raw Gain` Q16c, model="Is", data=a.Impable)

summary(z16c1.out)

\#FMCE Raw Gain` Q16e [\$ 2, \$ 4]

z16e1.out <- zelig('S FMCE Raw Gain` Q16e, model="Is", data=a.Impable)

summary(z16e1.out)

\#FMCE Raw Gain` Q16h [\$ 3, \$ 4]

z16h1.out <- zelig(`S FMCE Raw Gain` Q16h, model="Is", data=a.Impable) summary(z16h1.out)

\#FMCE Raw Gain` Q16i [\$\$ 4]

z16i1.out <- zelig('S FMCE Raw Gain` Q16i, model="Is", data=a.Impable)

summary(z16i1.out)

\# More complex linear regression models \#\#\#\#

z_Im1.out <- zelig('S FMCE Raw Gain Q7e.y + Q16c, model="Is", data=a.Impable)

summary(z_Im1.out)

z_Im2.out <- zelig('S FMCE Raw Gain` Q7e.y + Q16e , model="Is", data=a.Impable) summary(z_Im2.out) 


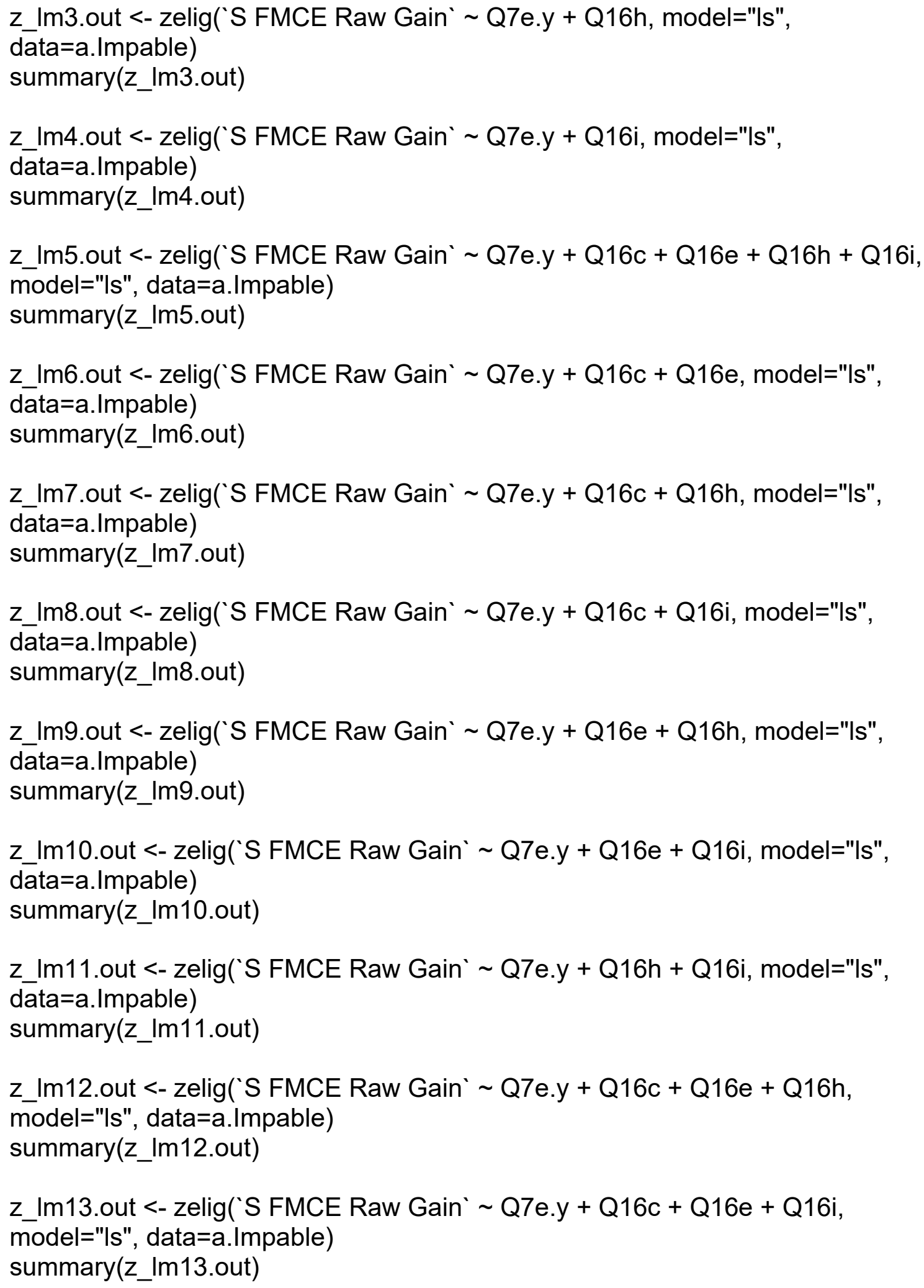




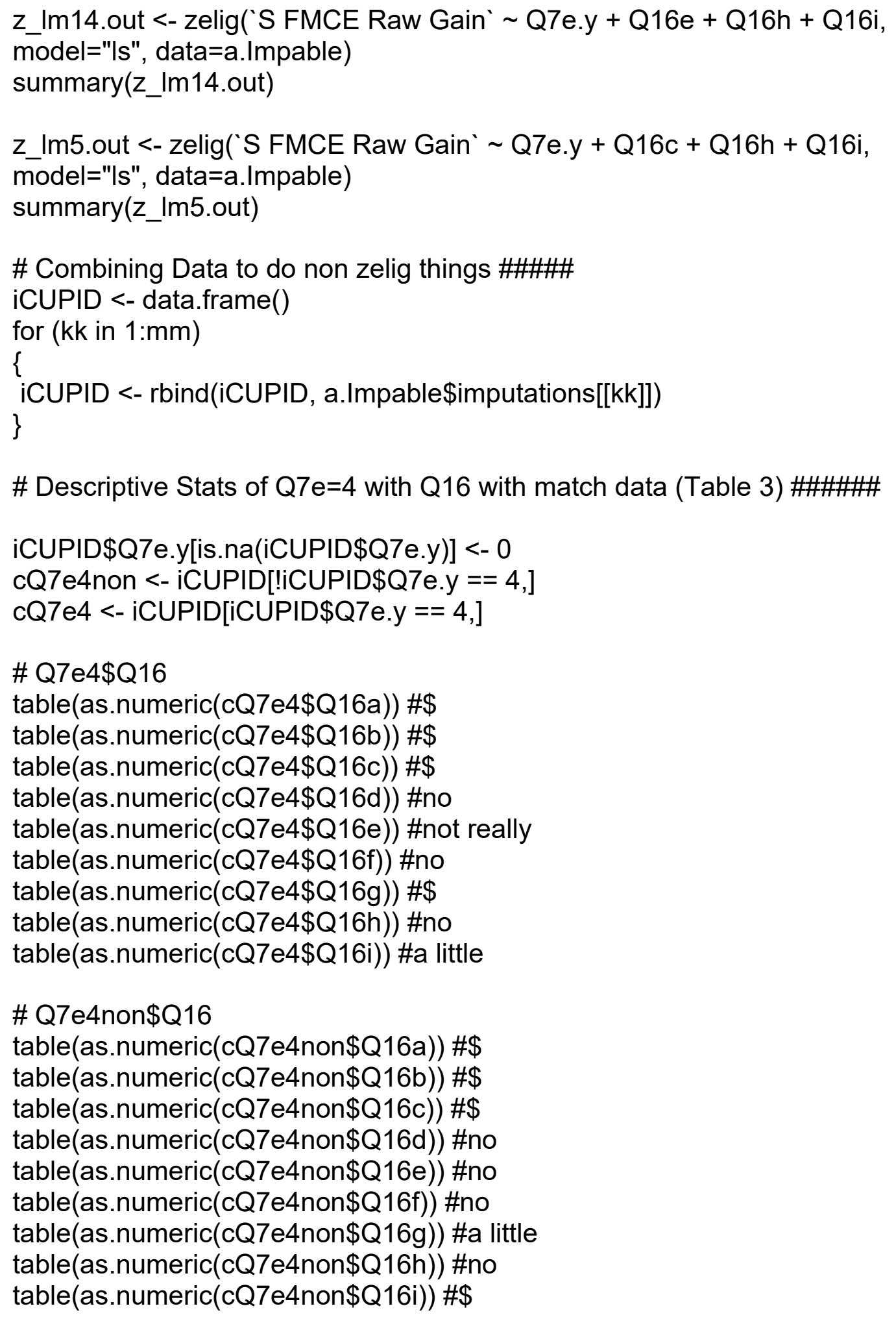




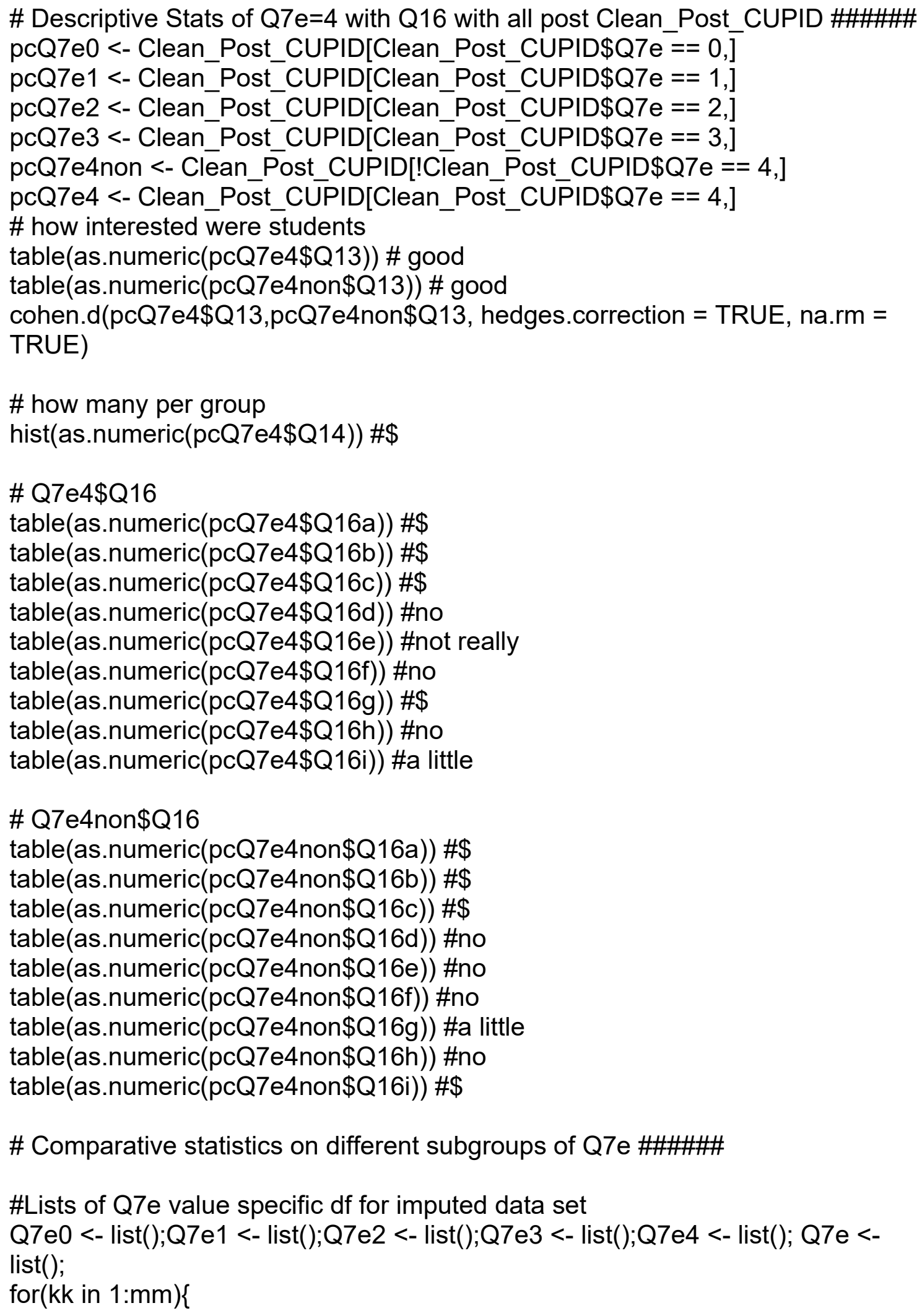


Q7e0[[kk]] <- a.Impable\$imputations[[kk]][a.Impable\$imputations[[kk]]\$Q7e.y == 0$,

Q7e1[[kk]] <- a.Impable\$imputations[[kk]][a.Impable\$imputations[[kk]]\$Q7e.y == 1$,

Q7e2[[kk]] <- a.Impable\$imputations[[kk]][a.Impable\$imputations[[kk]]\$Q7e.y == 2,]

Q7e3[[kk]] <- a.Impable\$imputations[[kk]][a.Impable\$imputations[[kk]]\$Q7e.y == 3,]

Q7e4[[kk]] <- a.Impable\$imputations[[kk]][a.Impable\$imputations[[kk]]\$Q7e.y == 4,]

\}

\# generating matrix that describes gain in each PI question for each subgroup of Q7

avg_Q7e.PI <- data.frame(); calc <- data.frame(); ii <- 1:1000 for(ii in 1:16)\{

for(kk in 1:5) \{

for(jj in 1:mm)\{

calc[kk,j]] <- as.numeric(Q7e0[[kk]][[j]][ii+16])- as.numeric(Q7e0[[kk]][[j]]][ii]) \# calc[kk,] \#for each question in Pl's gain

\}

avg_Q7e.PI[kk,ii] <- rowMeans(calc[kk,])

\}\}

\# generating matrix that describes gain in each Q16 for each subgroup of Q7 avg_Q7e.Q16 <- data.frame()

for(ii in 72:82)\{ for(kk in 1:5) \{

for(jj in $1: \mathrm{mm})\{$

calc[kk,jj] <- as.numeric(Q7e0[[kk]][[j]]][ii])

\# calc[kk,] \#for PI_diff and Q18,Q21

\}

avg_Q7e.Q16[kk,ii-71] <- rowMeans (calc[kk,])

\})

\# generating matrix that describes gain in each Q16 for each subgroup of Q7 avg_Q7e.Q18<- data.frame()

for(ii in 83:91)\{

for(kk in 1:5) \{

for(jj in 1:mm)\{

calc[kk,jj] <- as.numeric(Q7e0[[kk]][[j]]][ii])

\# calc[kk,] \#for PI_diff and Q18,Q21

\}

avg_Q7e.Q18[kk,ii-82] <- rowMeans(calc[kk,]) 


\section{\}\}}

\# generating matrix that describes raw fmce gain for each subgroup of Q7

avg_Q7e.fmce <- data.frame()

for $(k k$ in 1:5) \{

for(jj in $1: \mathrm{mm})\{$

calc[kk,j]] <- as.numeric(Q7e0[[kk]][[jj]])

\# calc[kk,] \#for PI_diff and Q18,Q21

\}

\}

avg_Q7e.Q18[kk,ii-82] <- rowMeans $($ calc[kk,])

\# Hedges g test of groups vs non groups (everyday)\$\#\#\#\#

cohen.d(cQ7e4\$'FMCE Raw Gain',cQ7e4non\$”FMCE Raw

Gain', hedges.correction = TRUE )

cohen.d(cQ7e4\$,cQ7e4non\$`FMCE Raw Gain`,hedges.correction = TRUE )

rm(group,ngroup)

\# Density histograms and density plots of groups to non groups \#\#\#\#

table(cQ7e4non\$'FMCE Raw Gain')

table(cQ7e4\$'FMCE Raw Gain`)

\#histograms by percent

DF <- rbind(data.frame(fill="red", obs=cQ7e4non\$'FMCE Raw Gain'), data.frame(fill="blue", obs=cQ7e4\$”FMCE Raw Gain`))

\# using fill to show proportion of percentage

$\operatorname{ggplot}(D F$, aes $(x=$ obs, fill=fill $))+$

geom_histogram(aes(y=..density..), binwidth=1, colour="black", position="fill") + scale_fill_identity()

\# using dodge to show density changes

ggplot(DF, aes $(x=$ obs, fill=fill $))+$

geom_histogram(aes(y=..density..), binwidth=1, colour="black",

position="dodge") +

scale_fill_identity () + ggtitle("Comparison of FMCE scores by Density") +

xlab("Pre to Post Raw FMCE Gain") + ylab("Fraction of Students (\%)")

\#histograms of question 16 (just change letter for DF16 to get each one)

\#Q16(LETTER)

DF16 <- rbind(data.frame(color="red", obs=as.numeric(cQ7e4non\$Q16a)), data.frame(color="blue", obs=as.numeric(cQ7e4\$Q16a)))

ggplot(DF16, aes(x=obs, fill=color) $)+$ geom_histogram(aes(y=..density..),

binwidth=1, colour="black", position=position_dodge(.9)) + scale_fill_identity ()$+$ 
ggtitle("Q16a (You worked at tables?)") + xlab("Frequency") + ylab("Fraction of Students (\%)")

\#Post Analysis, checking just post surveys (August 2019)

responses_po <- Clean_Post_CUPID[,184:200]

\#Creating key

key <-

data.frame(c("B","D","F","F","D","B","B","E","E","E","E","E","A","E","C","C","E"))

\#Grading each response using key

Logic3 <-responses_po $==$ key[col(responses_po)]

grade_po $<-1^{*}$ Logic3

\#Total score

FMCE_post_only <- as.data.frame(rowSums(grade_po))

colnames(FM̄CE_post_only) <- "Post FMCE Score"

Clean_Post_CUPID <- cbind(Clean_Post_CUPID, FMCE_post_only)

Im1 <- Im(Clean_Post_CUPID\$'Post FMCE Score` Clean_Post_CUPID\$Q7a) summary(Im1) \#not significant..

\# Wilcox tests for question 16 post CUPID \#\#\#\#\#

icQ7e <- list(); icQ7enon <- list()

for $(k k$ in $1: 20)$

\{

icQ7enon[[kk]] <- a.Impable\$imputations[[kk]][a.Impable\$imputations[[kk]]\$Q7e.y $==4$,]

icQ7e[[kk]] <- a.Impable\$imputations[[kk]][!a.Impable\$imputations[[kk]]\$Q7e.y == 4,]

\}

View(icQ7e[1])

wila <- vector(); wilb <- vector(); wilc <- vector(); wild <- vector(); wilf <- vector(); wilg $<-$ vector();wilh <- vector(); wile <- vector(); wili <- vector()

for (ii in 1:20)

\{

wila[[ii]] <- wilcox.test(as.numeric(icQ7e[[ii]]\$Q16a), as.numeric(icQ7enon[[ii]] \$Q16a))\$p.value wilb[[ii]] <- wilcox.test(as.numeric(icQ7e[[ii]]\$Q16b), as.numeric(icQ7enon[[ii]] \$Q16b))\$p.value

wilc[[ii]] <- wilcox.test(as.numeric(icQ7e[[ii]]\$Q16c), as.numeric(icQ7enon[[ii]] \$Q16c))\$p.value wild[[ii]] <- wilcox.test(as.numeric(icQ7e[[ii]]\$Q16d), as.numeric(icQ7enon[[ii]] 
\$Q16d))\$p.value

wile[[ii]] <- wilcox.test(as.numeric(icQ7e[[ii]]\$Q16e), as.numeric(icQ7enon[[ii]] \$Q16e))\$p.value

wilf[[ii]] <- wilcox.test(as.numeric(icQ7e[[ii]]\$Q16f), as.numeric(icQ7enon[[ii]] \$Q16f))\$p.value

wilg[[ii]] <- wilcox.test(as.numeric(icQ7e[[ii]]\$Q16g), as.numeric(icQ7enon[[ii]] \$Q16g))\$p.value

wilh[[ii]] <- wilcox.test(as.numeric(icQ7e[[ii]]\$Q16h), as.numeric(icQ7enon[[ii]] \$Q16h))\$p.value

wili[iii]] <- wilcox.test(as.numeric(icQ7e[[ii]]\$Q16i), as.numeric(icQ7enon[[ii]]

\$Q16i))\$p.value

\}

wilcoxon <- cbind(wila, wilb, wilc, wild, wile, wilf, wilg, wilh, wili)

\# Extracted the wilcoxon $p$ values for all results

\#write.csv(wilcoxon, " /PER/Projects/1- Frequent group learning leads to improved learning/Work on CUPID/wilcoxon.csv") 


\title{
Appendix 5: The $\mathbf{R}$ code for chapter 4 analysis
}

\author{
\# Header \#\#\#\#\# \\ library("effsize") \\ library("readr") \\ library("Amelia") \\ library("Zelig")
}

\# Loading in Data \#\#\#\#\#

\#Import the csv file

\# Pre survey Data collected 8 29

Pre_Survey_data <-read_csv(" $/$ PER/Projects/2,3 - Modeling through SIT lens and $a$ few other constructs related to it then effect on learning/Fall 18/Survey Data/Pre Survey 8-28-18 data.csv")

\#Survey from first group 822 collected on 96

Survey_2 <-read_csv(" $/$ PER/Projects/2,3 - Modeling through SIT lens and a few other constructs related to it then effect on learning/Fall 18/Survey Data/Survey 2 8-22-18 data.csv")

\#Survey of second group 944 collected on 9 18

Survey_3 <-read_csv(" $/$ PER/Projects/2,3 - Modeling through SIT lens and a few other constructs related to it then effect on learning/Fall 18/Survey Data/Survey 3 9-4-18 data.csv")

\#Survey of third group 9_18 collected on 10_9

Survey_4 <-read_csv(" $\sim /$ PER/Projects/2,3 - Modeling through SIT lens and a few other constructs related to it then effect on learning/Fall 18/Survey Data/Survey 4 9-18-18 data.csv")

\#Survey of forth group 10_2 collected on 10_23 o 10_25

Survey_5 <-read_csv(" $/$ PER/Projects/2,3 - Modeling through SIT lens and a few other constructs related to it then effect on learning/Fall 18/Survey Data/Survey 5 10-2-18 data.csv")

\#Survey of fifth group 10_23 collected on 11/15

Survey_6 <- read_csv(" /PER/Projects/2,3 - Modeling through SIT lens and a few other constructs related to it then effect on learning/Fall 18/Survey Data/Survey 6 10-23-18 data.csv")

\#Survey of sixth group 11/13 collected on last week

Survey_7 <-read_csv(" /PER/Projects/2,3 - Modeling through SIT lens and a few other constructs related to it then effect on learning/Fall 18/Survey 
\# Post survey Data collected on last week

Post_Survey_data <- read_csv(" /PER/Projects/2,3 - Modeling through SIT lens and $a$ few other constructs related to it then effect on learning/Fall 18/Survey Data/Post Survey 11-27-18 data.csv")

Pre_PI <- read_csv(" /PER/Projects/2,3 - Modeling through SIT lens and a few other constructs related to it then effect on learning/Fall 18/Survey Data/Pre PI Fall 18 data.csv")

Post_PI <- read_csv(" /PER/Projects/2,3 - Modeling through SIT lens and a few other constructs related to it then effect on learning/Fall 18/Survey Data/Post PI Fall 18 data.csv")

Pre_FMCE <- read_csv(" /PER/Projects/2,3 - Modeling through SIT lens and a few other constructs related to it then effect on learning/Fall 18/Survey Data/PRE_FMCE.csv") \#Already calculated

Post_FMCE <- read_csv(" /PER/Projects/2,3 - Modeling through SIT lens and a few other constructs related to it then effect on learning/Fall 18/Survey Data/POST_FMCE.csv") \#Already calculated

\#Moving data to new dataframe

data1 <- Pre_Survey_data

data2 <- Survey_2

data3 <- Survey_3

data4 <- Survey_4

data5 <- Survey_5

data6 $<$ - Survey_6

data7 <- Survey_ 7

data8 <- Post_Survey_data

rm(Pre_Survey_data,Survey_2,Survey_3,Survey_4,Survey_5,Survey_6,Survey_ 7, Post_Survey_data)

\#check for total missingness

raw_data <- merge(data1, data2, by = "Panther_ID")

raw_data <- merge(raw_data, data3, by = "Panther_ID")

raw_data <- merge(raw_data, data4, by = "Panther_ID")

raw_data <- merge(raw_data, data5, by = "Panther_ID")

raw_data <- merge(raw_data, data6, by = "Panther_ID")

raw_data <- merge(raw_data, data7, by = "Panther_ID")

raw_data <- merge(raw_data, data8, by = "Panther_ID") 
View(raw_data)

Amelia::missmap(raw_data) \#missingness is $16 \%$

rm(raw_data)

\#\# Organizing all the data \#\#\#\#\#

\#Creating sub matrices for each construct Survey 1 (Pre Survey)

ID <- data1[,2]

SIT_predictions1 <- data1 [c(3:9,13:15,18:24)]

Complete_scales1 <- data1[c(3:26)]

\#Scores for coop, Independence and dominance S2

pre_coop_score <- as.data.frame(rowSums(data1[c(3:9)]))/42 \#normalized with 42

pre_ind_score <- as.data.frame(rowSums(data1[c(13:15,18:24)]))/60

\#normalized with 60

names(pre_coop_score) <- "Pre_coop_score"

names(pre_ind_score) $<-$ "Pre_ind_score"

\#Scores for PI

pre_PI_self <- (Pre_PI\$Q7)/6 \#see yourself as a physics person

pre_PI_reco <- (Pre_PI\$Q5+Pre_PI\$Q6+Pre_PI\$Q8)/18 \#all the recognitions put together

pre_PI_int <-

(Pre_PI\$Q2a+Pre_PI\$Q2b+Pre_PI\$Q2c+Pre_PI\$Q2d+Pre_PI\$Q2e+Pre_PI\$Q2f

)/36 \#all the int questions

pre_PI_comp <-

(Pre_PI\$Q9a+Pre_PI\$Q9b+Pre_PI\$Q9c+Pre_PI\$Q9d+Pre_PI\$Q9e+Pre_PI\$Q9f + Pre_PI\$Q9g+Pre_PI\$Q9h+Pre_PI\$Q9i+Pre_PI\$Q9j)/60 \#all the comp questions

\#combining into new data

new_data1 <- cbind(ID, pre_coop_score, pre_ind_score, Pre_FMCE $\$$ 'Pre FMCE Score',pre_PI_self,pre_PI_reco,pre_PI_int,pre_PI_comp)

colnames(new_data1)[4] <- "Pre_FM̄ $\bar{C}$ E__Score"

rm(ID, pre_coop_score,

pre_ind_score,pre_PI_self,pre_PI_reco,pre_PI_int,pre_PI_comp)

\# Survey 2 (post for $8 \_22$ groups)

\#Creating sub matrices for Survey 2

measured_si_2 <- data2[,3:14]

task_si_2 $<-$ data2[,3:8]

initiated_si_2 <- data2[,3:5] 
recieved_si_2 <- data2[,6:8]

outcome_si_2 <- data2[,9:14]

\#Scores for initiated, received and outcomes si

ini_score_2 <- as.data.frame(rowSums(initiated_si_2)/18)

rec_score_2 <- as.data.frame(rowSums(recieved_si_2)/18)

out_score_2 <- as.data.frame(rowSums(outcome_si_2)/36)

names(ini_score_2) <- "Initialized_si_1"

names(rec_score_2) <- "Recieved_si_1"

names(out_score_2) <- "Outcome_si_1"

\#combining into new data

new_data2 <- cbind(data2[,2], ini_score_2,rec_score_2,out_score_2)

rm(ini_score_2, rec_score_2,out_score_2, measured_si_2, initiated_si_2,

recieved_si_2, task_si_2, outcome_si_2)

\#Survey 3 (post for 9_4 groups)

\#Creating sub matrices for Survey 3

measured_si_3 <- data3[,3:14]

task_si_3 $<-$ data3[,3:8]

initiated_si_3 <- data3[,3:5]

recieved_si_3 $<-$ data3[,6:8]

outcome_si_3 <- data3[,9:14]

\#Scores for initiated, received and outcomes si

ini_score_3 <- as.data.frame(rowSums(initiated_si_3)/18)

rec_score_3 <- as.data.frame(rowSums(recieved_si_3)/18)

out_score_3 <- as.data.frame(rowSums(outcome_si_3)/36)

names(ini_score_3) <- "Initialized_si_2"

names(rec_score_3) <- "Recieved_si_2"

names(out_score_3) <- "Outcome_si_2"

\#combining into new data

new_data3 <- cbind(data3[,2], ini_score_3,rec_score_3,out_score_3)

rm(ini_score_3, rec_score_3,out_score_3, measured_si_3, initiated_si_3, recieved_si_3, task_si_3, outcome_si_3)

\#Survey 4 (post for 9_18 groups)

\#Creating sub matrices for Survey 4

measured_si_4 <- data4[,3:14]

task_si_4 $<-$ data4[,3:8]

initiated_si_4 <- data4[,3:5] 
recieved_si_4 <- data4[,6:8]

outcome_si_4 <- data4[,9:14]

\#Scores for initiated, received and outcomes si

ini_score_4 <- as.data.frame(rowSums(initiated_si_4)/18)

rec_score_4 <- as.data.frame(rowSums(recieved_si_4)/18)

out_score_4 <- as.data.frame(rowSums(outcome_si_4)/36)

names(ini_score_4) <- "Initialized_si_3"

names(rec_score_4) <- "Recieved_si_3"

names(out_score_4) <- "Outcome_si_3"

\#combining into new data

new_data4 <- cbind(data4[,2], ini_score_4,rec_score_4,out_score_4)

rm(ini_score_4, rec_score_4,out_score_4, measured_si_4, initiated_si_4, recieved_si_4, task_si_4, outcome_si_4)

\#Survey 5 (post for groups 10/2)

\#Creating sub matrices for Survey 5

measured_si_5 <- data5[,3:14]

task_si_5 $<-$ data5[,3:8]

initiated_si_5 <- data5[,3:5]

recieved_si_5 $<-$ data5[,6:8]

outcome_si_5 <- data5[,9:14]

\#Scores for initiated, received and outcomes si

ini_score_5 <- as.data.frame(rowSums(initiated_si_5)/18)

rec_score_5 <- as.data.frame(rowSums(recieved_si_5)/18)

out_score_5 <- as.data.frame(rowSums(outcome_si_5)/36)

names(ini_score_5) <- "Initialized_si_4"

names(rec_score_5) <- "Recieved_si_4"

names(out_score_5) <- "Outcome_si_4"

\#combining into new data

new_data5 <- cbind(data5[,2], ini_score_5,rec_score_5,out_score_5)

rm(ini_score_5, rec_score_5,out_score_5, measured_si_5, initiated_si_5, recieved_si_5, task_si_5, outcome_si_5)

\#Survey 6 (post for groups 10/23)

\#Creating sub matrices for Survey 6

measured_si_6 <- data6[,3:14]

task_si_6 $<-$ data6[,3:8]

initiated_si_6 <- data6[,3:5] 
recieved_si_6 <- data6[,6:8]

outcome_si_6 <- data6[,9:14]

\#Scores for initiated, received and outcomes si

ini_score_6 <- as.data.frame(rowSums(initiated_si_6)/18)

rec_score_6 <- as.data.frame(rowSums(recieved_si_6)/18)

out_score_6 <- as.data.frame(rowSums(outcome_si_6)/36)

names(ini_score_6) <- "Initialized_si_5"

names(rec_score_6) <- "Recieved_si_5"

names(out_score_6) <- "Outcome_si_5"

\#combining into new data

new_data6 <- cbind(data6[,2], ini_score_6,rec_score_6,out_score_6)

rm(ini_score_6, rec_score_6,out_score_6, measured_si_6, initiated_si_6,

recieved_si_6, task_si_6, outcome_si_6)

\#Survey 7 (post for groups 11/13)

\#Creating sub matrices for Survey 7

measured_si_7 <- data7[,3:14]

task_si $7 \quad<-$ data7[,3:8]

initiated_si_7 <- data7[,3:5]

recieved_si_7 <- data7[,6:8]

outcome_si_7 <- data7[,9:14]

\#Scores for initiated, received and outcomes si

ini_score_7 <- as.data.frame(rowSums(initiated_si_7)/18)

rec_score_7 <- as.data.frame(rowSums(recieved_si_ 7)/18)

out_score_7 <- as.data.frame(rowSums(outcome_si_7)/36)

names(ini_score_7) <- "Initialized_si_6"

names(rec_score_7) <- "Recieved_si_6"

names(out_score_7) <- "Outcome_si_6"

\#combining into new data

new_data7 <- cbind(data7[,2], ini_score_7,rec_score_7,out_score_7)

rm(ini_score_7, rec_score_7,out_score_7, measured_si_7, initiated_si_7, recieved_si_7, task_si_7, outcome_si_7)

\#Creating sub matrices for each construct Survey 8 (Post Survey)

ID <- data8[,2]

SIT_predictions2 <- data8[c(3:9,13:15,18:24)]

Complete_scales $2<-$ data8[c(3:26)]

\#Scores for coop, Independence and dominance S2

post_coop_score <- as.data.frame(rowSums(data8[c(3:9)]))/42 \#normalized with 
42

post_ind_score <- as.data.frame(rowSums(data8[c(13:15,18:24)]))/60

\#normalized with 60

names(post_coop_score) <- "Post_coop_score"

names(post_ind_score) <- "Post_ind_score"

\#Post Physics Identity Normalized Scores

Post_PI_self <- (Post_PI\$Q7)/6 \#see yourself as a physics person

Post_PI_reco <- (Post_PI\$Q5+Post_PI\$Q6+Post_PI\$Q8)/18 \#all the recognitions put together

Post_PI_int <-

(Post_PI\$Q2a+Post_PI\$Q2b+Post_PI\$Q2c+Post_PI\$Q2d+Post_PI\$Q2e+Post_ $P(\$ Q \overline{2 f}) / 36$ \#all the interest questions

Post_PI_comp <-

(Post_PI\$Q9a+Post_PI\$Q9b+Post_PI\$Q9c+Post_PI\$Q9d+Post_PI\$Q9e+Post

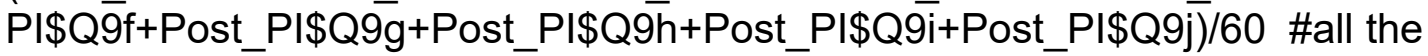
comp/perf questions

\#combining into new data

new_data8 <- cbind(ID, post_coop_score, post_ind_score,Post_FMCE\$Post

FMCE Score',Post_PI_self,Post_PI_reco,Post_PI_int,Post_PI_comp)

colnames(new_data8)[4] <- "Post_FMCE_Score"

rm(ID,Post_PI_self,Post_PI_reco,Post_PI_int,Post_PI_comp)

\section{\# EFAs \#\#\#\#\#}

\# FA of final original scales I used on survey - Not used, but explained

print(factanal(na.omit(Complete_scales 1$)$, 3, rotation = "promax"), cutoff=0.4)

\# FA of final items I used for coop and ind scores - Table 4

print(factanal(na.omit(SIT_predictions1), 2, rotation = "promax"), cutoff=0.4)

\# Factor Analysis of measured si - Table 6

print(factanal(na.omit(measured_si 2),3, rotation = "promax"), cutoff $=0.4$ )

print(factanal(na.omit(measured_si_3),3, rotation = "promax"), cutoff $=0.4$ )

print(factanal(na.omit(measured_si_4),3, rotation = "promax"), cutoff=0.4)

print(factanal(na.omit(measured_si_5),3, rotation = "promax"), cutoff=0.4)

print(factanal(na.omit(measured_si_6),3, rotation = "promax"), cutoff=0.4)

print(factanal(na.omit(measured_si_7),3, rotation = "promax"), cutoff=0.4)

\# Factor Analysis of CATME \#Not used in dissertation because they did not load consistently

print(factanal(na.omit(CATME_2),1, rotation = "promax"), cutoff=0.4) 
print (factanal(na.omit(CATME_3),2, rotation = "promax"), cutoff=0.4) print(factanal(na.omit(CATME_4), 1, rotation = "promax"), cutoff=0.4) print(factanal(na.omit(CATME_5), 1, rotation = "promax"), cutoff=0.4) print(factanal(na.omit(CATME_6), 1 , rotation = "promax"), cutoff=0.4) print(factanal(na.omit(CATME_7),1, rotation = "promax"), cutoff=0.4)

\#Friends made in comparison to other classes effsize::cohen.d(data8\$Friend_in, data8\$Friend_out, na.rm = TRUE) \# Friends made from beginning to end effsize::cohen.d(data1\$Friend_in, data8\$Friend_in, na.rm = TRUE) \# Cooperation beliefs from beginning to end effsize::cohen.d(new_data1\$Pre_coop_score, new_data8\$Post_coop_score, na.rm = TRUE)

\# Individualism beliefs from beginning to end effsize::cohen.d(new_data1\$Pre_ind_score, new_data8\$Post_ind_score, na.rm $=$ TRUE)

\#Combine common datasets \#\#\#

\#horizontally (Wide) with everything in it all data <- merge (new data1, new data2, by= "Panther ID") all_data <- merge(all_data, new_data3, by = "Panther_ID") all_data <- merge(all_data, new_data4, by = "Panther_ID") all_data <- merge(all_data, new_data5, by = "Panther_ID") all_data <- merge(all_data, new_data6, by = "Panther_ID") all_data <- merge(all_data, new_data7, by = "Panther_ID") all_data <- merge(all_data, new_data8, by = "Panther_ID")

View(all_data)

\#colMeans(na.omit(all_data[c(29:40)]))

\section{\#Imputation \#\#\#\#\#}

\#Reducing to variables Im interested in since I got error 34 in Amelia Impable_pre <- all_data[c(1:8)] \#4 is pre FMCE Impable_post <- all_data[c(1,27:33)] \#29 is post FMCE Impable_soin <- all_data[c $(1,9: 26)]$

\#Imputing $\mathrm{mm}=20$

a.pre <- Amelia::amelia(Impable_pre, idvars = "Panther_ID", $\mathrm{m}=\mathrm{mm}$ ) a.post <- Amelia::amelia(Impable_post, idvars = "Panther_ID", $\mathrm{m}=\mathrm{mm}$ ) a.soin <- Amelia::amelia(Impable_soin, idvars = "Panther_ID", $m=m m$ ) 


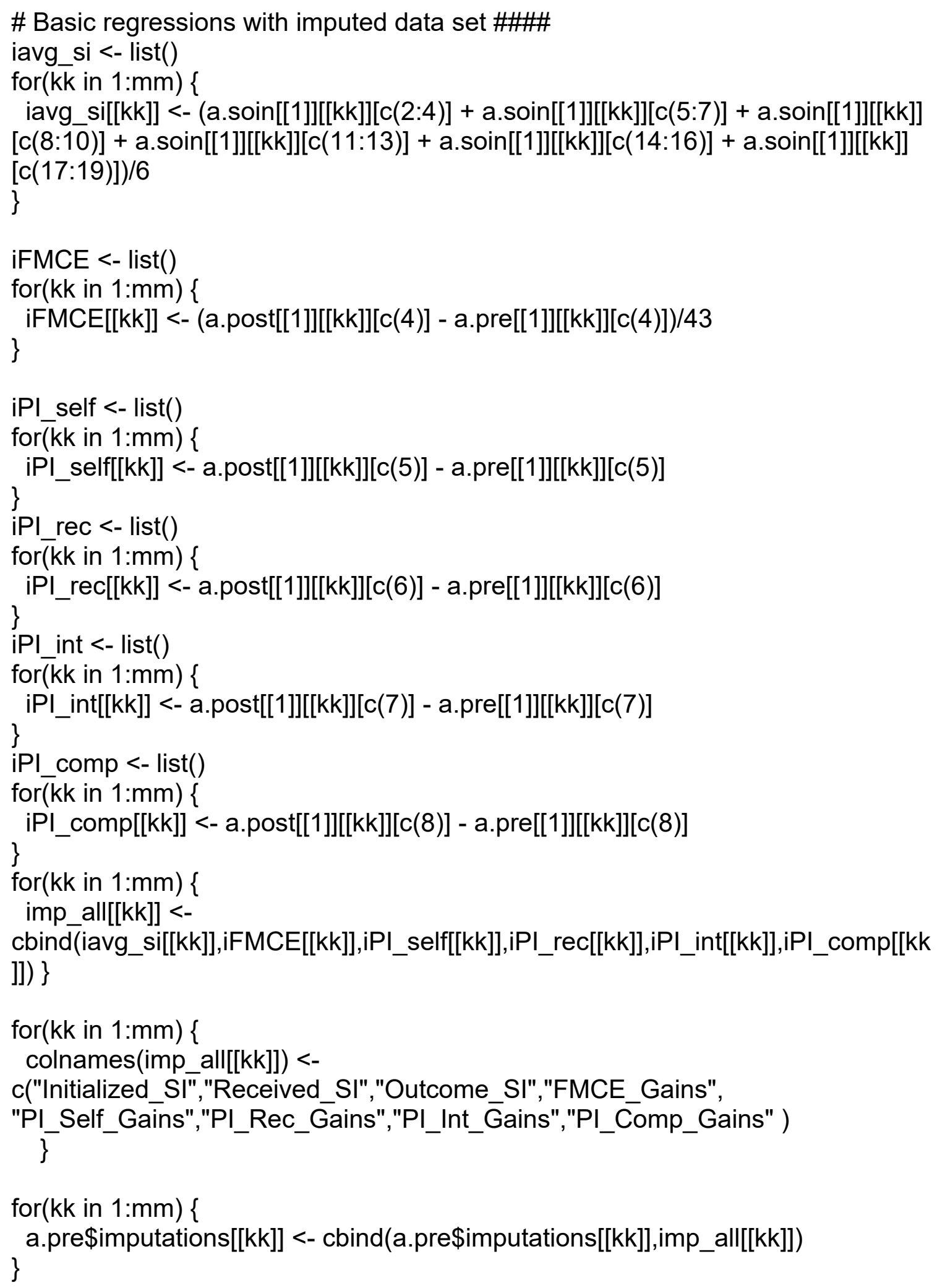


\#Recognition increases with initialized SI - Table 7 z1a.out <- zelig(PI_Rec_Gains Initialized_SI, data=a.pre, model="Is") summary(z1a.out) \#significant

\#Extending recognition model \#Did not add anything z1aa.out <- zelig(PI_Rec_Gains Initialized_SI + Pre_coop_score, data=a.pre, model="ls")

summary(z1aa.out) \# does not add or take away anything, coop is non significant

\#Interest increases with initialized $\mathrm{SI}$ - Not used, but mentioned z1b.out <- zelig(PI_Int_Gains Initialized_SI + Pre_coop_score, data=a.pre, model="ls")

summary(z1b.out) \# a little

\#Competence/Performance increases with initialized SI - Table 8 z1c.out <- zelig(PI_Comp_Gains Initialized_SI, data=a.pre, model="Is") summary(z1c.out) \#significant

\#Extending comp model \# Did not add anything z1cc.out <- zelig(PI_Comp_Gains Initialized_SI + Pre_coop_score, data=a.pre, model="ls")

summary(z1cc.out) \# does not add or take away anything, coop is non significant

\#FMCE losses with initialized SI - Not used, but mentioned z1d.out <- zelig(FMCE_Gains Received_SI + Pre_ind_score, data=a.pre, model="ls") summary(z1d.out) \# not significant

\#FMCE losses with initialized SI and coop- Not used, but mentioned z1d.out <- zelig(FMCE_Gains Received_SI + Pre_coop_score, data=a.pre, model="ls")

summary(z1d.out) \#not significant

\#FMCE losses with initialized SI and ind - Not used, but mentioned z1d.out <- zelig(FMCE_Gains Received_SI + Pre_ind_score, data=a.pre, model="ls")

summary(z1d.out) \# not significant

\#Cooperation attitudes predict outcome interdependence - Table 9 z1e.out <- zelig(Outcome_SI Pre_coop_score, data=a.pre, model="ls") summary(z1e.out) \#significant 
Appendix 6: Sample of Observation codes for chapter 6 Group A on Day 2 from 8 - 37 minutes

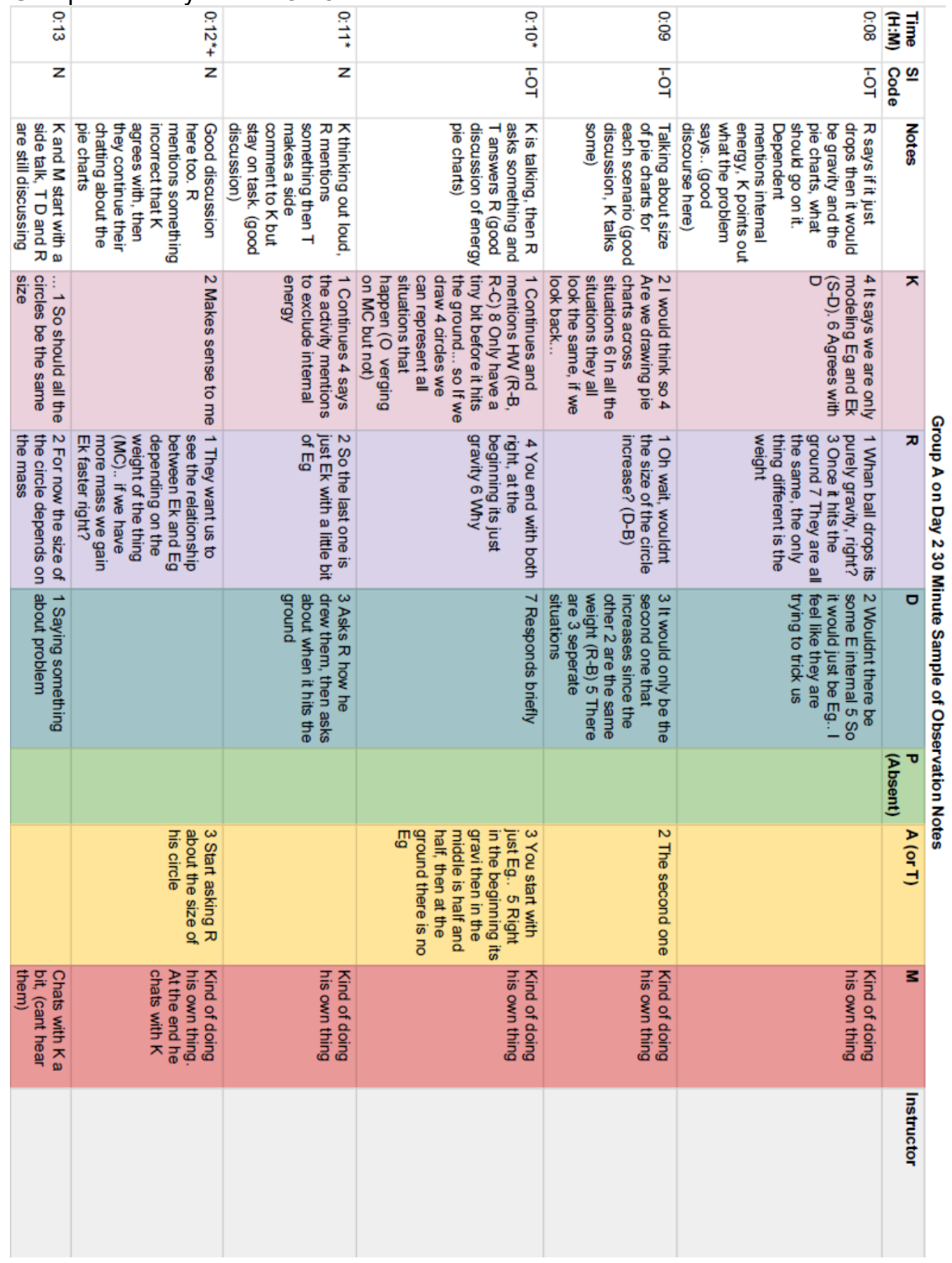




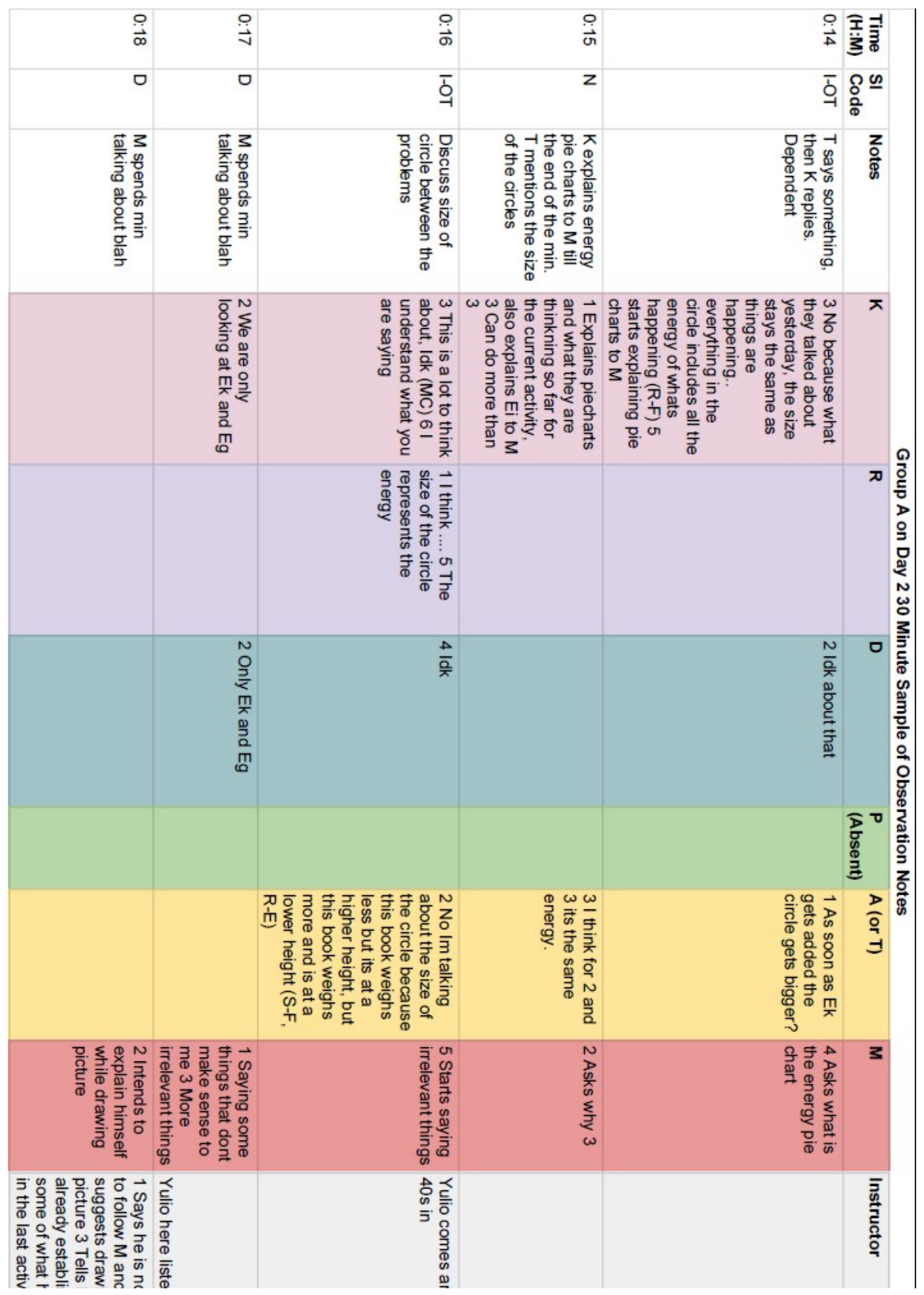




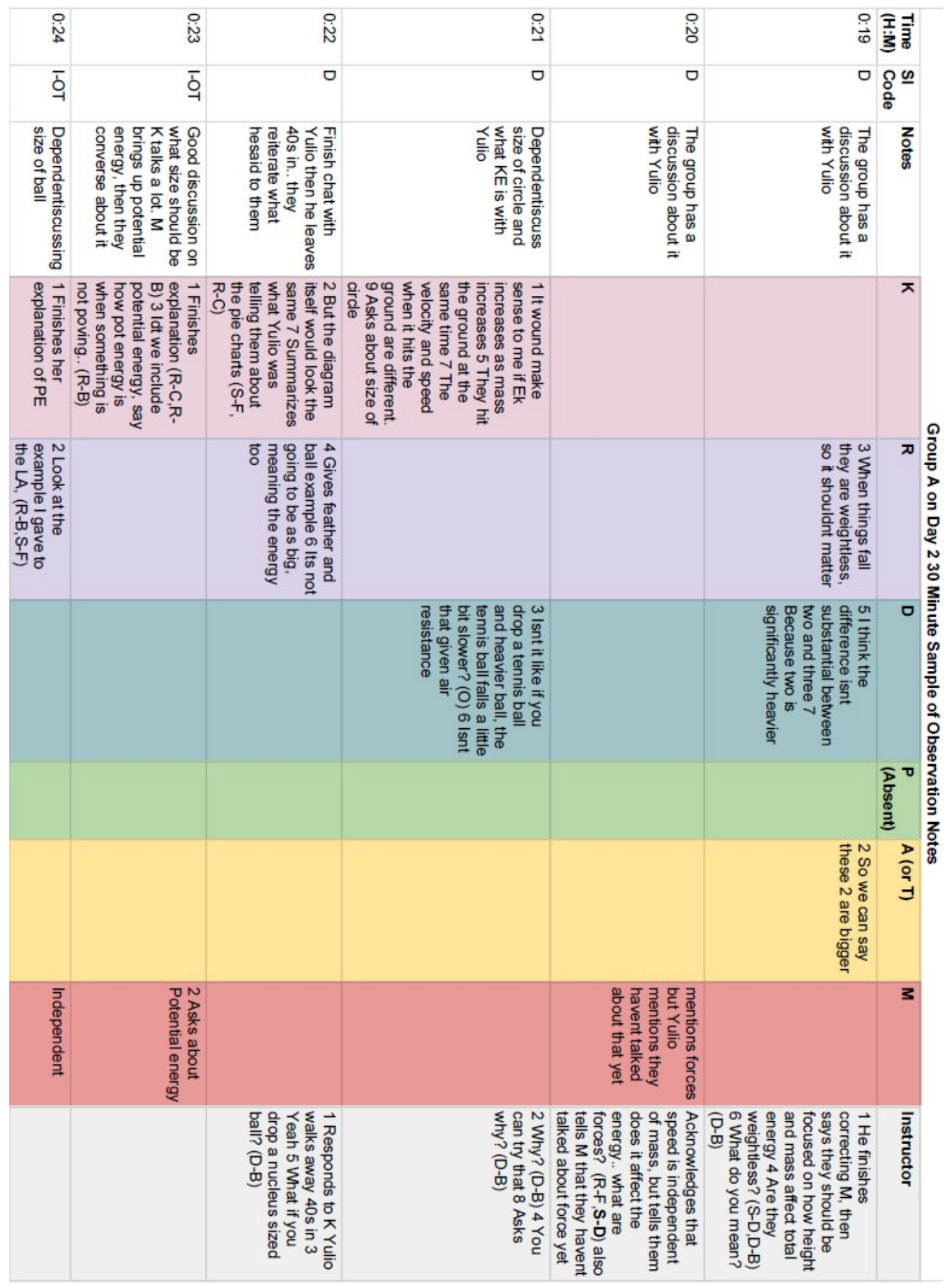




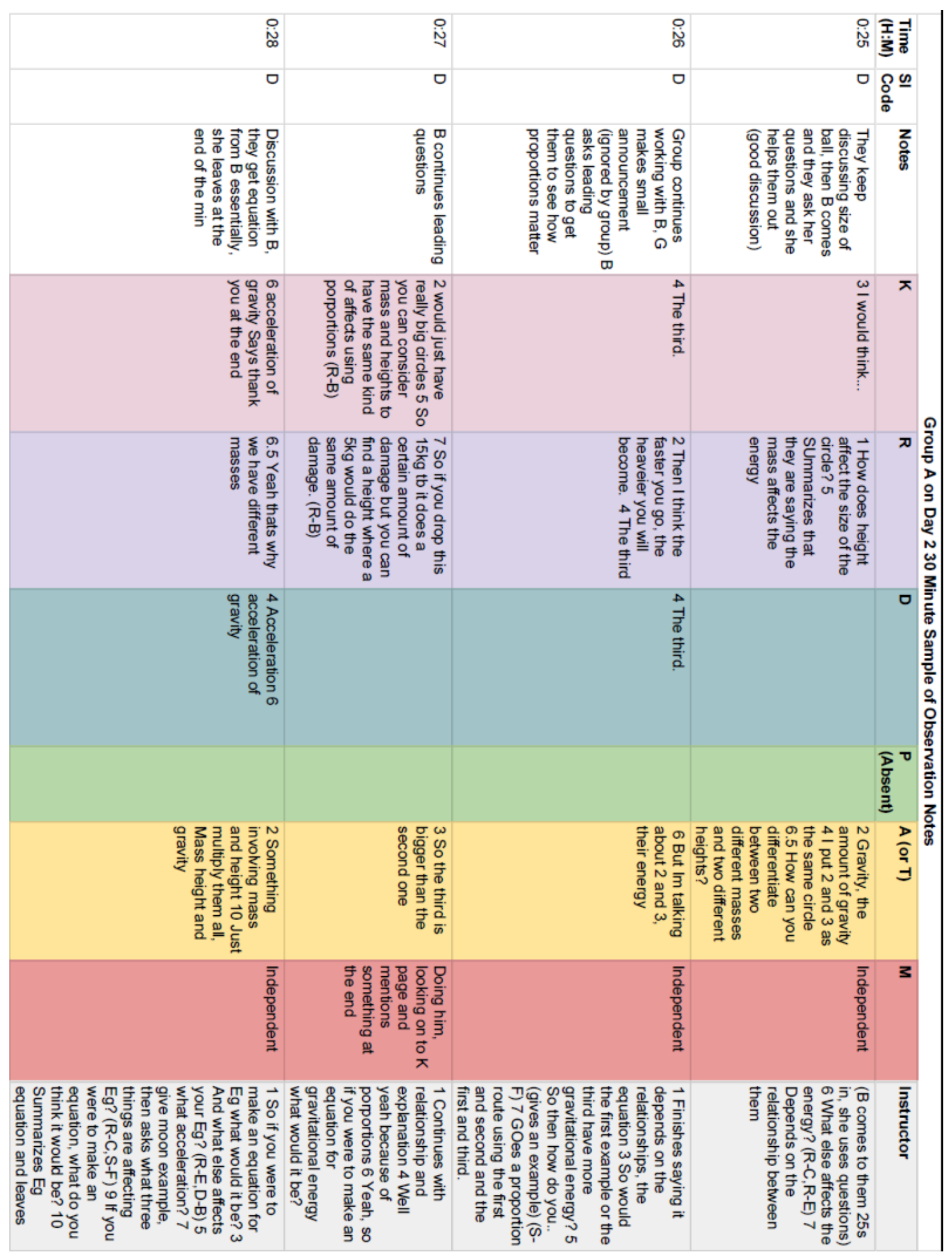




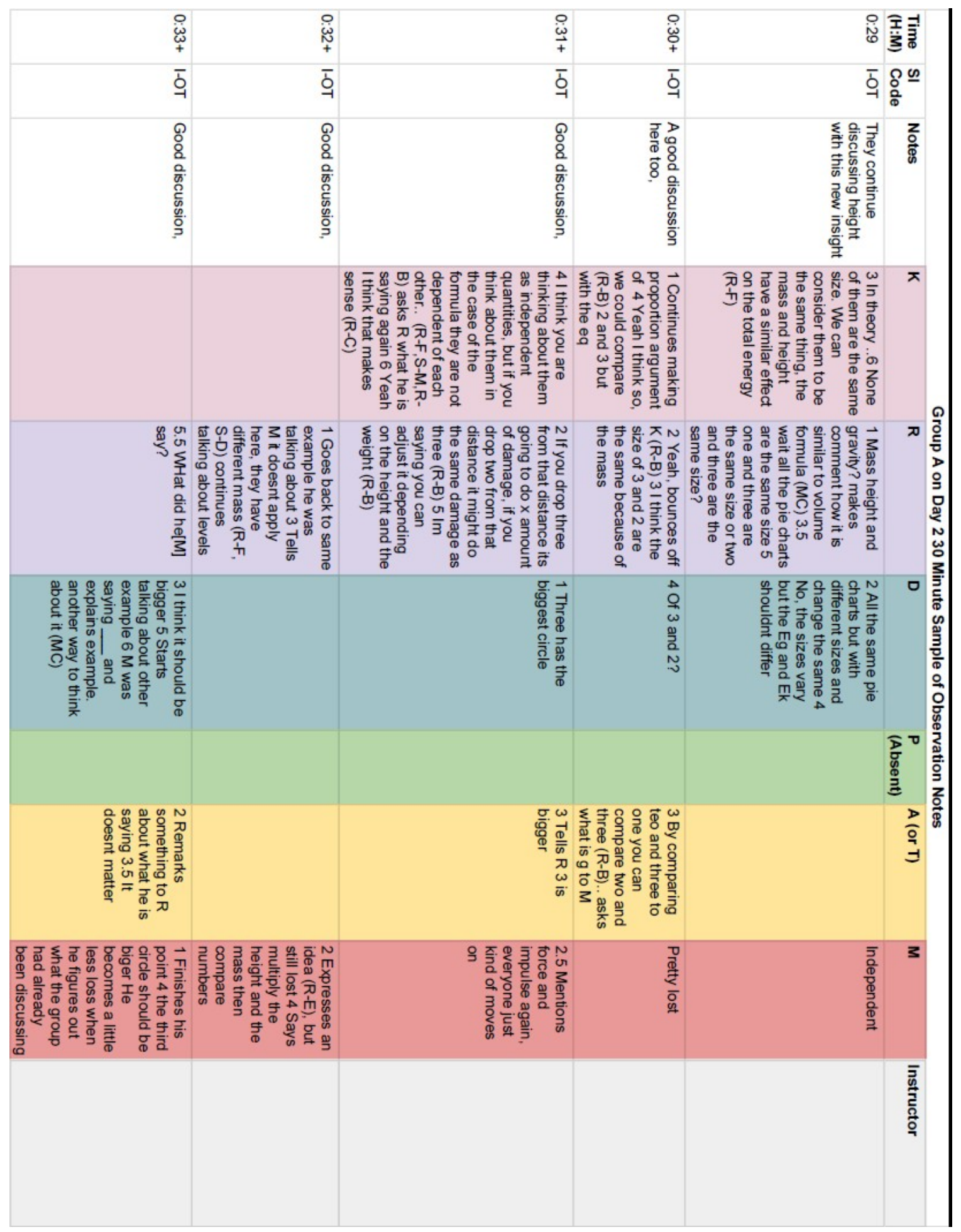




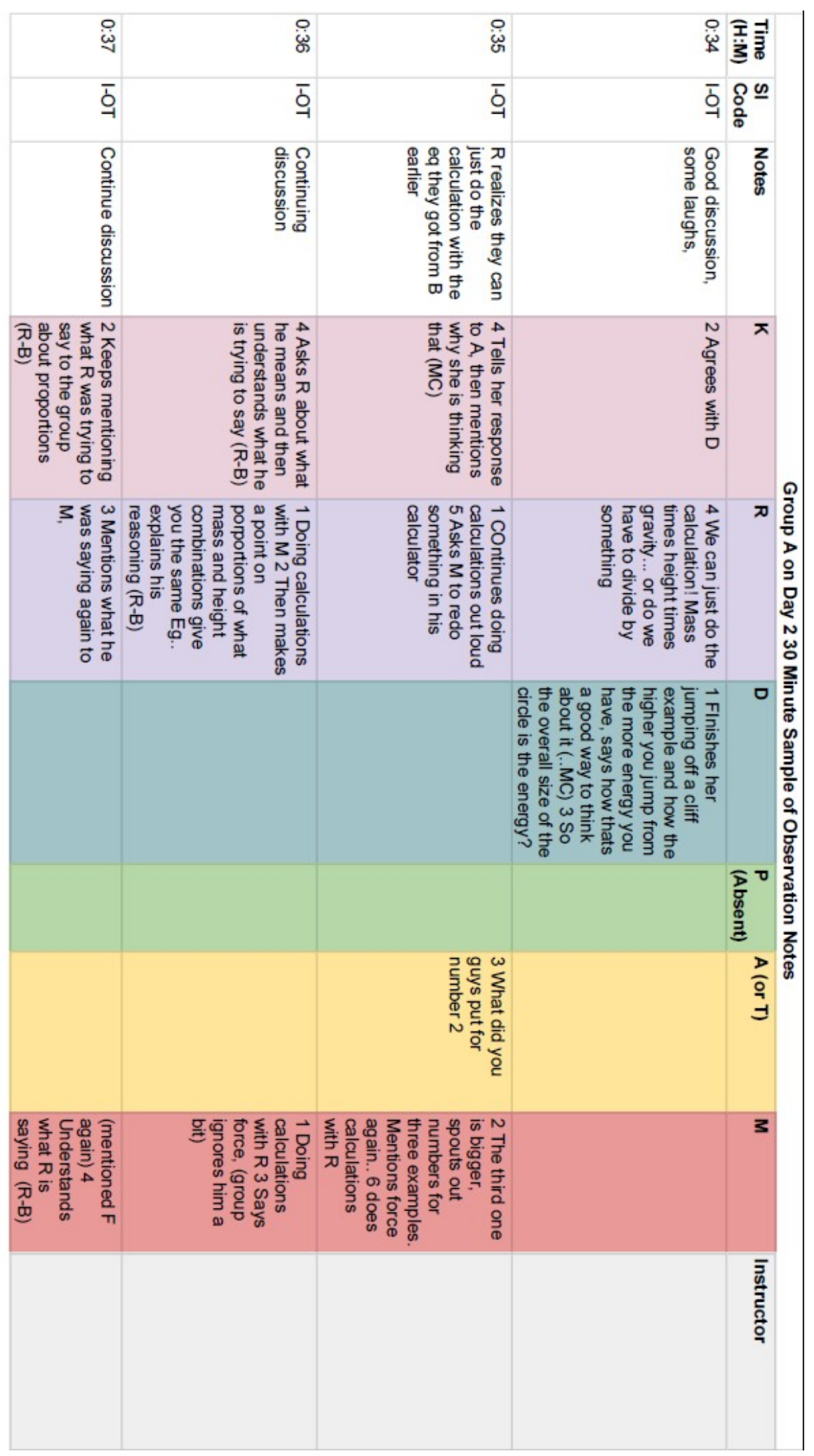




\section{Group B on Day 2 from 15 - 44 minutes}

\begin{tabular}{|c|c|c|c|c|c|c|c|c|c|}
\hline$\stackrel{\text { ن }}{\stackrel{\sim}{\omega}}$ & ㅇNㅁ & ن & : & $\begin{array}{l}\stackrel{9}{0} \\
\stackrel{0}{+} \\
+\end{array}$ & $\stackrel{\circ}{\stackrel{\infty}{\infty}}$ & $\stackrel{\circ}{\vec{v}}$ & 官 & & 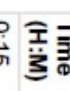 \\
\hline$z z$ & $\sigma$ & ఠ్త & ఫ్త & ס & $z$ & $z$ & $z$ & & 5 \\
\hline 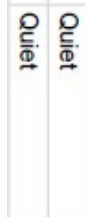 & 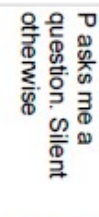 & 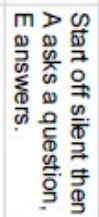 & 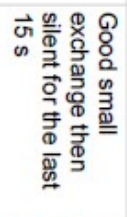 & 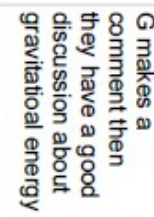 & 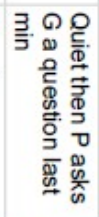 & . & & 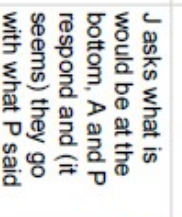 & \\
\hline
\end{tabular}

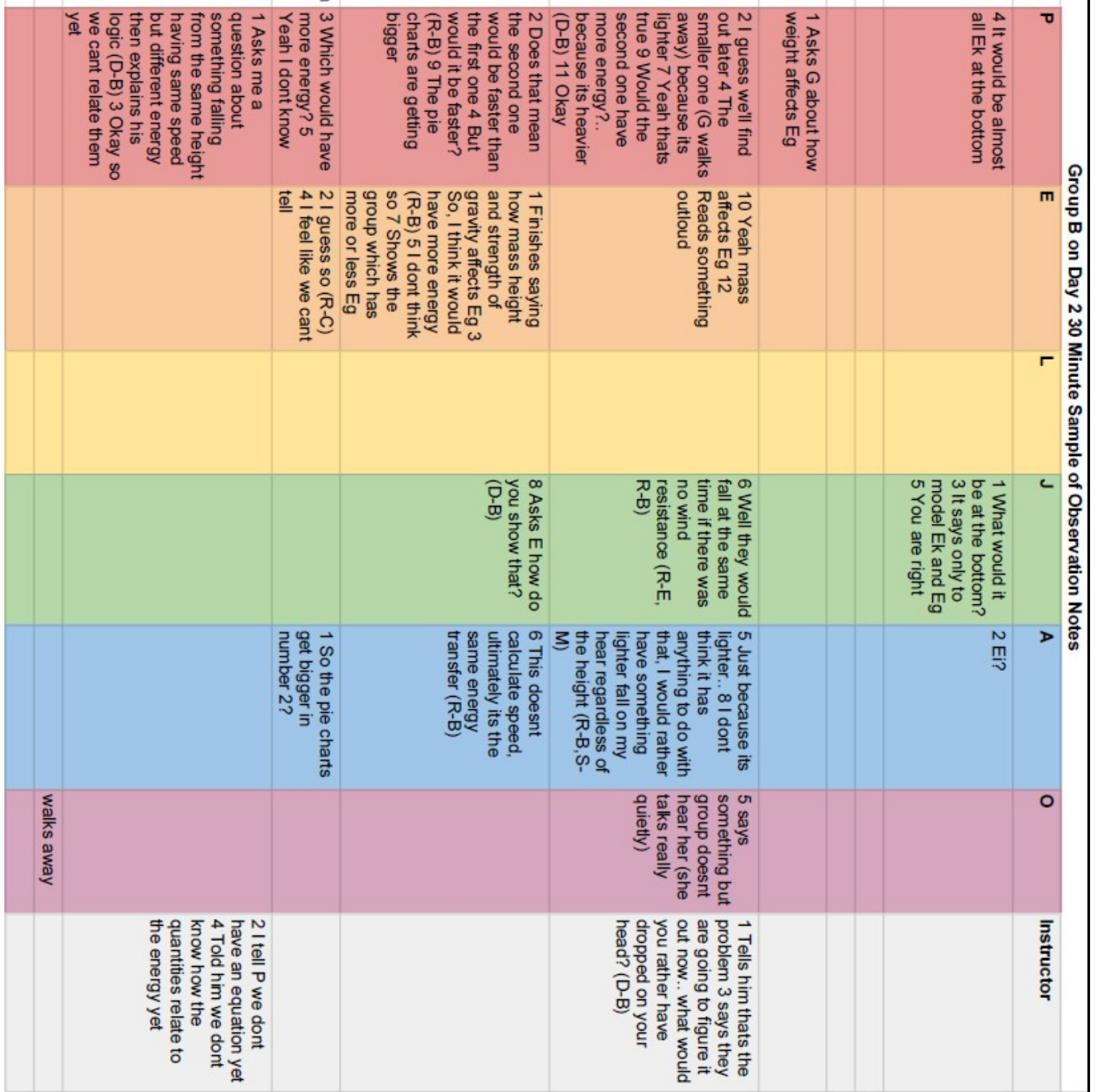




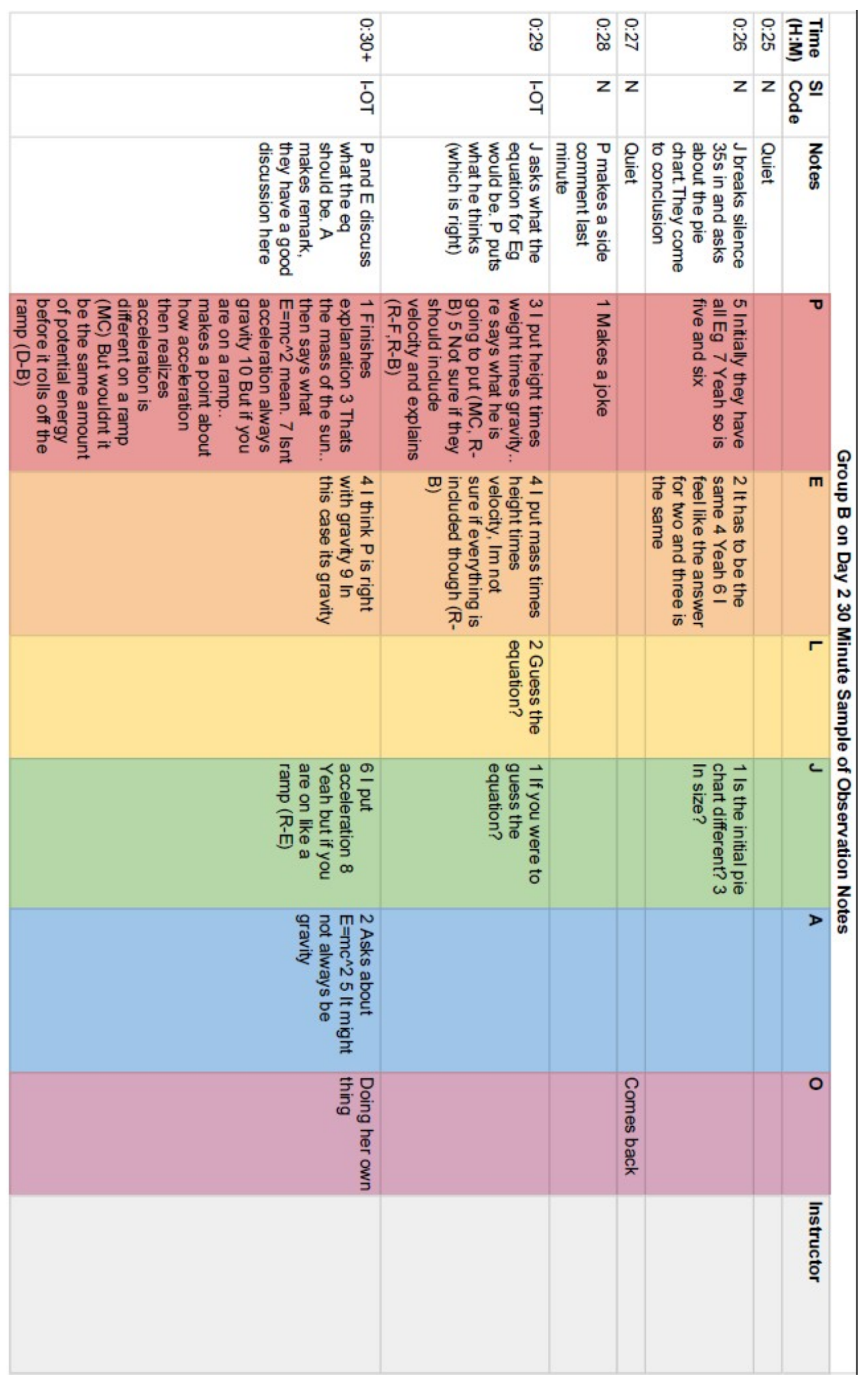




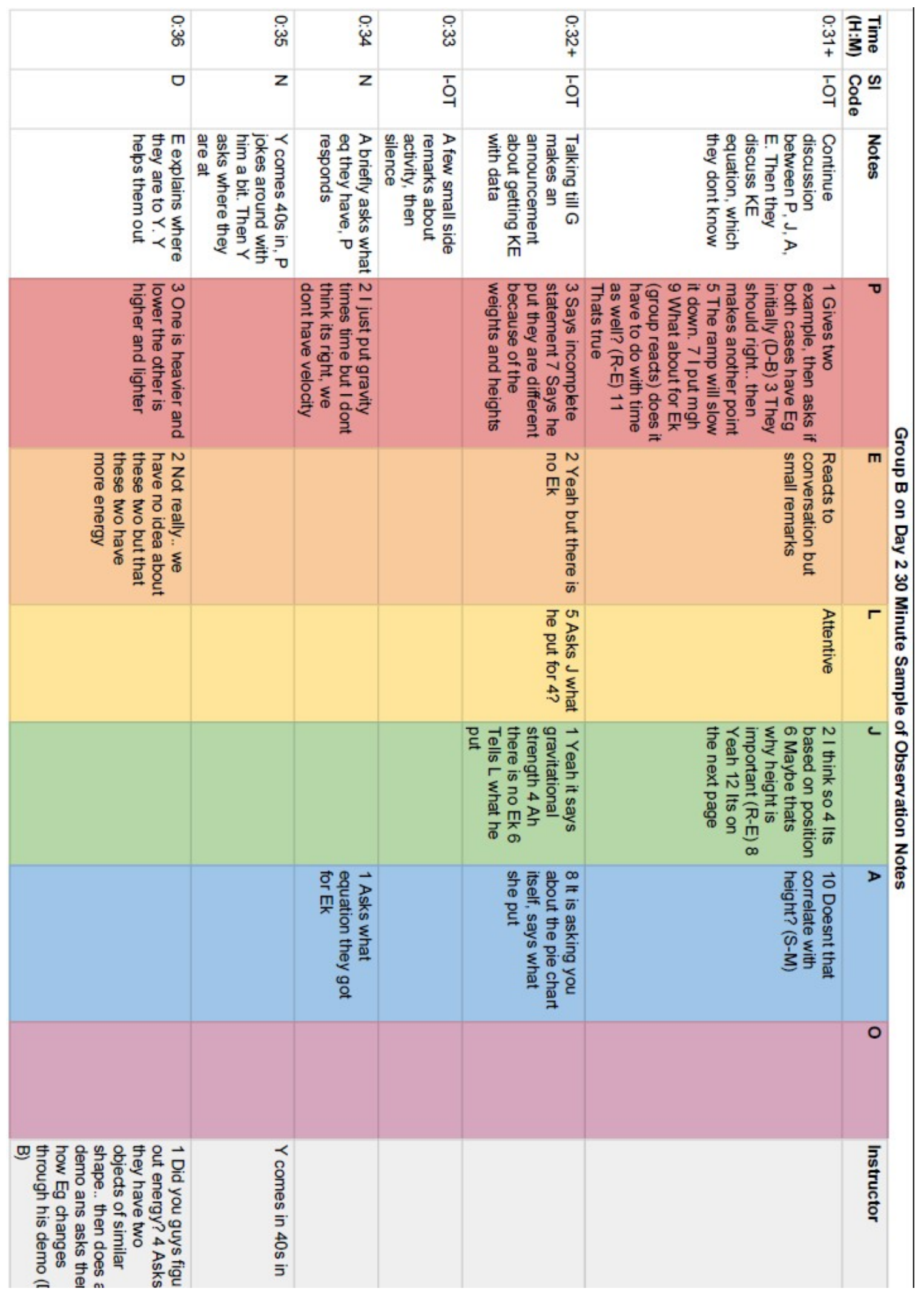




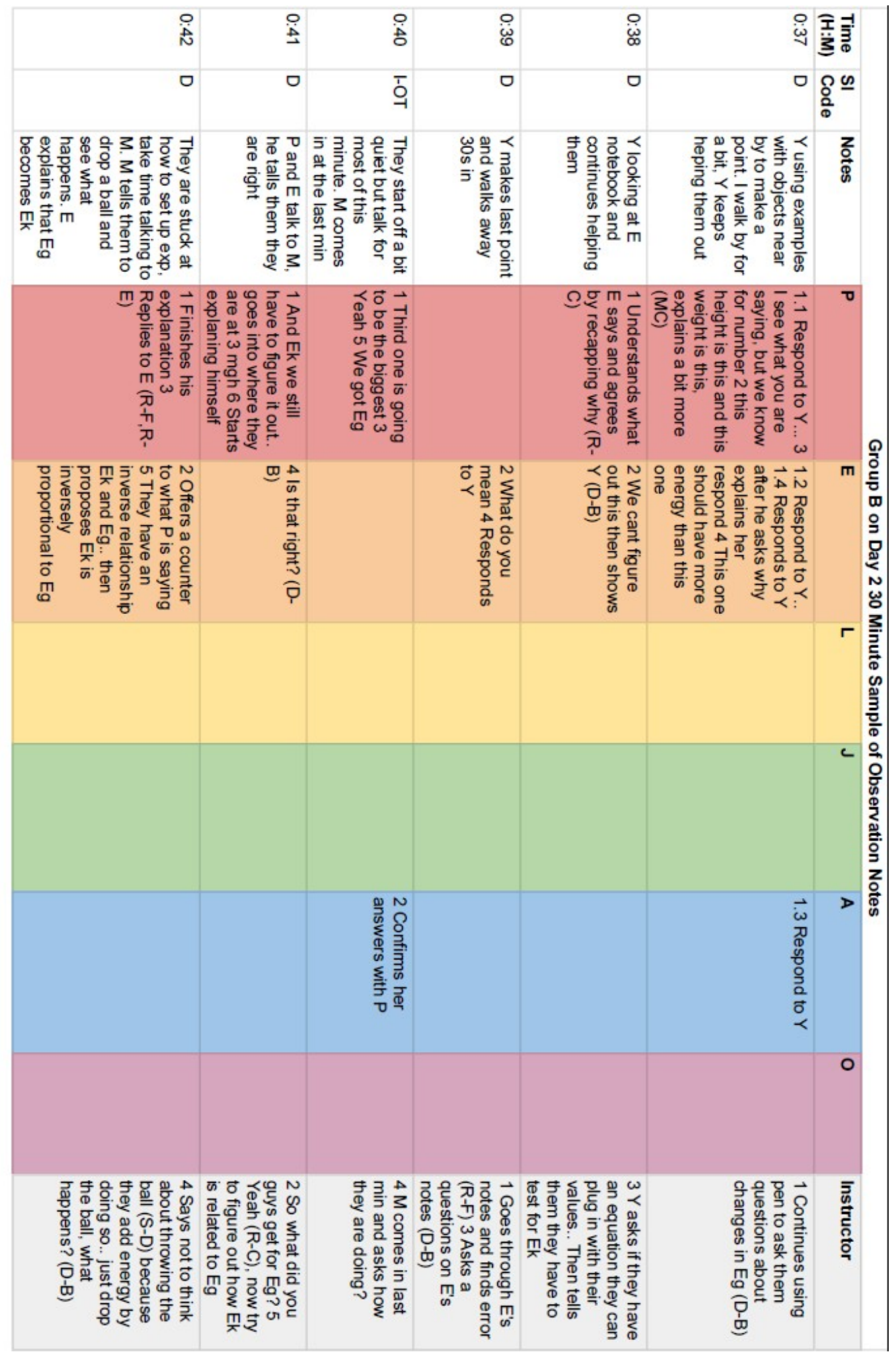




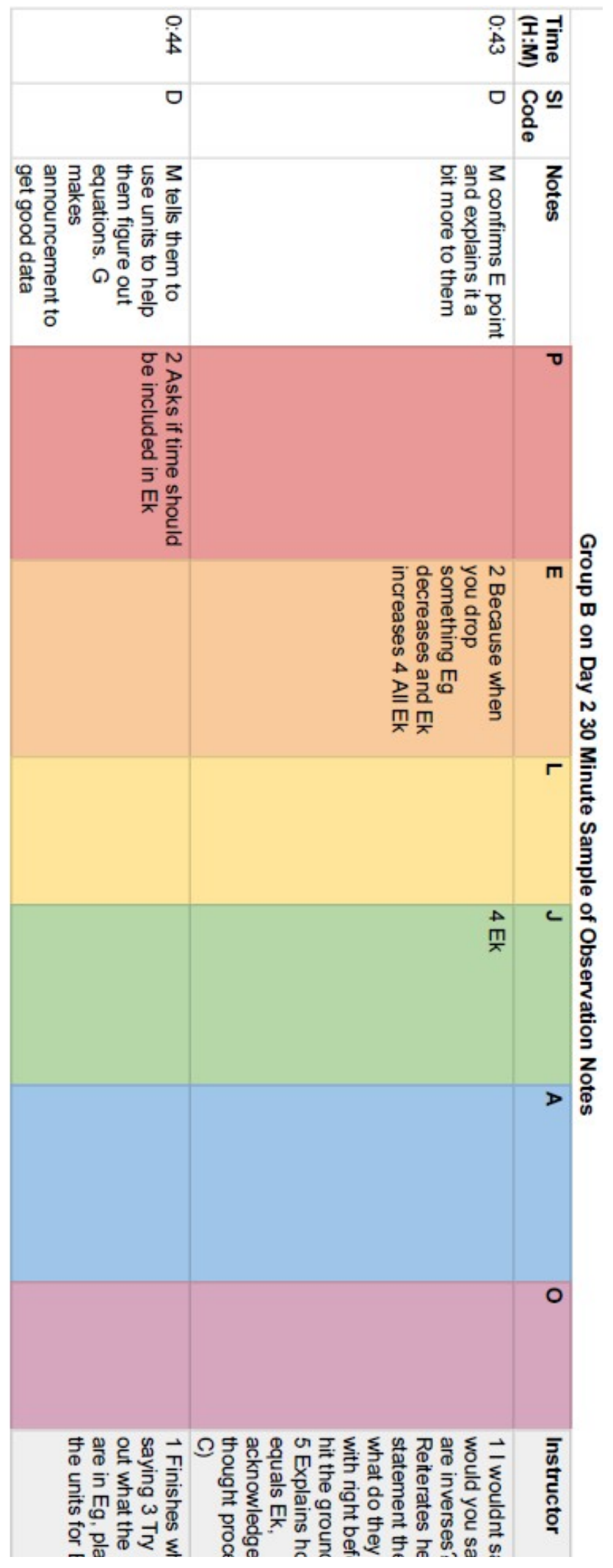


VITA

MIGUEL ANGEL RODRIGUEZ VELAZQUEZ

Born, Fajardo, Puerto Rico

2011

BS Physics

Florida Atlantic University

Boca Raton, FL

2015

MS Physics

University of Oklahoma

Norman, FL

Teaching Assistant

University of Oklahoma

Norman, OK

2020

Doctoral Candidate

Florida International University

Miami, FL

Teaching Assistant

Florida International University

Miami, FL

\section{PUBLICATIONS AND PRESENTATIONS}

Rodriguez, M. (2017). Frequent Group Interactions Improve Student Learning Gains in College Physics, 20th Annual Meeting of the Physics Education Research Conference.

Rodriguez, M. (2017). A study on the beliefs about the role of physics and physicists amongst introductory students, 20th Annual Meeting of the Physics Education Research Conference.

Rodriguez, M. (2017). Group Learning and Student Beliefs in Introductory Physics, Presentation, University of British Columbia, Vancouver, CA.

Rodriguez, M., \& Potvin, G. (2018). A study on the beliefs about the role of physics and physicists amongst introductory students. 2017 PERC Proceedings, 336-339.

Rodriguez, M. (2018). Examining Group Work in Modeling Physics through the Lens of Social Interdependence Theory, 21th Annual Meeting of the Physics Education Research Conference. 
Rodriguez, M. (2018). A Study on Positive Social Interdependence in Small Group Work, 21th Annual Meeting of the Physics Education Research Conference.

Rodriguez, M. (2018). Group Learning and Social Interdependence Theory, Presentation, University of Central Florida, Orlando, FL.

Rodriguez, M. (2019). Studying small group interactions in a collaborative learning environment through the lens of SI theory, 22th Annual Meeting of the Physics Education Research Conference.

Rodriguez, M. (2019). Social Interdependence Theory and Transfer in a Collaborative Learning Environment, 22th Annual Meeting of the Physics Education Research Conference.

Rohde, J., Satterfield, D., Rodriguez, M., ... (2020) Anyone, but not everyone: Undergraduate engineering students' claims of who can do engineering, Engineering Studies. (In press)

Rodriguez, M.\& Potvin, G. (2020) The associations between conceptual learning, physics identity and social interdependence, 2019 PERC Proceedings. (In review)

Rodriguez, M.\& Potvin, G. (2020) Frequent small group interactions improve student learning gains in college physics: Results from a nationally representative pre-post study, Physical Review Physics Education Research. (In review) 